\title{
Effects of developmental fluoxetine exposure on neurobehavioral outcomes
}

Citation for published version (APA):

Rayen, I. (2013). Effects of developmental fluoxetine exposure on neurobehavioral outcomes. [Doctoral Thesis, Maastricht University]. Maastricht University. https://doi.org/10.26481/dis.20131023ir

Document status and date:

Published: 01/01/2013

DOI:

10.26481/dis.20131023ir

Document Version:

Publisher's PDF, also known as Version of record

\section{Please check the document version of this publication:}

- A submitted manuscript is the version of the article upon submission and before peer-review. There can be important differences between the submitted version and the official published version of record.

People interested in the research are advised to contact the author for the final version of the publication, or visit the DOI to the publisher's website.

- The final author version and the galley proof are versions of the publication after peer review.

- The final published version features the final layout of the paper including the volume, issue and page numbers.

Link to publication

\footnotetext{
General rights rights.

- You may freely distribute the URL identifying the publication in the public portal. please follow below link for the End User Agreement:

www.umlib.nl/taverne-license

Take down policy

If you believe that this document breaches copyright please contact us at:

repository@maastrichtuniversity.nl

providing details and we will investigate your claim.
}

Copyright and moral rights for the publications made accessible in the public portal are retained by the authors and/or other copyright owners and it is a condition of accessing publications that users recognise and abide by the legal requirements associated with these

- Users may download and print one copy of any publication from the public portal for the purpose of private study or research.

- You may not further distribute the material or use it for any profit-making activity or commercial gain

If the publication is distributed under the terms of Article $25 \mathrm{fa}$ of the Dutch Copyright Act, indicated by the "Taverne" license above, 


\title{
Effects of developmental fluoxetine
}

\section{exposure on neurobehavioral

\author{
outcomes
}

\author{
Ine Rayen
}


Omslag: “Moeder en kind”, Gustav Klimt 


\section{Effects of developmental fluoxetine exposure on neurobehavioral outcomes}

\section{PROEFSCHRIFT}

ter verkrijging van de graad van doctor aan de Universiteit Maastricht, op gezag van de Rector Magnificus, Prof. dr. L.L.G. Soete volgens het besluit van het College van Decanen, in het openbaar te verdedigen op woensdag 23 oktober 2013 om 12.00 uur door

\section{Ine Rayen}




\section{Promotor:}

Prof. dr. H.W.M. Steinbusch

\section{Copromotores:}

dr. J.L. Pawluski

dr. T.D. Charlier (Ohio University, USA)

\section{Beoordelingscommissie:}

Prof. dr. Y. Temel (Chairman)

dr. D. van den Hove

dr. F van Leeuwen

Prof. dr. P.J. Lucassen (Universiteit van Amsterdam)

Prof. dr. T. Oberlander (University of British Columbia, Canada) 


\section{Content}

Chapter 1

General introduction

Chapter 2

Fluoxetine during development reverses the effects of prenatal stress on depressive-like

behavior and hippocampal neurogenesis in adolescence

Chapter 3

Developmental fluoxetine exposure differentially alters central and peripheral measures

of the HPA system in adolescent male and female offspring

Chapter 4

Developmental fluoxetine exposure and prenatal stress differentially affect hippocampal cell proliferation in adult male and female offspring

Chapter 5

Developmental fluoxetine exposure and prenatal stress alter sexual differentiation of the brain and reproductive behavior in male rat offspring

Chapter 6

Developmental fluoxetine exposure facilitates sexual behavior in female offspring

Chapter 7

General discussion

Summary

Samenvatting

Co-authors and affiliations

Curriculum Vitae

List of publications

Dankwoord 



\section{Abbreviations}

\begin{tabular}{|c|c|}
\hline 5-HT & Serotonin \\
\hline $5 \mathrm{HTT}$ & Serotonin transporter \\
\hline $5 \mathrm{HTP}$ & 5-hydroxytryptophan \\
\hline 5-HT1A & Serotonin receptor $1 \mathrm{~A}$ \\
\hline $5 \mathrm{HT} 1 \mathrm{~B}$ & Serotonin receptor $1 \mathrm{~B}$ \\
\hline $5 \mathrm{HT} 2$ & Serotonin receptor 2 \\
\hline $5 \mathrm{HT} 2 \mathrm{~A}$ & Serotonin receptor $2 \mathrm{~A}$ \\
\hline $\mathrm{ABC}$ & Avidine-biotine complex \\
\hline $\mathrm{AC}$ & Anterior commissure \\
\hline ACTH & Adrenocorticotrophin hormone \\
\hline AFP & $\alpha$-fetoprotein \\
\hline ANOVA & Analysis of variance tests \\
\hline AR & Androgenreceptor \\
\hline AVP & Arginine-vasopressine \\
\hline $\mathrm{AVPv}$ & Anteroventral periventricular nucleus \\
\hline BDNF & Brain derived neurotrophic factor \\
\hline BrdU & 5-bromo-2-deoxyuridine \\
\hline BST & Bed nucleus of the stria terminalis \\
\hline $\mathrm{CBG}$ & Corticosteroid binding globulin \\
\hline CORT & Corticosterone \\
\hline $\mathrm{CF}$ & Control + Fluoxetine \\
\hline CNS & Central nervous system \\
\hline CRH & Corticotropin-releasing hormone \\
\hline $\mathrm{CV}$ & Control + Vehicle \\
\hline DAB & 3,3-diaminobenzidine \\
\hline DCC & Dextran-coated charcoal \\
\hline DCX & Doublecortin \\
\hline DG & Dentate gyrus \\
\hline E2 & $17 \beta$-oestradiol \\
\hline FX & Fornix \\
\hline Fluox & Developmental fluoxetine exposure \\
\hline FST & Forced swim test \\
\hline G & Gestational day \\
\hline GCL & Granular cell layer \\
\hline GD & Gestation day \\
\hline GR & Glucocoricoid receptor \\
\hline GRIP1 & Glucocorticoid receptor interacting protein \\
\hline HPA & Hypothalamic-pituitary-adrenal \\
\hline HPG & Hypothalamic-pituitary-gonadal \\
\hline
\end{tabular}




\begin{tabular}{|c|c|}
\hline IHC & Immunohistochemistry \\
\hline i.p. & Intraperitoneal \\
\hline Ir & Immunoreactive \\
\hline MPOA & Medial preoptic area \\
\hline MR & Mineralocorticoid receptor \\
\hline NDS & Normal donkey serum \\
\hline NGS & Normal goat serum \\
\hline NR3C1 & Human glucocorticoid receptor gene \\
\hline $\mathrm{OC}$ & Optic chiasm \\
\hline OFT & Open field test \\
\hline OVX & Ovariectomized \\
\hline $\mathrm{P}$ & Postnatal day \\
\hline PBST & Phosphate-buffered saline $0.1 \%$ triton $\mathrm{X}-100$ \\
\hline pBST & Posterior bed nucleus of the stria terminalis \\
\hline PCPA & P-chlorophenylalanine \\
\hline PS & Prenatal stress \\
\hline PSF & Prenatal stress + Fluoxetine \\
\hline PSV & Prenatal stress + Vehicle \\
\hline PVN & Paraventricular nucleus \\
\hline RIA & Radioimmunoassay \\
\hline s.c. & Subcutaneous \\
\hline SDN-POA & Sexually dimorphic nucleus of the preoptic area \\
\hline SERT & Serotonin transporter \\
\hline SGZ & Subgranular zone \\
\hline SNRIs & Serotonin-norepinephrine reuptake inhibitors \\
\hline SSRIs & Selective serotonin reuptake inhibitor \\
\hline TBS & Tris-buffered saline \\
\hline TBST & Tris-buffered saline $0,1 \%$ triton $\mathrm{X}-100$ \\
\hline TBST & Tris-buffered saline $0,05 \%$ Tween \\
\hline $\mathrm{TH}$ & Tyrosine hydroxylase \\
\hline TPH & Tryptophan hydroxylase \\
\hline VAS & Vasectomized \\
\hline
\end{tabular}


Chapter 1 General introduction 
It is well known that women are more vulnerable to develop depression during their childbearing years (Burke et al. 1991). Depression occurring during pregnancy and the postpartum period affects up to $20 \%$ of the women (Almond 2009; Leung and Kaplan 2009; Limlomwongse and Liabsuetrakul 2006; Marcus 2009). Risk factors for developing depression during the perinatal period include having a history of depression, anxiety, stressful life events, lacking social support, an unplanned pregnancy, and being of lower socio-economic status (Lancaster et al. 2010; Stewart 2011). Women suffering from stress, depression, or anxiety during gestation can put their infant at risk for poor physical and mental development (Huizink et al. 2003; Oberlander et al. 2009; Talge et al. 2007). Children exposed to maternal stress or depression during gestation often show impairments in cognitive abilities, such as language development ( 2 year old), impulsivity in cognitive tasks (14 year old and 15 year old), lower school marks (6 year old), and also have an increased risk to develop neuropsychiatric disorders such as autism (4 to 12 year old) and have lower mental scores (3 months old and 8 months old) (Beversdorf et al. 2005; Huizink et al. 2003; Laplante et al. 2004; Niederhofer and Reiter 2004; Van den Bergh et al. 2005).

Numerous antidepressant treatments are available, including tricyclic inhibitors and serotonin-norepinephrine reuptake inhibitors and selective serotonin reuptake inhibitor (SSRI). Only the SSRI medications, with the exception of paroxetine, are considered to be safe for prenatal use, as neuroteratogenic effects have not been reported (Gentile 2005). Therefore, these medications are most often prescribed to treat maternal mood disorders during the perinatal period and up $10 \%$ of pregnant women on are SSRI medications (Cooper et al. 2007; Fleschler and Peskin 2008; Oberlander et al. 2006; Ververs et al. 2006). The most popular SSRIs used by pregnant women are fluoxetine, sertraline and citalopram (Andrade et al. 2008; Colvin et al. 2011).

Twenty-five percent of women already using antidepressant medications prior to conception continue this treatment during pregnancy, while 0.5 percent of women start using antidepressant medications during pregnancy (Ververs et al. 2006). SSRIs can affect fetal and neonatal development, as they pass through the placenta and are present in breast milk (Kristensen et al. 1999). Perinatal SSRI exposure increases extracellular serotonin concentrations in the brain by inhibiting the serotonin transporter, and, as a result, increases serotonin (5-HT) signalling in the fetus (Baumann and Rochat 1995; Oberlander et al. 2009). Clinical data has shown that developmental changes in serotonin concentration, after prenatal SSRI exposure, may cause reduced fetal head growth, antidepressant withdrawal in neonates in the first weeks of life, lower birth weight, younger gestational age, reduced heart rate 
variability, and behavioral abnormalities (El Marroun et al. 2012; Moses-Kolko et al. 2005; Nulman et al. 2002; Oberlander et al. 2009). However, the long term developmental outcomes have yet to be fully determined.

In order to determine the impact of developmental exposure to SSRI medications on offspring outcomes, a growing body of preclinical research has emerged which has shown reduced birth weight, cardiac anomalies and neurobehavioral outcomes in offspring (Bairy et al. 2007; Fornaro et al. 2007; Noorlander et al. 2008; Olivier et al. 2011; Van den Hove et al. 2008). However, the majority of preclinical studies investigate the effects of SSRI exposure on offspring outcomes in healthy, and non-stressed or 'depressed', animals. Therefore, the general aim of this thesis was to determine how developmental exposure to fluoxetine, a popular SSRI used during pregnancy, affects neurodevelopmental outcomes using an animal model of maternal adversity. In this chapter, I will describe my main areas of interest which encompass the developmental effects of SSRI exposure on (1) affect-related behavior, (2) the hypothalamic-pituitary-adrenal (HPA) axis, (3) hippocampal neuroplasticity, and (4) the hypothalamic-pituitary-gonadal (HPG) axis in male and female offspring. Knowledge of the long-term developmental implications of antidepressant medication exposure, in appropriate animal models of maternal adversity, is important in order to select the appropriate treatment and interventions for the mother and improve the outcome for the child.

\section{Role of serotonin in development}

Serotonin is known to play a neurotransmitter role in the adult brain, modulating emotion, learning, cognition, sleep and stress responses (Ansorge et al. 2007). During neurodevelopment, serotonin is implicated in several processes, such as cell division, migration, differentiation, growth cone elongation, myelination, dendritic pruning and synaptogenesis (Gaspar et al. 2003). Besides its role in developmental processes, serotonin has also a role as growth factor (Whitaker-Azmitia et al. 1996). Serotonin modulates the development of its own and other neuronal systems, including the HPA axis (Andrews and Matthews 2004; Whitaker-Azmitia et al. 1996). Exposure to SSRIs during development results in an acute increase in serotoninergic tone (Oberlander et al. 2009). However, perinatal SSRI exposed animals have shown reductions in serotonin levels during adulthood, through developmental activation of inhibitory autoreceptors (e.g. 5-HT $1 \mathrm{a}$ ) (Hensler 2006; Oberlander et al. 2009) (Figure 1). Therefore, changing the serotonergic tone, via perinatal 
SSRI exposure, has long term effects on the serotoninergic system and likely affects many developmental processes.
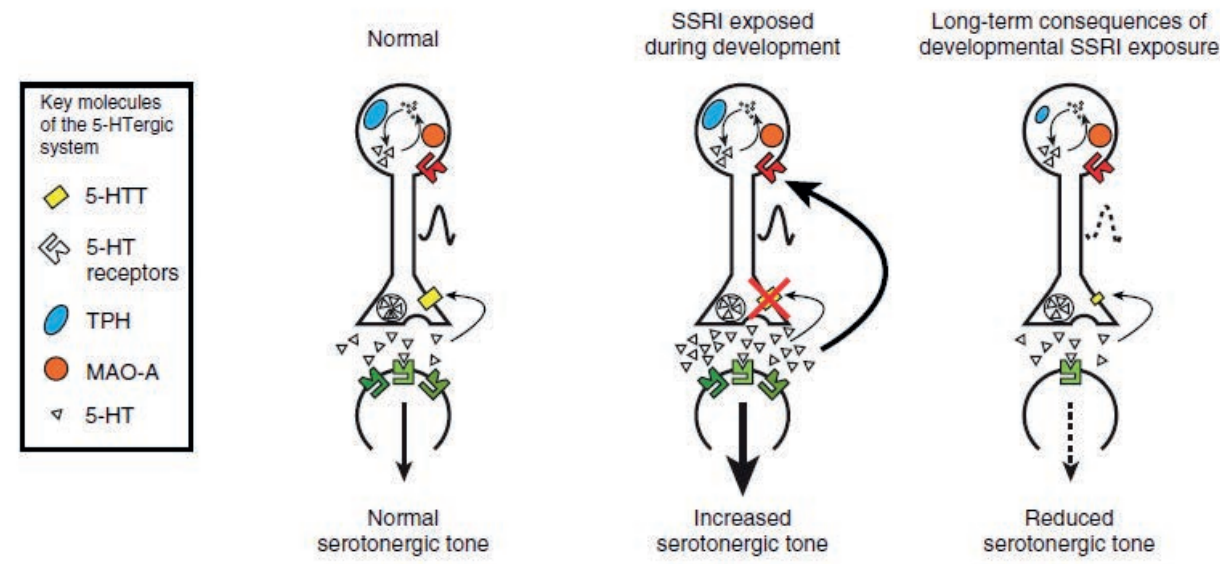

Figure 1. Long-term effects of increased serotoninergic tone during development. Under normal developmental conditions, serotonin synthesis, release, reuptake and degradation result in a normal serotoninergic tone (left). SSRI exposure during development increases the serotoninergic tone (middle), while the long-term effect of developmental SSRI exposure is a reduced serotoninergic tone later in life (right). (from Oberlander et al. 2009)

\section{The developmental effects of SSRI exposure on affect-related behavior}

Children exposed to maternal mood disorders early during development are at an increased risk for cognitive, behavioral and emotional disturbances (Glover et al. 2010; Huizink et al. 2003; Laplante et al. 2004; Niederhofer and Reiter 2004; Talge et al. 2007; Van den Bergh et al. 2005). Preclinical findings parallel the clinical work and show that adult offspring exposed to prenatal stress are more likely to display affect-related behaviors, such as anxiety and depressive-like behavior, as well as learning deficits and vulnerability to drug addiction (Maccari et al. 2003; Maccari and Morley-Fletcher 2007; Van den Hove et al. 2005; Weinstock 2008; Zagron and Weinstock 2006).

Developmental exposure to SSRI medications also impact affect-related behaviors in children (Oberlander et al. 2010; Oberlander et al. 2007; Oberlander et al. 2008b). Children, of 4 years old, exposed prenatally to SSRIs have higher scores of externalizing behaviors, such as aggression, attention/hyperactivity, and oppositional or defiant behaviors, than the clinical cutoff (Oberlander et al. 2007). On the other hand, exposure to both prenatal SSRI exposure and maternal depression results in increased internalizing behaviors (depression, 


\section{Chapter 1}

anxiety, and withdrawal) in 3 and 4 year old children (Oberlander et al. 2010). Preclinical studies have also demonstrated that developmental SSRI exposure has an impact on affectivelike behaviors in offspring. For example, developmental SSRI exposure impairs social play and response to novelty in juvenile offspring (Simpson et al. 2011), increases anxiety-like behavior in adult offspring (Ansorge et al. 2008; Ansorge et al. 2004; Lisboa et al. 2007; Olivier et al. 2011; Simpson et al. 2011), and increases depressive-like behavior in adult offspring (Hansen et al. 1997; Karpova et al. 2009; Lisboa et al. 2007; Popa et al. 2008). Others have also reported a decrease in anxiety-like behavior and depressive-like behavior in offspring (McAllister et al. 2012) (For an overview of these preclinical findings see Table 1). These studies highlight important effects of developmental SSRI exposure on the emergence of mood disorders in offspring. 


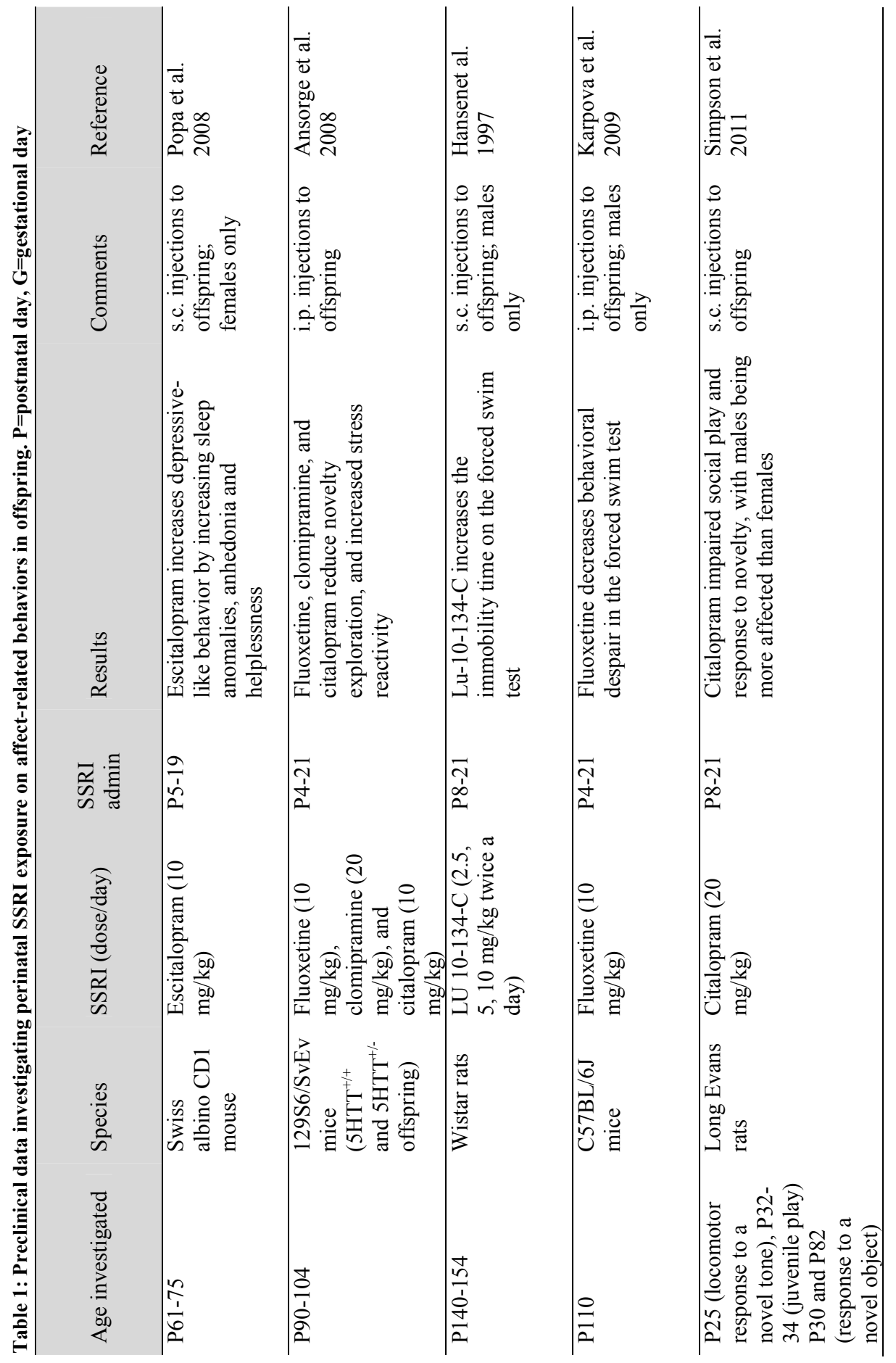


Chapter 1

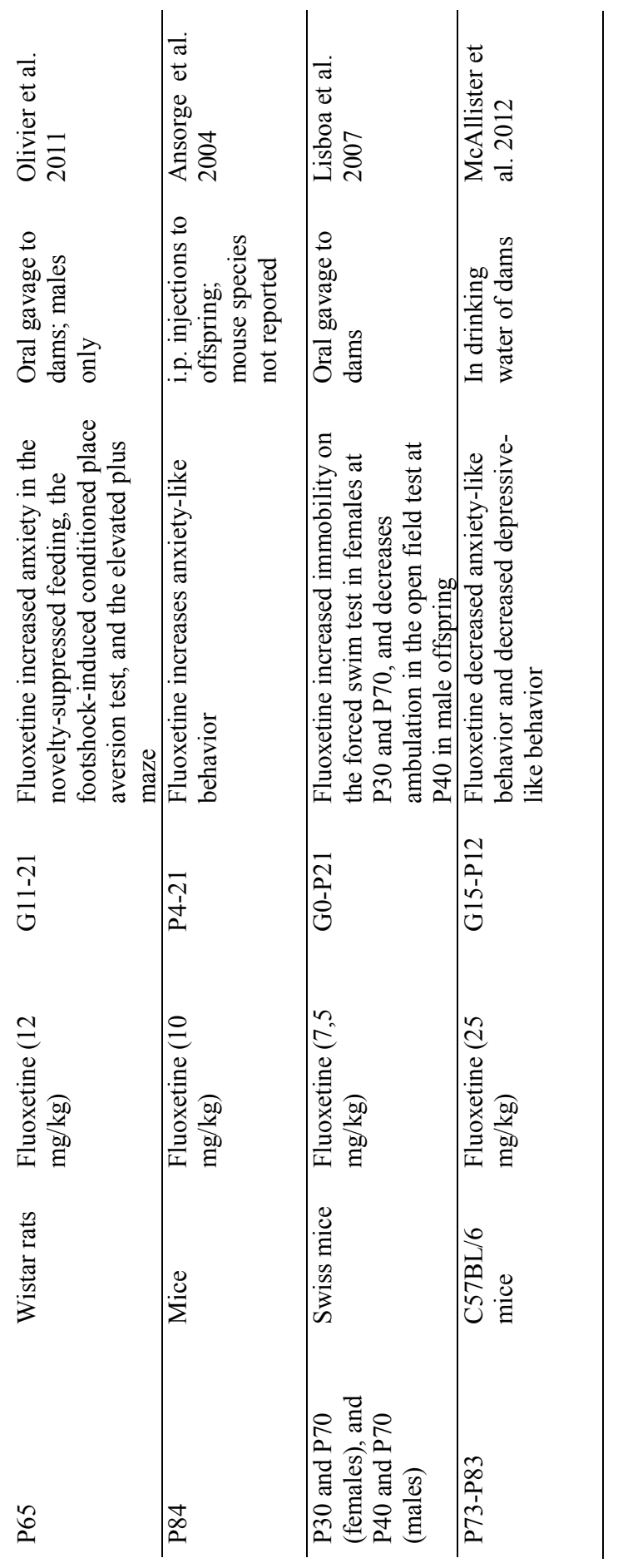




\section{The developmental effects of SSRI exposure on the HPA axis}

The development of mood disorders has long been linked to changes in stress regulation via alterations in the limbic hypothalamic-pituitary-adrenal axis (HPA axis) (Figure 2). When an organism is exposed to stress, several processes in the central nervous system (CNS) are initiated, primarily through the HPA axis. Stress stimulates the release of glucocorticoids, such as cortisol (in humans) or corticosterone (CORT; in rodents) into the circulation from the adrenal gland cortex (Palkovits 1987). These glucocorticoids feedback to the hippocampus and hypothalamus, via binding to the glucocorticoid receptor (GR) and mineralocorticoid receptor (MR), and regulate the HPA system (Herman et al. 2012; Palkovits 1987; Rothman and Mattson 2010). Chronic stress commonly results in glucocorticoid hypersecretion and, in susceptible individuals, chronic stress can lead to long lasting HPA responses which can result in mood disorders such as depression and anxiety (McEwen and Stellar 1993).

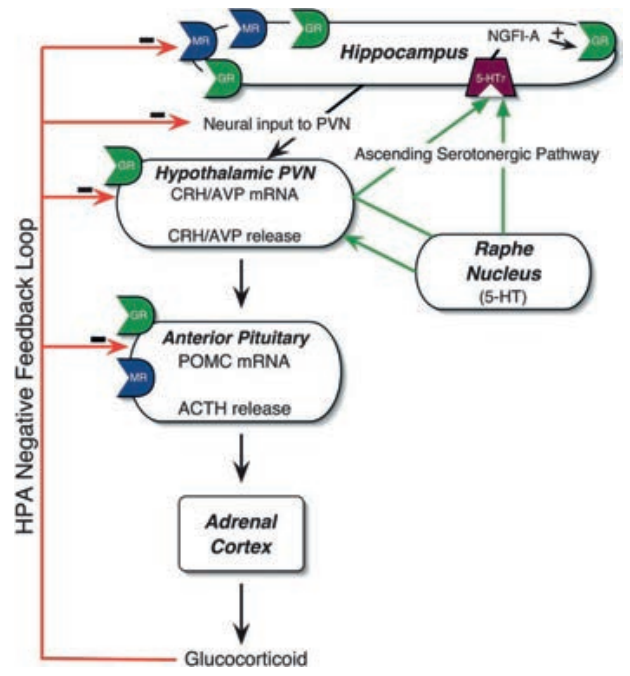

Figure 2. The HPA axis in the fetus is controlled by both positive (black arrows) and negative feedback. Stress stimulates the paraventricular nucleus (PVN) of the hypothalamus and corticotropin-releasing hormone (CRH) and arginine-vasopressin (AVP) are released. CRH and AVP reach the anterior pituitary gland, where adrenocorticotrophin hormone (ACTH) is released into the circulation. ACTH is transported to the adrenal cortex, where it stimulates the production of glucocorticoids into the circulation. Glucocorticoids increase the negative feedback signal by binding with mineralocorticoid receptors (MR) and glucocorticoid receptors (GR) at the different levels of the HPA axis. Ascending serotoninergic pathways from the dorsal raphe nucleus innervate the hippocampus and hypothalamus. Increases in serotonin levels lead to an up regulation of GR expression. (Andrews and Matthews 2004)

Serotonin plays a role in the development and function of the HPA axis (Andrews and Matthews 2004; Laplante et al. 2002; Meaney et al. 1994), and 
therefore changes in serotonin levels, via developmental SSRI exposure, will likely affect HPA axis function. Clinical data has shown that prenatal SSRI exposure alters HPA function in infants, by reducing early evening cortisol levels at 3 months of age (Oberlander et al. 2008a). In addition, prenatal exposure to SSRIs reduces basal cortisol levels in saliva at 6 months of age (Brennan et al. 2008). These reductions of basal cortisol levels may be caused by sequestration of increased levels in corticosterone-binding globulin in neonatal serum after prenatal SSRI exposure (Pawluski et al. 2012). With regards to stress reactivity, neonates (around birth) and infants (2 month old) prenatally exposed to SSRIs display less facial activity and a lower heart rate during recovery from a heel lance compared to non SSRI-exposed infants (Oberlander et al. 2002; Oberlander et al. 2005). These findings suggest that prenatal SSRI exposure blunts the response to acute pain and the HPA response in newborns.

Although limited, preclinical data has shown that prenatal SSRI exposure (fluoxetine) increases plasma cortisol levels in fetal lambs (Morrison et al. 2004) and early postnatal fluoxetine exposure attenuates the serum corticosterone response to stress in juvenile mouse offspring exposed to maternal stress (Ishiwata et al. 2005). However, much more research is needed to determine the long term effects of developmental exposure to SSRI medications on HPA function.

\section{The developmental effects of SSRI exposure on hippocampal plasticity}

The hippocampus has long been implicated in the etiology of mood disorders and regulation of stress (Eisch et al. 2008; Kempermann et al. 2004; McEwen 2005). Interestingly, the hippocampus is one of two brain regions where there is a high rate of neurogenesis throughout the lifespan (the other region being the subventricular zone) (Eriksson et al. 1998; Leuner and Gould 2010). Neurogenesis in the hippocampus is the process in which hippocampal neural progenitor cells in the subgranular zone (SGZ) divide and mature into granule cell neurons (Abrous et al. 2002; Eisch et al. 2008; Galea et al. 2006; Kempermann et al. 2004; Pawluski et al. 2009a) (Figure 3). These new neurons and plasticity in the hippocampus are thought to play an important role in depression and the effects of antidepressant medications (Dranovsky and Hen 2006; Mateus-Pinheiro et al. 2013; Santarelli et al. 2003). 

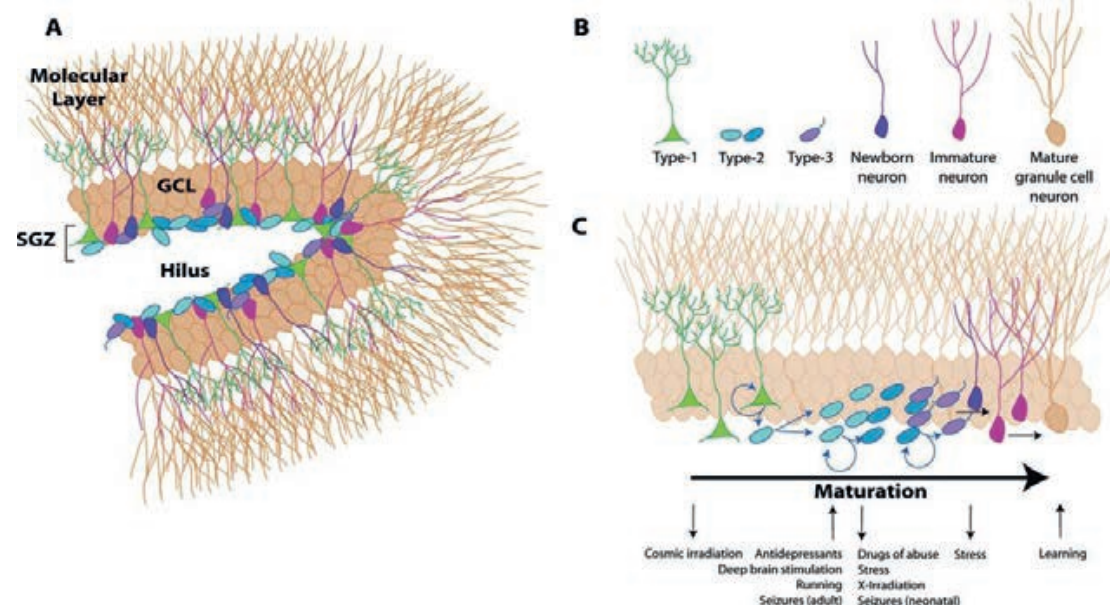

Figure 3. Hippocampal cell proliferation in the dentate gyrus. (A) Neural progenitor cells divide and mature into neurons in the subgranular zone (SGZ) of the dentate gyrus. (B) The SGZ contains cells at several stages of neuron development. (C) Cells in different stages of development can be differentially affected by physiological and pharmacological stimuli. (from Eisch et al. 2008).

Serotonin is an important neurotransmitter involved in regulating the rate of hippocampal neurogenesis during adulthood (Brezun and Daszuta 1999; Djavadian 2004). Depletion of serotonin reduces the number of newly formed neurons in the hippocampus, whereas increased levels of serotonin increases the rate of cell proliferation, via actions on the 5-HT 1 a receptor (Brezun and Daszuta 1999; Malberg et al. 2000; Varrault et al. 1992). Increases in serotonin levels, after SSRI exposure, upregulate hippocampal neurogenesis significantly during adulthood (Malberg et al. 2000; Perera et al. 2007) and it has been suggested that hippocampal neurogenesis may be important for the behavioral effects obtained after antidepressant medication exposure (Eisch and Petrik 2012; Santarelli et al. 2003; Wainwright and Galea 2013). Moreover, the effects of stress on hippocampal neurogenesis and the associated affect-related behavior can be reversed by antidepressant medication in adulthood (Eisch and Petrik 2012; Malberg and Duman 2003; Wainwright and Galea 2013).

SSRI exposure during development may have a very different effect on hippocampal neurogenesis than SSRI administration during adulthood. For example, prenatal SSRI exposure decreases S100B protein levels in neonates and this protein stimulates glial cell proliferation and neuronal survival, and induces neurite outgrowth (Bhattacharyya et al. 1992; Gonzalez-Martinez et al. 2003; Pawluski et al. 2009b; 
Winningham-Major et al. 1989). To date, only a few studies have investigated how developmental fluoxetine exposure affects hippocampal plasticity in a model of maternal adversity (Ishiwata et al. 2005). It has been shown that developmental SSRI administration reverses the prenatally stress-induced decrease in CA3 spine and synapse density in juvenile and adolescent mouse offspring (Ishiwata et al. 2005) and reverses hippocampal cell proliferation and cell death in juvenile rat offspring prematurely separated from their mother (Lee et al. 2001).

\section{The developmental effects of SSRI exposure on the HPG axis}

It has been well documented that depression, the function of HPA system and hippocampal plasticity differ in males and females (Fernandez-Guasti et al. 2012; Galea et al. 2006; Vega et al. 2011). Not surprisingly, serotonin plays a key role in sexual differentiation through its role in the development of the hypothalamicpituitary-gonadal (HPG) axis (Dohler et al. 1991; Jarzab and Dohler 1984).

Sexual differentiation of the brain depends on actions of estrogens and androgens (Dohler 1991; Segarra et al. 1991). In male rats, plasma testosterone levels peak on days 18-19 of gestation (Ward and Weisz 1984; Weisz and Ward 1980) and a second peak in testosterone occurs during the first few hours after birth (Baum et al. 1988; Corbier et al. 1978; Lalau et al. 1990; Slob et al. 1980). Testosterone, and mainly its estrogenic metabolites synthesized from local aromatization, are essential for masculinization and defeminization of the brain during this critical period of sexual differentiation (Rhees et al. 1997). In females, $\alpha$-fetoprotein (AFP), an important plasma binding globulin during fetal development, sequesterd systemic estradiol and prevents the masculinization effect of systemic estradiol on the brain (Bakker and Brock 2010).

In females, postnatal stimulation of serotonin synthesis, by injection of Ltryptophan, results in an inhibition of sexual behavior (Dohler et al. 1991; Jarzab and Dohler 1984). Serotonin has also been shown to have an inhibitory effect on postnatal 'organization' of female sexual behavior as well as on 'activation' of female sexual behavior in adulthood (Dohler et al. 1991; Jarzab and Dohler 1984). In addition, the defeminization of several sexually dimorphic brain structures in females has been shown after stimulation of serotonin synthesis (Wilson et al. 1986). In males, there is 
a drop in serotonin levels between the $2^{\text {nd }}$ and $3^{\text {rd }}$ week postnatal, which is needed to establish full masculinization of the brain (Ladosky and Gaziri 1970).

Preclinical data has also shown that developmental exposure to SSRIs may have a long-term effect on sexual behavior in male offspring (Maciag et al. 2006b; Maciag et al. 2006c; Soga et al. 2012). Recent research has shown that postnatal exposure to the SSRI citalopram inhibits sexual behavior in male offspring (Maciag et al. 2006b; Maciag et al. 2006c). These behavioral changes, after SSRI exposure, are paralleled with a reduction of the number of androgen receptor-immunoreactive cells in the medial preoptic area (MPOA) (Soga et al. 2012). However, others have shown that prenatal fluoxetine exposure does not significantly alter male sexual behavior (Olivier et al. 2011d). To date, this work has focused on how SSRIs impact the developing HPG axis in male offspring. However, it addresses only the effects of developmental SSRI exposure in male offspring from healthy non-stressed mothers. Preclinical data has also shown that maternal adversity, itself, can impact sexual differentiation of the brain and behavior in male and female offspring (Anderson et al. 1986; Frye and Orecki 2002; Gerardin et al. 2005; Gerecke et al. 2011; Gutierrez et al. 1989; Herrenkohl and Whitney 1976; Rhees et al. 1999; Wang et al. 2006; Ward 1972; Ward and Weisz 1980). Therefore, it is important to investigate how developmental SSRI exposure affects the HPG axis in both male and female offspring in a model of maternal adversity.

\section{Aim and outline of the thesis}

The general aim of this thesis was to determine how developmental exposure to fluoxetine, a commonly used SSRI, affects neurodevelopmental outcomes in offspring, using an animal model of maternal adversity (Figure 4). To do this, a model of prenatal maternal stress was used. This stress paradigm has been shown to induce depressive-like behavior in the dam during the postpartum period (O'Mahony et al. 2006; Smith et al. 2004). Furthermore, the postnatal period in the rat offspring is a period of neurodevelopment similar to neurodevelopment during the third trimester in humans (Romijn et al. 1991). Therefore, we chose this period to administer fluoxetine to the dam, and offspring were exposed to the SSRI medication via suckling. Previous work, using a similar paradigm of fluoxetine administration to the dam, has shown that fluoxetine and its active metabolite, norfluoxetine, are present in the serum of rat 
pups (Knaepen et al. 2013). Fluoxetine and norfluoxetine have also been detected in human breast milk (Berle and Spigset 2011; Berle et al. 2004; Kim et al. 2006; Kristensen et al. 1999). Thus, this is a viable and less stressful mode of SSRI administration to pups.

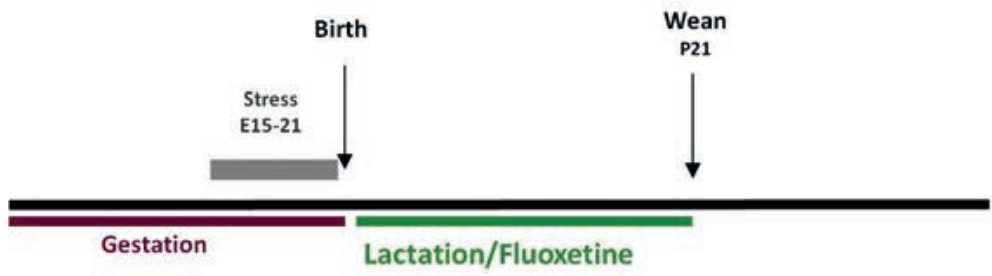

Figure 4. Timeline reflecting the general aim of the thesis. Dams were exposed to stress between gestational day (G) 15 and 21. Fluoxetine was administered to the mother at postpartum day 1 (P1). At P21 offspring were separated from the mothers. In this thesis, 4 different groups of offspring were used: control + vehicle $(\mathrm{CV})$, control + fluoxetine (CF), prenatal stress + vehicle (PSV), prenatal stress + fluoxetine (PSF)

Using this model of maternal adversity, Chapter 2 shows how anxiety- and depressive-related behaviors and hippocampal neurogenesis are affected by developmental fluoxetine exposure in adolescent male and female offspring. In Chapter 3, the effects of developmental fluoxetine exposure on peripheral measures in the blood and on central measures in the hippocampus, of the HPA axis are investigated in adolescent male and female offspring. The impact of postnatal fluoxetine exposure on hippocampal neurogenesis in adult male and female offspring is described in Chapter 4. Chapter 5 investigates the effects of developmental fluoxetine exposure on sexual behaviors and sexual differentiation of the brain in adult male offspring. Chapter 6 examines the role of developmental fluoxetine exposure on sexual behaviors and sexual differentiation of the brain in female offspring. Finally, a general discussion and a main conclusion of this thesis are given in Chapter 7. For a general overview of the research in this thesis see Figure 5. 
Chapter 1

MATERNAL ADVERSITY
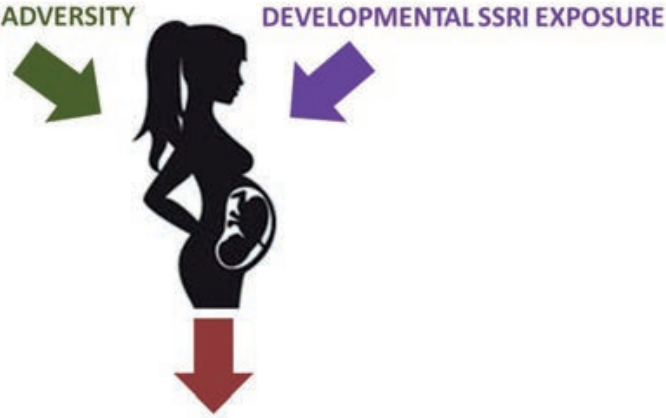

\section{HPA axis development}

Affect-related behavior in adolescent male and female offspring

Hippocampal neurogenesis in adolescent male and female offspring

Hippocampal neurogenesis in adult male and female offspring

\section{HPG axis development}

Reproductive behavior in male and female offspring Sexual differentiation of the brain in male and female offspring

Figure 5. General overview of the research investigated. This thesis investigated how developmental SSRI exposure affects aspects of the HPA and HPG axes in male and female offspring. 


\section{References}

Abrous DN, Adriani W, Montaron MF, Aurousseau C, Rougon G, Le Moal M, Piazza PV (2002) Nicotine self-administration impairs hippocampal plasticity. J Neurosci 22: 3656-62

Almond P (2009) Postnatal depression: a global public health perspective. Perspect Public Health 129: $221-7$

Anderson RH, Fleming DE, Rhees RW, Kinghorn E (1986) Relationships between sexual activity, plasma testosterone, and the volume of the sexually dimorphic nucleus of the preoptic area in prenatally stressed and non-stressed rats. Brain Res 370: 1-10

Andrade SE, Raebel MA, Brown J, Lane K, Livingston J, Boudreau D, Rolnick SJ, Roblin D, Smith DH, Willy ME, Staffa JA, Platt R (2008) Use of antidepressant medications during pregnancy: a multisite study. Am J Obstet Gynecol 198: 194 e1-5

Andrews MH, Matthews SG (2004) Programming of the hypothalamo-pituitary-adrenal axis: serotonergic involvement. Stress 7: 15-27

Ansorge MS, Hen R, Gingrich JA (2007) Neurodevelopmental origins of depressive disorders. Curr Opin Pharmacol 7: 8-17

Ansorge MS, Morelli E, Gingrich JA (2008) Inhibition of serotonin but not norepinephrine transport during development produces delayed, persistent perturbations of emotional behaviors in mice. J Neurosci 28: 199-207

Ansorge MS, Zhou M, Lira A, Hen R, Gingrich JA (2004) Early-life blockade of the 5-HT transporter alters emotional behavior in adult mice. Science 306: 879-81

Bairy KL, Madhyastha S, Ashok KP, Bairy I, Malini S (2007) Developmental and behavioral consequences of prenatal fluoxetine. Pharmacology 79: 1-11

Bakker J, Brock O (2010) Early oestrogens in shaping reproductive networks: evidence for a potential organisational role of oestradiol in female brain development. J Neuroendocrinol 22: 728-35

Baum MJ, Brand T, Ooms M, Vreeburg JT, Slob AK (1988) Immediate postnatal rise in whole body androgen content in male rats: correlation with increased testicular content and reduced body clearance of testosterone. Biol Reprod 38: 980-6

Baumann P, Rochat B (1995) Comparative pharmacokinetics of selective serotonin reuptake inhibitors: a look behind the mirror. Int Clin Psychopharmacol 10 Suppl 1: 15-21

Berle JO, Spigset O (2011) Antidepressant Use During Breastfeeding. Curr Womens Health Rev 7: 2834

Berle JO, Steen VM, Aamo TO, Breilid H, Zahlsen K, Spigset O (2004) Breastfeeding during maternal antidepressant treatment with serotonin reuptake inhibitors: infant exposure, clinical symptoms, and cytochrome p450 genotypes. J Clin Psychiatry 65: 1228-34

Beversdorf DQ, Manning SE, Hillier A, Anderson SL, Nordgren RE, Walters SE, Nagaraja HN, Cooley WC, Gaelic SE, Bauman ML (2005) Timing of prenatal stressors and autism. J Autism Dev Disord 35: 471-8

Bhattacharyya A, Oppenheim RW, Prevette D, Moore BW, Brackenbury R, Ratner N (1992) S100 is present in developing chicken neurons and Schwann cells and promotes motor neuron survival in vivo. J Neurobiol 23: 451-66

Brennan PA, Pargas R, Walker EF, Green P, Newport DJ, Stowe Z (2008) Maternal depression and infant cortisol: influences of timing, comorbidity and treatment. J Child Psychol Psychiatry 49: 1099-107

Brezun JM, Daszuta A (1999) Depletion in serotonin decreases neurogenesis in the dentate gyrus and the subventricular zone of adult rats. Neuroscience 89: 999-1002

Burke KC, Burke JD, Jr., Rae DS, Regier DA (1991) Comparing age at onset of major depression and other psychiatric disorders by birth cohorts in five US community populations. Arch Gen Psychiatry 48: 789-95

Colvin L, Slack-Smith L, Stanley FJ, Bower C (2011) Dispensing patterns and pregnancy outcomes for women dispensed selective serotonin reuptake inhibitors in pregnancy. Birth Defects Res A Clin Mol Teratol 91: 142-52

Cooper WO, Willy ME, Pont SJ, Ray WA (2007) Increasing use of antidepressants in pregnancy. Am J Obstet Gynecol 196: 544 e1-5

Corbier P, Kerdelhue B, Picon R, Roffi J (1978) Changes in testicular weight and serum gonadotropin and testosterone levels before, during, and after birth in the perinatal rat. Endocrinology 103: 1985-91

Djavadian RL (2004) Serotonin and neurogenesis in the hippocampal dentate gyrus of adult mammals. Acta Neurobiol Exp (Wars) 64: 189-200 
Dohler KD (1991) The pre- and postnatal influence of hormones and neurotransmitters on sexual differentiation of the mammalian hypothalamus. Int Rev Cytol 131: 1-57

Dohler KD, Jarzab B, Sickmoller PM, Kokocinska D, Kaminski M, Gubala E, Achtelik W, Wagiel J (1991) Influence of neurotransmitters on sexual differentiation of brain structure and function. Exp Clin Endocrinol 98: 99-109

Dranovsky A, Hen R (2006) Hippocampal neurogenesis: regulation by stress and antidepressants. Biol Psychiatry 59: 1136-43

Eisch AJ, Cameron HA, Encinas JM, Meltzer LA, Ming GL, Overstreet-Wadiche LS (2008) Adult neurogenesis, mental health, and mental illness: hope or hype? J Neurosci 28: 11785-91

Eisch AJ, Petrik D (2012) Depression and hippocampal neurogenesis: a road to remission? Science 338: $72-5$

El Marroun H, Jaddoe VW, Hudziak JJ, Roza SJ, Steegers EA, Hofman A, Verhulst FC, White TJ, Stricker BH, Tiemeier H (2012) Maternal use of selective serotonin reuptake inhibitors, fetal growth, and risk of adverse birth outcomes. Arch Gen Psychiatry 69: 706-14

Eriksson PS, Perfilieva E, Bjork-Eriksson T, Alborn AM, Nordborg C, Peterson DA, Gage FH (1998) Neurogenesis in the adult human hippocampus. Nat Med 4: 1313-7

Fernandez-Guasti A, Fiedler JL, Herrera L, Handa RJ (2012) Sex, stress, and mood disorders: at the intersection of adrenal and gonadal hormones. Horm Metab Res 44: 607-18

Fleschler R, Peskin MF (2008) Selective serotonin reuptake inhibitors (SSRIs) in pregnancy: a review. MCN Am J Matern Child Nurs 33: 355-61; quiz 362-3

Fornaro E, Li D, Pan J, Belik J (2007) Prenatal exposure to fluoxetine induces fetal pulmonary hypertension in the rat. Am J Respir Crit Care Med 176: 1035-40

Frye CA, Orecki ZA (2002) Prenatal stress alters reproductive responses of rats in behavioral estrus and paced mating of hormone-primed rats. Horm Behav 42: 472-83

Galea LA, Spritzer MD, Barker JM, Pawluski JL (2006) Gonadal hormone modulation of hippocampal neurogenesis in the adult. Hippocampus 16: 225-32

Gaspar P, Cases O, Maroteaux L (2003) The developmental role of serotonin: news from mouse molecular genetics. Nat Rev Neurosci 4: 1002-12

Gentile S (2005) SSRIs in pregnancy and lactation: emphasis on neurodevelopmental outcome. CNS Drugs 19: 623-33

Gerardin DC, Pereira OC, Kempinas WG, Florio JC, Moreira EG, Bernardi MM (2005) Sexual behavior, neuroendocrine, and neurochemical aspects in male rats exposed prenatally to stress. Physiol Behav 84: 97-104

Gerecke KM, Kishore R, Jasnow A, Quadros-Menella P, Parker S, Kozub FJ, Lambert KG, Kinsley $\mathrm{CH}$ (2011) Alterations of sex-typical microanatomy: prenatal stress modifies the structure of medial preoptic area neurons in rats. Dev Psychobiol 54: 16-27

Glover V, O'Connor TG, O'Donnell K (2010) Prenatal stress and the programming of the HPA axis. Neurosci Biobehav Rev 35: 17-22

Gonzalez-Martinez T, Perez-Pinera P, Diaz-Esnal B, Vega JA (2003) S-100 proteins in the human peripheral nervous system. Microsc Res Tech 60: 633-8

Gutierrez J, Alvarez-Ordas I, Rojo M, Marin B, Menendez-Patterson A (1989) Reproductive function and sexual behaviour in female rats exposed to immobilization stress or ACTH injections during gestation. Physiol Bohemoslov 38: 13-20

Hansen HH, Sanchez C, Meier E (1997) Neonatal administration of the selective serotonin reuptake inhibitor Lu 10-134-C increases forced swimming-induced immobility in adult rats: a putative animal model of depression? J Pharmacol Exp Ther 283: 1333-41

Hensler JG (2006) Serotonergic modulation of the limbic system. Neurosci Biobehav Rev 30: 203-14

Herman JP, McKlveen JM, Solomon MB, Carvalho-Netto E, Myers B (2012) Neural regulation of the stress response: glucocorticoid feedback mechanisms. Braz J Med Biol Res 45: 292-8

Herrenkohl LR, Whitney JB (1976) Effects of prepartal stress on postpartal nursing behavior, litter development and adult sexual behavior. Physiol Behav 17: 1019-21

Huizink AC, Robles de Medina PG, Mulder EJ, Visser GH, Buitelaar JK (2003) Stress during pregnancy is associated with developmental outcome in infancy. J Child Psychol Psychiatry 44: $810-8$

Ishiwata H, Shiga T, Okado N (2005) Selective serotonin reuptake inhibitor treatment of early postnatal mice reverses their prenatal stress-induced brain dysfunction. Neuroscience 133: 893-901

Jarzab B, Dohler KD (1984) Serotoninergic influences on sexual differentiation of the rat brain. Prog Brain Res 61: 119-26 
Karpova NN, Lindholm J, Pruunsild P, Timmusk T, Castren E (2009) Long-lasting behavioural and molecular alterations induced by early postnatal fluoxetine exposure are restored by chronic fluoxetine treatment in adult mice. Eur Neuropsychopharmacol 19: 97-108

Kempermann G, Jessberger S, Steiner B, Kronenberg G (2004) Milestones of neuronal development in the adult hippocampus. Trends Neurosci 27: 447-52

Kim J, Riggs KW, Misri S, Kent N, Oberlander TF, Grunau RE, Fitzgerald C, Rurak DW (2006) Stereoselective disposition of fluoxetine and norfluoxetine during pregnancy and breastfeeding. Br J Clin Pharmacol 61: 155-63

Knaepen L, Rayen I, Charlier TD, Fillet M, Houbart V, van Kleef M, Steinbusch HW, Patijn J, Tibboel D, Joosten EA, Pawluski JL (2013) Developmental fluoxetine exposure normalizes the longterm effects of maternal stress on post-operative pain in Sprague-Dawley rat offspring. PLoS One 8: e57608

Kristensen JH, Ilett KF, Hackett LP, Yapp P, Paech M, Begg EJ (1999) Distribution and excretion of fluoxetine and norfluoxetine in human milk. Br J Clin Pharmacol 48: 521-7

Ladosky W, Gaziri LC (1970) Brain serotonin and sexual differentiation of the nervous system. Neuroendocrinology 6: 168-74

Lalau JD, Aubert ML, Carmignac DF, Gregoire I, Dupouy JP (1990) Reduction in testicular function in rats. II. Reduction by dexamethasone in fetal and neonatal rats. Neuroendocrinology 51: 28993

Lancaster CA, Gold KJ, Flynn HA, Yoo H, Marcus SM, Davis MM (2010) Risk factors for depressive symptoms during pregnancy: a systematic review. Am J Obstet Gynecol 202: 5-14

Laplante DP, Barr RG, Brunet A, Galbaud du Fort G, Meaney ML, Saucier JF, Zelazo PR, King S (2004) Stress during pregnancy affects general intellectual and language functioning in human toddlers. Pediatr Res 56: 400-10

Laplante P, Diorio J, Meaney MJ (2002) Serotonin regulates hippocampal glucocorticoid receptor expression via a 5-HT7 receptor. Brain Res Dev Brain Res 139: 199-203

Lee HJ, Kim JW, Yim SV, Kim MJ, Kim SA, Kim YJ, Kim CJ, Chung JH (2001) Fluoxetine enhances cell proliferation and prevents apoptosis in dentate gyrus of maternally separated rats. Mol Psychiatry 6: 610, 725-8

Leuner B, Gould E (2010) Structural plasticity and hippocampal function. Annu Rev Psychol 61: 111$40, \mathrm{C} 1-3$

Leung BM, Kaplan BJ (2009) Perinatal depression: prevalence, risks, and the nutrition link--a review of the literature. J Am Diet Assoc 109: 1566-75

Limlomwongse N, Liabsuetrakul T (2006) Cohort study of depressive moods in Thai women during late pregnancy and 6-8 weeks of postpartum using the Edinburgh Postnatal Depression Scale (EPDS). Arch Womens Ment Health 9: 131-8

Lisboa SF, Oliveira PE, Costa LC, Venancio EJ, Moreira EG (2007) Behavioral evaluation of male and female mice pups exposed to fluoxetine during pregnancy and lactation. Pharmacology 80: 4956

Maccari S, Darnaudery M, Morley-Fletcher S, Zuena AR, Cinque C, Van Reeth O (2003) Prenatal stress and long-term consequences: implications of glucocorticoid hormones. Neurosci Biobehav Rev 27: 119-27

Maccari S, Morley-Fletcher S (2007) Effects of prenatal restraint stress on the hypothalamus-pituitaryadrenal axis and related behavioural and neurobiological alterations. Psychoneuroendocrinology 32 Suppl 1: S10-5

Maciag D, Simpson KL, Coppinger D, Lu Y, Wang Y, Lin RC, Paul IA (2006a) Neonatal antidepressant exposure has lasting effects on behavior and serotonin circuitry. Neuropsychopharmacology 31: 47-57

Maciag D, Williams L, Coppinger D, Paul IA (2006b) Neonatal citalopram exposure produces lasting changes in behavior which are reversed by adult imipramine treatment. Eur J Pharmacol 532: 265-9

Malberg JE, Duman RS (2003) Cell proliferation in adult hippocampus is decreased by inescapable stress: reversal by fluoxetine treatment. Neuropsychopharmacology 28: 1562-71

Malberg JE, Eisch AJ, Nestler EJ, Duman RS (2000) Chronic antidepressant treatment increases neurogenesis in adult rat hippocampus. J Neurosci 20: 9104-10

Marcus SM (2009) Depression during pregnancy: rates, risks and consequences--Motherisk Update 2008. Can J Clin Pharmacol 16: e15-22

Mateus-Pinheiro A, Pinto L, Bessa JM, Morais M, Alves ND, Monteiro S, Patricio P, Almeida OF, Sousa N (2013) Sustained remission from depressive-like behavior depends on hippocampal neurogenesis. Transl Psychiatry 3: e210 
McAllister BB, Kiryanova V, Dyck RH (2012) Behavioural outcomes of perinatal maternal fluoxetine treatment. Neuroscience 226: 356-66

McEwen BS (2005) Glucocorticoids, depression, and mood disorders: structural remodeling in the brain. Metabolism 54: 20-3

McEwen BS, Stellar E (1993) Stress and the individual. Mechanisms leading to disease. Arch Intern Med 153: 2093-101

Meaney MJ, Diorio J, Francis D, LaRocque S, O'Donnell D, Smythe JW, Sharma S, Tannenbaum B (1994) Environmental regulation of the development of glucocorticoid receptor systems in the rat forebrain. The role of serotonin. Ann N Y Acad Sci 746: 260-73; discussion 274, 289-93

Morrison JL, Riggs KW, Chien C, Gruber N, McMillen IC, Rurak DW (2004) Chronic maternal fluoxetine infusion in pregnant sheep: effects on the maternal and fetal hypothalamicpituitary-adrenal axes. Pediatr Res 56: 40-6

Moses-Kolko EL, Bogen D, Perel J, Bregar A, Uhl K, Levin B, Wisner KL (2005) Neonatal signs after late in utero exposure to serotonin reuptake inhibitors: literature review and implications for clinical applications. JAMA 293: 2372-83

Niederhofer H, Reiter A (2004) Prenatal maternal stress, prenatal fetal movements and perinatal temperament factors influence behavior and school marks at the age of 6 years. Fetal Diagn Ther 19: 160-2

Noorlander CW, Ververs FF, Nikkels PG, van Echteld CJ, Visser GH, Smidt MP (2008) Modulation of serotonin transporter function during fetal development causes dilated heart cardiomyopathy and lifelong behavioral abnormalities. PLoS One 3: e2782

Nulman I, Rovet J, Stewart DE, Wolpin J, Pace-Asciak P, Shuhaiber S, Koren G (2002) Child development following exposure to tricyclic antidepressants or fluoxetine throughout fetal life: a prospective, controlled study. Am J Psychiatry 159: 1889-95

O'Mahony SM, Myint AM, van den Hove D, Desbonnet L, Steinbusch H, Leonard BE (2006) Gestational stress leads to depressive-like behavioural and immunological changes in the rat. Neuroimmunomodulation 13: 82-8

Oberlander TF, Eckstein Grunau R, Fitzgerald C, Ellwood AL, Misri S, Rurak D, Riggs KW (2002) Prolonged prenatal psychotropic medication exposure alters neonatal acute pain response. Pediatr Res 51: 443-53

Oberlander TF, Gingrich JA, Ansorge MS (2009) Sustained neurobehavioral effects of exposure to SSRI antidepressants during development: molecular to clinical evidence. Clin Pharmacol Ther 86: 672-7

Oberlander TF, Grunau R, Mayes L, Riggs W, Rurak D, Papsdorf M, Misri S, Weinberg J (2008a) Hypothalamic-pituitary-adrenal (HPA) axis function in 3-month old infants with prenatal selective serotonin reuptake inhibitor (SSRI) antidepressant exposure. Early Hum Dev 84: 689-97

Oberlander TF, Grunau RE, Fitzgerald C, Papsdorf M, Rurak D, Riggs W (2005) Pain reactivity in 2month-old infants after prenatal and postnatal serotonin reuptake inhibitor medication exposure. Pediatrics 115: 411-25

Oberlander TF, Papsdorf M, Brain UM, Misri S, Ross C, Grunau RE (2010) Prenatal effects of selective serotonin reuptake inhibitor antidepressants, serotonin transporter promoter genotype (SLC6A4), and maternal mood on child behavior at 3 years of age. Arch Pediatr Adolesc Med 164: 444-51

Oberlander TF, Reebye P, Misri S, Papsdorf M, Kim J, Grunau RE (2007) Externalizing and attentional behaviors in children of depressed mothers treated with a selective serotonin reuptake inhibitor antidepressant during pregnancy. Arch Pediatr Adolesc Med 161: 22-9

Oberlander TF, Warburton W, Misri S, Aghajanian J, Hertzman C (2006) Neonatal outcomes after prenatal exposure to selective serotonin reuptake inhibitor antidepressants and maternal depression using population-based linked health data. Arch Gen Psychiatry 63: 898-906

Oberlander TF, Weinberg J, Papsdorf M, Grunau R, Misri S, Devlin AM (2008b) Prenatal exposure to maternal depression, neonatal methylation of human glucocorticoid receptor gene (NR3C1) and infant cortisol stress responses. Epigenetics 3: 97-106

Olivier JD, Valles A, van Heesch F, Afrasiab-Middelman A, Roelofs JJ, Jonkers M, Peeters EJ, KorteBouws GA, Dederen JP, Kiliaan AJ, Martens GJ, Schubert D, Homberg JR (2011) Fluoxetine administration to pregnant rats increases anxiety-related behavior in the offspring. Psychopharmacology (Berl) 217: 419-32

Palkovits M (1987) Organization of the stress response at the anatomical level. Prog Brain Res 72: 4755 
Pawluski JL, Brain UM, Underhill CM, Hammond GL, Oberlander TF (2012) Prenatal SSRI exposure alters neonatal corticosteroid binding globulin, infant cortisol levels, and emerging HPA function. Psychoneuroendocrinology 37: 1019-28

Pawluski JL, Brummelte S, Barha CK, Crozier TM, Galea LA (2009a) Effects of steroid hormones on neurogenesis in the hippocampus of the adult female rodent during the estrous cycle, pregnancy, lactation and aging. Front Neuroendocrinol 30: 343-57

Pawluski JL, Galea LA, Brain U, Papsdorf M, Oberlander TF (2009b) Neonatal S100B protein levels after prenatal exposure to selective serotonin reuptake inhibitors. Pediatrics 124: e662-70

Perera TD, Coplan JD, Lisanby SH, Lipira CM, Arif M, Carpio C, Spitzer G, Santarelli L, Scharf B, Hen R, Rosoklija G, Sackeim HA, Dwork AJ (2007) Antidepressant-induced neurogenesis in the hippocampus of adult nonhuman primates. J Neurosci 27: 4894-901

Popa D, Lena C, Alexandre C, Adrien J (2008) Lasting syndrome of depression produced by reduction in serotonin uptake during postnatal development: evidence from sleep, stress, and behavior. J Neurosci 28: 3546-54

Rhees RW, Al-Saleh HN, Kinghorn EW, Fleming DE, Lephart ED (1999) Relationship between sexual behavior and sexually dimorphic structures in the anterior hypothalamus in control and prenatally stressed male rats. Brain Res Bull 50: 193-9

Rhees RW, Kirk BA, Sephton S, Lephart ED (1997) Effects of prenatal testosterone on sexual behavior, reproductive morphology and LH secretion in the female rat. Dev Neurosci 19: 4307

Romijn HJ, Hofman MA, Gramsbergen A (1991) At what age is the developing cerebral cortex of the rat comparable to that of the full-term newborn human baby? Early Hum Dev 26: 61-7

Rothman SM, Mattson MP (2010) Adverse stress, hippocampal networks, and Alzheimer's disease. Neuromolecular Med 12: 56-70

Santarelli L, Saxe M, Gross C, Surget A, Battaglia F, Dulawa S, Weisstaub N, Lee J, Duman R, Arancio O, Belzung C, Hen R (2003) Requirement of hippocampal neurogenesis for the behavioral effects of antidepressants. Science 301: 805-9

Segarra AC, Luine VN, Strand FL (1991) Sexual behavior of male rats is differentially affected by timing of perinatal ACTH administration. Physiol Behav 50: 689-97

Simpson KL, Weaver KJ, de Villers-Sidani E, Lu JY, Cai Z, Pang Y, Rodriguez-Porcel F, Paul IA, Merzenich M, Lin RC (2011) Perinatal antidepressant exposure alters cortical network function in rodents. Proc Natl Acad Sci U S A 108: 18465-70

Slob AK, Ooms MP, Vreeburg JT (1980) Prenatal and early postnatal sex differences in plasma and gonadal testosterone and plasma luteinizing hormone in female and male rats. J Endocrinol 87: $81-7$

Smith JW, Seckl JR, Evans AT, Costall B, Smythe JW (2004) Gestational stress induces post-partum depression-like behaviour and alters maternal care in rats. Psychoneuroendocrinology 29: 22744

Soga T, Wong DW, Putteeraj M, Song KP, Parhar IS (2012) Early-life citalopram-induced impairments in sexual behavior and the role of androgen receptor. Neuroscience 225: 172-84

Stewart DE (2011) Clinical practice. Depression during pregnancy. N Engl J Med 365: 1605-11

Talge NM, Neal C, Glover V (2007) Antenatal maternal stress and long-term effects on child neurodevelopment: how and why? J Child Psychol Psychiatry 48: 245-61

Van den Bergh BR, Mennes M, Oosterlaan J, Stevens V, Stiers P, Marcoen A, Lagae L (2005) High antenatal maternal anxiety is related to impulsivity during performance on cognitive tasks in 14- and 15-year-olds. Neurosci Biobehav Rev 29: 259-69

Van den Hove DL, Blanco CE, Aendekerk B, Desbonnet L, Bruschettini M, Steinbusch HP, Prickaerts J, Steinbusch HW (2005) Prenatal restraint stress and long-term affective consequences. Dev Neurosci 27: 313-20

Van den Hove DL, Blanco CE, Scheepens A, Desbonnet L, Myint AM, Leonard BE, Prickaerts J, Steinbusch HW (2008) Prenatal maternal paroxetine treatment and neonatal mortality in the rat: a preliminary study. Neonatology $93: 52-5$

Varrault A, Bockaert J, Waeber C (1992) Activation of 5-HT1A receptors expressed in NIH-3T3 cells induces focus formation and potentiates EGF effect on DNA synthesis. Mol Biol Cell 3: 961-9

Vega P, Barbeito S, Ruiz de Azua S, Martinez-Cengotitabengoa M, Gonzalez-Ortega I, Saenz M, Gonzalez-Pinto A (2011) Bipolar disorder differences between genders: special considerations for women. Womens Health (Lond Engl) 7: 663-74; quiz 675-6

Ververs T, Kaasenbrood H, Visser G, Schobben F, de Jong-van den Berg L, Egberts T (2006) Prevalence and patterns of antidepressant drug use during pregnancy. Eur J Clin Pharmacol 62: 863-70 


\section{Chapter 1}

Wainwright SR, Galea LA (2013) The Neural Plasticity Theory of Depression: Assessing the Roles of Adult Neurogenesis and PSA-NCAM within the Hippocampus. Neural Plast 2013: 805497

Wang CT, Shui HA, Huang RL, Tai MY, Peng MT, Tsai YF (2006) Sexual motivation is demasculinized, but not feminized, in prenatally stressed male rats. Neuroscience 138: 357-64

Ward IL (1972) Prenatal stress feminizes and demasculinizes the behavior of males. Science 175: 82-4

Ward IL, Weisz J (1980) Maternal stress alters plasma testosterone in fetal males. Science 207: 328-9

Ward IL, Weisz J (1984) Differential effects of maternal stress on circulating levels of corticosterone, progesterone, and testosterone in male and female rat fetuses and their mothers. Endocrinology 114: 1635-44

Weinstock M (2008) The long-term behavioural consequences of prenatal stress. Neurosci Biobehav Rev 32: 1073-86

Weisz J, Ward IL (1980) Plasma testosterone and progesterone titers of pregnant rats, their male and female fetuses, and neonatal offspring. Endocrinology 106: 306-16

Whitaker-Azmitia PM, Druse M, Walker P, Lauder JM (1996) Serotonin as a developmental signal. Behav Brain Res 73: 19-29

Wilson CA, Pearson JR, Hunter AJ, Tuohy PA, Payne AP (1986) The effect of neonatal manipulation of hypothalamic serotonin levels on sexual activity in the adult rat. Pharmacol Biochem Behav 24: $1175-83$

Winningham-Major F, Staecker JL, Barger SW, Coats S, Van Eldik LJ (1989) Neurite extension and neuronal survival activities of recombinant $\mathrm{S} 100$ beta proteins that differ in the content and position of cysteine residues. J Cell Biol 109: 3063-71

Zagron G, Weinstock M (2006) Maternal adrenal hormone secretion mediates behavioural alterations induced by prenatal stress in male and female rats. Behav Brain Res 175: 323-8 


\section{Chapter 2}

Fluoxetine during development reverses the effects of prenatal stress on depressive-like behavior and hippocampal neurogenesis in adolescence

Authors: Ine Rayen, Daniël L. van den Hove, Jos Prickaerts, Harry W.

M. Steinbusch, Jodi L. Pawluski

PLoS ONE 6(9): e24003. doi:10.1371/journal.pone.0024003 
Chapter 2

\section{Abstract}

Depression during pregnancy and the postpartum period is a growing health problem, which affects up to $20 \%$ of women. Currently, selective serotonin reuptake inhibitor (SSRIs) medications are commonly used for treatment of maternal depression. Unfortunately, there is very little research on the long-term effect of maternal depression and perinatal SSRI exposure on offspring development. Therefore, the aim of this study was to determine the role of exposure to fluoxetine during development on affective-like behaviors and hippocampal neurogenesis in adolescent offspring in a rodent model of maternal depression. To do this, gestationally stressed and non-stressed Sprague-Dawley rat dams were treated with either fluoxetine $(5 \mathrm{mg} / \mathrm{kg} /$ day $)$ or vehicle beginning on postnatal day 1 (P1). Adolescent male and female offspring were divided into 4 groups: 1) prenatal stress + fluoxetine exposure, 2) prenatal stress + vehicle, 3) fluoxetine exposure alone, and 4) vehicle alone. Adolescent offspring were assessed for anxiety-like behavior using the Open Field Test and depressive-like behavior using the Forced Swim Test. Brains were analyzed for endogenous markers of hippocampal neurogenesis via immunohistochemistry. Results demonstrate that maternal fluoxetine exposure reverses the reduction in immobility evident in prenatally stressed adolescent offspring. In addition, maternal fluoxetine exposure reverses the decrease in hippocampal cell proliferation and neurogenesis in maternally stressed adolescent offspring. This research provides important evidence on the long-term effect of fluoxetine exposure during development in a model of maternal adversity. 


\section{Introduction}

Depression during pregnancy and the postpartum period is a growing health concern that affects up to $20 \%$ of women (Almond 2009; Leung and Kaplan 2009; Limlomwongse and Liabsuetrakul 2006; Marcus 2009). Maternal stress, depression and anxiety, can have long-term effects on the physical and mental development of children (Huizink et al. 2003; Oberlander et al. 2009; Talge et al. 2007). For example, antenatal maternal depression can lead to neurobehavioral disturbances, such as impaired cognitive and social developmental outcomes (Glover et al. 2010; Huizink et al. 2003; Laplante et al. 2004; Niederhofer and Reiter 2004; Talge et al. 2007; Van den Bergh et al. 2005). In rodent models, stress during gestation, which results in depressive-like behavior in the dam (O'Mahony et al. 2006; Smith et al. 2004), models the clinical findings (Glover et al. 2010; Zagron and Weinstock 2006). Several animal studies have indicated that adult offspring of prenatally stressed mothers show increases in affective-related behavior (Maccari et al. 2003; Maccari and MorleyFletcher 2007; Weinstock 2008; Zagron and Weinstock 2006) and decreased levels of hippocampal neurogenesis (Coe et al. 2003; Kawamura et al. 2006; Lucassen et al. 2009; Odagiri et al. 2008). Given the development effect of exposure to maternal depression, it is crucial to treat this disorder in order to improve maternal and child outcomes.

Selective serotonin reuptake inhibitor (SSRIs) medications are commonly used for the treatment of maternal depression (Fleschler and Peskin 2008). Current estimates suggest that there is an increasing incidence of SSRI use in mothers that ranges between 5-10\% (Cooper et al. 2007; Oberlander et al. 2006; Ververs et al. 2006). However, the effects of these medications on the developing child have yet to be fully determined (Homberg et al. 2010; Oberlander et al. 2009). Recent clinical studies report that neonates exposed to SSRI medications during gestation, regardless of maternal mood state, have an increased risk for low birth weight, younger gestational age, neurobehavioral disturbances, and reduced heart rate variability (Moses-Kolko et al. 2005; Nulman et al. 2002; Oberlander et al. 2009). Recent evidence also demonstrates that prenatal exposure to SSRI-medications may alter neurodevelopment as evidenced via alterations in S100B levels (Pawluski et al. 2009c). In addition, perinatal exposure to SSRI medications may have long term effects on mood in children (Oberlander et al. 2008; Oberlander et al. 2010). For 
example, children perinatally exposed to maternal depression and SSRIs exhibit increased internalizing behaviors at 3 years (Oberlander et al. 2010).

Preclinical data is beginning to show that exposure to SSRIs during development significantly impacts offspring affective-like behaviors and neural plasticity (Homberg et al. 2010; Oberlander et al. 2009; Pawluski in press). For example, SSRI treatment, via intraperitoneal (i.p.) injection to offspring, during the early postnatal period can result in increased depressive- and anxiety-like behavior during adulthood (Ansorge et al. 2008; Hansen et al. 1997; Karpova et al. 2009). Developmental exposure to SSRIs may also influence neuroplasticity in the hippocampus, through effects on brain derived neurotrophic factor (BDNF) mRNA levels (Karpova et al. 2009).

Although these studies point to a role for SSRIs in development, it should be noted that in preclinical studies offspring are treated with or exposed to SSRIs alone, and not in combination with maternal depression. To date, very little research has looked at the effect of maternal stress and SSRIs on offspring outcomes (Ishiwata et al. 2005; Van den Hove et al. 2008) and only one study has combined both a model of maternal stress and fluoxetine exposure (Ishiwata et al. 2005). This study demonstrated that postnatal oral administration of the SSRI, fluoxetine, to pups reverses the stress induced reduction in CA3 spine and synapse density in juveniles and young adults (Ishiwata et al. 2005). In this study, SSRI treatment alone, in the absence of maternal stress, had no affect on spine density measures in the CA3 region of the hippocampus (Ishiwata et al. 2005). Thus the actions of early exposure to SSRI medications may be very different in the presence of maternal adversity. Therefore to better translate these findings to the clinic, the effects of maternal use of SSRI medications need to be investigated in animal models of maternal adversity.

The aim of the present study was to investigate the developmental effect of fluoxetine, a popular SSRI antidepressant used during pregnancy, in a model of maternal adversity, on anxiety and depression-related behavior and hippocampal neurogenesis in adolescent male and female offspring. Although research has investigated the developmental impact of perinatal SSRI exposure on offspring outcomes, little research has been done on the neurodevelopmental effects of postnatal fluoxetine treatment in an animal model of maternal depression. In addition, much less research has looked at the long-term effects of developmental SSRI exposure during adolescence, a time of vulnerability to stress (Lopez-Duran et al. 
2009; McCormick and Mathews 2007; Romeo 2010; Romeo et al. 2007; Romeo and McEwen 2006). Our data shows that the exposure to fluoxetine during development can reverse the effect of prenatal stress on aspects of adolescent development. Knowledge of the effects of maternal depression and antidepressant treatment during the perinatal period is needed to ameliorate treatment and intervention options, and thus improve neurodevelopmental outcomes.

\section{Methods}

Animals. Twenty-two adult female Sprague-Dawley rats (250-300g; Charles River Laboratories, France) were used in the present study. Rats were kept under standard laboratory conditions in a 12h:12h light/dark schedule (lights on at 07:00 h) with $\mathrm{ad}$ libitum access to rat chow (Sniff) and tap water. All experiments were approved by the Animal Ethics Board of Maastricht University in accordance with Dutch governmental regulations (approval IDs: DEC 2008-157 and DEC 2008-158). All efforts were made to minimize the pain and stress levels experienced by the animals.

On gestation day (GD) 15 , dams were randomly assigned to stress $(n=12)$ or control groups $(\mathrm{n}=10)$. Dams in the stress group were individually restrained three times a day for 45 min in transparent plastic cylinders under bright light (between 810am, 12-2pm, 4-6pm) on GD15-20 and twice on GD21 as previously described (Van den Hove et al. 2005; Ward and Weisz 1984). This time period during pregnancy is when stress can result in postpartum depressive-like behavior in the dam (O'Mahony et al. 2006; Smith et al. 2004) and a period of stress that affects offspring outcomes (Darnaudery and Maccari 2008; Weinstock 2008).

One day after birth (birth day $=\mathrm{P} 0$ ), litters were culled to 5 males and 5 females and dams (with offspring) were randomly assigned to one of two treatment groups: fluoxetine $(5 \mathrm{mg} / \mathrm{kg} / \mathrm{day})$ or vehicle, for a total of four groups of dams: 1) Prenatal Stress + Vehicle (PSV; n=5), 2) Prenatal Stress + Fluoxetine (PSF; n=7), 3) Control + Fluoxetine $(\mathrm{CF} ; \mathrm{n}=5)$, and 4) Control + Vehicle $(\mathrm{CV} ; \mathrm{n}=5)$. A maximum of 2 male and 2 female offspring per litter were used in the present experiment $(n=9$ 11/sex/group). Offspring litter was weighed on P21 and individual weights were taken once between P29-31 and once between P39-42. For assessment of hippocampal cell proliferation and neurogenesis, 5 animals per group were used (1 male and 1 female from each litter). For a time line of the experiment see Figure 1. 


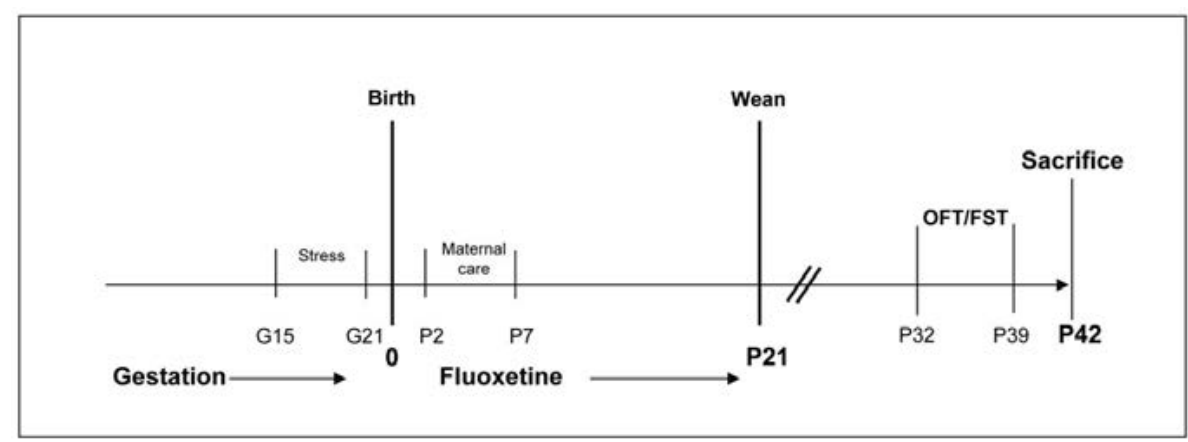

Figure 1. Timeline of experiment. Stress was administered between G15-21. Fluoxetine treatment to the mother began 1 day after birth and continued until weaning (P21). Between P32 and P39, offspring were subjected to behavioral tasks. At P42, offspring were sacrificed.

Fluoxetine treatment. Fluoxetine treatment was administered via osmotic minipumps (Alzet Osmotic pumps, 2ML4) to the dam on P1. Fluoxetine and its active metabolite, norfluoxetine, can pass to offspring through lactation (Gentile et al. 2007), therefore we used this mode of delivery to prevent the stress of administration via injection, or oral gavage to the offspring. In addition, rodent brain development during the early postpartum period is analogous to human brain development during the third trimester (Romijn et al. 1991).

Implants were filled with either fluoxetine (Fagron, Belgium), dissolved in vehicle $(50 \%$ propylenediol in saline; $5 \mathrm{mg} / \mathrm{kg} /$ day $)$, or with vehicle as previously described (Alahmed and Herbert 2008). Minipumps were implanted subcutaneously in the dorsal region while the dams were under mild isofluorene anesthesia on postpartum day $1(\mathrm{P} 1)$.

Maternal care. Maternal care was assessed twice a day for 5 minutes from P2 to P7 based on previous literature (Pawluski et al. 2009). Scoring took place in the morning (between 8:30 a.m. and 10:30 a.m.) and the afternoon (between 13:30 p.m. and 15:30 p.m.) with at least $3 \mathrm{~h}$ between the sessions. During each testing period the duration of the following maternal behaviors was assessed: licking (licking/grooming; licking/grooming/nursing), nursing (arched-back nursing, "blanket" nursing, and passive nursing) and nest building. Data were aggregated across days and were calculated as total percent time spent in each behavior.

The Open Field Test (OFT). The OFT was used to study anxiety-like behavior and locomotor activity in adolescent offspring (Prut and Belzung 2003). The open field test consisted of a $100 \mathrm{~cm} \times 100 \mathrm{~cm}$ area divided into central and peripheral areas with 
$40 \mathrm{~cm}$ high walls. For the test, a rat was placed in the centre of the field and behavior was recorded for five minutes. All animals were tested once between 9:30 a.m. and 2 p.m. (age P32-34). A video-tracking system (Anymaze, Stoelting) was used to score the distance travelled, number of entries into the central and peripheral areas, and total time spent in the central and peripheral areas. The apparatus was cleaned with $70 \%$ ethanol and dried between rats.

The Forced Swim Test (FST). The forced swim test (FST) was used to assess depressive-like behavior in the adolescent offspring as previously described (Pawluski et al. 2009; Pawluski et al. 2011; Reed et al. 2008). The apparatus consisted of a vertical cylindrical glass tank (height $50 \mathrm{~cm}$ x diameter $20 \mathrm{~cm}$ ) filled to a depth of 20 $\mathrm{cm}$ with tap water at $27 \pm 1{ }^{\circ} \mathrm{C}$. For the test, an animal was placed in a cylindrical glass tank for 10min. Offspring were tested on the FST, between 9 a.m. and 1 p.m. (age P37-39). Using the Best Collection System (Educational Consulting Inc.), behaviors scored in the FST were (1) immobility - floating with the absence of any movement and (2) struggling - quick movements of the forelimbs such that the front paws break the surface of the water.

Immunohistochemistry (IHC). A minimum of 2 days after the last behavioral test, offspring were deeply anesthetised with an overdose of pentobarbital, and decapitated. Half of the brain was used for IHC, the hippocampus of the other half was used for further analysis not included in the present study. Brains were post-fixed in $4 \%$ paraformaldehyde for 48 hours, cryoprotected in 30\% sucrose/phosphate-buffered saline solution for up to one week, frozen on dry ice and kept at $-80^{\circ} \mathrm{C}$. Brain tissue was sliced in $40 \mu \mathrm{m}$ sections on a cryostat (Leica). Tissue was stored in antifreeze solution and maintained at $-15^{\circ} \mathrm{C}$. The number of proliferating cells and immature neurons were assessed in the dentate gyrus of the hippocampus using endogenous markers, i.e. Ki67 for cell proliferation and doublecortin (DCX) for immature neurons. Every $6^{\text {th }}$ section throughout half the hippocampus was stained as previously described (Balthazart et al. 2008; Epp et al. 2009). Sections were blocked with $\mathrm{H}_{2} \mathrm{O}_{2}$ and incubated overnight in either rabbit anti-Ki67 (1:500; Vector Laboratories) or goat anti-DCX (1:200; Santa Cruz). Sections were then incubated overnight in biotinylated donkey anti-rabbit (1:500; Jackson ImmunoResearch, Suffolk, UK) or for 2 hours in biotinylated rabbit anti-goat (1:500; Jackson ImmunoResearch) secondary antibody. Brain sections were further processed by using the avidine-biotine complex (ABC Elite kit; 1:1000; Vector laboratories). DAB (3,3-diaminobenzidine; Sigma) 
was used as a substrate to obtain a color reaction. Sections were mounted on gelatincoated slides, dried overnight, counterstained with Cresyl Violet acetate, dehydrated and coverslipped with Permount (Fisher Scientific).

The number of Ki67 immunoreactive (-ir) cells and DCX-ir cells were counted under 40x objective with oil as previously described (Balthazart et al. 2008; Epp et al. 2009). Cells were considered Ki67-ir if they were intensely stained and exhibited medium round or oval cell bodies (Figure 2A). Cells were considered DCX-ir if they exhibited medium round or oval cell bodies and dendrites (Figure 2B). The areas of the granule cell layer/subgranular zone (GCL/SGZ) and hilus were measured using StereoInvestigator software (MicroBrightField, Williston, VT, USA) and estimates of GCL/SGZ and hilus volumes were made using Cavalieri's principle (Gundersen et al. 1988).
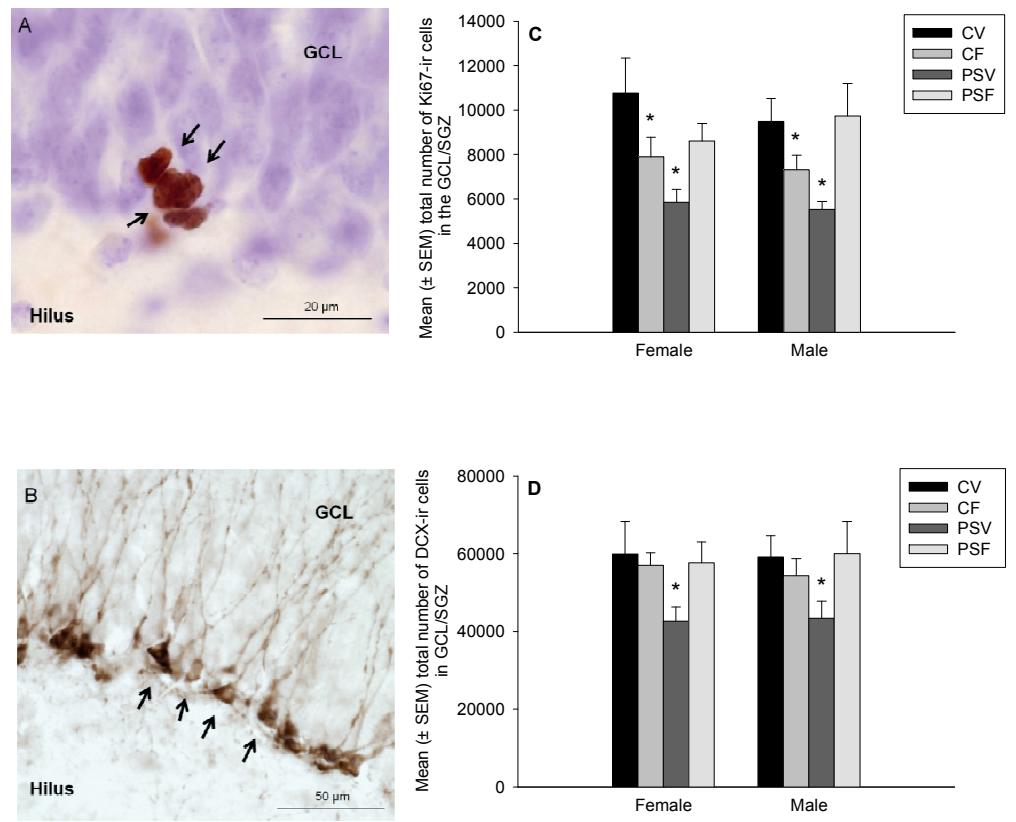

Figure 2. Photomicrographs of representative A) Ki67-ir cells and B) DCX-ir cells in the GCL/SGZ and mean ( \pm SEM) number of C) Ki67-ir cells and D) DCX-ir cells in the GCL/SGZ. C) PSV adolescent offspring had significantly fewer Ki-67-ir cells in the GCL/SVZ compared to all other groups $(.0001 \leq p \leq .01)$. CF adolescent offspring had significantly more Ki67-ir cells in the GCL/SVZ compared to PSV offspring ( $\leq .0001$ ), but significantly fewer Ki67-ir cells in the GCL/SVZ compared to CV and PSF offspring (.002 $\leq p \leq .04)$, regardless of sex. D) PSV adolescent offspring had significantly fewer number of DCX-ir cells in the GCL/SGZ of the 
hippocampus compared to all other groups $(.006 \leq p \leq .03)$, regardless of sex. ${ }^{\text {'*'denotes }}$ significantly different from all other groups. ( $\mathrm{n}=\mathbf{5} / \mathrm{sex} / \mathrm{group}$ ).

Statistical analyses. Analysis of variance tests (ANOVA) were done for maternal behaviors with condition (prenatal stress/no stress) and treatment (fluoxetine/vehicle) as independent factors. ANOVAs were done on offspring weight gain, FST measures, OFT measures, Ki67-ir and DCX-ir cell numbers with condition (prenatal stress/no stress), treatment (fluoxetine/vehicle), and sex (male/female) as independent factors. Pearson product moment correlations were conducted between behaviors on the OFT (central entries, central time, and central distance) and FST (struggling and floating), and the total number of Ki67-ir and DCX-ir cells for all groups and separately by treatment and condition. Any differences in age, weight, time of testing or test order of the litter, were accounted for, where appropriate, via an analysis of covariance. In cases where clear sex differences were evident stratified analysis were done separately for each sex. Posthoc comparisons utilized the Fisher LSD test.

\section{Results}

Maternal care. Stressed dams spent a significantly greater percentage of time nest building compared to non-stressed dams, regardless of fluoxetine treatment (main effect of treatment; $\mathrm{F}(1,18)=10.66, \mathrm{p} \leq .004$; Table 1). Independent of treatment condition, dams spent a significantly greater percentage of time nursing offspring than licking offspring (main effect of time; $F(1,18)=358.37, \mathrm{p} \leq .00001$; Table 1).

Table 1. Mean ( \pm SEM) percentage of time in maternal behaviors.

\begin{tabular}{l|cccc}
\hline & CV & CF & PSV & PSF \\
\hline Licking (\%) & $11.00 \pm 2.68$ & $6.92 \pm 1.68$ & $10.56 \pm 3.03$ & $7.82 \pm 1.89$ \\
Nursing (\%) & $71.5 \pm 5.84$ & $79.19 \pm 6.70$ & $73.14 \pm 4.06$ & $72.98 \pm 5.06$ \\
Nest building (\%) & $0.36 \pm 0.12$ & $0.28 \pm 0.13$ & $2.78 \pm 0.89^{*}$ & $1.32 \pm 0.51^{*}$ \\
\hline
\end{tabular}

Stressed dams spent a significantly greater percentage of time nest building compared to nonstressed dams, regardless of fluoxetine treatment $(\mathrm{p} \leq .004)$. Regardless of treatment or condition, dams spent a significantly greater percentage of time nursing offspring than licking offspring ( $\mathrm{p} \leq .00001)$. '*' denotes significantly different from $\mathrm{CV}$ and $\mathrm{CF}$.

Body weight change. CF and PSF offspring gained significantly less weight than CV and PSV offspring, regardless of stress (main effect of treatment; $F(1,68)=15.33, p \leq$ .0002 ; Figure 3 ). Overall, male offspring gained significantly more weight than 
female offspring (main effect of sex; $F(1,68)=16.71, p \leq .0001$; Figure 3 ), even when controlling for any age differences at the time of weighing.

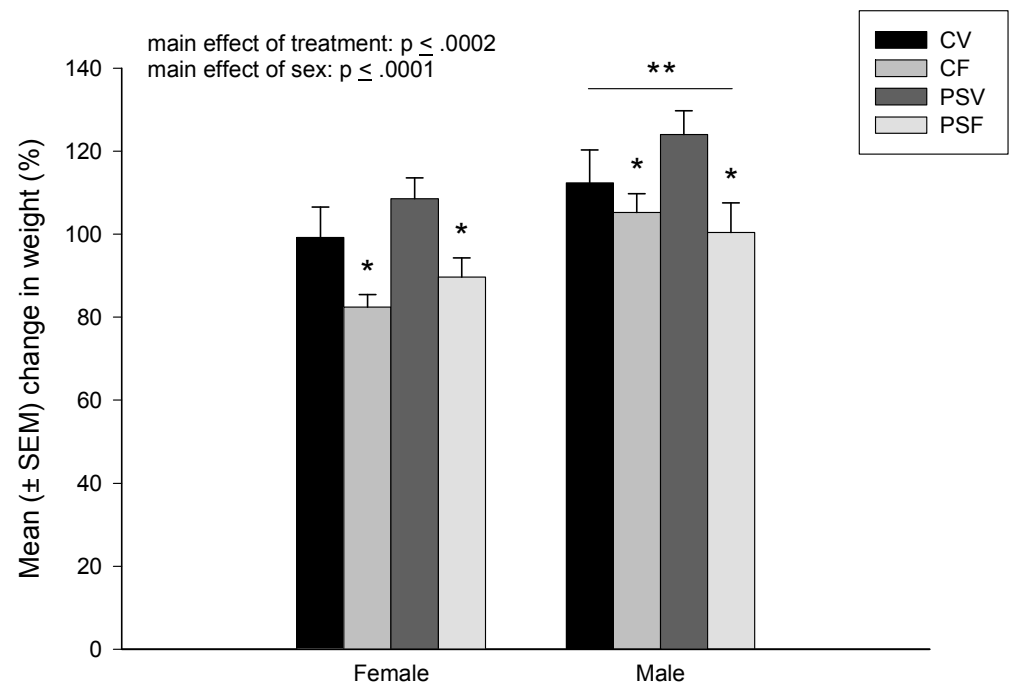

Figure 3. Mean ( \pm SEM) percentage in weight change from P29 to P42. CF and PSF offspring gained significantly less weight than CV and PSV offspring, regardless of stress $(p \leq .0002)$. Overall, male adolescent offspring gained significantly more weight than female offspring ( $p \leq$ .0001). '*'denotes CF and PSF significantly different from CV and PSV groups. "**' denotes males significantly different from females. ( $n=9-11 /$ sex/group)

The OFT. PSV male offspring made significantly fewer central entries compared to $\mathrm{CF}$ and PSV female offspring $(.007 \leq \mathrm{p} \leq .02$ : condition $\mathrm{x}$ treatment $\mathrm{x}$ sex effect; $\mathrm{F}(1,69)=4.43, \mathrm{p} \leq .04$; Figure $4 \mathrm{~A})$. There was also a significant main effect of sex with male offspring making significantly fewer central entries compared to female offspring $(\mathrm{F}(1,69)=4.14, \mathrm{p} \leq .05)$. Further analysis by sex revealed that PSV males made fewer central entries than CV, CF and PSF adolescent males, however this did not reach significance $(\mathrm{p} \geq 0.09)$ and there were no significant effects of treatment or condition in female adolescent offspring $(p \geq 0.14)$. There were no other significant differences between groups in measures on the OFT $(.07 \leq p \leq .90$; Table 2). 
Chapter 2

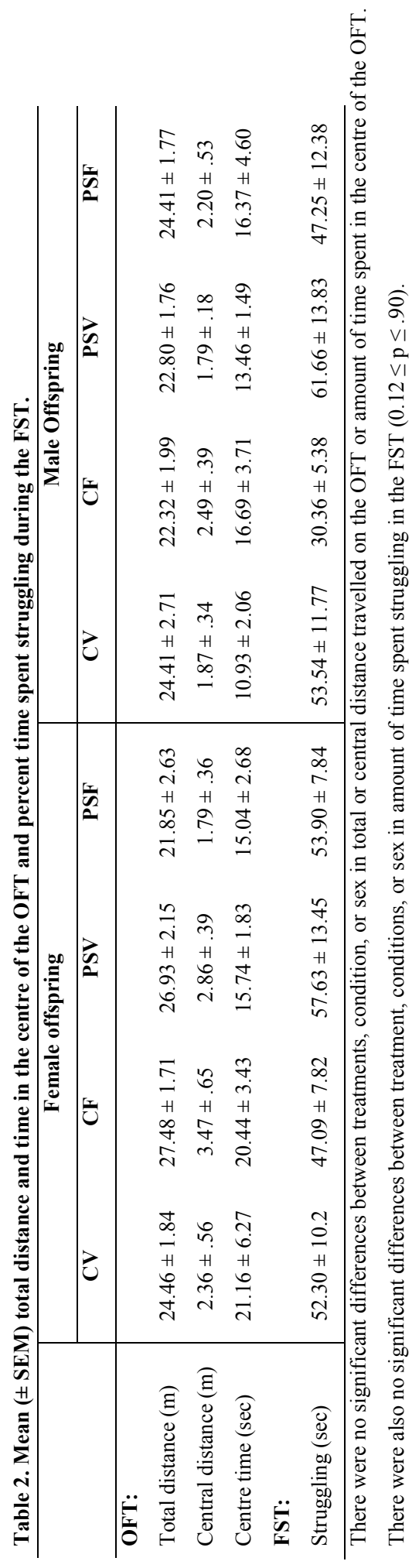


The FST. PSV adolescent offspring spent significantly less time immobile compared to CV and PSF offspring $(.02 \leq \mathrm{p} \leq .04$ : condition $\mathrm{x}$ treatment effect; $\mathrm{F}(1,68)=7.17, \mathrm{p} \leq .09$, controlling for weight differences; Figure 4B). There were no significant differences between conditions, treatment or sex in amount of time spent struggling in the FST and no other significant main effects or interactions on measures of the FST $(0.12 \leq \mathrm{p} \leq .90)$.
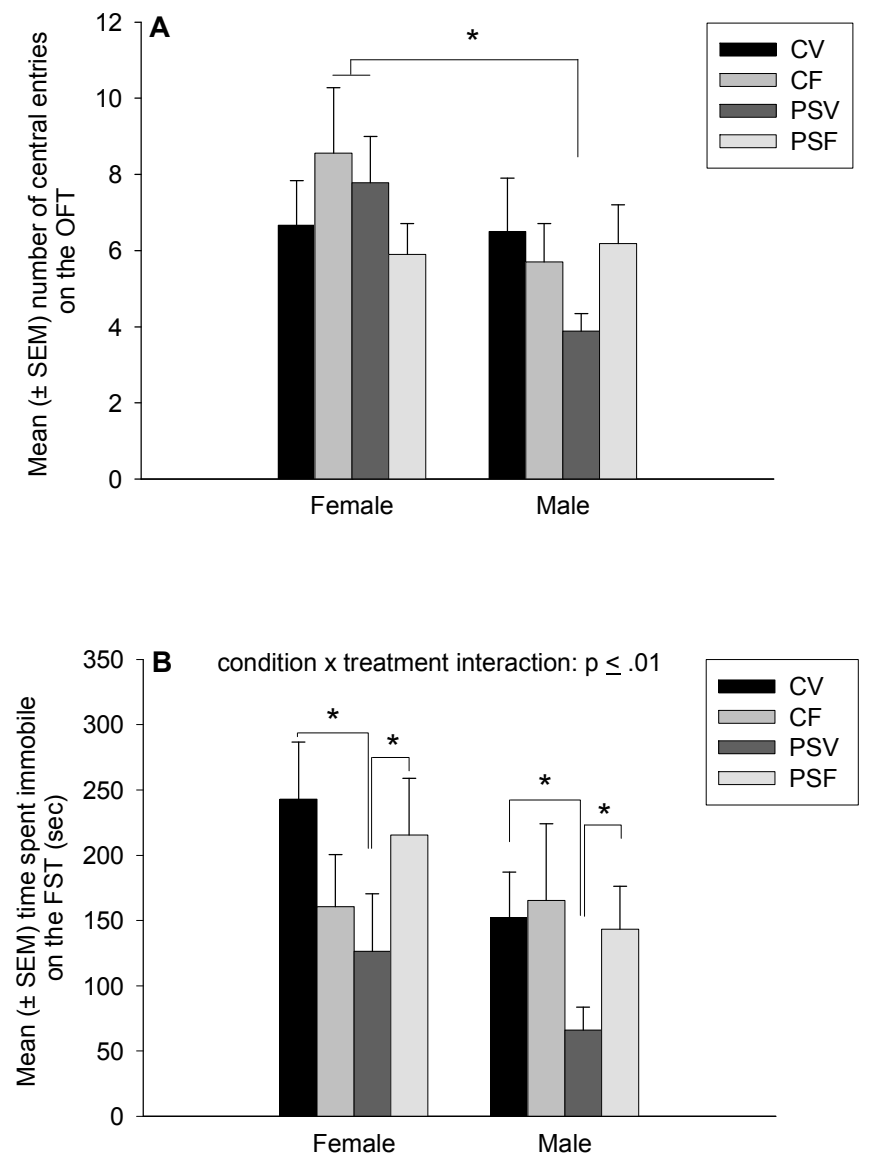

Figure 4. Mean ( \pm SEM) A) number of central entries (OFT) and B) time spent immobile (FST). A) PSV male offspring made significantly fewer central entries compared to CF and PSV female offspring (.007 $\leq$ $\mathrm{p} \leq .02)$. There was also a significant main effect of sex with male offspring making significantly fewer central entries compared to female offspring $(p \leq .05)$. Further analysis by sex revealed that PSV males made fewer central entries than CV, CF and PSF adolescent males, however this did not reach significance $(p \geq 0.09)$ and there were no significant effect of treatment or condition in female adolescent offspring ( $p \geq 0.14)$. B) PSV adolescent offspring spent significantly less time immobile compared to $\mathrm{CV}$ and PSF offspring $(.02 \leq p \leq .04)$. (n=9-11/sex/group). 
Ki67-ir cells. There were no significant differences between groups in the volume of the GCL/SGZ and the hilus of the hippocampus $(p>.07)$, therefore total number of Ki67-ir cell counts were used for statistical analysis. Results demonstrate that PSV adolescent offspring had significantly fewer Ki-67-ir cells in the GCL/SVZ compared to all other groups $(.0001 \leq$ $\mathrm{p} \leq .01)$. CF adolescent offspring had significantly more Ki67-ir cells in the GCL/SVZ compared to PSV offspring ( $\mathrm{p} \leq .0001$ ), but significantly fewer Ki67-ir cells in the GCL/SVZ compared to $\mathrm{CV}$ and PSF offspring $(.002 \leq \mathrm{p} \leq .04$; condition $\mathrm{x}$ fluoxetine $\mathrm{x}$ region (GCL, hilus) effect; $F(1,32)=14.58, \mathrm{p} \leq .0006$; Figure $2 \mathrm{C})$, regardless of sex. There was also a significant interaction effect between stress and fluoxetine $(F(1,32)=18.1, p \leq .0002)$, a main effect of stress $(\mathrm{F}(1,32)=4.18, \mathrm{p} \leq .05)$ and a significant effect of region with more Ki67-ir cells in the GCL/SVZ compared to the hilus $(\mathrm{F}(1,32)=466.03, \mathrm{p} \leq .0001)$. There were no significant correlations between number of Ki67-ir in the GCL/SVZ and measures on the OFT or FST and no other significant main effects of interactions $(0.07 \leq p \leq .92)$.

DCX-ir cells. PSV adolescent offspring had significantly fewer number of DCX-ir cells in the GCL/SGZ of the hippocampus compared to all other groups $(.009 \leq \mathrm{p} \leq .03$, condition $\mathrm{x}$ treatment effect; $\mathrm{F}(1,32)=5.97, \mathrm{p} \leq .020$; Figure $2 \mathrm{D}$ ), regardless of sex. There was a significant negative correlation between number of DCX-ir cells in the GCL/SGZ and time spent in the centre of the OFT in PSV offspring $(r=-.83, p \leq .003)$ and a significant positive correlation between number of DCX-ir cells in the GCL/SVZ and amount of time spent struggling in the FST in CF offspring $(r=.67, \mathrm{p} \leq .03)$. There were no other significant correlations between number of DCX-ir cells in the GCL/SVZ and measures on the OFT or FST and no other significant main effects of interactions $(.07 \leq \mathrm{p} \leq .84)$.

\section{Discussion}

The results of the present study demonstrate that early exposure to fluoxetine in combination with maternal stress has long-term effects on body weight, depressive-like behavior, and hippocampal neurogenesis in offspring. Our primary findings show that early postnatal exposure to maternal fluoxetine reversed the decrease in immobility in the FST, hippocampal cell proliferation and hippocampal neurogenesis in maternally stressed adolescent offspring. In addition, we found that fluoxetine exposure alone significantly reduced hippocampal cell proliferation in comparison to controls and maternally stressed offspring exposed to fluoxetine. We did not find any differences in pup-directed maternal care with fluoxetine treatment or maternal stress suggesting that our data point to a 
developmental impact of fluoxetine, in the presence of maternal adversity, on offspring outcomes.

\section{Developmental exposure to fluoxetine reduces weight gain in adolescent offspring. We} found that postnatal fluoxetine exposure, regardless of exposure to prenatal maternal stress, significantly decreased post-weaning weight gain in adolescent male and female offspring. Previous research showed that a high dose of in utero fluoxetine, via drinking water to dams, resulted in a decrease of birth weight and also a reduction in weight gain during the preweaning period in rats (Bairy et al. 2007). Moreover, several studies have shown that postnatal treatment of fluoxetine, via injection to offspring, leads to a loss of body weight in adult mice and guinea pigs (Ansorge et al. 2004; Karpova et al. 2009; McAdam et al. 2008). A reduction in weight gain during the pre-weaning period may be a result of the involvement of 5-HT in glucoregulation in the hypothalamus (Tuomisto and Mannisto 1985) such that high levels of 5-HT, as a result of the blockade of 5-HT reuptake by fluoxetine, may inhibit the ingestion of carbohydrates and, as a consequence, lead to weight loss (Leibowitz and Alexander 1998).

Prenatal stress and anxiety-like behavior in adolescent offspring. In the present study we found that adolescent male offspring had increased anxiety-like behaviors, as evident by fewer central entries in the open field test, compared to adolescent female offspring. We also report that prenatal stress increased anxiety-like behavior in the adolescent male, but only significantly different in comparison to prenatally stressed or fluoxetine-treated adolescent females. Although further work is needed on the effect of prenatal stress and maternal fluoxetine use on anxiety-like behavior of offspring during adolescence, these data are in partial agreement with work done in prenatally stressed adult offspring. For example, previous research has shown an increase in anxiety-like behavior in prenatally stressed adult male, but not female, offspring (Zuena et al. 2008). More recently work has also demonstrated an increase in anxiety-like behavior in prenatally stressed male offspring, using a similar maternal stress paradigm as in the present study (Morley-Fletcher et al. 2011).

We did not find an effect of developmental fluoxetine exposure on anxiety-like behavior in adolescent offspring. Previous work has also shown minimal effects of early fluoxetine exposure alone, via i.p. injections to pups from postnatal day 4-21, on anxiety-like behavior in adult male mice in the light-dark box or open field test (Karpova et al. 2009). However, more recent work has shown that administration of fluoxetine during gestation, to 
healthy non-stressed dams, results in increased anxiety-like behavior in adult male rats, as measured on the elevated plus maze (Olivier et al. 2011). Therefore, it seems likely that the effect of early exposure to SSRIs, on anxiety-like behavior later in life may depend on many factors which include the timing of the SSRI exposure, the timing of the test, and the test used to assess anxiety-like behavior.

We also did not find a marked relationship between anxiety-like behaviors and measures of hippocampal neurogenesis in the adolescent rats. Previous work has demonstrated that hippocampal neurogenesis is associated with anxiety-like behavior in adulthood. Revest et al (2009) demonstrated that transgenic mice with decreased levels of hippocampal neurogenesis had increased anxiety-like behavior (Revest et al. 2009). However, more research is needed to determine the role of hippocampal neurogenesis in anxiety-like behavior during development. It should also be noted that the relationship between hippocampal neurogenesis and anxiety-like behavior in adolescent rats may significantly vary compared to that of transgenic adult mice as there are well known strain and species differences in hippocampal neurogenesis (Galea et al. 2006).

\section{Developmental exposure to fluoxetine reverses the effects of prenatal stress on} immobility in adolescent offspring. In the present study we found that developmental fluoxetine exposure to prenatally stressed offspring reversed the decrease in immobility in the FST seen in adolescent offspring exposed to prenatal stress alone, while developmental fluoxetine exposure alone had no significant effect on immobility in adolescent offspring. Previous work on the effects of postnatal SSRI treatment on depressive-like behavior in offspring has shown that i.p. injection of SSRIs to offspring during development, in the absence of maternal stress, leads to increased immobility in the FST during adulthood (Hansen et al. 1997; Noorlander et al. 2008). Others have shown that oral fluoxetine administration to the dam during pregnancy and lactation increases immobility in the forced swim test during adolescence (P30) and adulthood (P70) in female mouse offspring (Lisboa et al. 2007). Discrepancies between our findings and others may be due to the timing and dose of fluoxetine administration, the species tested, and when, after weaning, animals were tested. For example, Lisboa et al (2007) found that fluoxetine exposure $(7.5 \mathrm{mg} / \mathrm{kg})$, via oral gavage, to mouse dams during pregnancy and lactation resulted in increased depressive-like behavior in female mouse offspring during adolescence, where as we administered fluoxetine $(5 \mathrm{mg} / \mathrm{kg})$ to rat dams during lactation only and tested rat offspring during adolescence. Therefore, the developmental impact of SSRIs may also depend on when during development 
the exposure occurred. It is also possible that other tests of depressive-like behavior, such as the sucrose preference test, may provide more insight in to the effects of stress and/or SSRIs on offspring behavior.

Although, the exact mechanisms by which fluoxetine counteracts the decrease in immobility in prenatally stressed adolescent offspring is not known, considerable evidence suggests that prenatal maternal stress programs the hypothalamic-pituitary-adrenal (HPA) axis as well as behavior, and that plasticity of the developing monoamine system in the brain underlies, in part, these changes (Charil et al. 2010; Glover et al. 2010). Furthermore, prenatal exposure to fluoxetine can alter HPA function (Ishiwata et al. 2005; Morrison et al. 2005; Oberlander et al. 2009), and thus may act to 'regulate' physiological systems impacted by early exposure to maternal adversity.

\section{Developmental exposure to fluoxetine increases hippocampal neurogenesis in prenatally} stressed adolescent offspring. In the present study postnatal fluoxetine exposure to maternally stressed offspring reversed the decrease in hippocampal neurogenesis evident after prenatal stress. In addition, postnatal fluoxetine exposure alone decreased hippocampal cell proliferation but had no effect on hippocampal neurogenesis. During adulthood, chronic fluoxetine treatment can significantly upregulate hippocampal neurogenesis (Malberg et al. 2000; Perera et al. 2007). However, our data suggests that developmental exposure to fluoxetine reverses the decrease in hippocampal cell proliferation and hippocampal neurogenesis in prenatally stressed offspring and returns the levels of hippocampal neurogenesis back to those of control animals. Interestingly, these data point to a long-term impact of developmental exposure to fluoxetine on hippocampal neurogenesis which are dependent on exposure to maternal adversity. Whether these changes in hippocampal cell proliferation and production of immature neurons impact hippocampal circuitry and behavioral correlates remains to be determined. Further work is also needed to investigate the persistence of the effects of maternal adversity and developmental exposure to fluoxetine on hippocampal neurogenesis in adult offspring.

The mechanism behind the effects of SSRI exposure on the developing hippocampus has yet to be determined, but developmental exposure to SSRIs have been reported to affect the developing serotonergic system (Laine et al. 2003; Weaver et al. 2010), and BDNF levels in the hippocampus (Karpova et al. 2009). For example, postnatal citalopram treatment, via subcutaneous injections to the pups (P8-21) can lead to a decrease in the serotonin transporter levels in the hippocampus of rat offspring (Weaver et al. 2010). In addition, postnatal 
treatment with SSRIs, via i.p. injections to the offspring, can lead to upregulation of BDNF mRNA in the hippocampus (Karpova et al. 2009). Thus exposure to SSRIs during development may act to alter hippocampal neurogenesis through its actions on many systems of the developing brain.

Our data also demonstrates that the action of fluoxetine on the hippocampal neurogenesis varies in the presence of maternal stress. Although most research to date has investigated the developmental impact of SSRIs in offspring of healthy mothers, one study has shown that early treatment with fluoxetine may act to 'correct' the effect of maternal stress on neuron morphology (Ishiwata et al. 2005). In this work Ishiwata et al (2005) demonstrated that postnatal SSRI administration, via oral administration of fluoxetine to pups, reverses the prenatal stress induced reduction in CA3 spine density at 3 and 9 weeks of age but SSRI treatment alone, in the absence of maternal stress, had no long-term effect on spine density measures in the CA3 region of the hippocampus of offspring (Ishiwata et al. 2005). As mentioned previously, it is likely that developmental exposure to fluoxetine in offspring exposed to maternal adversity, may act to regulate the HPA axis and thus 'normalize' the effect of glucocorticoids on hippocampal plasticity in prenatally stressed offspring. Further work is needed to investigate the mechanism of fluoxetine action on the developing brain in response to maternal adversity.

\section{Conclusions}

A growing number of children are exposed to SSRI medications during perinatal development (Oberlander et al. 2009), yet our knowledge of the long-term impact of this drug exposure is limited. Findings from our work show that developmental exposure to maternal fluoxetine, in combination with exposure to prenatal maternal stress, reverses the effects of prenatal stress on depressive-like behavior and hippocampal neurogenesis in adolescent offspring. Thus, there may be a potential beneficial role of developmental exposure to fluoxetine in the presence of maternal adversity. However, before conclusions can be made much more work is needed not only in models of maternal adversity, but using other popular SSRIs, serotonin-norepinephrine reuptake inhibitors (SNRIs) and psychotropic medications being used to treat mood disorders during pregnancy and postpartum (Pawluski in press).

In conclusion, further preclinical work is needed to understand the long-term implications of developmental exposure to SSRIs and other antidepressant medications in the 


\section{Chapter 2}

presence of maternal adversity before conclusions can be made about the use of antidepressant medications to treat maternal depression during the perinatal period.

Acknowledgements: We gratefully acknowledge the technical help from Dr. Thierry Charlier, Julia Vennemeier, Therese Alich, Hellen Steinbusch, and Denise Hermes. 


\section{References}

Alahmed S, Herbert J (2008) Strain differences in proliferation of progenitor cells in the dentate gyrus of the adult rat and the response to fluoxetine are dependent on corticosterone. Neuroscience 157: 677-82

Almond P (2009) Postnatal depression: a global public health perspective. Perspect Public Health 129: 221-7

Ansorge MS, Morelli E, Gingrich JA (2008) Inhibition of serotonin but not norepinephrine transport during development produces delayed, persistent perturbations of emotional behaviors in mice. J Neurosci 28: 199-207

Ansorge MS, Zhou M, Lira A, Hen R, Gingrich JA (2004) Early-life blockade of the 5-HT transporter alters emotional behavior in adult mice. Science 306: 879-81

Bairy KL, Madhyastha S, Ashok KP, Bairy I, Malini S (2007) Developmental and behavioral consequences of prenatal fluoxetine. Pharmacology 79: 1-11

Balthazart J, Boseret G, Konkle AT, Hurley LL, Ball GF (2008) Doublecortin as a marker of adult neuroplasticity in the canary song control nucleus HVC. Eur J Neurosci 27: 801-17

Charil A, Laplante DP, Vaillancourt C, King S (2010) Prenatal stress and brain development. Brain Res Rev 65: 56-79

Coe CL, Kramer M, Czeh B, Gould E, Reeves AJ, Kirschbaum C, Fuchs E (2003) Prenatal stress diminishes neurogenesis in the dentate gyrus of juvenile rhesus monkeys. Biol Psychiatry 54: 1025-34

Cooper WO, Willy ME, Pont SJ, Ray WA (2007) Increasing use of antidepressants in pregnancy. Am J Obstet Gynecol 196: 544 e1-5

Darnaudery M, Maccari S (2008) Epigenetic programming of the stress response in male and female rats by prenatal restraint stress. Brain Res Rev 57: 571-85

Epp JR, Barker JM, Galea LA (2009) Running wild: neurogenesis in the hippocampus across the lifespan in wild and laboratory-bred Norway rats. Hippocampus 19: 1040-9

Fleschler R, Peskin MF (2008) Selective serotonin reuptake inhibitors (SSRIs) in pregnancy: a review. MCN Am J Matern Child Nurs 33: 355-61; quiz 362-3

Galea LA, Spritzer MD, Barker JM, Pawluski JL (2006) Gonadal hormone modulation of hippocampal neurogenesis in the adult. Hippocampus 16: 225-32

Gentile S, Rossi A, Bellantuono C (2007) SSRIs during breastfeeding: spotlight on milk-to-plasma ratio. Arch Womens Ment Health 10: 39-51

Glover V, O'Connor TG, O'Donnell K (2010) Prenatal stress and the programming of the HPA axis. Neurosci Biobehav Rev 35: 17-22

Gundersen HJ, Bagger P, Bendtsen TF, Evans SM, Korbo L, Marcussen N, Moller A, Nielsen K, Nyengaard JR, Pakkenberg B, et al. (1988) The new stereological tools: disector, fractionator, nucleator and point sampled intercepts and their use in pathological research and diagnosis. APMIS 96: 857-81

Hansen HH, Sanchez C, Meier E (1997) Neonatal administration of the selective serotonin reuptake inhibitor Lu 10-134-C increases forced swimming-induced immobility in adult rats: a putative animal model of depression? J Pharmacol Exp Ther 283: 1333-41

Homberg JR, Schubert D, Gaspar P (2010) New perspectives on the neurodevelopmental effects of SSRIs. Trends Pharmacol Sci 31: 60-5

Huizink AC, Robles de Medina PG, Mulder EJ, Visser GH, Buitelaar JK (2003) Stress during pregnancy is associated with developmental outcome in infancy. J Child Psychol Psychiatry 44: 810-8

Ishiwata H, Shiga T, Okado N (2005) Selective serotonin reuptake inhibitor treatment of early postnatal mice reverses their prenatal stress-induced brain dysfunction. Neuroscience 133: 893-901

Karpova NN, Lindholm J, Pruunsild P, Timmusk T, Castren E (2009) Long-lasting behavioural and molecular alterations induced by early postnatal fluoxetine exposure are restored by chronic fluoxetine treatment in adult mice. Eur Neuropsychopharmacol 19: 97-108

Kawamura T, Chen J, Takahashi T, Ichitani Y, Nakahara D (2006) Prenatal stress suppresses cell proliferation in the early developing brain. Neuroreport 17: 1515-8

Laine K, Heikkinen T, Ekblad U, Kero P (2003) Effects of exposure to selective serotonin reuptake inhibitors during pregnancy on serotonergic symptoms in newborns and cord blood monoamine and prolactin concentrations. Arch Gen Psychiatry 60: 720-6

Laplante DP, Barr RG, Brunet A, Galbaud du Fort G, Meaney ML, Saucier JF, Zelazo PR, King S (2004) Stress during pregnancy affects general intellectual and language functioning in human toddlers. Pediatr Res 56: $400-10$

Leibowitz SF, Alexander JT (1998) Hypothalamic serotonin in control of eating behavior, meal size, and body weight. Biol Psychiatry 44: 851-64

Leung BM, Kaplan BJ (2009) Perinatal depression: prevalence, risks, and the nutrition link--a review of the literature. J Am Diet Assoc 109: 1566-75 
Limlomwongse N, Liabsuetrakul T (2006) Cohort study of depressive moods in Thai women during late pregnancy and 6-8 weeks of postpartum using the Edinburgh Postnatal Depression Scale (EPDS). Arch Womens Ment Health 9: 131-8

Lisboa SF, Oliveira PE, Costa LC, Venancio EJ, Moreira EG (2007) Behavioral evaluation of male and female mice pups exposed to fluoxetine during pregnancy and lactation. Pharmacology 80: 49-56

Lopez-Duran NL, Kovacs M, George CJ (2009) Hypothalamic-pituitary-adrenal axis dysregulation in depressed children and adolescents: a meta-analysis. Psychoneuroendocrinology 34: 1272-83

Lucassen PJ, Bosch OJ, Jousma E, Kromer SA, Andrew R, Seckl JR, Neumann ID (2009) Prenatal stress reduces postnatal neurogenesis in rats selectively bred for high, but not low, anxiety: possible key role of placental 11 beta-hydroxysteroid dehydrogenase type 2. Eur J Neurosci 29: 97-103

Maccari S, Darnaudery M, Morley-Fletcher S, Zuena AR, Cinque C, Van Reeth O (2003) Prenatal stress and long-term consequences: implications of glucocorticoid hormones. Neurosci Biobehav Rev 27: 119-27

Maccari S, Morley-Fletcher S (2007) Effects of prenatal restraint stress on the hypothalamus-pituitary-adrenal axis and related behavioural and neurobiological alterations. Psychoneuroendocrinology 32 Suppl 1: S10-5

Malberg JE, Eisch AJ, Nestler EJ, Duman RS (2000) Chronic antidepressant treatment increases neurogenesis in adult rat hippocampus. J Neurosci 20: 9104-10

Marcus SM (2009) Depression during pregnancy: rates, risks and consequences--Motherisk Update 2008. Can J Clin Pharmacol 16: e15-22

McAdam TD, Brien JF, Reynolds JN, Dringenberg HC (2008) Altered water-maze search behavior in adult guinea pigs following chronic prenatal ethanol exposure: lack of mitigation by postnatal fluoxetine treatment. Behav Brain Res 191: 202-9

McCormick CM, Mathews IZ (2007) HPA function in adolescence: role of sex hormones in its regulation and the enduring consequences of exposure to stressors. Pharmacol Biochem Behav 86: 220-33

Morley-Fletcher S, Mairesse J, Soumier A, Banasr M, Fagioli F, Gabriel C, Mocaer E, Daszuta A, McEwen B, Nicoletti F, Maccari S (2011) Chronic agomelatine treatment corrects behavioral, cellular, and biochemical abnormalities induced by prenatal stress in rats. Psychopharmacology (Berl)

Morrison JL, Riggs KW, Rurak DW (2005) Fluoxetine during pregnancy: impact on fetal development. Reprod Fertil Dev 17: 641-50

Moses-Kolko EL, Bogen D, Perel J, Bregar A, Uhl K, Levin B, Wisner KL (2005) Neonatal signs after late in utero exposure to serotonin reuptake inhibitors: literature review and implications for clinical applications. JAMA 293: 2372-83

Niederhofer H, Reiter A (2004) Prenatal maternal stress, prenatal fetal movements and perinatal temperament factors influence behavior and school marks at the age of 6 years. Fetal Diagn Ther 19: 160-2

Noorlander CW, Ververs FF, Nikkels PG, van Echteld CJ, Visser GH, Smidt MP (2008) Modulation of serotonin transporter function during fetal development causes dilated heart cardiomyopathy and lifelong behavioral abnormalities. PLoS One 3: e2782

Nulman I, Rovet J, Stewart DE, Wolpin J, Pace-Asciak P, Shuhaiber S, Koren G (2002) Child development following exposure to tricyclic antidepressants or fluoxetine throughout fetal life: a prospective, controlled study. Am J Psychiatry 159: 1889-95

O'Mahony SM, Myint AM, van den Hove D, Desbonnet L, Steinbusch H, Leonard BE (2006) Gestational stress leads to depressive-like behavioural and immunological changes in the rat. Neuroimmunomodulation 13: $82-8$

Oberlander TF, Gingrich JA, Ansorge MS (2009) Sustained neurobehavioral effects of exposure to SSRI antidepressants during development: molecular to clinical evidence. Clin Pharmacol Ther 86: 672-7

Oberlander TF, Papsdorf M, Brain UM, Misri S, Ross C, Grunau RE (2010) Prenatal effects of selective serotonin reuptake inhibitor antidepressants, serotonin transporter promoter genotype (SLC6A4), and maternal mood on child behavior at 3 years of age. Arch Pediatr Adolesc Med 164: 444-51

Oberlander TF, Warburton W, Misri S, Aghajanian J, Hertzman C (2006) Neonatal outcomes after prenatal exposure to selective serotonin reuptake inhibitor antidepressants and maternal depression using population-based linked health data. Arch Gen Psychiatry 63: 898-906

Oberlander TF, Weinberg J, Papsdorf M, Grunau R, Misri S, Devlin AM (2008) Prenatal exposure to maternal depression, neonatal methylation of human glucocorticoid receptor gene (NR3C1) and infant cortisol stress responses. Epigenetics 3: 97-106

Odagiri K, Abe H, Kawagoe C, Takeda R, Ikeda T, Matsuo H, Nonaka H, Ebihara K, Nishimori T, Ishizuka Y, Hashiguchi H, Ishida Y (2008) Psychological prenatal stress reduced the number of BrdU immunopositive cells in the dorsal hippocampus without affecting the open field behavior of male and female rats at one month of age. Neurosci Lett 446: 25-9 
Olivier JD, Valles A, van Heesch F, Afrasiab-Middelman A, Roelofs JJ, Jonkers M, Peeters EJ, Korte-Bouws GA, Dederen JP, Kiliaan AJ, Martens GJ, Schubert D, Homberg JR (2011) Fluoxetine administration to pregnant rats increases anxiety-related behavior in the offspring. Psychopharmacology (Berl)

Pawluski JL (in press) Perinatal SSRI antidepressant exposure: impact on brain development and neural plasticity Neuroendocrinology

Pawluski JL, Charlier TD, Lieblich SE, Hammond GL, Galea LA (2009a) Reproductive experience alters corticosterone and CBG levels in the rat dam. Physiol Behav 96: 108-14

Pawluski JL, Galea LA, Brain U, Papsdorf M, Oberlander TF (2009b) Neonatal S100B protein levels after prenatal exposure to selective serotonin reuptake inhibitors. Pediatrics 124: e662-70

Pawluski JL, Lieblich SE, Galea LA (2009c) Offspring-exposure reduces depressive-like behaviour in the parturient female rat. Behav Brain Res 197: 55-61

Pawluski JL, van den Hove DL, Rayen I, Prickaerts J, Steinbusch HW (2011) Stress and the pregnant female: Impact on hippocampal cell proliferation, but not affective-like behaviors. Horm Behav

Perera TD, Coplan JD, Lisanby SH, Lipira CM, Arif M, Carpio C, Spitzer G, Santarelli L, Scharf B, Hen R, Rosoklija G, Sackeim HA, Dwork AJ (2007) Antidepressant-induced neurogenesis in the hippocampus of adult nonhuman primates. J Neurosci 27: 4894-901

Prut L, Belzung C (2003) The open field as a paradigm to measure the effects of drugs on anxiety-like behaviors: a review. Eur J Pharmacol 463: 3-33

Reed AL, Happe HK, Petty F, Bylund DB (2008) Juvenile rats in the forced-swim test model the human response to antidepressant treatment for pediatric depression. Psychopharmacology (Berl) 197: 433-41

Revest JM, Dupret D, Koehl M, Funk-Reiter C, Grosjean N, Piazza PV, Abrous DN (2009) Adult hippocampal neurogenesis is involved in anxiety-related behaviors. Mol Psychiatry 14: 959-67

Romeo RD (2010) Adolescence: a central event in shaping stress reactivity. Dev Psychobiol 52: 244-53

Romeo RD, Karatsoreos IN, Ali FS, McEwen BS (2007) The effects of acute stress and pubertal development on metabolic hormones in the rat. Stress 10: 101-6

Romeo RD, McEwen BS (2006) Stress and the adolescent brain. Ann N Y Acad Sci 1094: 202-14

Romijn HJ, Hofman MA, Gramsbergen A (1991) At what age is the developing cerebral cortex of the rat comparable to that of the full-term newborn human baby? Early Hum Dev 26: 61-7

Smith JW, Seckl JR, Evans AT, Costall B, Smythe JW (2004) Gestational stress induces post-partum depression-like behaviour and alters maternal care in rats. Psychoneuroendocrinology 29: 227-44

Talge NM, Neal C, Glover V (2007) Antenatal maternal stress and long-term effects on child neurodevelopment: how and why? J Child Psychol Psychiatry 48: 245-61

Tuomisto J, Mannisto P (1985) Neurotransmitter regulation of anterior pituitary hormones. Pharmacol Rev 37 : 249-332

Van den Bergh BR, Mennes M, Oosterlaan J, Stevens V, Stiers P, Marcoen A, Lagae L (2005) High antenatal maternal anxiety is related to impulsivity during performance on cognitive tasks in 14- and 15-yearolds. Neurosci Biobehav Rev 29: 259-69

Van den Hove DL, Blanco CE, Aendekerk B, Desbonnet L, Bruschettini M, Steinbusch HP, Prickaerts J, Steinbusch HW (2005) Prenatal restraint stress and long-term affective consequences. Dev Neurosci 27: $313-20$

Van den Hove DL, Blanco CE, Scheepens A, Desbonnet L, Myint AM, Leonard BE, Prickaerts J, Steinbusch HW (2008) Prenatal maternal paroxetine treatment and neonatal mortality in the rat: a preliminary study. Neonatology 93: 52-5

Ververs T, Kaasenbrood H, Visser G, Schobben F, de Jong-van den Berg L, Egberts T (2006) Prevalence and patterns of antidepressant drug use during pregnancy. Eur J Clin Pharmacol 62: 863-70

Ward IL, Weisz J (1984) Differential effects of maternal stress on circulating levels of corticosterone, progesterone, and testosterone in male and female rat fetuses and their mothers. Endocrinology 114: $1635-44$

Weaver KJ, Paul IA, Lin RC, Simpson KL (2010) Neonatal exposure to citalopram selectively alters the expression of the serotonin transporter in the hippocampus: dose-dependent effects. Anat Rec (Hoboken) 293: 1920-32

Weinstock M (2008) The long-term behavioural consequences of prenatal stress. Neurosci Biobehav Rev 32: 1073-86

Zagron G, Weinstock M (2006) Maternal adrenal hormone secretion mediates behavioural alterations induced by prenatal stress in male and female rats. Behav Brain Res 175: 323-8

Zuena AR, Mairesse J, Casolini P, Cinque C, Alema GS, Morley-Fletcher S, Chiodi V, Spagnoli LG, Gradini R, Catalani A, Nicoletti F, Maccari S (2008) Prenatal restraint stress generates two distinct behavioral and neurochemical profiles in male and female rats. PLoS One 3: e2170 



\title{
Chapter 3
}

\section{Developmental fluoxetine exposure differentially alters central and peripheral measures of the HPA system in adolescent male and female offspring}

\begin{abstract}
Authors: Jodi L. Pawluski, Ine Rayen, Neville A. Niessen, Stephanie Kristensen, Eva L. van Donkelaar, Jacques Balthazart, Harry W. M. Steinbusch, Thierry D. Charlier
\end{abstract}

Neuroscience 2012, 220:131-41 
Chapter 3

\begin{abstract}
A significant number of women suffer from depression during pregnancy and the postpartum period. Selective serotonin reuptake inhibitors (SSRIs) are commonly used to treat maternal depression. While maternal stress and depression have long-term effects on the physical and behavioural development of offspring, numerous studies also point to a significant action of developmental exposure to SSRIs. Surprisingly, preclinical data are limited concerning the combined effect of maternal depression and maternal SSRI exposure on neurobehavioural outcomes in offspring. Therefore, the aim of the present study was to determine how maternal fluoxetine treatment affects the developing HPA system of adolescent male and female offspring using a model of maternal adversity. To do this, gestationally stressed and non-stressed Sprague-Dawley rat dams were chronically treated throughout lactation with either fluoxetine $(5 \mathrm{mg} / \mathrm{kg} /$ day $)$ or vehicle. Four groups of male and female adolescent offspring were used: 1) Prenatal Stress + Fluoxetine, 2) Prenatal Stress + Vehicle, 3) Fluoxetine alone, and 4) Vehicle alone. Primary results show that developmental fluoxetine exposure, regardless of prenatal stress, decreases circulating levels of corticosterone and reduces the expression of the glucocorticoid receptor (GR), and its coactivator the glucocorticoid receptor interacting protein (GRIP1), in the hippocampus. Interestingly, these effects occurred primarily in male, and not in female, adolescent offspring. Together, these results highlight a marked sex difference in the long-term effect of developmental exposure to SSRI medications that may differentially alter the capacity of the hippocampus to respond to stress.
\end{abstract}

Keywords: SSRI, hippocampus, stress, transcortin, corticosterone, GRIP1, glucocorticoid receptor 
Chapter 3

\section{Introduction}

Emerging clinical and preclinical evidence is demonstrating that exposure to maternal mood disorders, maternal stress and other aspects of maternal adversity programme the developing hypothalamic-pituitary-adrenal (HPA) axis (Glover et al. 2009; Harris and Seckl 2011; Kapoor and Matthews 2008; Levine 2005). In humans, maternal stress and depression have been associated with altered neonatal stress regulation (Davis et al. 2011), methylation status on the human glucocorticoid receptor gene (NR3C1) in neonates (Oberlander et al. 2008b), and elevated basal levels of salivary or urinary cortisol in infants (Brennan et al. 2008; Field et al. 2006; Field et al. 2004). Perinatal exposure to maternal adversity, particularly anxiety, also has long-lasting effects into adolescence with adolescent girls showing blunted diurnal cortisol levels and increased depressive symptoms (Van den Bergh et al. 2008). Similarly, using animal models, it has been well established that maternal adversity significantly and persistently impacts the development of the HPA system (Glover et al. 2010; Green et al. 2011; Maccari et al. 2003) through multiple facets such as changes in diurnal fluctuation in basal corticosterone, prolongation of the corticosterone response to novelty, and reductions in glucocorticoid receptor (GR) expression in the hippocampus of adult offspring (Green et al. 2011; Maccari et al. 2003).

In response to maternal adversity and maternal mood disorders, a significant number of women are prescribed selective serotonin reuptake inhibitor (SSRI) medications during pregnancy and the postpartum period (Cooper et al. 2007; Oberlander et al. 2006; Ververs et al. 2006). These medications cross the placental barrier and are also found in breast milk, therefore reaching the infant both pre- and post-natally (Gentile 2005; Hendrick et al. 2001). SSRI medications are thought to alleviate symptoms of mood disorders in adults partly by normalizing the function of the HPA axis (Barden et al. 1995). However, physiological serotonin plays an integral part in the development and function of the HPA axis (Andrews and Matthews 2004; Laplante et al. 2002; Meaney et al. 1994). For example, decreasing serotonin input to the hippocampus during the early postnatal period results in decreased GR expression in adult rat offspring (Mitchell et al. 1990), and in vitro work has shown that serotonin can increase GR mRNA levels in fetal hippocampal cells (Erdeljan et al. 2005). Therefore, questions have been raised about the impact of perinatal exposure to SSRIs on the developing HPA system.

Recent clinical research demonstrates that prenatal exposure to psychotropic medications, such as SSRIs, attenuates basal salivary cortisol levels (Brennan et al. 2008) and 


\section{Chapter 3}

'blunts' the response to acute stress (Oberlander et al. 2002; Oberlander et al. 2005) in infants. Prenatal SSRI exposure also results in increased neonatal serum corticosteroid binding globulin (CBG) levels at birth (Pawluski et al. in press). In animal models, treatment with fluoxetine, a popular SSRI, during gestation results in increased fetal plasma cortisol levels in sheep (Morrison et al. 2004), and fluoxetine treatment during the early postnatal period can decrease serum corticosterone response to stress in prenatally stressed mouse offspring (Ishiwata et al. 2005).

To date, most preclinical research in this area has investigated the developmental impact of perinatal SSRI exposure in healthy mothers and offspring (Cabrera-Vera et al. 1997; Olivier et al. 2011a; Olivier et al. 2011b; Pawluski et al. in press), and very little research has analyzed the neurodevelopmental effects of perinatal fluoxetine exposure using a model of maternal adversity (Ishiwata et al. 2005; Pawluski et al. in press; Rayen et al. 2011). In addition, much less research has looked at how perinatal exposure to SSRI medications, via the mother, affects offspring outcomes during adolescence, a period of development characterized by marked physiological changes and increased vulnerability to stress (McCormick and Mathews 2007; Romeo 2010; Romeo and McEwen 2006). Therefore, the aim of this study was to investigate the developmental effects of fluoxetine exposure, using a model of maternal adversity, on peripheral and central measures of the HPA system in adolescent rat offspring. For this work we investigated peripheral levels of corticosterone and its binding globulin, $\mathrm{CBG}$, as well as hippocampal expression of the GR and mineralocorticoid receptor (MR) in adolescent male and female offspring. Furthermore, to investigate the functionality of GRs and MRs, we looked at the expression of the glucocorticoid receptor interacting protein, GRIP1, a steroid receptor coactivator, which is required for the action of GRs and MRs during transcription (Charlier 2009; Hong et al. 1996; Tetel et al. 2009). Knowledge of the long-term effects of maternal adversity and perinatal SSRI medication exposure on the developing HPA system is fundamental to understanding how these factors affect key physiological systems later in life.

\section{Methods}

Animals. Twenty-two adult female Sprague-Dawley rats (250-300g; Charles River Laboratories, France) were used in the present study. Females were initially housed in pairs in clear polyurethane bins $(48 \times 27 \times 20 \mathrm{~cm})$ with corn cob bedding and ad libitum access to rat chow (Sniff) and tap water. Rats were kept under standard laboratory conditions in a $12 \mathrm{~h}: 12 \mathrm{~h}$ 


\section{Chapter 3}

light/dark schedule (lights on at 07:00 h). All experiments were approved by the Animal Ethics Board of Maastricht University and were in accordance with Dutch governmental regulations (DEC 2008-157, 2008-158). All efforts were made to minimize the pain and stress levels experienced by the animals and the number of animals used in the study.

For breeding, one female and one male were paired in a wire mesh cage. On gestation day (GD) 15 , dams were randomly assigned to stress $(n=12)$ or control groups $(n=10)$. Dams in the stress group were individually restrained three times a day for $45 \mathrm{~min}$ in transparent plastic cylinders under bright light (between 8-10am, 12-2pm, 4-6pm) on GD15-20 and twice on GD21 as previously described (Rayen et al. 2011; Van den Hove et al. 2005; Ward and Weisz 1984). This time period of stress during gestation has been shown to result in depressive-like behaviour in the dam (O'Mahony et al. 2006; Smith et al. 2004) and therefore provided a model of maternal depression. This time period during gestation is also when stress markedly affects offspring outcomes related to stress reactivity, 'mood', and cognition (Darnaudery and Maccari 2008; Weinstock 2008).

One day after birth (birth day = day 0), litters were culled to 5 males and 5 females and dams (with offspring) were randomly assigned to one of two treatment groups: fluoxetine $(5 \mathrm{mg} / \mathrm{kg} /$ day) or vehicle, for a total of four groups of dams with litters: 1) Prenatal Stress + Vehicle (PSV; n=5), 2) Prenatal Stress + Fluoxetine (PSF; n=7), 3) Control + Fluoxetine (CF; $\mathrm{n}=5)$, and 4) Control + Vehicle $(\mathrm{CV} ; \mathrm{n}=5)$. Offspring were weaned on postnatal day $21(\mathrm{P} 21)$ and were housed in litter groups of 2 males and 2 females per cage. All offspring were housed in clear polyurethane bins $(48 \times 27 \times 20 \mathrm{~cm})$ with corn cob bedding and ad libitum access to rat chow (Sniff) and tap water. Rats were kept under standard laboratory conditions in a $12 \mathrm{~h}: 12 \mathrm{~h}$ light/dark schedule (lights on at 07:00 h).

In the majority of litters, 1 male and 1 female offspring were used in the present experiment, with no more than 2 males or 2 females being used per litter ( $n=6-8 /$ sex/group). Offspring weights were measured at sacrifice. All offspring were previously used for behavioural analysis such that all offspring were exposed in exactly the same manner to the open field test for 5 minutes and the forced swim test for 10 minutes (Rayen et al. 2011). To ensure that this exposure to behavioral tests did not affect outcomes in the present study, data was correlated with behavioural measures. After weaning dams were included in an additional study (Pawluski et al., 2012b).

Fluoxetine treatment to dams. Fluoxetine treatment was administered via osmotic minipumps to the dams for 28 days (Alzet Osmotic pumps, 2ML4). These osmotic minipumps have successfully been used during the postpartum period (Oliveira et al. 2010; 


\section{Chapter 3}

$\mathrm{Xu}$ et al. 2009). Implants were filled with either fluoxetine-HCl (Fagron, Belgium) dissolved in vehicle (50\% propylenediol in saline; $5 \mathrm{mg} / \mathrm{kg}$ /day), or with vehicle as previously described (Alahmed and Herbert 2008; Pawluski et al. 2012b; Rayen et al. 2011). The dose of fluoxetine used provides serum levels of fluoxetine and its active metabolite norfluoxetine similar to what is found in postpartum women (Epperson et al, 2003; Pawluski et al., 2012b).

Minipumps were implanted subcutaneously in the dorsal region while the dams were under mild isofluorene anaesthesia on post-partum day 1 (P1) and remained there until after pups were weaned (P21). We chose to administer fluoxetine after parturition as this is a time when the dam may exhibit depressive-like behavior after gestational stress (Smith et al, 2004). Implantations took a maximum of $20 \mathrm{~min}$ and therefore moms were separated from their litters for a maximum of $20 \mathrm{~min}$. Fluoxetine exposure to offspring occurred during a stage of neural development in rodents analogous to that of the third trimester in humans (Romijn et al. 1991).

Maternal behaviour. Maternal behaviour of dams towards offspring was assessed twice a day for 5 min from P2 to P7 based on previous literature (Pawluski et al. 2009; Rayen et al. 2011). These maternal observations were brief and done in order to detect any gross differences in maternal care between groups. Scoring took place in the morning (between 8:30 a.m. and 10:30 a.m.) and the afternoon (between 13:30 p.m. and 15:30 p.m.) with at least $3 \mathrm{~h}$ between the sessions. During each testing period the duration of the following maternal behaviours were assessed: 1) licking (licking/grooming) and 2) nursing (archedback nursing, blanket nursing or passive nursing). Data were compiled across days and were calculated as percent time spent in each maternal behaviour.

Corticosterone analysis. To investigate any effects of treatment on corticosterone levels of adolescent offspring, blood samples were collected by cardiac puncture at the time of death (between 10a.m. and noon). Blood samples were stored at $4{ }^{\circ} \mathrm{C}$ overnight and centrifuged at $10,000 \times \mathrm{g}$ for $10 \mathrm{~min}$. Serum was collected and all samples were run in duplicate using a commercially available RIA kit for rat corticosterone from MP Biomedicals (Corticosterone $\mathrm{I}^{125}$ for rats and mice, MP Biomedicals). The average intra- and inter-assay coefficients of variation for all assays were below $10 \%$. The assay had a sensitivity of $7.7 \mathrm{ng} / \mathrm{mL}$.

Corticosteroid binding capacity. Corticosteroid binding capacity, which reflects the level of corticosteroid binding globulin (CBG), was determined following procedures developed by Hammond and Lähteenmäki (Hammond and Lahteenmaki 1983; Pawluski et al. 2009b). Briefly, serum samples were diluted $1 / 1000$ and incubated $30 \mathrm{~min}$ at room temperature with dextran-coated charcoal (DCC) suspension to remove endogenous steroids. The dextran- 


\section{Chapter 3}

coated charcoal was then precipitated by centrifugation and an aliquot of the samples was added into duplicate tubes containing [1,2-3H] corticosterone (specific activity: $50 \mathrm{Ci} / \mathrm{mmol}$; ARC, St Louis, MO, USA, final concentration $3.5 \mathrm{nM}$ ) and to one tube containing $0.5 \mu \mathrm{M}$ of cold corticosterone in addition to the tritiated corticosterone for the evaluation of the nonspecific binding. After incubation for $1 \mathrm{~h}$ at room temperature, tubes were placed into an ice-water bath for $30 \mathrm{~min}$. Ice-cold DCC was then added to remove unbound steroids and the reaction was incubated for another $10 \mathrm{~min}$ and centrifuged at $1800 \mathrm{xg}$ at $4{ }^{\circ} \mathrm{C}$ for 10 min. The incubation with the cold DCC requires a correction factor (off rate) in the calculation of the binding capacity to account for the dissociation during DCC separation. This correction was determined experimentally and estimated at $80 \%$. Supernatants were transferred into scintillation vials and $4 \mathrm{ml}$ of Aqueous Counting Scintillant (Amersham Bioscience, UK) was added. The samples were counted in a Beckman Coulter LS6000K scintillation spectrophotometer. Specifically-bound counts were obtained by subtracting the non-specific background counts from the average of the total bound counts and converted in $\mathrm{pmol} / \mathrm{ml}$ of serum. Interassay variability was $6.2 \%$.

Free corticosterone index. The free corticosterone index was used to give an indication of the amount of free corticosterone that was circulating in the system. It was calculated as previously described (total corticosterone X 100/CBG, with both total corticosterone and CBG in molar units) (Clinchy et al. 2011; Davidson et al. 2006; Hamrahian et al. 2004; le Roux et al. 2002).

Histology. Between 39-42 days of age, offspring were deeply anesthetized (sodium pentobarbital), weighed, and brains were extracted. Following extraction from the skull, brains were cut in half along the midline and the hippocampus was quickly dissected from the right hemisphere of the brain, frozen on dry ice, kept at $-80^{\circ} \mathrm{C}$ and used for western blot analysis. The left hemisphere was stored at $4^{\circ} \mathrm{C}$ in $4 \%$ paraformaldehyde for $24 \mathrm{~h}$, then cryoprotected in $30 \%$ sucrose/phosphate-buffered saline solution for up to one week, frozen on dry ice and kept at $-80^{\circ} \mathrm{C}$. Brain tissue was sliced in $40 \mu \mathrm{m}$ coronal sections on a cryostat (Leica). Tissue was stored in antifreeze solution and maintained at $-15^{\circ} \mathrm{C}$ until immunohistochemical analysis.

Glucocorticoid receptor (GR) immunohistochemistry. Every $6^{\text {th }}$ section throughout the hippocampus was stained for GR using immunohistochemistry based on previous work (Uys et al. 2006). Briefly, endogenous peroxidase activity was blocked by incubating the sections for $30 \mathrm{~min}$ in $0.6 \%$ hydrogen peroxide. Sections were incubated overnight in rabbit anti-GR (1:500; Santa Cruz Biotechnology, CA, sc-8992) and then incubated for $2 \mathrm{~h}$ in biotinylated 


\section{Chapter 3}

donkey anti-rabbit (1:500; Jackson ImmunoResearch) secondary antibody. Brain sections were further processed by using the avidin-biotin complex (ABC Elite kit; 1:1000; Vector laboratories) for $2 \mathrm{~h}$. All reagents were diluted in phosphate-buffered saline containing $0.1 \%$ triton X-100 (PBST) and several rinses were performed between the different steps. The peroxidase enzymatic activity was visualized with Nickel chloride enhanced 3, 3' diaminobenzidine tetrahydrochloride (DAB). Sections were rinsed several times, mounted on gelatin-coated slides, dried overnight, dehydrated, and coverslipped with Permount (Fisher Scientific).

GRIP1 Immunocytochemistry. Every $6^{\text {th }}$ section throughout the hippocampus was stained for GRIP1 by immunohistochemistry based on previous work (Niessen et al. 2011; Yore et al. 2010). Endogenous peroxidase activity was blocked by incubating the sections for $20 \mathrm{~min}$ in $0.6 \%$ hydrogen peroxide. The non-specific antibody binding sites were blocked for $120 \mathrm{~min}$ with $20 \%$ NGS (normal goat serum), and the sections were then incubated for $48 \mathrm{~h}$ with the primary antibody diluted in 5\% NGS at $4^{\circ} \mathrm{C}$ (rabbit anti-SRC-2/GRIP1 antibody 1:3000, Novus Antibodies). Sections were then left for $2 \mathrm{~h}$ in secondary biotinylated goat anti-rabbit antibody (1/400, Dako A/S, Gosltrup, Denmark) and finally incubated in ABC Vectastain elite Kit PK-6100 (Vector Laboratories) for 2h. All reagents were diluted in PBST and several rinses were performed between the different steps. The peroxidase enzymatic activity was then visualized with Nickel II-sulfate enhanced 3, 3' diaminobenzidine tetrahydrochloride (DAB, 2\%), 0.012\% hydrogen peroxide in $0.175 \mathrm{M}$ Sodium Acetate Buffer. The reaction was terminated by several rinses in Sodium Acetate Buffer and the sections were mounted in Fluka-Eukitt ${ }^{\circledR}$ Quick-hardening mounting medium (Sigma Aldrich) and coverslipped.

GR and GRIP1 quantification. Three dorsal sections of the hippocampus, located between stereotaxic coordinates bregma $-2.64 \mathrm{~mm}$ to $-4.92 \mathrm{~mm}$ (Paxinos and Watson 2004), were analyzed per animal for GR- or GRIP1-positive cells by an observer blind to conditions. Photomicrographs were taken for 2 randomly chosen areas within the CA1, CA3 and granule cell layer of the dentate gyrus of the hippocampus from each of the 3 sections (for example see Figure 1). For GR density, cells were examined under 40x objective with oil using a AX70 microscope (Olympus) and Cell-P (Olympus) was used for acquiring images. For GRIP1 density, cells were examined under 40x objective using a Leica DMRB microscope and a Leica FireCam 3.4.1 was used for acquiring images. The software ImageJ64 (Wayne Rasband, NIH, Bethesda, MD, USA) was used for quantification of optical densities of GR and GRIP1. The relative optical density was defined as the difference between optical density 


\section{Chapter 3}

(grey level) measures after calibration (Kodak, Photographic step tablet $\mathrm{N}^{\circ} 3$ ) within the area of interest and in an equivalent adjacent area (background). For representative photomicrographs of GR and GRIP1 density see Figure 2.

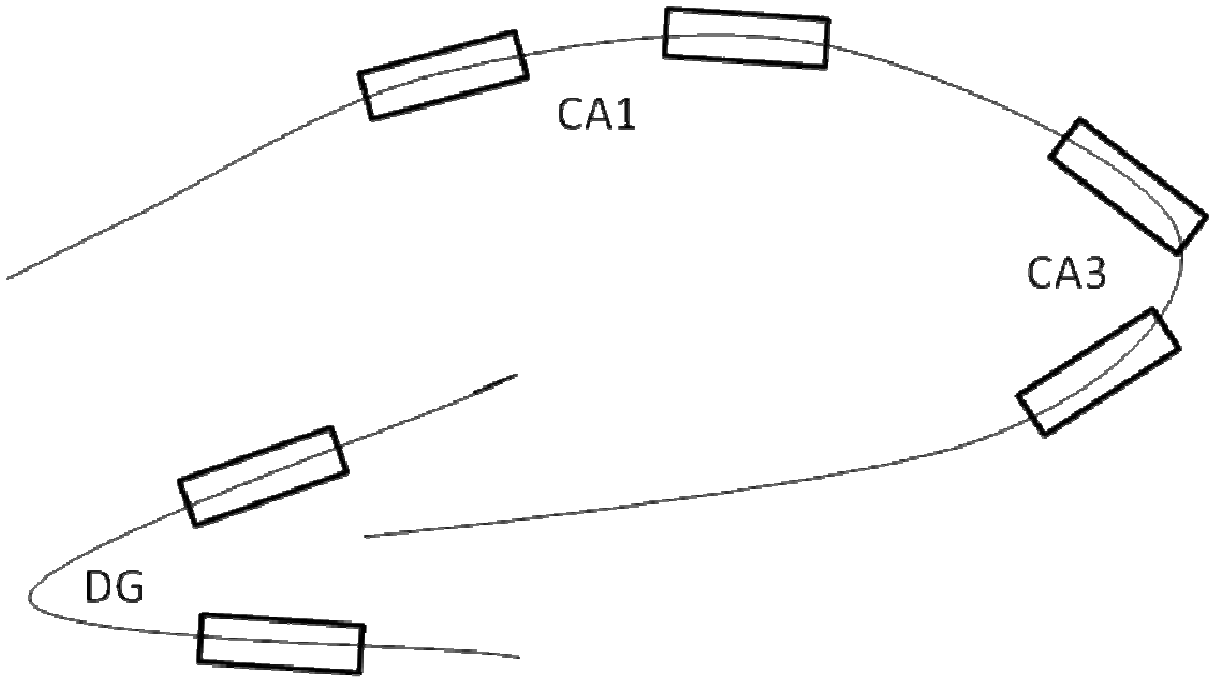

Figure 1. Drawing of hippocampal areas selected for quantification of GR and GRIP1 expression.

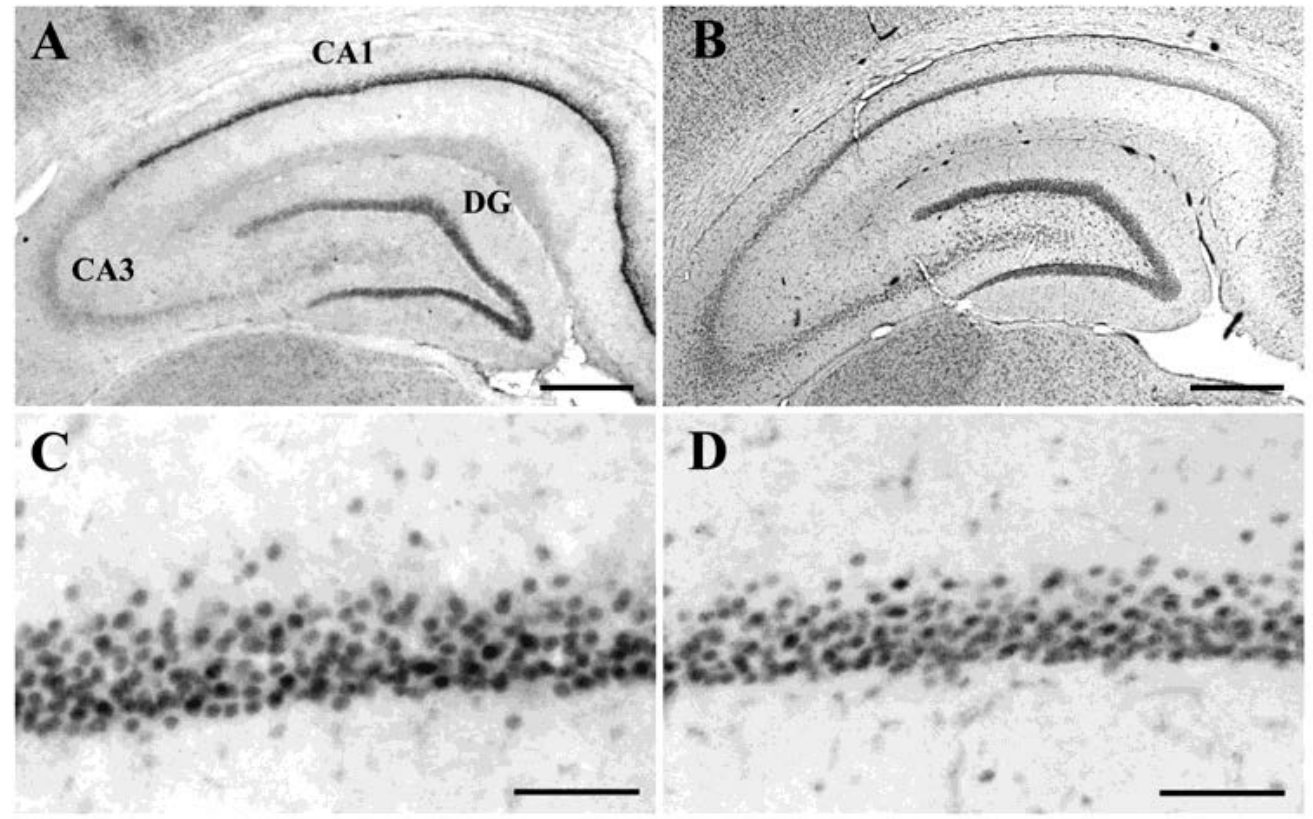

Figure 2. Photomicrographs representing GR (A, C) and GRIP1 (B, D) immunohistochemistry in the hippocampus. $\mathrm{C}, \mathrm{D}$ represent expression in the $\mathrm{CA1}$ region at a higher magnification. Scale bars are 500 $\mu \mathrm{m}$ (A-B) or $50 \mu \mathrm{m}$ (C-D). 


\section{Chapter 3}

Mineralocorticoid (MR) western blot. MR receptor density was assessed using western blot as suitable immunohistochemical techniques were not available. For the MR western blot, fresh frozen half hippocampus of each animal was homogenized in ice-cold lysis buffer (50 $\mathrm{mM}$ Tris-HCl, $\mathrm{pH}$ 7.2, $0.1 \mathrm{mM}$ EDTA, 0.1\% Nonidet P-40, 0.25\% Sodium deoxycholate, and protease inhibitor (Roche Molecular, Mannheim, Germany). The protein content was measured by the micro BCA Protein Assay (Pierce, Rockford, IL). Proteins (10 $\mu \mathrm{g} / \mathrm{lane}$ ) were separated by electrophoresis on SDS/PAGEgels (8\%) and transferred to polyvinylidene difluoride membranes (GE Healthcare). The membranes were blocked at room temperature for $2 \mathrm{~h}$ in blocking buffer (5\% nonfat dry milk in TBS). The membrane was incubated overnight at $4^{\circ} \mathrm{C}$ with the rabbit primary antibody to MR (1:1000 in TBS containing $1 \%$ milk and $0.05 \%$ Tween (TBST), Santa Cruz Biotechnology, CA, sc-11412). The primary MR antibody was visualized with a secondary goat antibody coupled to horseradish peroxidase (1/5000, Abcam). Membranes were rinsed 5 times 10 min between antibody incubations. The peroxidase activity was revealed with the enhanced chemiluminescence system (SuperSignal West Pico chemiluminescent substrate, Thermo Scientific). After the visualization of the MR signal, membranes were stripped, and the procedure was repeated to visualize $\beta$-actin (AC74, 1:3000 in TBST, Sigma Aldrich). The optical density was calculated as the ratio of the optical density of the band (grey level) measured after calibration (Kodak, Photographic step tablet $\mathrm{N}^{\circ} 3$ ) to the optical density of an identical surface measured just above that band (background). The final results were expressed as the ratio of the optical density of the MR band normalized by the optical density of $\beta$-actin.

Statistical analyses. Analysis of variance tests (ANOVA) were used to analyze offspring weight, serum corticosterone levels, CBG levels, the free corticosterone index, and MR, GR and GRIP1 densities as the dependent variable and group (treatment: fluoxetine/vehicle, condition: stress/control, sex: male/female) as independent variables. Because of the well know sex differences in physiology of the HPA during puberty (Romeo, 2010) and the numerous sex differences previously observed after exposure to perinatal factors (Weinstock 2008) further analyses by sex were used where appropriate. Correlations were conducted between MR, GR and GRIP1 density measures, serum corticosterone and CBG levels, and previous behavioural measures on the open field test and forced swim test (Rayen et al. 2011). Posthoc comparisons utilized the LSD test. Differences were considered significant with $\mathrm{p} \leq 0.05$. All data are represented in the text and figures by their mean \pm standard error of the mean (SEM). Statistical analyses were performed with Statistica (version 9). 
Chapter 3

\section{Results}

Maternal care. There were no significant differences associated with treatment or condition in percent time spent licking or nursing offspring $(.38 \leq \mathrm{p} \leq .70)$. All dams spent significantly more time nursing than licking offspring (main effect: $F(1,18)=778.68, p=.00001$ : licking $8.85 \pm 1.12 \%$, nursing $83.06 \pm 2.31 \%$ ).

Offspring weight. There was a significant main effect of $\operatorname{sex}(F(1,47)=26.94, p=.00001)$ with males weighing significantly more than females (Figure 3 ). There was also a significant condition by treatment interaction $(\mathrm{F}(1,48)=7.21, \mathrm{p}=.01$, controlling for any differences in age), and post hoc analysis showed that $\mathrm{CV}$ offspring weighed significantly more than all other groups $(.001 \leq \mathrm{p} \leq .02$; Figure 3$)$.

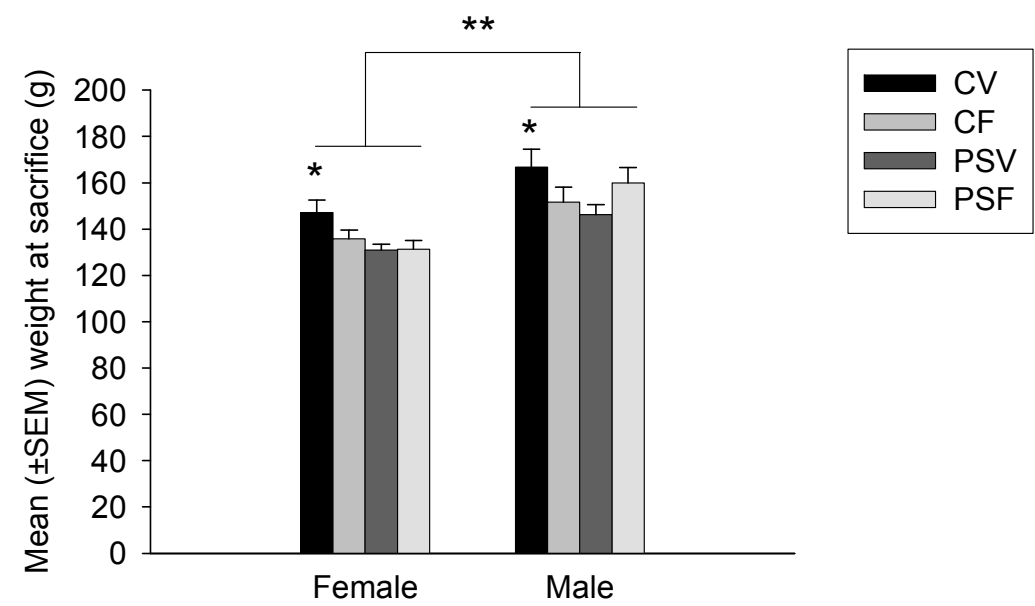

Figure 3. Mean ( \pm SEM) weight of offspring at sacrifice. There was a significant main effect of sex with males weighing significantly more than females. There was also a significant condition by treatment interaction, and post hoc analysis showed that $\mathrm{CV}$ offspring weighed significantly more than all other groups. $\left({ }^{\wedge}\right)$ denotes $\mathrm{CV}$ offspring significantly different from all other groups. $\left({ }^{* *}\right)$ denotes males significantly different from females. $(n=6-8 /$ sex/group)

Serum corticosterone levels. There was a significant main effect of fluoxetine exposure on corticosterone levels with the two groups of fluoxetine-exposed adolescent offspring having significantly lower levels of corticosterone compared to the two groups of vehicle-exposed offspring $(\mathrm{F}(1,38)=4.50, \mathrm{p}=.04$; Figure $4 \mathrm{~A})$. Further stratified analysis by sex revealed that this reduction in serum corticosterone levels after fluoxetine-exposure was only present in male offspring $(F(1,20)=4.84, p=.04)$, and not in female offspring $(F(1,18)=.36, p=.56)$.

Serum CBG levels. There was a significant main effect of sex with male offspring having significantly lower CBG levels than female offspring $(F(1,38)=17.23, p=.0002)$. There was 


\section{Chapter 3}

a significant interaction between treatment, stress and sex in serum CBG levels $(\mathrm{F}(1$, $38)=5.68, \mathrm{p}=.022$; Figure $4 \mathrm{~B}$ ) and post hoc analysis showed that PSF males had significantly higher CBG levels than PSV males $(\mathrm{p} \leq .03)$, PSV males and CF males had significantly lower CBG levels compared to all females $(.0003 \leq \mathrm{p} \leq .035)$, and CV males had significantly lower CBG levels than CF females $(\mathrm{p}=.007)$. Further stratified analysis by sex revealed differences in male offspring only with PSF males having significantly higher CBG levels than PSV and CF males $(.021 \leq \mathrm{p} \leq .038)$. There were no significant main effects or interaction effects between groups of females $(.31 \leq \mathrm{p} \leq .55)$.

Free corticosterone index. There was a significant main effect of treatment $(F(1,38)=7.93$, $\mathrm{p}=.0077$ ), with fluoxetine exposed offspring having lower free corticosterone index than vehicle exposed offspring, and a significant main effect of $\operatorname{sex}(F(1,38)=7.68, p=.0086)$, with males having a higher free corticosterone index than females. There was also a significant interaction between treatment and $\operatorname{sex}(F(1,38)=4.39, p=.043$; Figure $4 C)$, and post hoc analysis revealed that the two groups of vehicle exposed adolescent males had a significantly higher free corticosterone index than all other groups $(.006 \leq p \leq .02)$. Further stratified analysis by sex revealed that the two groups of vehicle exposed adolescent male offspring had a significantly higher free corticosterone index compared to the two groups of fluoxetine exposed adolescent male offspring $(F(1,20)=8.28, p=.009)$, and this effect of fluoxetine exposure was not evident in female offspring $(\mathrm{F}(1,18)=.60, \mathrm{p}=.45)$. 
Chapter 3
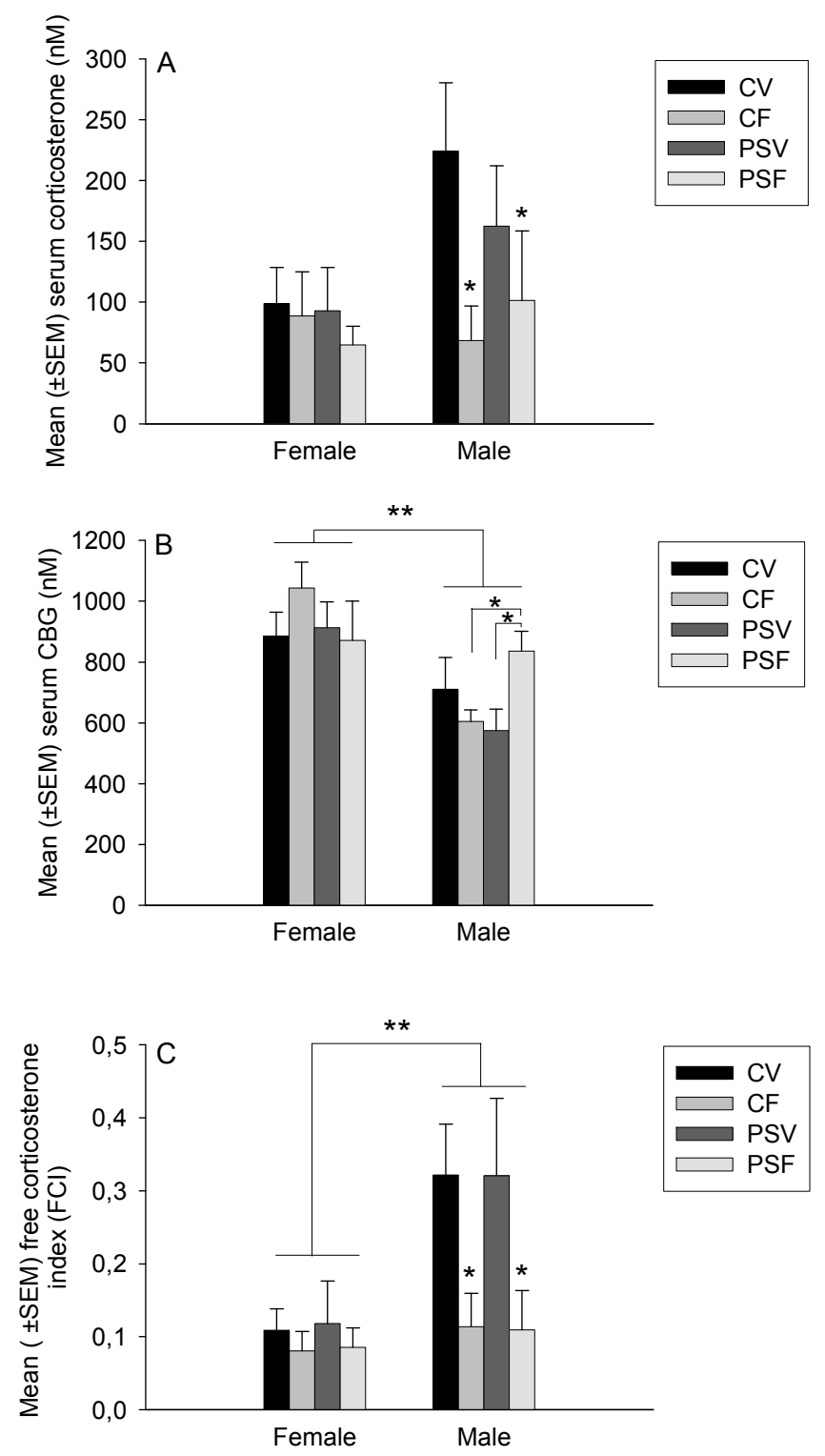

Figure 4. Mean ( \pm SEM) serum levels of $A$ ) corticosterone, $B)$ CBG, and $C$ ) the free corticosterone index. A) Fluoxetine exposed males had significantly lower serum corticosterone levels than vehicle exposed males. B) PSF males had significantly higher CBG levels than PSV and CF males. C) Fluoxetine exposed adolescent male offspring had significantly lower free corticosterone index compared to vehicle exposed adolescent male offspring. There were no significant differences in female offspring for corticosterone levels, CBG levels or the free corticosterone index. (*) denotes fluoxetine exposed adolescent males significantly different from vehicle exposed adolescent males. $(* *)$ denotes males significantly different from females. (n=5-6/sex/group) 


\section{Chapter 3}

GR density in the hippocampus. In the CA1 region, there were no significant main effects or interactions between GR density and condition, treatment or sex $(.08 \leq \mathrm{p} \leq .99$; Figure $5 A)$. In the CA3 region, there was a significant main effect of fluoxetine treatment $(F(1$, $32)=5.70, p=.023$; Figure $5 B$ ), with the fluoxetine exposed offspring having significantly lower GR density compared to vehicle exposed adolescent offspring, regardless of prenatal stress. Further stratified analysis by sex revealed that only the two groups of fluoxetine exposed adolescent male offspring had significantly lower GR density in the CA3 region compared to the two groups of vehicle exposed male offspring $(F(1,16)=5.38, p=.034)$, and this effect of fluoxetine exposure was not evident in female offspring $(F(1,16)=1.58, p=$ .23). In the dentate gyrus, there was a strong tendency toward a significant main effect of fluoxetine on GR density ( $\mathrm{p}=.054$; Figure $5 \mathrm{C}$ ), with fluoxetine exposed animals having decreased GR densities. Further stratified analysis by sex revealed that there was only a strong tendency for fluoxetine exposed adolescent male offspring to have lower GR density in the dentate gyrus compared to vehicle exposed male offspring $(p=.057)$ but this trend was not present in females $(F(1,16)=.78, \mathrm{p}=.39)$. 
Chapter 3
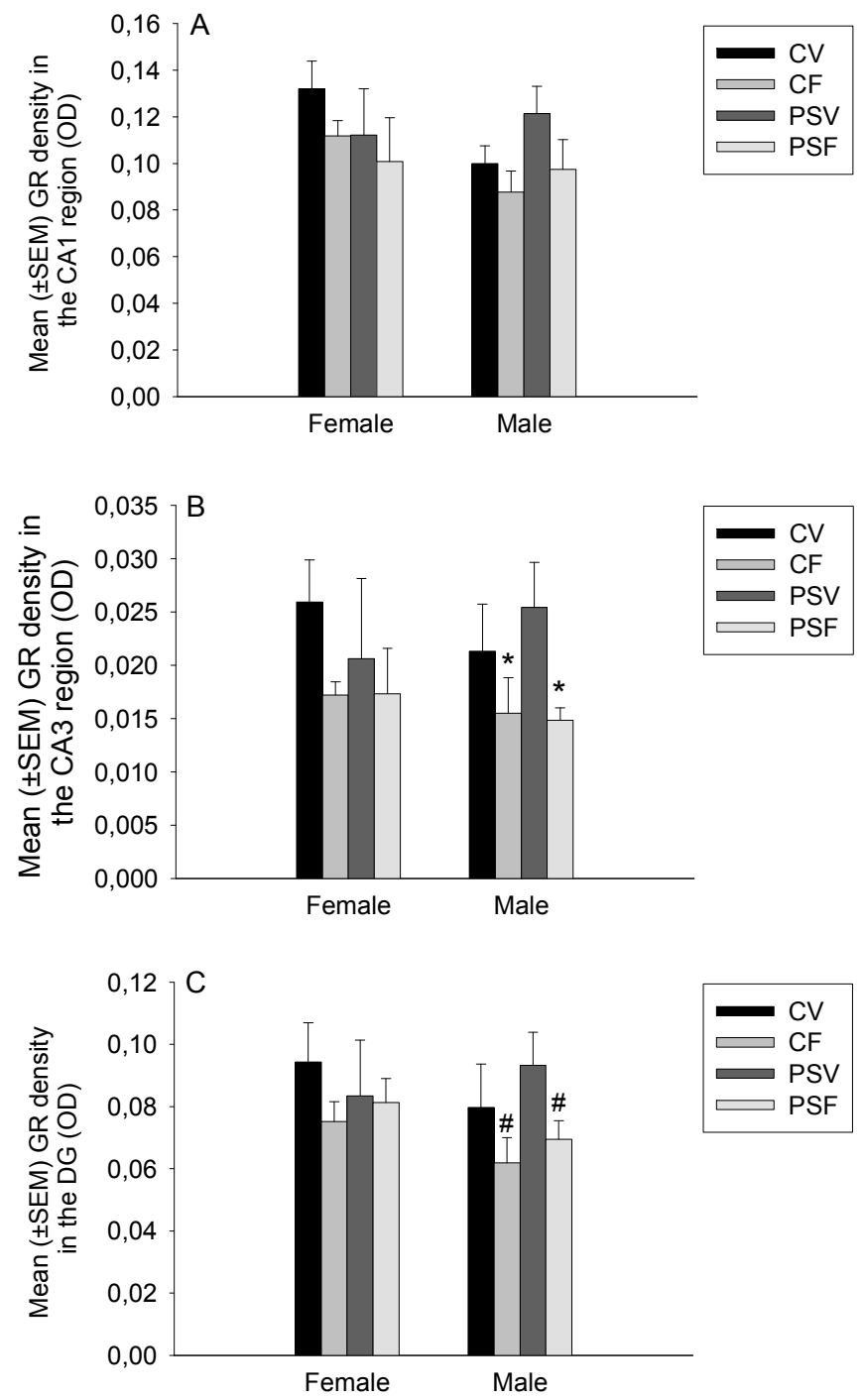

Figure 5. Mean ( \pm SEM) GR expression in the A) CA1, B) CA3, and C) dentate gyrus of the hippocampus of adolescent male and female offspring. A) In the CA1 region, there were no significant main effects or interactions between groups in GR expression. B) In the CA3 region, fluoxetine exposed adolescent male offspring had significantly lower GR expression in the CA3 region than vehicle exposed males. C) In the dentate gyrus, there was a strong tendency for fluoxetine exposed adolescent male offspring to have lower GR expression in the dentate gyrus compared to vehicle exposed male offspring. There were no significant differences with fluoxetine exposure or prenatal stress in GR expression in the hippocampus of adolescent female offspring. (*) denotes fluoxetine exposed adolescent males significantly different from vehicle exposed adolescent males. $\left({ }^{\#}\right)$ denotes fluoxetine exposed adolescent males tend to differ from vehicle exposed adolescent males. $(n=5-6 /$ sex/group) 
Chapter 3

GRIP1 density in the hippocampus. In the CA1 region, there were no significant main effects or interactions in GRIP1 density $(.17 \leq \mathrm{p} \leq .94$; Figure 6A). However, stratified analysis by sex revealed a tendency for fluoxetine exposed adolescent male offspring to have lower GRIP1 density in the CA1 compared to the two groups of vehicle exposed adolescent male offspring $(\mathrm{p}=.07)$, and this effect was not evident in female offspring $(\mathrm{F}(1,20)=.01, \mathrm{p}$ $=.91)$. In the CA3 region, there was a significant main effect of fluoxetine exposure on GRIP1 density in adolescent offspring $(F(1,39)=8.31, \mathrm{p}=.006$; Figure $6 \mathrm{~B})$ with fluoxetine exposed offspring having lower GRIP1 densities. Stratified analysis by sex revealed that only fluoxetine exposed adolescent male offspring had significantly lower GRIP1 density in the CA3 compared to vehicle exposed male offspring $(F(1,19)=5.35, p=.03)$ and this significant effect was not evident in female offspring $(F(1,20)=3.27, p=.09)$. For the dentate gyrus, there were no significant main effects or interactions in GRIP1 density $(.16 \leq \mathrm{p} \leq .95$; Figure 6C). 
Chapter 3
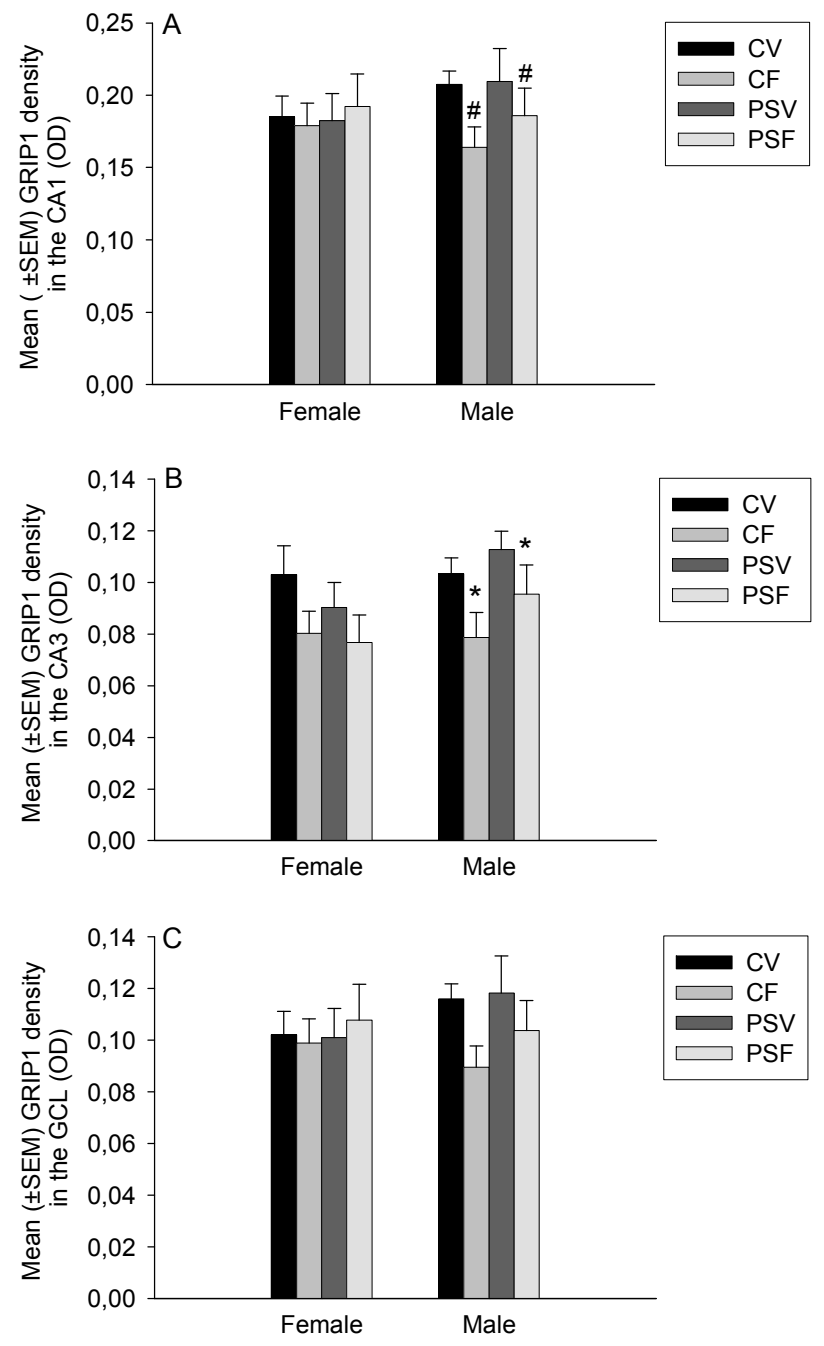

Figure 6. Mean ( \pm SEM) GRIP1 expression (OD) in the A) CA1, B) CA3, and C) dentate gyrus of the hippocampus of adolescent male and female offspring. A) In the CA1 region, there was a tendency for adolescent fluoxetine exposed male offspring to have lower GRIP1 expression in the CA1 compared to vehicle exposed males. B) In the CA3 region, fluoxetine exposed adolescent male offspring had significantly lower GRIP1 expression in the CA3 compared to vehicle exposed male offspring. C) For the dentate gyrus, there were no significant main effects or interactions in GRIP1 expression. There were no significant differences with fluoxetine exposure or prenatal stress in GR expression in the hippocampus of adolescent female offspring. (*) denotes fluoxetine exposed adolescent males significantly different from vehicle exposed adolescent males. (") denotes fluoxetine exposed adolescent males tend to differ from vehicle exposed adolescent males. ( $n=5-6 /$ sex/group) 


\section{Chapter 3}

MR density in the hippocampus. There were no significant interactions or main effects in the density of MR throughout the hippocampus $(.27 \leq \mathrm{p} \leq .90$; Table 1$)$.

Table 1: Mean ( \pm SEM) optical density (OD) of MR expression in the hippocampus of adolescent offspring. There were no significant interactions or main effects in the expression of MR throughout the hippocampus. (n=5/sex/group).

\begin{tabular}{|c|c|c|c|c|c|c|c|c|}
\hline & \multicolumn{4}{|c|}{ Female offspring } & \multicolumn{4}{|c|}{ Male offspring } \\
\hline & $\mathrm{CV}$ & $\mathbf{C F}$ & PSV & PSF & $\mathrm{CV}$ & $\mathrm{CF}$ & PSV & PSF \\
\hline MR/actin & $1.17 \pm .21$ & $1.03 \pm .20$ & $1.017 \pm .27$ & $1.39 \pm .49$ & $1.32 \pm .57$ & $1.87 \pm .58$ & $1.42 \pm .27$ & $1.26 \pm .26$ \\
\hline
\end{tabular}

There were no other significant main effects or interaction effects and no further correlations between any measures including previous behavioural measures on the open field test and forced swim test (Rayen et al. 2011) $(.09 \leq \mathrm{p} \leq .98)$.

\section{Discussion}

This study is one of the very first to investigate the developmental effect of SSRI medication, in a model of maternal adversity, on the developing HPA system in adolescent offspring. Contrary to previous studies that investigated only one sex (Cabrera-Vera et al. 1997; Glover et al. 2010; Ishiwata et al. 2005; Mastorci et al. 2009; Weinstock 2008), we also compared outcomes in both male and female offspring. Our findings show that developmental exposure to fluoxetine has significant long-term effects on components of the HPA axis with decreased serum corticosterone levels, and a reduction in GR and GRIP1 expression in the hippocampus. We also found that prenatal maternal stress, in combination with developmental fluoxetine exposure, increased $\mathrm{CBG}$ levels, thus altering the free corticosterone index. Interestingly, these effects were particularly evident in male, and not female, adolescent offspring. These data point to the long term effect of developmental exposure to SSRI medications on the HPA system, particularly in male offspring. With the increasing use of SSRI medications to treat maternal mood disorders during pregnancy and the postpartum period (Cooper et al. 2007; Oberlander et al. 2006; Ververs et al. 2006), there is a growing need to understand how exposure to these medications affects offspring outcomes. 


\section{Chapter 3}

\section{The role of developmental exposure to fluoxetine on the HPA system during}

adolescence. We previously showed that early postnatal exposure to maternal fluoxetine prevents the decrease in immobility in forced swim test and hippocampal neurogenesis in both male and female offspring born from stressed mothers (Rayen et al. 2011). These results confirmed the effectiveness of prenatal maternal stress and its reversibility by maternal SSRI treatment. These neurobehavioural outcomes also strongly suggest that prenatal maternal adversity and developmental fluoxetine exposure have long-lasting effects on the HPA system, including changes in serum corticosterone levels and/or GR expression at the level of the hippocampus.

In the present study, we found that maternal stress and/or fluoxetine exposure lowered circulating corticosterone levels and altered CBG levels at sacrifice, thus resulting in decreased estimated free corticosterone levels. These effects were evident in adolescent male offspring only, even though female offspring were manipulated in the same way. This finding of attenuated corticosterone levels in male offspring with developmental fluoxetine exposure is consistent with preclinical work showing that oral administration of fluoxetine (from postnatal weeks 1-3) to male offspring attenuates the corticosterone response to acute stress at 3 weeks of age (Ishiwata et al. 2005). In addition, our finding of long-term alterations in serum CBG levels complement recent clinical work showing that prenatal SSRI-exposed neonates have increased serum levels of CBG levels at birth, and this change in CBG levels is strongly associated with a decrease in basal levels of free cortisol in the infant at 3 months of age (Pawluski et al, in press). Others have shown that 3 month old prenatally SSRI-exposed infants have lower evening salivary cortisol levels and a more regulated stress response compared to non-exposed infants (Oberlander et al. 2008a). Thus, alterations in serum CBG and cortisol, with perinatal SSRI exposure, likely play a dominant role in the regulation of the HPA system, particularly 'blunting' or tightly regulating the response to stress. Our preclinical data further complement this clinical work by showing that developmental exposure to SSRI medications may have long-term effects on peripheral measures of the HPA system, at least into adolescence.

Our work also shows that developmental exposure to SSRIs, independently of prenatal maternal stress, may modulate the HPA axis via alterations in GR and GRIP1 expression at the level of the hippocampus. The decreased hippocampal GR and GRIP1 expression, particularly in the CA3 region of adolescent male rats, is of special interest as pyramidal neurones of the CA3 region of the hippocampus are particularly sensitive to stress (Galea et al. 1997; Margarinos and McEwen 1995), and the hippocampus itself plays an 


\section{Chapter 3}

active role in regulating the stress response (Lupien et al. 2009; McEwen 2008; McEwen et al. 1993). Thus inhibition of serotonin reuptake during development may markedly affect the response to stress during adolescence via changes in hippocampal GR and GRIP1 expression. Previous studies suggest that serotonin can increase hippocampal GR mRNA in vitro (Erdeljan et al. 2005; Erdeljan et al. 2001) and the chronic use of SSRIs during adulthood generally increase GR expression in the rat hippocampus (Yau et al. 2002). However, in this previous work it is unclear whether there were regional and temporal differences in the effects of serotonin on GR expression in the hippocampal formation. In vivo, we found that developmental exposure to fluoxetine decreased GR expression in the CA3 region and dentate gyrus of the dorsal hippocampus, showing regional differences in the control of GR expression in the hippocampus by serotonin. It should also be noted that the decrease in GR expression was observed during adolescence and thus the persistence of this effect into adulthood remains to be determined.

We have yet to determine the functional significance of decreased GR expression in the hippocampus as a result of developmental exposure to fluoxetine. However, we found that developmental fluoxetine exposure also decreased GRIP1 expression in all 3 regions of the hippocampus, but most markedly in the CA3 region. GRIP1 is a key protein involved in the modulation of GR and MR action in the brain and has been shown to enhance transcriptional effects of GRs and MRs in numerous cell types (Grenier et al. 2006; Hong et al. 1997; Li et al. 2004; Mitchell et al. 1990; Trousson et al. 2007). Thus, our data point to alterations in the transcriptional activity of GR in the hippocampus after exposure to maternal fluoxetine treatment. This parallel decrease in GR and GRIP1 expression in the hippocampus suggests that the down regulation of GRIP1 could result from a decrease in GR expression or from a direct effect of inhibition of serotonin reuptake, via fluoxetine exposure, during development. Together, it can be concluded that developmental fluoxetine treatment leads to a long-term down-regulation of serum corticosterone levels and GR and GRIP1 expression in the hippocampus of adolescent male offspring, independently of exposure to maternal adversity. The mechanisms and consequences of these changes remain to be investigated.

\section{Developmental fluoxetine exposure differentially affects male and female offspring. Our} findings also highlight a marked sex difference in the physiological levels of corticosterone and $\mathrm{CBG}$ during adolescence with vehicle-exposed males having elevated serum corticosterone levels and decreased CBG levels compared to females. In addition, there were marked sex differences resulting from developmental fluoxetine exposure with significant 


\section{Chapter 3}

long-term effects of developmental fluoxetine exposure on the physiology and neurobiology of male, but not female, adolescent offspring.

It is currently unclear why male and female offspring exhibit such marked differences in response to developmental fluoxetine exposure, but it seems likely that these differences are mediated by circulating sex steroid hormone levels, as estradiol has been shown to modulate the HPA system (Atkinson and Waddell 1997; Viau 2002; Viau and Meaney 1991). There are also well known sex differences in serum corticosterone and CBG levels, with females generally having elevated levels of basal corticosterone and CBG when compared to males (Kudielka and Kirschbaum 2005). Serotonin levels in many brain regions differ in male and female offspring (Duchesne et al. 2009) and it may be that the actions of developmental exposure to SSRI medications alter the serotonergic system in a sexually dimorphic way. In support of this hypothesis, perinatal exposure to non-SSRI medications such as diazepam, a benzodiazepine, can differentially alter serotonin levels in the brain of adult female and male rat offspring (Frieder and Grimm 1985). It may also be that males and females are at different maturational stages at this time and thus the effects of maternal fluoxetine exposure on the female brain and physiology may be evident at a different time point in development. Much more work is needed to determine the significance and mechanisms underlying these sex differences in HPA development as well as the role of steroid hormones and monoamines in regulating these effects. Furthermore, the behavioural implications of these differences and how this information translates to the clinic have yet to be determined. Clearly we cannot disregard the pertinent sex differences that exist.

\section{Conclusions}

The enduring impact of perinatal exposure to SSRI medications on offspring development is a growing concern as up to $10 \%$ of women are taking SSRI medications during pregnancy and continuing into the postpartum period (Cooper et al. 2007; Oberlander et al. 2006). The present study shows that developmental exposure to fluoxetine has a significant long-term impact on physiological and neural measures of the HPA system. In addition, these effects were often independent of previous exposure to maternal adversity and, importantly, markedly differed in male and female adolescent offspring. Long-term alterations in the HPA system may significantly impact immune function, pain responsiveness and vulnerability to disease (Harris and Seckl 2011; Lupien et al. 2009; McEwen 2008). Therefore, much more 


\section{Chapter 3}

work is needed to understand the benefits and risks of perinatal exposure to SSRI medications on the developing HPA system.

\section{Acknowledgements}

We gratefully acknowledge the technical help from Denise Hermes. JLP was funded by a Natural Sciences and Engineering Research Council of Canada Postdoctoral Fellowships and presently holds a Chargé de Recherche position with Fonds de la Recherche Scientifique (FRS-FNRS). TDC is Research Associate at ULg. 


\section{Chapter 3}

\section{References}

Alahmed S, Herbert J (2008), Strain differences in proliferation of progenitor cells in the dentate gyrus of the adult rat and the response to fluoxetine are dependent on corticosterone. Neuroscience 157:677-682.

Andrews MH, Matthews SG (2004), Programming of the hypothalamo-pituitary-adrenal axis: serotonergic involvement. Stress 7:15-27.

Atkinson HC, Waddell BJ (1997), Circadian variation in basal plasma corticosterone and adrenocorticotropin in the rat: sexual dimorphism and changes across the estrous cycle. Endocrinology 138:3842-3848.

Barden N, Reul JM, Holsboer F (1995), Do antidepressants stabilize mood through actions on the hypothalamicpituitary-adrenocortical system? Trends Neurosci 18:6-11.

Brennan PA, Pargas R, Walker EF, Green P, Newport DJ, Stowe Z (2008), Maternal depression and infant cortisol: influences of timing, comorbidity and treatment. J Child Psychol Psychiatry 49:1099-1107.

Cabrera-Vera TM, Garcia F, Pinto W, Battaglia G (1997), Effect of prenatal fluoxetine (Prozac) exposure on brain serotonin neurons in prepubescent and adult male rat offspring. J Pharmacol Exp Ther 280:138145.

Charlier TD (2009), Importance of steroid receptor coactivators in the modulation of steroid action on brain and behavior. Psychoneuroendocrinology 34 Suppl 1:S20-29.

Clinchy M, Zanette L, Charlier TD, Newman AE, Schmidt KL, Boonstra R, Soma KK (2011), Multiple measures elucidate glucocorticoid responses to environmental variation in predation threat. Oecologia 166:607-614.

Cooper WO, Willy ME, Pont SJ, Ray WA (2007), Increasing use of antidepressants in pregnancy. AmJ ObstetGynecol 196:544 e541-545.

Darnaudery M, Maccari S (2008), Epigenetic programming of the stress response in male and female rats by prenatal restraint stress. Brain Res Rev 57:571-585.

Davidson JS, Bolland MJ, Croxson MS, Chiu W, Lewis JG (2006), A case of low cortisol-binding globulin: use of plasma free cortisol in interpretation of hypothalamic-pituitary-adrenal axis tests. Ann Clin Biochem 43:237-239.

Davis EP, Glynn LM, Waffarn F, Sandman CA (2011), Prenatal maternal stress programs infant stress regulation. J Child Psychol Psychiatry 52:119-129.

Duchesne A, Dufresne MM, Sullivan RM (2009), Sex differences in corticolimbic dopamine and serotonin systems in the rat and the effect of postnatal handling. Progress in neuro-psychopharmacology \& biological psychiatry 33:251-261.

Epperson CN, Jatlow PI, Czarkowski K, Anderson GM (2003), Maternal fluoxetine treatment in the postpartum period: effects on platelet serotonin and plasma drug levels in breastfeeding mother-infant pairs. Pediatrics 112:e425.

Erdeljan P, Andrews MH, MacDonald JF, Matthews SG (2005), Glucocorticoids and serotonin alter glucocorticoid receptor mRNA levels in fetal guinea-pig hippocampal neurons, in vitro. Reprod Fertil Dev 17:743-749.

Erdeljan P, MacDonald JF, Matthews SG (2001), Glucocorticoids and serotonin alter glucocorticoid receptor (GR) but not mineralocorticoid receptor (MR) mRNA levels in fetal mouse hippocampal neurons, in vitro. Brain Res 896:130-136.

Field T, Diego M, Hernandez-Reif M (2006), Prenatal depression effects on the fetus and newborn: a review. Infant Behav Dev 29:445-455.

Field T, Diego M, Hernandez-Reif M, Vera Y, Gil K, Schanberg S, Kuhn C, Gonzalez-Garcia A (2004), Prenatal maternal biochemistry predicts neonatal biochemistry. Int J Neurosci 114:933-945.

Frieder B, Grimm VE (1985), Some long-lasting neurochemical effects of prenatal or early postnatal exposure to diazepam. J Neurochem 45:37-42.

Galea L, McEwen BS, Tanapat P, Deak T, Spencer RL, Dhabhar FS (1997), Sex differences in dendritic atrophy of CA3 pyramidal neurons in response to chronic restraint stress. Neuroscience 81:689-697.

Gentile S (2005), The safety of newer antidepressants in pregnancy and breastfeeding. Drug Saf 28:137-152.

Glover V, O'Connor TG, O'Donnell K (2010), Prenatal stress and the programming of the HPA axis. Neurosci Biobehav Rev 35:17-22.

Green MK, Rani CS, Joshi A, Soto-Pina AE, Martinez PA, Frazer A, Strong R, Morilak DA (2011), Prenatal stress induces long term stress vulnerability, compromising stress response systems in the brain and impairing extinction of conditioned fear after adult stress. Neuroscience 192:438-451.

Grenier J, Trousson A, Chauchereau A, Cartaud J, Schumacher M, Massaad C (2006), Differential recruitment of p160 coactivators by glucocorticoid receptor between Schwann cells and astrocytes. Mol Endocrinol 20:254-267.

Hammond GL, Lahteenmaki PL (1983), A versatile method for the determination of serum cortisol binding globulin and sex hormone binding globulin binding capacities. Clin Chim Acta 132:101-110. 


\section{Chapter 3}

Hamrahian AH, Oseni TS, Arafah BM (2004), Measurements of serum free cortisol in critically ill patients. N Engl J Med 350:1629-1638.

Harris A, Seckl J (2011), Glucocorticoids, prenatal stress and the programming of disease. Horm Behav 59:279289.

Hendrick V, Stowe ZN, Altshuler LL, Mintz J, Hwang S, Hostetter A, Suri R, Leight K, Fukuchi A (2001), Fluoxetine and norfluoxetine concentrations in nursing infants and breast milk. BiolPsychiatry 50:775782.

Hong H, Kohli K, Garabedian MJ, Stallcup MR (1997), GRIP1, a transcriptional coactivator for the AF-2 transactivation domain of steroid, thyroid, retinoid, and vitamin D receptors. Mol Cell Biol 17:27352744.

Hong H, Kohli K, Trivedi A, Johnson DL, Stallcup MR (1996), GRIP1, a novel mouse protein that serves as a transcriptional coactivator in yeast for the hormone binding domains of steroid receptors. Proceedings of the National Academy of Sciences of the United States of America 93:4948-4952.

Ishiwata H, Shiga T, Okado N (2005), Selective serotonin reuptake inhibitor treatment of early postnatal mice reverses their prenatal stress-induced brain dysfunction. Neuroscience 133:893-901.

Kapoor A, Matthews SG (2008), Prenatal stress modifies behavior and hypothalamic-pituitary-adrenal function in female guinea pig offspring: effects of timing of prenatal stress and stage of reproductive cycle. Endocrinology 149:6406-6415.

Kudielka BM, Kirschbaum C (2005), Sex differences in HPA axis responses to stress: a review. BiolPsychol 69:113-132.

Laplante P, Diorio J, Meaney MJ (2002), Serotonin regulates hippocampal glucocorticoid receptor expression via a 5-HT7 receptor. Brain Res Dev Brain Res 139:199-203.

le Roux CW, Sivakumaran S, Alaghband-Zadeh J, Dhillo W, Kong WM, Wheeler MJ (2002), Free cortisol index as a surrogate marker for serum free cortisol. Ann Clin Biochem 39:406-408.

Levine S (2005), Developmental determinants of sensitivity and resistance to stress. Psychoneuroendocrinology 30:939-946.

Li H, Kim JH, Koh SS, Stallcup MR (2004), Synergistic effects of coactivators GRIP1 and beta-catenin on gene activation: cross-talk between androgen receptor and Wnt signaling pathways. The Journal of biological chemistry 279:4212-4220.

Lupien SJ, McEwen BS, Gunnar MR, Heim C (2009), Effects of stress throughout the lifespan on the brain, behaviour and cognition. Nat Rev Neurosci 10:434-445.

Maccari S, Darnaudery M, Morley-Fletcher S, Zuena AR, Cinque C, Van Reeth O (2003), Prenatal stress and long-term consequences: implications of glucocorticoid hormones. Neurosci Biobehav Rev 27:119127.

Margarinos A, McEwen B (1995), Stress-induced atrophy of apical dendrites of hippocampal CA3c neurons: involvement of glucocorticosteroneicoid secretion and excitatory amino acid receptors. Neuroscience 69:89-98.

Mastorci F, Vicentini M, Viltart O, Manghi M, Graiani G, Quaini F, Meerlo P, Nalivaiko E, Maccari S, Sgoifo A (2009), Long-term effects of prenatal stress: Changes in adult cardiovascular regulation and sensitivity to stress. Neurosci Biobehav Rev 33:191-203.

McCormick CM, Mathews IZ (2007), HPA function in adolescence: role of sex hormones in its regulation and the enduring consequences of exposure to stressors. PharmacolBiochemBehav 86:220-233.

McEwen BS (2008), Central effects of stress hormones in health and disease: Understanding the protective and damaging effects of stress and stress mediators. EurJ Pharmacol 583:174-185.

McEwen BS, Cameron H, Chao HM, Gould E, Magarinos AM, Watanabe Y, Woolley CS (1993), Adrenal steroids and plasticity of hippocampal neurons: toward an understanding of underlying cellular and molecular mechanisms. Cell Mol Neurobiol 13:457-482.

Meaney MJ, Diorio J, Francis D, LaRocque S, O'Donnell D, Smythe JW, Sharma S, Tannenbaum B (1994), Environmental regulation of the development of glucocorticoid receptor systems in the rat forebrain. The role of serotonin. Ann N Y Acad Sci 746:260-273; discussion 274, 289-293.

Mitchell JB, Iny LJ, Meaney MJ (1990), The role of serotonin in the development and environmental regulation of type II corticosteroid receptor binding in rat hippocampus. Brain Res Dev Brain Res 55:231-235.

Morrison JL, Riggs KW, Chien C, Gruber N, McMillen IC, Rurak DW (2004), Chronic maternal fluoxetine infusion in pregnant sheep: effects on the maternal and fetal hypothalamic-pituitary-adrenal axes. Pediatr Res 56:40-46.

Niessen NA, Balthazart J, Ball GF, Charlier TD (2011), Steroid Receptor Coactivator 2 (SRC-2) Modulates Steroid-Dependent Male Sexual Behavior and Neuroplasticity in Japanese Quail (Coturnix Japonica). J Neurochem. 


\section{Chapter 3}

O'Mahony SM, Myint AM, van den Hove D, Desbonnet L, Steinbusch H, Leonard BE (2006), Gestational stress leads to depressive-like behavioural and immunological changes in the rat. Neuroimmunomodulation 13:82-88.

Oberlander TF, Eckstein Grunau R, Fitzgerald C, Ellwood AL, Misri S, Rurak D, Riggs KW (2002), Prolonged prenatal psychotropic medication exposure alters neonatal acute pain response. Pediatr Res 51:443-453.

Oberlander TF, Grunau R, Mayes L, Riggs W, Rurak D, Papsdorf M, Misri S, Weinberg J (2008a), Hypothalamic-pituitary-adrenal (HPA) axis function in 3-month old infants with prenatal selective serotonin reuptake inhibitor (SSRI) antidepressant exposure. Early Hum Dev 84:689-697.

Oberlander TF, Grunau RE, Fitzgerald C, Papsdorf M, Rurak D, Riggs W (2005), Pain reactivity in 2-month-old infants after prenatal and postnatal serotonin reuptake inhibitor medication exposure. Pediatrics 115:411-425.

Oberlander TF, Warburton W, Misri S, Aghajanian J, Hertzman C (2006), Neonatal outcomes after prenatal exposure to selective serotonin reuptake inhibitor antidepressants and maternal depression using population-based linked health data. Arch Gen Psychiatry 63:898-906.

Oberlander TF, Weinberg J, Papsdorf M, Grunau R, Misri S, Devlin AM (2008b), Prenatal exposure to maternal depression, neonatal methylation of human glucocorticoid receptor gene (NR3C1) and infant cortisol stress responses. Epigenetics 3:97-106.

Oliveira E, Pinheiro CR, Santos-Silva AP, Trevenzoli IH, Abreu-Villaca Y, Nogueira Neto JF, Reis AM, Passos MC, Moura EG, Lisboa PC (2010), Nicotine exposure affects mother's and pup's nutritional, biochemical, and hormonal profiles during lactation in rats. J Endocrinol 205:159-170.

Olivier JD, Blom T, Arentsen T, Homberg JR (2011a), The age-dependent effects of selective serotonin reuptake inhibitors in humans and rodents: A review. Progress in neuro-psychopharmacology \& biological psychiatry 35:1400-1408.

Olivier JD, Valles A, van Heesch F, Afrasiab-Middelman A, Roelofs JJ, Jonkers M, Peeters EJ, Korte-Bouws GA, Dederen JP, Kiliaan AJ, Martens GJ, Schubert D, Homberg JR (2011b), Fluoxetine administration to pregnant rats increases anxiety-related behavior in the offspring. Psychopharmacology 217:419-432.

Pawluski JL (in press), Perinatal Selective Serotonin Reuptake Inhibitor Exposure: Impact on Brain Development and Neural Plasticity. Neuroendocrinology.

Pawluski JL, Brain U, Underhill CM, Hammond GL, Oberlander T (2012a), Prenatal SSRI exposure, neonatal corticosteroid binding globulin and infant cortisol Psychoneuroendocrinology 37:1019-1028.

Pawluski JL, Charlier TD, Fillet M, Houbart V, Crispin HT, Steinbusch HW, van den Hove DL (2012b), Chronic fluoxetine treatment and maternal adversity differentially alter neurobehavioral outcomes in the rat dam. Behavioural Brain Research 228:159-168.

Pawluski JL, Charlier TD, Lieblich SE, Hammond GL, Galea LA (2009), Reproductive experience alters corticosterone and CBG levels in the rat dam. Physiol Behav 96:108-114.

Paxinos G, Watson C (2004) The Rat Brain in Stereotaxic Coordinates: Elsevier Academic Press.

Rayen I, van den Hove DL, Prickaerts J, Steinbusch HW, Pawluski JL (2011), Fluoxetine during development reverses the effects of prenatal stress on depressive-like behavior and hippocampal neurogenesis in adolescence. PLoS ONE 6:e24003.

Romeo RD (2010), Pubertal maturation and programming of hypothalamic-pituitary-adrenal reactivity. Front Neuroendocrinol 31:232-240.

Romeo RD, McEwen BS (2006), Stress and the adolescent brain. Ann N Y Acad Sci 1094:202-214.

Romijn HJ, Hofman MA, Gramsbergen A (1991), At what age is the developing cerebral cortex of the rat comparable to that of the full-term newborn human baby? Early Hum Dev 26:61-67.

Smith JW, Seckl JR, Evans AT, Costall B, Smythe JW (2004), Gestational stress induces post-partum depression-like behaviour and alters maternal care in rats. Psychoneuroendocrinology 29:227-244.

Tetel MJ, Auger AP, Charlier TD (2009), Who's in charge? Nuclear receptor coactivator and corepressor function in brain and behavior. Front Neuroendocrinol 30:328-342.

Trousson A, Grenier J, Fonte C, Massaad-Massade L, Schumacher M, Massaad C (2007), Recruitment of the p160 coactivators by the glucocorticoid receptor: dependence on the promoter context and cell type but not hypoxic conditions. The Journal of steroid biochemistry and molecular biology 104:305-311.

Uys JD, Muller CJ, Marais L, Harvey BH, Stein DJ, Daniels WM (2006), Early life trauma decreases glucocorticoid receptors in rat dentate gyrus upon adult re-stress: reversal by escitalopram. Neuroscience 137:619-625.

Van den Bergh BR, Van Calster B, Smits T, Van Huffel S, Lagae L (2008), Antenatal maternal anxiety is related to HPA-axis dysregulation and self-reported depressive symptoms in adolescence: a prospective study on the fetal origins of depressed mood. Neuropsychopharmacology 33:536-545.

Van den Hove DL, Blanco CE, Aendekerk B, Desbonnet L, Bruschettini M, Steinbusch HP, Prickaerts J, Steinbusch HW (2005), Prenatal restraint stress and long-term affective consequences. Dev Neurosci 27:313-320. 


\section{Chapter 3}

Ververs T, Kaasenbrood H, Visser G, Schobben F, de Jong-van den Berg L, Egberts T (2006), Prevalence and patterns of antidepressant drug use during pregnancy. Eur J Clin Pharmacol 62:863-870.

Viau V (2002), Functional cross-talk between the hypothalamic-pituitary-gonadal and -adrenal axes. J Neuroendocrinol 14:506-513.

Viau V, Meaney MJ (1991), Variations in the hypothalamic-pituitary-adrenal response to stress during the estrous cycle in the rat. Endocrinology 129:2503-2511.

Ward IL, Weisz J (1984), Differential effects of maternal stress on circulating levels of corticosterone, progesterone, and testosterone in male and female rat fetuses and their mothers. Endocrinology 114:1635-1644.

Weinstock M (2008), The long-term behavioural consequences of prenatal stress. Neurosci Biobehav Rev 32:1073-1086.

Xu J, Kirigiti MA, Grove KL, Smith MS (2009), Regulation of food intake and gonadotropin-releasing hormone/luteinizing hormone during lactation: role of insulin and leptin. Endocrinology 150:42314240.

Yau JL, Hibberd C, Noble J, Seckl JR (2002), The effect of chronic fluoxetine treatment on brain corticosteroid receptor mRNA expression and spatial memory in young and aged rats. Brain research Molecular brain research 106:117-123.

Yore MA, Im D, Webb LK, Zhao Y, Chadwick JG, Jr., Molenda-Figueira HA, Haidacher SJ, Denner L, Tetel MJ (2010), Steroid receptor coactivator-2 expression in brain and physical associations with steroid receptors. Neuroscience 169:1017-1028. 


\section{Chapter 4}

Developmental fluoxetine exposure and prenatal stress differentially affect hippocampal cell proliferation in adult male and female offspring

Authors: Ine Rayen, Harry W.M. Steinbusch, Jodi L. Pawluski 
Chapter 4

\begin{abstract}
During pregnancy and postpartum period, $20 \%$ of women are affected by depression, which is a growing health concern. Selective serotonin reuptake inhibitor (SSRIs) medications are popular treatments for maternal depression, however, the effect of maternal depression and perinatal SSRI exposure on offspring neural development needs further investigation. Recently we have demonstrated that developmental fluoxetine exposure reverses the effects of prenatal stress on hippocampal neurogenesis during adolescence. Therefore, the goal of this study was to determine the role of exposure to fluoxetine during development on plasticity in the adult hippocampus. To do this, prenatally stressed and non-stressed SpragueDawley rat offspring were exposed, via lactation, to either fluoxetine or vehicle beginning on postnatal day 1. Four groups of male and female offspring were used: 1) prenatal stress + fluoxetine, 2) prenatal stress + vehicle, 3) fluoxetine alone, and 4) vehicle alone. Brains of adult male and female offspring were analyzed for levels of cell proliferation (Ki67-ir) and new cell survival ( 3 weeks after BrdU injection) in the dentate gyrus of the hippocampus. Results show that developmental fluoxetine exposure reduces hippocampal cell proliferation (ki67-ir cells) in prenatally stressed adult female offspring and prenatal stress, but not developmental fluoxetine exposure, decreases hippocampal cell proliferation (ki67-ir cells) in adult male offspring. Developmental fluoxetine exposure and prenatal maternal stress did not affect new cell survival (BrdU-ir cells) in the hippocampus of adult male and female offspring. These results provide important insights in the long-term developmental effects of maternal adversity and developmental fluoxetine exposure on neural plasticity in male and female offspring.
\end{abstract}

Keywords: antidepressants, development, hippocampus, SSRI, neurogenesis, BrdU, Ki67, rat 


\section{Introduction}

Early exposure to traumatic life events, such as maternal stress and maternal mood disorders, can induce long-term neurobiological and behavioral effects in offspring (Glover et al. 2010; Talge et al. 2007; Weinstock 2001). Children who have been exposed to maternal stress or depression during gestation often show impairment in cognitive abilities and language development, altered hypothalamic-pituitary-adrenal axis as well as an increased risk to develop neuropsychiatric disorders such as schizophrenia, autism, anxiety and depression (Beversdorf et al. 2005; Huizink et al. 2003; Laplante et al. 2004; Niederhofer and Reiter 2004; Van den Bergh et al. 2005; van Os and Selten 1998; Weinstock 2001). These neuropsychiatric disorders are often associated with morphological alterations of the brain, such as enlarged ventricles and a reduction of the hippocampal size (Altshuler et al. 2000; Bremner et al. 2000; Bremner et al. 1995; Bremner et al. 1997; Gur et al. 2000). In animal models of gestational stress, offspring exhibit a number of cognitive and behavioral impairments that mimick aspects of the clinical situation (Glover et al. 2010; Maccari et al. 2003; Maccari and Morley-Fletcher 2007; Weinstock 2008; Zagron and Weinstock 2006). In addition, reductions of hippocampal volume, inhibition of hippocampal cell proliferation and neurogenesis have also been shown after prenatal stress exposure in animal models (Coe et al. 2003; Gong et al. 2012; Kawamura et al. 2006; Koehl et al. 2009; Lemaire et al. 2000; Lucassen et al. 2009; Odagiri et al. 2008), suggesting a strong link between behavioral outcomes and hippocampal plasticity, so called morphofunctional interactions.

Maternal depression during the perinatal period is most often treated with selective serotonin reuptake inhibitor medications (SSRIs), which target the serotoninergic system (Fleschler and Peskin 2008). These drugs can transfer to the fetus via the placenta and are also present in breast milk, and as such, can have an impact on the offspring neurodevelopment (Berle and Spigset 2011; Berle et al. 2004; Kim et al. 2006; Kristensen et al. 1999). Prenatal SSRI exposure has been shown to decrease serum S100B protein levels in neonates (Pawluski et al. 2009b) and this may be an indication of alterations in neurodevelopment as S100B stimulates glial cell proliferation and neuronal survival, and induces neurite outgrowth (Bhattacharyya et al. 1992; Gonzalez-Martinez et al. 2003; Pawluski et al. 2009b; Winningham-Major et al. 1989). SSRI exposure during the fetal period has also been correlated with decreased levels of 5-HT and 5-hydroxyindoleacetic in cord blood, suggesting a suppression of the central serotoninergic activity (Laine et al. 2003). 
Further preclinical research has shown the perinatal SSRI exposure can have an impact on the developing brain (Maciag et al. 2006b; Rayen et al. 2013; Simpson et al. 2011). For example, perinatal exposure to the SSRI citalopram results in changes in raphe and callosal connections, sensory processing and myelin sheath formation in adult male and female rat offspring (Simpson et al. 2011). Reductions in tryptophan hydroxylase (TPH) expression are evident in the dorsal raphe and the medial raphe after perinatal citalopram exposure in adult male and female rat offspring (Maciag et al. 2006b; Simpson et al. 2011). Neonatal citalopram exposure in male rats also results in reductions in the serotonin transporter expression in the cortex during adulthood (Maciag et al. 2006b). Finally, developmental fluoxetine exposure has been shown to decrease the area of the sexually dimorphic nucleus of the preoptic area in adult male, but not female, offspring (Rayen et al. 2013; Rayen et al. Accepted, 2013).

SSRIs have also an impact on neural plasticity in the hippocampus (Ishiwata et al. 2005; Rayen et al. 2011). Previously, we have shown that developmental exposure to fluoxetine, a popular SSRI used during the perinatal period, reverses the decrease in hippocampal neurogenesis after prenatal maternal stress in both adolescent male and female rat offspring. But, when administered in the absence of maternal stress, the developmental fluoxetine exposure alone decreased hippocampal neurogenesis in adolescent male and female offspring (Rayen et al. 2011). Others have shown that postnatal fluoxetine exposure reverses the reduction in CA3 spine and synapse density, induced by prenatal stress, in juvenile and adolescent mice (Ishiwata et al. 2005). Finally, an upregulation of BDNF expression in the hippocampus occurs after postnatal fluoxetine administration in adult mouse offspring (Karpova et al. 2009).

The aim of the current study was to investigate the long-term effects of developmental fluoxetine exposure on hippocampal plasticity in the dentate gyrus of adult male and female offspring which have been exposed to maternal adversity. Our previous study shows a beneficial effect of developmental fluoxetine on neurogenesis in adolescent offspring after gestational stress (Rayen et al. 2011). However, it remains to be determined whether or not the same effects of developmental exposure to SSRIs on hippocampal neurogenesis persist into adulthood. Knowledge of the long-term implications of early SSRI exposure on neurodevelopmental outcomes is essential to improve treatment and intervention for mother and child. 


\section{Methods}

Animals. Twenty-one adult female Sprague-Dawley rats (250-300g; Charles River Laboratories, France) were used as dams in the present study. Rats were kept under standard laboratory conditions in a $12 \mathrm{~h}: 12 \mathrm{~h}$ light/dark schedule (lights on at 07:00 am), and were initially housed in pairs in clear polyutherane bins $(48 \mathrm{~cm} \times 27 \mathrm{~cm} \times 20 \mathrm{~cm})$ with ad libitum access to rat chow (Sniff) and tap water. All experiments were approved by the Animal Ethics Board of Maastricht University in accordance with Dutch governmental regulations (DEC 2010-150). All efforts were made to minimize the pain and stress levels experienced by the animals.

Dams were bred by putting 1 female and 1 male together in a wire mesh cage. The day of vaginal plug release was regarded as gestation day (GD) 1. Dams were randomly assigned to stress or control groups on GD15. Restraint of dams in the stress group took place three times daily in transparent plastic cylinders under bright light for 45 min (between 8$10 \mathrm{am}, 12-2 \mathrm{pm}, 4-6 \mathrm{pm}$ ) on GD15-20 and twice on GD21 as previously described (Pawluski et al. 2012a; Rayen et al. 2011; Van den Hove et al. 2005; Ward and Weisz 1984). This time period during pregnancy is when stress can result in postpartum depressive-like behavior in the dam (O'Mahony et al. 2006; Smith et al. 2004) and, thus was used as a model of maternal stress/depression, as previously described (Pawluski et al. 2012b; Rayen et al. 2013; Rayen et al. 2011). Litters were culled to 5 males and 5 females on postpartum day 1 (P1; birth day $=$ P0). Dams and litters were randomly assigned to one of two treatment groups: fluoxetine $(5 \mathrm{mg} / \mathrm{kg} /$ day $)$ or vehicle, for a total of four groups of dams and litters: 1) Control + Vehicle (CV) 2) Control + Fluoxetine (CF), 3) Prenatal Stress + Vehicle (PSV), and 4) Prenatal Stress + Fluoxetine (PSF). Weaning of litters occurred on P21, followed by housing of litters groups in clear polyutherane bins $(48 \mathrm{~cm} \times 27 \mathrm{~cm} \times 20 \mathrm{~cm})$.

Beginning on P31-35, litters were housed per sex (4 animals/cage) and on P45-49 they were housed in pairs in clear polyurethane bins $(48 \mathrm{~cm} \times 27 \mathrm{~cm} \times 20 \mathrm{~cm})$. Per litter, a maximum 2 male and 2 female offspring were used in the four groups; 1) CV, 2) CF, 3) PSV and 4) PSF (n=7-9/group).

Fluoxetine treatment to dams. Dams were chronically exposed to fluoxetine treatment for 4 weeks, via osmotic minipumps (Alzet Osmotic pumps, 2ML4, Charles River, The Netherlands), as previously described (Oliveira et al. 2010; Pawluski et al. 2012a; Rayen et al. 2013; Xu et al. 2009). Minipumps were implanted subcutaneously in the dorsal region on P1 while the dams were under mild isofluorane anesthesia. Implants took a maximum of 20 
minutes and offspring were separated from their mother for a maximum of 20 minutes. Minipumps were filled with either fluoxetine (Fagron, Belgium) dissolved in vehicle (50\% propylenediol in saline; $5 \mathrm{mg} / \mathrm{kg} /$ day), or with vehicle as previously described (Alahmed and Herbert 2008; Pawluski et al. 2012b; Rayen et al. 2013; Rayen et al. 2011)

Fluoxetine, and its active metabolite, norfluoxetine, are present in breast milk and can pass to offspring through suckling (Gentile et al. 2007). Therefore, minipumps were chosen as the method of fluoxetine delivery, as previously described (Gentile et al. 2007; Pawluski et al. 2012b; Rayen et al. 2013; Rayen et al. 2011; Xu et al. 2009). These implants also reduced the effect of stress associated with repeated injections or oral gavage. Previous work we have done in rats, using a similar paradigm of fluoxetine administration to the dam, has shown that fluoxetine and its active metabolite, norfluoxetine are present in the serum of rat pups (Knaepen et al. 2013). It should also be noted that fluoxetine exposure to the pups occurred at a time period in neural development similar to human neural development during the third trimester (Romijn et al. 1991).

BrdU injections. During adulthood (P69-76), male and female offspring received one i.p. injection of 5-bromo-2-deoxyuridine (BrdU; 200mg/kg; Sigma, St. Louis, MO) dissolved in 0.9\% saline as previously described (Barha et al. 2011; Pawluski et al. 2011a; Pawluski and Galea 2007). After BrdU injection, all animals were single housed with standard enrichment for the duration of the study ( 3 weeks). This was done in order to minimize any effects of social interactions and dominance on neural outcomes.

Immunohistochemistry. Three weeks after BrdU injection, adult offspring were deeply anesthetized (between 8.00 am and noon) with an overdose of pentobarbital, weighed and perfused transcardially with saline followed by $4 \%$ paraformaldehyde. Brains were post-fixed in $4 \%$ paraformaldehyde for 24 hours, cryoprotected in 30\% sucrose/phosphate-buffered saline solution for up to one week, frozen on dry ice and kept at $-80^{\circ} \mathrm{C}$. Brain tissue was sliced in $40 \mu \mathrm{m}$ sections on a cryostat (Leica). Tissue sections were stored in antifreeze solution and maintained at $-15^{\circ} \mathrm{C}$. The dentate gyrus of the hippocampus was assessed for the number of proliferating cells, by using the endogenous marker Ki67, and for the number of new surviving cells, by using the exogenous marker BrdU. Every $12^{\text {th }}$ section throughout the hippocampus was stained as previously described (Epp et al. 2009; Pawluski et al. 2009a; Pawluski et al. 2011a; Pawluski and Galea 2007).

Briefly, for Ki67 staining, sections were rinsed betweens steps in TBS. Tissue was first incubated in $0.6 \% \mathrm{H}_{2} \mathrm{O}_{2}$ for 30 minutes at room temperature, followed by application of rabbit anti-Ki67 (1:500; Vector Laboratories) monoclonal primary antibody at $4{ }^{\circ} \mathrm{C}$. The 
following day, sections were incubated with biotinylated donkey anti-rabbit (1:500; Jackson ImmunoResearch, Suffolk, UK) secondary antibody for 2 hours at room temperature. Brain sections were further processed by using the avidine-biotine complex (ABC Elite kit; 1:1000; Vector laboratories) and DAB (3,3-diaminobenzidine; Sigma). Sections were mounted on gelatin-coated slides, dried overnight, dehydrated and coverslipped with Depex (Fisher Scientific).

For BrdU staining, sections were rinsed betweens steps in Tris-buffered saline (TBS). Tissue was pretreated with $0.6 \% \mathrm{H}_{2} \mathrm{O}_{2}$ for 30 minutes at room temperature, followed by incubation in $2 \mathrm{~N}$ hydrochloric acid at $37^{\circ} \mathrm{C}$ for 30 minutes to denature the DNA. Sections were blocked with 3\% normal donkey serum (NDS) for 30 minutes and incubated in mouse anti-BrdU (1:200 in 3\% NDS in TBST, Roche) monoclonal primary antibody at $4{ }^{\circ} \mathrm{C}$ for 48 hours. Tissue was incubated with biotinylated donkey anti-mouse (1:100; Jackson ImmunoResearch) secondary antibody for 4 hours. Further processing occurred by using the avidine-biotine complex (ABC Elite kit; 1:1000; Vector laboratories) and $\mathrm{DAB}(3,3-$ diaminobenzidine; Sigma).

The number of Ki67 immunoreactive (-ir) cells and BrdU-ir cells were counted under 40x objective with water as previously described (Pawluski et al. 2011b). Cells were counted separately in the dorsal and ventral regions of the hippocampus with bregma $-4.2 \mathrm{~mm}$ for the division between dorsal and ventral. This was done as the dorsal region of the hippocampus is more related to cognitive functions and the ventral region towards emotion, stress and affect (Fanselow and Dong 2010). Cells were considered Ki67-ir and BrdU-ir if they were intensely stained and exhibited medium round or oval cell bodies. The areas of the GCL/SGZ and hilus were measured using StereoInvestigator software (MicroBrightField, Williston, VT, USA) and estimates of GCL/SGZ and hilus volumes were made using Cavalieri's principle (Gundersen et al. 1988). For representative photomicrographs see Figure 1. 


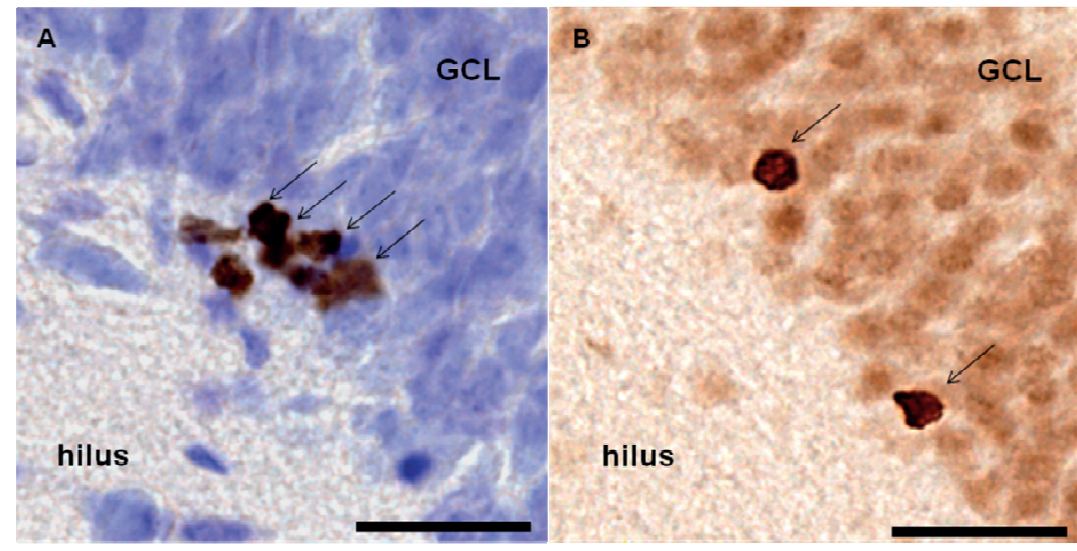

Figure 1. Representative photomicrographs of A) Ki67-ir and B) BrdU-ir cells, highlighted by the arrows, in the granule cell layer (GCL) of the hippocampus. Magnification bar is set at $25 \mu \mathrm{m}$.

Statistical analysis. Analysis of variance tests (ANOVA) were done on weight at sacrifice in offspring, with condition (prenatal stress/no stress), treatment (fluoxetine/vehicle), and sex (male/female) as independent factors. A repeated measures analysis of variance tests (ANOVA) were done on the volume, density of Ki67-ir, and density of BrdU-ir cells in the dorsal and ventral regions of the GCL/SGZ hilus, with condition (prenatal stress/no stress), treatment (fluoxetine/vehicle) as independent factors. Because of the well-known sex differences in the hippocampal plasticity (Galea et al. 2006) and the numerous sex differences previously observed after exposure to perinatal factors (Weinstock 2008), analyses by sex (male/female) were used where appropriate. Posthoc comparisons utilized the Fisher LSD test. Significance was set at $\mathrm{p} \leq 0.05$.

\section{Results}

Body weight at sacrifice. As expected, there was a significant main effect of sex on body weight at sacrifice $(F(1,56)=854.35, p=.00$, Figure 2$)$, with adult female offspring weighing significantly less than adult male offspring. There was also a significant main effect of stress on offspring body weight at sacrifice $(F(1,56)=6,1541, p=.02)$, with offspring exposed to prenatal stress having a significantly lower weight compared to offspring not exposed to prenatal stress. Further stratified analysis per sex revealed that female offspring exposed to prenatal stress have a significantly lower body weight compared to non-stressed female offspring (main effect: $F(1,27)=4.6803, p=.04$, Figure 2). In male offspring, there was a tendency for male offspring exposed to prenatal stress to have lower body weight compared to non stressed male offspring (main effect: $F(1,29)=3.1163$, $p=.09$, Figure 2). There were no 
other main or interaction effects on body weight at sacrifice in adult male and female offspring $(.381 \leq \mathrm{p} \leq .923)$.

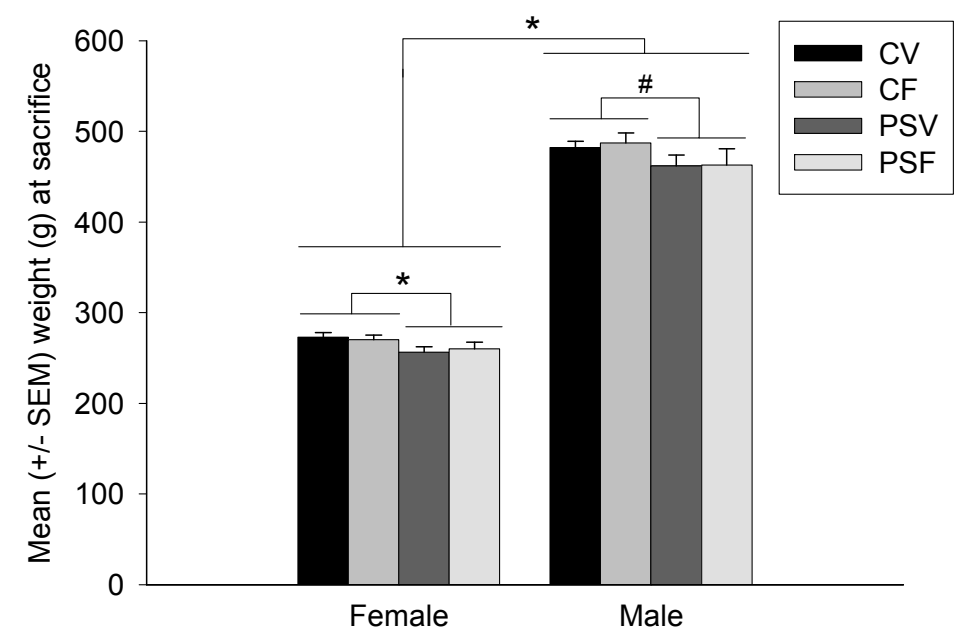

Figure 2. Mean ( \pm SEM) weight at sacrifice. Females had a significantly lower body weight compared to males $(p \leq .00)$. Prenatal stress significantly lowered body weight in adult female offspring $(p \leq .04)$ and tended to reduce body weight in adult male offspring $(p \leq .09)$. '*'denotes significantly different. ‘" denotes tendency CV $=$ Control + Vehicle, $C F=$ Control + Fluoxetine, $P S V=$ Prenatal Stress + Vehicle, and PSF $=$ Prenatal Stress + Fluoxetine. $(\mathrm{n}=7-9 / \mathrm{sex} /$ group $)$.

Volume GCL/SGZ. There were no significant differences between groups in volume of the dorsal and ventral regions of the GCL/SGZ and hilus, however there was a tendency toward an interaction of region (GCL/SGZ, hilus) x prenatal stress on volumes in male offspring $(\mathrm{p}=.08)$. Therefore, cell densities, and not total cell counts, were used throughout the analysis.

Ki67-ir cells. In adult male offspring, prenatally stressed male offspring had a significantly lower density of Ki67-ir cells in the dorsal $(\mathrm{p} \leq .01)$ and ventral $(\mathrm{p} \leq .03)$ GCL/SGZ compared to non-stressed male offspring (Region by stress interaction effect: $F(3,57)=3.4991, p=.02$; Figure 3A). There was also a tendency, in male offspring, toward an interaction effect between stress and fluoxetine on Ki67 cell density $(F(1,19)=3.1838, p=.09)$. In adult female offspring, PSF females had a significantly lower density of Ki67-ir compared to CF offspring overall $(\mathrm{p} \leq .04$ : significant stress by fluoxetine interaction effect $\mathrm{F}(1,18)=5.9083, \mathrm{p}=.03$; Figure 3B). 

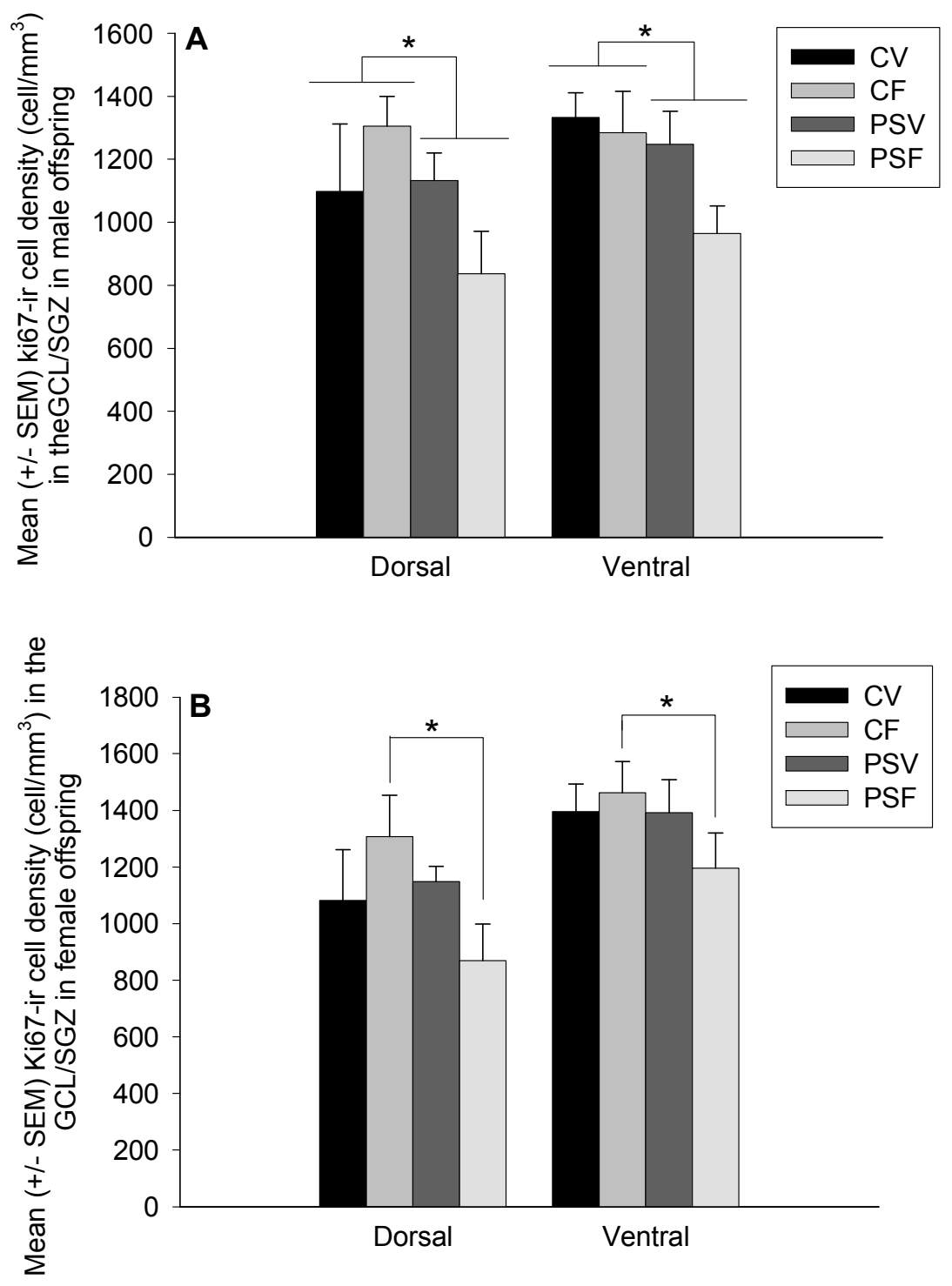

Figure 3. Mean ( \pm SEM) Ki67-ir cell density in the GCL/SGZ in A) male and B) female offspring. A) PSV and PSF male offspring had a significantly lower Ki67-ir cell density in the dorsal and ventral GCL/SGZ compared to CV and CF male offspring $(p \leq .02)$. B) PSF female offspring had a significantly lower density of Ki67-ir cells compared to CF female offspring overall $(p \leq .03)$. '**'denotes significantly different. $\mathbf{C V}=$ Control + Vehicle, $\mathbf{C F}=$ Control + Fluoxetine, $\mathbf{P S V}=$ Prenatal Stress + Vehicle, and PSF $=$ Prenatal Stress + Fluoxetine. $(\mathrm{n}=5-7 /$ sex $/$ group $)$.

As expected there was a significantly higher density of Ki67-ir cells in the GCL/SGZ compared to the hilus of both adult male and female offspring (main effect of region; Female: 
$\mathrm{F}(3,54)=202.71, \mathrm{p}=0.0000$; male: $\mathrm{F}(3,57)=202.73, \mathrm{p}=0.0000)$. There were no other significant main or interaction effects on the density of Ki67-ir cells in male or female offspring $(.121 \leq \mathrm{p} \leq .886$; Table 1$)$.

Table 1. Mean (+SEM) density (cell/ $\mathrm{mm}^{3}$ ) of proliferating cells (Ki67-ir) and new surviving cells (BrdUir) in the hilus of adult male and female offspring. PSF females had a significantly lower density of Ki67ir compared to $\mathbf{C F}$ offspring overall $(\mathbf{p} \leq .04)$. $\mathbf{C V}=\mathrm{Control}+$ Vehicle, $\mathbf{C F}=$ Control + Fluoxetine, $\mathrm{PSV}=$ Prenatal Stress + Vehicle, and PSF $=$ Prenatal Stress + Fluoxetine. $(\mathrm{n}=5-7 /$ sex/group).

\begin{tabular}{lcccc}
\hline & CV & CF & PSV & PSF \\
\hline Male & & & & \\
Dorsal Ki67-ir cell density & $84.27 \pm 29.00$ & $89.36 \pm 14.02$ & $161.00 \pm 37.41$ & $161.50 \pm 50.57$ \\
Ventral Ki67-ir cell density & $144.01 \pm 36,14$ & $217.52 \pm 29.86$ & $175.96 \pm 30.55$ & $153.83 \pm 31.04$ \\
Dorsal BrdU-ir cell density & $39.15 \pm 12.73$ & $68.68 \pm 16.72$ & $62.00 \pm 22.08$ & $67.56 \pm 9.41$ \\
Ventral BrdU-ir cell density & $51.15 \pm 15.72$ & $63.63 \pm 6.47$ & $39.98 \pm 9.55$ & $36.00 \pm 6.63$ \\
Female & & & & \\
Dorsal Ki67-ir cell density & $121.75 \pm 25.64$ & $147.30 \pm 26.23$ & $135.26 \pm 38.86$ & $113.92 \pm 26.31$ \\
Ventral Ki67-ir cell density & $134.12 \pm 14.72$ & $182.80 \pm 14.66$ & $190.95 \pm 41.24$ & $123.84 \pm 13.00$ \\
Dorsal BrdU-ir cell density & $70.82 \pm 36.13$ & $116.20 \pm 33.55$ & $56.12 \pm 20.86$ & $65.44 \pm 15.01$ \\
Ventral BrdU-ir cell density & $63.64 \pm 8.25$ & $82.03 \pm 31.55$ & $39.19 \pm 8.36$ & $40.49 \pm 12.53$ \\
\hline
\end{tabular}

BrdU-ir cells. In male offspring, there was a tendency toward an interaction effect on BrdUir cell density (Region by stress by fluoxetine interaction; $F(3,54)=2.5404, p=.07$ ). As expected there was a significantly higher density of BrdU-ir cells, 3 weeks after BrdU injection, in the GCL/SGZ compared to the hilus of both male and female offspring (main effect of region; Female: $\mathrm{F}(3,57)=57.387, \mathrm{p}=0.0000 ;$ male: $\mathrm{F}(3,54)=106.78$, $\mathrm{p}=0.0000$ ). There are no other significant main or interaction effects on the density of BrdU-ir cells in the dorsal and ventral GCL/SGZ or hilus in male offspring or female offspring (.176 $\leq \mathrm{p} \leq .926$; Table 2).

Table 2. Mean $\left( \pm\right.$ SEM) BrdU-ir cell density $\left(\mathrm{cell} / \mathrm{mm}^{3}\right)$ in the GCL/SGZ in adult male and female offspring. There were no significant differences between the groups in BrdU-ir cell density in male and female offspring. $\mathbf{C V}=$ Control + Vehicle, $\mathbf{C F}=$ Control + Fluoxetine, $\mathbf{P S V}=$ Prenatal Stress + Vehicle, and PSF $=$ Prenatal Stress + Fluoxetine. $(\mathrm{n}=4-7 /$ sex/group $)$.

\begin{tabular}{lcccc}
\hline & CV & CF & PSV & PSF \\
\hline Male & & & & \\
Dorsal BrdU-ir cell density & $230.11 \pm 79.95$ & $374.28 \pm 39.73$ & $331.87 \pm 54.27$ & $277.13 \pm 42.64$ \\
Ventral BrdU-ir cell density & $315.62 \pm 79.47$ & $332.08 \pm 32.25$ & $270.44 \pm 39.19$ & $250.61 \pm 40.84$ \\
Female & & & & \\
Dorsal BrdU-ir cell density & $325.01 \pm 28.59$ & $377.62 \pm 83.23$ & $327.09 \pm 66.42$ & $306.61 \pm 56.24$ \\
Ventral BrdU-ir cell density & $287.02 \pm 36.01$ & $399.96 \pm 74.64$ & $305.36 \pm 55.17$ & $241.86 \pm 38.44$ \\
\hline
\end{tabular}




\section{Discussion}

Findings of the present study show that developmental fluoxetine exposure differentially affects long-term neuroplasticity in male and female offspring, and these effects differ in the presence of prenatal maternal stress. More specifically, we show that developmental fluoxetine exposure to prenatally stressed female offspring reduces adult hippocampal cell proliferation and that prenatal stress, but not developmental fluoxetine exposure, reduces hippocampal cell proliferation in adult male offspring. Furthermore, prenatal stress reduced body weight in both adult male and female offspring. No effects of developmental fluoxetine exposure or prenatal maternal stress were found on new cell survival in the hippocampus of adult male and female offspring and effects did not differ between the dorsal and ventral regions of the hippocampus.

Prenatal maternal stress reduces body weight in adult male and female offspring. Here we show that adult body weight was reduced after prenatal stress, and not after developmental fluoxetine exposure, in adult male and female offspring. Numerous studies have also investigated the effects of SSRIs on infant weight gain during breastfeeding, but they failed to find an association (Chambers et al. 1999; Hendrick et al. 2003; Merlob et al. 2004). Previous preclinical work has shown no effect of postnatal fluoxetine exposure on body weight in adult mice offspring (Karpova et al. 2009; Soga et al. 2012). However, others have shown that perinatal exposure to fluoxetine reduces body weight in early adulthood in female mice (McAllister et al. 2012), suggesting that a longer exposure to SSRI during development may impact body weight. Interestingly, previous work we have done, in adolescent offspring, has shown that postnatal fluoxetine exposure decreases body weight in both male and female offspring (Rayen et al. 2011). Therefore, the effect of SSRIs on weight gain may be related to stage of development and timing of the exposure.

In line with our observation of a lower body weight in animals exposed to prenatal stress, previous work has shown reductions in body weight of adult offspring after prenatal restraint stress (Herrenkohl 1979; Rhees and Fleming 1981). However, others have also reported no alterations in adult body weight of offspring after prenatal stress exposure (Gerardin et al. 2005; Gong et al. 2012; Herrenkohl and Whitney 1976; Van den Hove et al. 2005). Discrepancies between studies are possibly due to the timing and intensity of the prenatal stressor as well as housing conditions during adulthood (Konkle et al. 2010; McDonald et al. 1963; Scalera 1992). 
Developmental fluoxetine exposure affects hippocampal cell proliferation in adult female, but not male, offspring. Here we show that in adult female offspring, developmental fluoxetine exposure, after prenatal maternal stress, decreases cell proliferation in the hippocampus compared to females exposed to fluoxetine alone. On the other side, no effects of developmental fluoxetine exposure were seen in adult male offspring. Our previous work in adolescent offspring has shown that developmental fluoxetine exposure reverses the effects of prenatal stress on hippocampal cell proliferation and the number of immature neurons in both adolescent male and female offspring (Rayen et al. 2011). The fact that we did not observe here a reversing effect of developmental fluoxetine exposure on cell proliferation indicates that other factors are playing a role in the effects observed.

Interestingly, when SSRIs are administered to adult female mice, a rise in hippocampal cell proliferation is observed (Hodes et al. 2010a; Hodes et al. 2010b). However, the effect of SSRI administration to the developing offspring differs consistently from adult exposure. Exposure to SSRIs during development results in an acute increase in serotoninergic tone (Oberlander et al. 2009) and preclinical studies have shown that perinatal SSRI exposed animals have a suppression of the serotoninergic tone during adulthood, possibly through increased auto-inhibitory feedback signalling (Kinney et al. 1997; Maciag et al. 2006b; Simpson et al. 2011; Weaver et al. 2010). The effects of developmental exposure to SSRIs on the serotonin circuitry during adulthood are evident in the dorsal and medial raphe via reductions in TPH expression (Maciag et al. 2006b; Simpson et al. 2011) and in the cortex and hippocampus via reductions in serotonin transporter expression (Maciag et al. 2006b; Weaver et al. 2010). These studies clearly indicate a suppression of the serotoninergic tone in adulthood, after increased serotoninergic toned during development. Possibly the switch from increased serotoninergic tone after developmental SSRI exposure to reduced serotoninergic tone in adulthood occurs during puberty, when steroid hormones come into play.

It is also possible that changing steroid hormone levels during puberty may lead to structural changes in the hippocampus, as a result of altered expression of estrogen and androgen receptors (Galea et al. 2006; Tabori et al. 2005; Weiland et al. 1997), and therefore differentially affect cell proliferation and new cell survival. The fact that developmental fluoxetine exposure affects hippocampal cell proliferation differently in male and in female adult offspring can also be the result of the role of serotonin in sexual differentiation of the brain, as it is implicated in the development of the hypothalamic-pituitary-gonadal axis (Dohler et al. 1991; Jarzab and Dohler 1984) and can potentially change estrogen and 
androgen receptor expression permanently. Much more work is needed to determine underlying mechanism responsible for the changes observed.

\section{Prenatal maternal stress decreases hippocampal cell proliferation in adult male, but not}

female, offspring. In the present study we show that prenatal stress decreases hippocampal cell proliferation in the dorsal and ventral region of the dentate gyrus of adult male offspring. The effects of prenatal restraint stress on hippocampal cell proliferation have been studied extensively in male offspring and have consistently shown a decrease in hippocampal cell proliferation after prenatal stress (Brummelte et al. 2006; Gong et al. 2012; Lemaire et al. 2000; Lucassen et al. 2009; Mandyam et al. 2008; Mirescu et al. 2004; Odagiri et al. 2008; Weinstock 2011). Reductions in hippocampal neurogenesis after prenatal stress have also been reported in male and female juvenile-adolescent rhesus macaques (Pryce et al. 2011) and adolescent male and female rat offspring (Rayen et al. 2011). In adult female offspring, the effects of prenatal stress on hippocampal cell proliferation have been less clear with reports of no effect of prenatal stress (Zuena et al. 2008) or reductions due to prenatal stress (Mandyam et al. 2008). One study reports that hippocampal cell proliferation was only reduced in female rat offspring when senescence was reached (Koehl et al. 2009). The mechanism behind sex differences as result of prenatal stress on hippocampal cell proliferation in this study and others are not fully understood (Koehl et al. 2009; Zuena et al. 2008). It is important to note that the proliferation rate is increased during proestrus in adult female rats due to increased estradiol levels (Falconer and Galea 2003; Tanapat et al. 1999). Also, estrogen and androgen receptors are highly expressed throughout the hippocampus, and activation of these receptors may differentially regulate hippocampal neurogenesis in the male and female rats (Galea et al. 2006; Galea et al. 2008; Pawluski et al. 2009a; Tabori et al. 2005; Weiland et al. 1997).

\section{Hippocampal new cell survival is not affected by developmental fluoxetine exposure or} prenatal stress. In the present study we found no significant differences between groups in number of surviving new cells, 3 weeks after the BrdU injection, in the hippocampus of adult male and female offspring. Reductions in new cell survival in the hippocampus after prenatal stress have been reported (Lemaire et al. 2006; Odagiri et al. 2008; Zuena et al. 2008). For example, adult male rats, but not adult female rats, exposed to prenatal restraint stress show reductions in hippocampal new cell survival, 2 weeks after the last BrdU injection (Zuena et al. 2008). Prenatal restraint stress alone reduces the survival of new cells (3 weeks after the 
last BrdU injection), the number of immature neurons and the number of differentiated new neurons in 4 month old and 26 month old male rats (Lemaire et al. 2006). Also, exposure to psychological prenatal stress decreased survival of newborn cells (1 week and 11 weeks after the BrdU injection) in the dorsal hippocampus of adolescent and adult male and female rats (Odagiri et al. 2008). Furthermore, it has been shown that the survival of new hippocampal neurons (4.5 weeks after BrdU injection) in adolescent male offspring is reduced after prenatal restraint stress and maternal defeat stress exposure in dams with high anxiety-related behavior (Lucassen et al. 2009). Previous work we have done also shows a decrease in the number of immature neurons in the hippocampus of adolescent male and female offspring exposed to prenatal restraint stress (Rayen et al. 2011). Therefore, the timing and intensity of the stressor, the age of the surviving new cells, as well as the sex and age of the animal are all important factors when investigating prenatal stress effects of hippocampal neurogenesis.

\section{Conclusions}

As the use of SSRIs during the perinatal period is increasing, it is very important to address how these medications affect offspring development. Our study shows that developmental fluoxetine exposure differentially affects hippocampal plasticity in adult male and female offspring. More specifically, developmental fluoxetine exposure reduces hippocampal cell proliferation, in prenatally stressed adult female offspring, and prenatal stress, but not developmental fluoxetine exposure, reduces hippocampal cell proliferation in adult male offspring. Much more work is needed to determine which mechanisms are responsible for these effects on hippocampal cell proliferation. In addition, further work needs to address how other processes, such as neuronal maturation and cell death, are affected in order to determine how these changes in hippocampal plasticity may affect the development of mood disorders in offspring (Dranovsky and Hen 2006; Mateus-Pinheiro et al. 2013; Santarelli et al. 2003). 


\section{References}

Alahmed S, Herbert J (2008) Strain differences in proliferation of progenitor cells in the dentate gyrus of the adult rat and the response to fluoxetine are dependent on corticosterone. Neuroscience 157: 677-82

Altshuler LL, Bartzokis G, Grieder T, Curran J, Jimenez T, Leight K, Wilkins J, Gerner R, Mintz J (2000) An MRI study of temporal lobe structures in men with bipolar disorder or schizophrenia. Biol Psychiatry 48: $147-62$

Barha CK, Brummelte S, Lieblich SE, Galea LA (2011) Chronic restraint stress in adolescence differentially influences hypothalamic-pituitary-adrenal axis function and adult hippocampal neurogenesis in male and female rats. Hippocampus 21: 1216-27

Berle JO, Spigset O (2011) Antidepressant Use During Breastfeeding. Curr Womens Health Rev 7: 28-34

Berle JO, Steen VM, Aamo TO, Breilid H, Zahlsen K, Spigset O (2004) Breastfeeding during maternal antidepressant treatment with serotonin reuptake inhibitors: infant exposure, clinical symptoms, and cytochrome p450 genotypes. J Clin Psychiatry 65: 1228-34

Beversdorf DQ, Manning SE, Hillier A, Anderson SL, Nordgren RE, Walters SE, Nagaraja HN, Cooley WC, Gaelic SE, Bauman ML (2005) Timing of prenatal stressors and autism. J Autism Dev Disord 35: 4718

Bhattacharyya A, Oppenheim RW, Prevette D, Moore BW, Brackenbury R, Ratner N (1992) S100 is present in developing chicken neurons and Schwann cells and promotes motor neuron survival in vivo. $\mathrm{J}$ Neurobiol 23: 451-66

Bremner JD, Narayan M, Anderson ER, Staib LH, Miller HL, Charney DS (2000) Hippocampal volume reduction in major depression. Am J Psychiatry 157: 115-8

Bremner JD, Randall P, Scott TM, Bronen RA, Seibyl JP, Southwick SM, Delaney RC, McCarthy G, Charney DS, Innis RB (1995) MRI-based measurement of hippocampal volume in patients with combat-related posttraumatic stress disorder. Am J Psychiatry 152: 973-81

Bremner JD, Randall P, Vermetten E, Staib L, Bronen RA, Mazure C, Capelli S, McCarthy G, Innis RB, Charney DS (1997) Magnetic resonance imaging-based measurement of hippocampal volume in posttraumatic stress disorder related to childhood physical and sexual abuse--a preliminary report. Biol Psychiatry 41: 23-32

Brummelte S, Pawluski JL, Galea LA (2006) High post-partum levels of corticosterone given to dams influence postnatal hippocampal cell proliferation and behavior of offspring: A model of post-partum stress and possible depression. Horm Behav 50: 370-82

Chambers CD, Anderson PO, Thomas RG, Dick LM, Felix RJ, Johnson KA, Jones KL (1999) Weight gain in infants breastfed by mothers who take fluoxetine. Pediatrics 104: e61

Coe CL, Kramer M, Czeh B, Gould E, Reeves AJ, Kirschbaum C, Fuchs E (2003) Prenatal stress diminishes neurogenesis in the dentate gyrus of juvenile rhesus monkeys. Biol Psychiatry 54: 1025-34

Dohler KD, Jarzab B, Sickmoller PM, Kokocinska D, Kaminski M, Gubala E, Achtelik W, Wagiel J (1991) Influence of neurotransmitters on sexual differentiation of brain structure and function. Exp Clin Endocrinol 98: 99-109

Dranovsky A, Hen R (2006) Hippocampal neurogenesis: regulation by stress and antidepressants. Biol Psychiatry 59: 1136-43

Epp JR, Barker JM, Galea LA (2009) Running wild: neurogenesis in the hippocampus across the lifespan in wild and laboratory-bred Norway rats. Hippocampus 19: 1040-9

Falconer EM, Galea LA (2003) Sex differences in cell proliferation, cell death and defensive behavior following acute predator odor stress in adult rats. Brain Res 975: 22-36

Fanselow MS, Dong HW (2010) Are the dorsal and ventral hippocampus functionally distinct structures? Neuron 65: 7-19

Fleschler R, Peskin MF (2008) Selective serotonin reuptake inhibitors (SSRIs) in pregnancy: a review. MCN Am J Matern Child Nurs 33: 355-61; quiz 362-3

Galea LA, Spritzer MD, Barker JM, Pawluski JL (2006) Gonadal hormone modulation of hippocampal neurogenesis in the adult. Hippocampus 16: 225-32

Galea LA, Uban KA, Epp JR, Brummelte S, Barha CK, Wilson WL, Lieblich SE, Pawluski JL (2008) Endocrine regulation of cognition and neuroplasticity: our pursuit to unveil the complex interaction between hormones, the brain, and behaviour. Can J Exp Psychol 62: 247-60

Gentile S, Rossi A, Bellantuono C (2007) SSRIs during breastfeeding: spotlight on milk-to-plasma ratio. Arch Womens Ment Health 10: 39-51

Gerardin DC, Pereira OC, Kempinas WG, Florio JC, Moreira EG, Bernardi MM (2005) Sexual behavior, neuroendocrine, and neurochemical aspects in male rats exposed prenatally to stress. Physiol Behav 84: 97-104

Glover V, O'Connor TG, O'Donnell K (2010) Prenatal stress and the programming of the HPA axis. Neurosci Biobehav Rev 35: 17-22 
Gong Y, Sun XL, Wu FF, Su CJ, Ding JH, Hu G (2012) Female early adult depression results in detrimental impacts on the behavioral performance and brain development in offspring. CNS Neurosci Ther 18: 461-70

Gonzalez-Martinez T, Perez-Pinera P, Diaz-Esnal B, Vega JA (2003) S-100 proteins in the human peripheral nervous system. Microsc Res Tech 60: 633-8

Gundersen HJ, Bagger P, Bendtsen TF, Evans SM, Korbo L, Marcussen N, Moller A, Nielsen K, Nyengaard JR, Pakkenberg B, et al. (1988) The new stereological tools: disector, fractionator, nucleator and point sampled intercepts and their use in pathological research and diagnosis. APMIS 96: 857-81

Gur RE, Turetsky BI, Cowell PE, Finkelman C, Maany V, Grossman RI, Arnold SE, Bilker WB, Gur RC (2000) Temporolimbic volume reductions in schizophrenia. Arch Gen Psychiatry 57: 769-75

Hendrick V, Smith LM, Hwang S, Altshuler LL, Haynes D (2003) Weight gain in breastfed infants of mothers taking antidepressant medications. J Clin Psychiatry 64: 410-2

Herrenkohl LR (1979) Prenatal stress reduces fertility and fecundity in female offspring. Science 206: 1097-9

Herrenkohl LR, Whitney JB (1976) Effects of prepartal stress on postpartal nursing behavior, litter development and adult sexual behavior. Physiol Behav 17: 1019-21

Hodes GE, Hill-Smith TE, Lucki I (2010a) Fluoxetine treatment induces dose dependent alterations in depression associated behavior and neural plasticity in female mice. Neurosci Lett 484: 12-6

Hodes GE, Hill-Smith TE, Suckow RF, Cooper TB, Lucki I (2010b) Sex-specific effects of chronic fluoxetine treatment on neuroplasticity and pharmacokinetics in mice. J Pharmacol Exp Ther 332: 266-73

Huizink AC, Robles de Medina PG, Mulder EJ, Visser GH, Buitelaar JK (2003) Stress during pregnancy is associated with developmental outcome in infancy. J Child Psychol Psychiatry 44: 810-8

Ishiwata H, Shiga T, Okado N (2005) Selective serotonin reuptake inhibitor treatment of early postnatal mice reverses their prenatal stress-induced brain dysfunction. Neuroscience 133: 893-901

Jarzab B, Dohler KD (1984) Serotoninergic influences on sexual differentiation of the rat brain. Prog Brain Res 61: 119-26

Karpova NN, Lindholm J, Pruunsild P, Timmusk T, Castren E (2009) Long-lasting behavioural and molecular alterations induced by early postnatal fluoxetine exposure are restored by chronic fluoxetine treatment in adult mice. Eur Neuropsychopharmacol 19: 97-108

Kawamura T, Chen J, Takahashi T, Ichitani Y, Nakahara D (2006) Prenatal stress suppresses cell proliferation in the early developing brain. Neuroreport 17: 1515-8

Kim J, Riggs KW, Misri S, Kent N, Oberlander TF, Grunau RE, Fitzgerald C, Rurak DW (2006) Stereoselective disposition of fluoxetine and norfluoxetine during pregnancy and breast-feeding. Br J Clin Pharmacol 61: 155-63

Kinney GG, Vogel GW, Feng P (1997) Decreased dorsal raphe nucleus neuronal activity in adult chloral hydrate anesthetized rats following neonatal clomipramine treatment: implications for endogenous depression. Brain Res 756: 68-75

Knaepen L, Rayen I, Charlier TD, Fillet M, Houbart V, van Kleef M, Steinbusch HW, Patijn J, Tibboel D, Joosten EA, Pawluski JL (2013) Developmental fluoxetine exposure normalizes the long-term effects of maternal stress on post-operative pain in Sprague-Dawley rat offspring. PLoS One 8: e57608

Koehl M, Lemaire V, Le Moal M, Abrous DN (2009) Age-dependent effect of prenatal stress on hippocampal cell proliferation in female rats. Eur J Neurosci 29: 635-40

Konkle AT, Kentner AC, Baker SL, Stewart A, Bielajew C (2010) Environmental-enrichment-related variations in behavioral, biochemical, and physiologic responses of Sprague-Dawley and Long Evans rats. J Am Assoc Lab Anim Sci 49: 427-36

Kristensen JH, Ilett KF, Hackett LP, Yapp P, Paech M, Begg EJ (1999) Distribution and excretion of fluoxetine and norfluoxetine in human milk. Br J Clin Pharmacol 48: 521-7

Laine K, Heikkinen T, Ekblad U, Kero P (2003) Effects of exposure to selective serotonin reuptake inhibitors during pregnancy on serotonergic symptoms in newborns and cord blood monoamine and prolactin concentrations. Arch Gen Psychiatry 60: 720-6

Laplante DP, Barr RG, Brunet A, Galbaud du Fort G, Meaney ML, Saucier JF, Zelazo PR, King S (2004) Stress during pregnancy affects general intellectual and language functioning in human toddlers. Pediatr Res 56: $400-10$

Lemaire V, Koehl M, Le Moal M, Abrous DN (2000) Prenatal stress produces learning deficits associated with an inhibition of neurogenesis in the hippocampus. Proc Natl Acad Sci U S A 97: 11032-7

Lemaire V, Lamarque S, Le Moal M, Piazza PV, Abrous DN (2006) Postnatal stimulation of the pups counteracts prenatal stress-induced deficits in hippocampal neurogenesis. Biol Psychiatry 59: 786-92

Lucassen PJ, Bosch OJ, Jousma E, Kromer SA, Andrew R, Seckl JR, Neumann ID (2009) Prenatal stress reduces postnatal neurogenesis in rats selectively bred for high, but not low, anxiety: possible key role of placental 11beta-hydroxysteroid dehydrogenase type 2. Eur J Neurosci 29: 97-103 
Maccari S, Darnaudery M, Morley-Fletcher S, Zuena AR, Cinque C, Van Reeth O (2003) Prenatal stress and long-term consequences: implications of glucocorticoid hormones. Neurosci Biobehav Rev 27: 119-27

Maccari S, Morley-Fletcher S (2007) Effects of prenatal restraint stress on the hypothalamus-pituitary-adrenal axis and related behavioural and neurobiological alterations. Psychoneuroendocrinology 32 Suppl 1: S10-5

Maciag D, Simpson KL, Coppinger D, Lu Y, Wang Y, Lin RC, Paul IA (2006) Neonatal antidepressant exposure has lasting effects on behavior and serotonin circuitry. Neuropsychopharmacology 31:47-57

Mandyam CD, Crawford EF, Eisch AJ, Rivier CL, Richardson HN (2008) Stress experienced in utero reduces sexual dichotomies in neurogenesis, microenvironment, and cell death in the adult rat hippocampus. Dev Neurobiol 68: 575-89

Mateus-Pinheiro A, Pinto L, Bessa JM, Morais M, Alves ND, Monteiro S, Patricio P, Almeida OF, Sousa N (2013) Sustained remission from depressive-like behavior depends on hippocampal neurogenesis. Transl Psychiatry 3: e210

McAllister BB, Kiryanova V, Dyck RH (2012) Behavioural outcomes of perinatal maternal fluoxetine treatment. Neuroscience 226: 356-66

McDonald DG, Stern JA, Hahn WW (1963) Effects of Differential Housing and Stress on Diet Selection, Water Intake, and Body Weight in the Rat. J Appl Physiol 18: 937-42

Merlob P, Stahl B, Sulkes J (2004) Paroxetine during breast-feeding: infant weight gain and maternal adherence to counsel. Eur J Pediatr 163: 135-9

Mirescu C, Peters JD, Gould E (2004) Early life experience alters response of adult neurogenesis to stress. Nat Neurosci 7: 841-6

Niederhofer H, Reiter A (2004) Prenatal maternal stress, prenatal fetal movements and perinatal temperament factors influence behavior and school marks at the age of 6 years. Fetal Diagn Ther 19: 160-2

O'Mahony SM, Myint AM, van den Hove D, Desbonnet L, Steinbusch H, Leonard BE (2006) Gestational stress leads to depressive-like behavioural and immunological changes in the rat. Neuroimmunomodulation 13: $82-8$

Oberlander TF, Gingrich JA, Ansorge MS (2009) Sustained neurobehavioral effects of exposure to SSRI antidepressants during development: molecular to clinical evidence. Clin Pharmacol Ther 86: 672-7

Odagiri K, Abe H, Kawagoe C, Takeda R, Ikeda T, Matsuo H, Nonaka H, Ebihara K, Nishimori T, Ishizuka Y, Hashiguchi H, Ishida Y (2008) Psychological prenatal stress reduced the number of BrdU immunopositive cells in the dorsal hippocampus without affecting the open field behavior of male and female rats at one month of age. Neurosci Lett 446: 25-9

Oliveira E, Pinheiro CR, Santos-Silva AP, Trevenzoli IH, Abreu-Villaca Y, Nogueira Neto JF, Reis AM, Passos MC, Moura EG, Lisboa PC (2010) Nicotine exposure affects mother's and pup's nutritional, biochemical, and hormonal profiles during lactation in rats. J Endocrinol 205: 159-70

Pawluski JL, Brummelte S, Barha CK, Crozier TM, Galea LA (2009a) Effects of steroid hormones on neurogenesis in the hippocampus of the adult female rodent during the estrous cycle, pregnancy, lactation and aging. Front Neuroendocrinol 30: 343-57

Pawluski JL, Charlier TD, Fillet M, Houbart V, Crispin HT, Steinbusch HW, van den Hove DL (2011a) Chronic fluoxetine treatment and maternal adversity differentially alter neurobehavioral outcomes in the rat dam. Behav Brain Res 228: 159-68

Pawluski JL, Charlier TD, Fillet M, Houbart V, Crispin HT, Steinbusch HW, van den Hove DL (2012a) Chronic fluoxetine treatment and maternal adversity differentially alter neurobehavioral outcomes in the rat dam. Behav Brain Res 228: 159-68

Pawluski JL, Galea LA (2007) Reproductive experience alters hippocampal neurogenesis during the postpartum period in the dam. Neuroscience 149: 53-67

Pawluski JL, Galea LA, Brain U, Papsdorf M, Oberlander TF (2009b) Neonatal S100B protein levels after prenatal exposure to selective serotonin reuptake inhibitors. Pediatrics 124: e662-70

Pawluski JL, Rayen I, Niessen NA, Kristensen S, van Donkelaar EL, Balthazart J, Steinbusch HW, Charlier TD (2012b) Developmental fluoxetine exposure differentially alters central and peripheral measures of the HPA system in adolescent male and female offspring. Neuroscience

Pawluski JL, van den Hove DL, Rayen I, Prickaerts J, Steinbusch HW (2011b) Stress and the pregnant female: Impact on hippocampal cell proliferation, but not affective-like behaviors. Horm Behav 59: 572-80

Pryce CR, Aubert Y, Maier C, Pearce PC, Fuchs E (2011) The developmental impact of prenatal stress, prenatal dexamethasone and postnatal social stress on physiology, behaviour and neuroanatomy of primate offspring: studies in rhesus macaque and common marmoset. Psychopharmacology (Berl) 214: 33-53

Rayen I, Steinbusch HW, Charlier TD, Pawluski JL (2013) Developmental fluoxetine exposure and prenatal stress alter sexual differentiation of the brain and reproductive behavior in male rat offspring. Psychoneuroendocrinology 
Rayen I, Steinbusch HW, Pawluski JL (Accepted, 2013) Developmental fluoxetine exposure facilitates sexual behavior in female offspring. Psychopharmacology (Berl)

Rayen I, van den Hove DL, Prickaerts J, Steinbusch HW, Pawluski JL (2011) Fluoxetine during development reverses the effects of prenatal stress on depressive-like behavior and hippocampal neurogenesis in adolescence. PLoS One 6: e24003

Rhees RW, Fleming DE (1981) Effects of malnutrition, maternal stress, or ACTH injections during pregnancy on sexual behavior of male offspring. Physiol Behav 27: 879-82

Romijn HJ, Hofman MA, Gramsbergen A (1991) At what age is the developing cerebral cortex of the rat comparable to that of the full-term newborn human baby? Early Hum Dev 26: 61-7

Santarelli L, Saxe M, Gross C, Surget A, Battaglia F, Dulawa S, Weisstaub N, Lee J, Duman R, Arancio O, Belzung C, Hen R (2003) Requirement of hippocampal neurogenesis for the behavioral effects of antidepressants. Science 301: 805-9

Scalera G (1992) Taste preferences, body weight gain, food and fluid intake in singly or group-housed rats. Physiol Behav 52: 935-43

Simpson KL, Weaver KJ, de Villers-Sidani E, Lu JY, Cai Z, Pang Y, Rodriguez-Porcel F, Paul IA, Merzenich M, Lin RC (2011) Perinatal antidepressant exposure alters cortical network function in rodents. Proc Natl Acad Sci U S A 108: 18465-70

Smith JW, Seckl JR, Evans AT, Costall B, Smythe JW (2004) Gestational stress induces post-partum depression-like behaviour and alters maternal care in rats. Psychoneuroendocrinology 29: 227-44

Soga T, Wong DW, Putteeraj M, Song KP, Parhar IS (2012) Early-life citalopram-induced impairments in sexual behavior and the role of androgen receptor. Neuroscience 225: 172-84

Tabori NE, Stewart LS, Znamensky V, Romeo RD, Alves SE, McEwen BS, Milner TA (2005) Ultrastructural evidence that androgen receptors are located at extranuclear sites in the rat hippocampal formation. Neuroscience 130: 151-63

Talge NM, Neal C, Glover V (2007) Antenatal maternal stress and long-term effects on child neurodevelopment: how and why? J Child Psychol Psychiatry 48: 245-61

Tanapat P, Hastings NB, Reeves AJ, Gould E (1999) Estrogen stimulates a transient increase in the number of new neurons in the dentate gyrus of the adult female rat. J Neurosci 19: 5792-801

Van den Bergh BR, Mennes M, Oosterlaan J, Stevens V, Stiers P, Marcoen A, Lagae L (2005) High antenatal maternal anxiety is related to impulsivity during performance on cognitive tasks in 14- and 15-yearolds. Neurosci Biobehav Rev 29: 259-69

Van den Hove DL, Blanco CE, Aendekerk B, Desbonnet L, Bruschettini M, Steinbusch HP, Prickaerts J, Steinbusch HW (2005) Prenatal restraint stress and long-term affective consequences. Dev Neurosci 27: $313-20$

van Os J, Selten JP (1998) Prenatal exposure to maternal stress and subsequent schizophrenia. The May 1940 invasion of The Netherlands. Br J Psychiatry 172: 324-6

Ward IL, Weisz J (1984) Differential effects of maternal stress on circulating levels of corticosterone, progesterone, and testosterone in male and female rat fetuses and their mothers. Endocrinology 114: $1635-44$

Weaver KJ, Paul IA, Lin RC, Simpson KL (2010) Neonatal exposure to citalopram selectively alters the expression of the serotonin transporter in the hippocampus: dose-dependent effects. Anat Rec (Hoboken) 293: 1920-32

Weiland NG, Orikasa C, Hayashi S, McEwen BS (1997) Distribution and hormone regulation of estrogen receptor immunoreactive cells in the hippocampus of male and female rats. J Comp Neurol 388: 60312

Weinstock M (2001) Alterations induced by gestational stress in brain morphology and behaviour of the offspring. Prog Neurobiol 65: 427-51

Weinstock M (2008) The long-term behavioural consequences of prenatal stress. Neurosci Biobehav Rev 32: 1073-86

Weinstock M (2011) Sex-dependent changes induced by prenatal stress in cortical and hippocampal morphology and behaviour in rats: an update. Stress 14: 604-13

Winningham-Major F, Staecker JL, Barger SW, Coats S, Van Eldik LJ (1989) Neurite extension and neuronal survival activities of recombinant $\mathrm{S} 100$ beta proteins that differ in the content and position of cysteine residues. J Cell Biol 109: 3063-71

Xu J, Kirigiti MA, Grove KL, Smith MS (2009) Regulation of food intake and gonadotropin-releasing hormone/luteinizing hormone during lactation: role of insulin and leptin. Endocrinology 150: 4231-40

Zagron G, Weinstock M (2006) Maternal adrenal hormone secretion mediates behavioural alterations induced by prenatal stress in male and female rats. Behav Brain Res 175: 323-8 


\section{Chapter 4}

Zuena AR, Mairesse J, Casolini P, Cinque C, Alema GS, Morley-Fletcher S, Chiodi V, Spagnoli LG, Gradini R, Catalani A, Nicoletti F, Maccari S (2008) Prenatal restraint stress generates two distinct behavioral and neurochemical profiles in male and female rats. PLoS One 3: e2170 


\section{Chapter 5}

\section{Developmental fluoxetine exposure and prenatal stress alter sexual differentiation of the brain and reproductive behavior in male rat offspring}

Authors: Ine Rayen, Harry W.M. Steinbusch, Thierry D. Charlier, Jodi L. Pawluski

Psychoneuroendocrinology 2013, pii: S0306-4530(13)00012-7. doi: 10.1016/j.psyneuen.2013.01.007. [epub ahead of print] 
Chapter 5

\begin{abstract}
Depression during pregnancy and postpartum is a significant health problem and affects up to $20 \%$ of women. While selective serotonin reuptake inhibitor (SSRI) medications are the drug of choice for treatment of maternal depression, the combined effect of maternal depression and perinatal SSRI exposure on offspring development is poorly investigated. Our aim was to determine the role of exposure to fluoxetine during development on sexual behavior and sexually dimorphic brain structures in male offspring using a rodent model of maternal adversity. Sprague-Dawley rat dams were stressed during gestation and were chronically treated throughout lactation with either fluoxetine or vehicle beginning on postnatal day 1 . Four groups of offspring were used: 1) Control + Vehicle, 2) Control + Fluoxetine, 3) Prenatal Stress + Vehicle, and 4) Prenatal Stress + Fluoxetine. We show here that developmental fluoxetine treatment decreases the anogenital distance in juvenile male offspring. In adult male offspring, maternal fluoxetine treatment, regardless of exposure to prenatal stress, results in a decrease in the number of intromissions, a longer latency to the first intromission, and a longer latency to the first ejaculation. Furthermore, developmental fluoxetine and/or prenatal stress decrease the volume of the sexually dimorphic nucleus of the preoptic area (SDN-POA). Prenatal stress, but not exposure to developmental fluoxetine, decreases the number of tyrosine hydroxylase (TH)-positive cells in anteroventral periventricular nucleus (AVPv) and the volume of the posterior bed nucleus of the stria terminalis (pBST) in male offspring. These results provide important evidence for the longterm impact of maternal adversity and maternal fluoxetine use on the development of primary endocrinology systems in juvenile and adult male offspring.
\end{abstract}

Keywords: SSRI; depression; hypothalamus; sexual differentiation; development; antidepressant medication; prenatal stress; reproduction; maternal depression 


\section{Introduction}

The early organization of the central nervous system in vertebrates is strongly influenced by the environment. Parental influence during the pre- and post-natal period is by far one of the main environmental inputs affecting the development of brain and behavior (Talge et al. 2007; Weinstock 2001). As such, any factor affecting the physiology and the behavior of the mother is likely to modulate the developmental output of the offspring. For example, maternal stress, depression and anxiety, can have long-term influences on the physical and mental development of children and can significantly impair cognitive and emotional outcomes, such as general intellectual and language functioning, impulsivity during cognitive tasks, and anxiety (Talge et al. 2007). Similarly in rodent models, maternal stress during gestation can significantly affect offspring outcomes related to cognition and affect-related behaviors (Weinstock 2001). In addition, gestational stress disrupts the development of the neuroendocrine and reproductive systems in offspring (Maccari et al. 1995).

An estimated $20 \%$ of women are affected by depression during pregnancy and the postpartum period (Leung and Kaplan 2009). Current treatments of maternal depression mainly target the serotoninergic system with selective serotonin reuptake inhibitors (SSRI) being the most frequently prescribed medications for maternal depression both during pregnancy and postpartum (Fleschler and Peskin 2008). Recent estimates suggest that SSRI use during gestation ranges between 5-10\% (Cooper et al. 2007; Oberlander et al. 2006). SSRIs cross the placental barrier and are present in breast milk and, therefore, can affect fetal and neonatal development (Kristensen et al. 1999). Serotonin itself is implicated in several developmental processes, including cell division, neural migration, cell differentiation and synaptogenesis (Azmitia 2001). Thus, altering the availability of serotonin to the neonate, via SSRI exposure, may affect crucial developmental mechanisms. Present clinical and preclinical research has began to show that prenatal SSRI exposure alters serotonin levels (Laine et al. 2003; Weaver et al. 2010) and the hypothalamic-pituitary-adrenal axis (Oberlander et al. 2009; Pawluski et al. 2012a; Pawluski et al. 2012b; Rayen et al. 2011). However, it remains unclear how developmental SSRI exposure, and the consequential changes in serotonin, affect key physiological systems related to reproduction in the offspring, such as the hypothalamic-pituitary-gonadal (HPG) system.

Serotonin plays a key role in the development and function of the HPG axis (Dohler et al. 1991; Jarzab and Dohler 1984; Ladosky and Gaziri 1970). In addition, serotonin is a major 
neurotransmitter implicated in the control of sexual behavior during adulthood and fibers originating from the serotoninergic-synthesizing cells in the dorsal raphe strongly innervate sexually dimorphic structures, like the medial preoptic area (MPOA), the bed nucleus of the stria terminalis (BST), and the anteroventral periventricular nucleus (AVPv) (Simerly et al. 1985a; Wilson et al. 1986). This sexual dimorphism is established in the early postnatal period by the action of gonadal steroids and is modulated in part by serotonin Although little work has been done on the effects of developmental exposure to SSRIs on sexual differentiation of the brain and sexual behavior, recent preclinical research has shown that developmental exposure to SSRIs may have a long-term impact on sexual behavior in male offspring. For example, male offspring postnatally exposed to the SSRI citalopram show decreased sexual behavior (Harris et al. 2012; Maciag et al. 2006a; Maciag et al. 2006b; Maciag et al. 2006c). However, others did not show significant differences in sexual behavior after prenatal exposure to fluoxetine (Olivier et al. 2011b). Although this work points to a potential impact of SSRIs on the development of the HPG axis, it should be noted that these effects were investigated using healthy mothers and offspring, and did not accurately model the clinical situation (Maciag et al. 2006a; Maciag et al. 2006c). It remains to be determined how developmental exposure to SSRIs may alter the HPG system, both brain and behavior, when using a model of maternal adversity.

The aim of the present study was to investigate the effect of developmental exposure to the commonly used SSRI, fluoxetine (Prozac ${ }^{\circledR}$ ), on the HPG system, using a model of maternal adversity. We focused our attention on the long-term effect of fluoxetine, via maternal exposure, on sexual behavior and the sexually differentiated brain regions, including the AVPv, the BST, and the sexually dimorphic nucleus of the preoptic area SDN-POA in adult male offspring. Insights in the effects of maternal SSRI exposure on the developing HPG system is essential in understanding how these medications affect underlying physiological mechanisms of sexual differentiation.

\section{Methods}

Animals. Forty-five adult female Sprague-Dawley rats (250-300g; Charles River Laboratories, France) were used as dams in the present study. Twenty-four adult females were used for Experiment 1 (Exp 1) and twenty-one adult females were used for Experiment 2 (Exp 2). Rats were kept under standard laboratory conditions in a 1200h:1200h light/dark schedule (lights on at $0700 \mathrm{~h})$, initially housed in pairs in clear polyutherane bins $(48 \mathrm{~cm} \mathrm{x}$ 
$27 \mathrm{~cm} \times 20 \mathrm{~cm}$ ) with ad libitum access to rat chow (Sniff) and tap water. All experiments were approved by the Animal Ethics Board of Maastricht University in accordance with Dutch governmental regulations (DEC 2009-158, DEC 2010-150). All efforts were made to minimize the pain and stress levels experienced by the animals.

For breeding, one female was paired with one male in a wire mesh cage until release of a vaginal plug. The day of plug release was considered gestation day (GD) 1. On GD 15, dams were randomly assigned to stress or control groups. Dams in the stress group were individually immobilized three times daily for $45 \mathrm{~min}$ in transparent plastic cylinders under bright light (13 Watt TL Lamp) (between 0800h-1000h, 1200h-1400h, 1600h-1800h) on GD15-20 and twice on GD21 as previously described (Pawluski et al. 2012b; Rayen et al. 2011). One day after birth (birth day = P0), litters were culled to five males and five females and dams (with offspring) were randomly assigned to one of two treatment groups: fluoxetine $(5 \mathrm{mg} / \mathrm{kg} /$ day) or vehicle, for a total of four groups of dams: 1) Control + Vehicle (CV) 2) Control + Fluoxetine (CF), 3) Prenatal Stress + Vehicle (PSV), and 4) Prenatal Stress + Fluoxetine (PSF). All litters were weaned on postpartum day 21 and were housed in litter groups in clear polyutherane bins $(48 \mathrm{~cm} \times 27 \mathrm{~cm} \times 20 \mathrm{~cm})$.

Fluoxetine treatment to dams. Fluoxetine treatment was administered to the dam for four weeks, via osmotic minipumps (Alzet Osmotic pumps, 2ML4, Charles River, The Netherlands), beginning on postpartum day one. Minipumps have successfully been used during the postpartum period ( $\mathrm{Xu}$ et al. 2009). Fluoxetine, and its active metabolite norfluoxetine, can pass to offspring through lactation (Gentile et al. 2007). Therefore, we chose this mode of delivery instead of repeated injections or oral gavage, to minimize the effect of repeated stress. Minipump implants were filled with either fluoxetine (Fagron, Belgium) dissolved in vehicle (50\% propylenediol in saline; $5 \mathrm{mg} / \mathrm{kg} / \mathrm{day}$ ), or with vehicle as previously described (Pawluski et al. 2012b; Rayen et al. 2011). Minipumps were implanted subcutaneously in the dorsal region while the dams were under mild isofluorane anesthesia on post-partum day one. Implants took a maximum of 20 minutes and offspring were separated from their mother for a maximum of 20 minutes.

\section{Experiment 1: Juvenile offspring}

For Exp 1, a total of six dams were in each of the four groups: 1) Control + Vehicle (CV) 2) Control + Fluoxetine (CF), 3) Prenatal Stress + Vehicle (PSV), and 4) Prenatal Stress + Fluoxetine (PSF). In most cases only 1 male and 1 female per litter were used, and overall only a maximum of two male and two female pups per litter were used for a total of 
$\mathrm{n}=6 /$ sex/group. On P21-25 offspring were weighed, the anogenital distance was recorded and trunk blood was taken from rapid decapitation. The anogenital distance, which is the distance from the anus to the genitals, was measured by use of a vernier-caliper as previously described (Vandenbergh and Huggett 1995). The relative anogenital distance was determined by dividing the anogenital distance by the cube root of body weight (Gallavan et al. 1999).

Steroid hormone assays. To investigate whether treatment affects sex steroid levels in juvenile offspring, blood samples were taken at sacrifice (between $1000 \mathrm{~h}$ and noon). Blood samples were stored at $4^{\circ} \mathrm{C}$ overnight and centrifuged at $10,000 \mathrm{~g}$ for 10 minutes. Serum was collected and stored at $-80^{\circ} \mathrm{C}$ until analysis. All samples for each animal were run in duplicate using commercially available radioimmunoassay (RIA) kits from MP Biomedicals (MP Biomedicals, Belgium). A 17ß-oestradiol (E2) $\mathrm{I}^{125}$ kit was used for detection of estradiol in serum from female offspring and a Testosterone $\mathrm{I}^{125}$ kit was used for detection of testosterone in serum from male offspring. The average intra-coefficient of variation for the assays was 3.28\% (E2 assay) and 7.04\% (testosterone assay). The lowest detection limit for estradiol was $1.4 \mathrm{pg} / \mathrm{ml}$ and for testosterone $0.03 \mathrm{ng} / \mathrm{ml}$.

\section{Experiment 2: Adult male offspring}

For Exp 2, separate dams and offspring were used and a maximum of two male offspring per litter were used in the four groups: 1) CV, 2) CF, 3) PSV, and 4) PSF. Offspring were initially housed in litter groups after weaning and beginning on postpartum day 31-35 they were housed per sex (four animals/cage) and on postpartum day 45-49 they were housed in pairs in clear polyurethane bins $(48 \mathrm{~cm} \times 27 \mathrm{~cm}$ x $20 \mathrm{~cm})$. Only male offspring were used in the present study. Female offspring were used in additional work reported elsewhere. Adult male offspring were investigated for locomotor activity ( $\mathrm{n}=10-12 /$ group) and sex behavior testing ( $\mathrm{n}=10-12$ /group) as stated below. For immunohistochemical analyses of the AVPv, BST and SDN-POA, a subset of male offspring were used ( $n=5-7 /$ group, with a maximum of 2 males from each litter).

Locomotion and habituation. Locomotor activity was tested in adult male offspring, between P70-P76, based on previous work (Rayen et al. 2011). This was done to determine if the developmental exposure to fluoxetine or maternal stress had any gross effects on locomotor activity. This also served to habituate each animal to the testing chamber used for sexual behavior testing. To do this each male offspring was separately placed in a transparent glass chamber $(50 \mathrm{~cm} \times 25 \mathrm{~cm} \times 30 \mathrm{~cm})$, for a total of 15 minutes, once between $0800 \mathrm{~h}$ and 1230h The chamber was cleaned with $70 \%$ ethanol and dried between rats. All sessions were 
recorded and an experimenter blind to conditions scored the distance travelled using a videotracking system (Anymaze, Stoelting).

Sexual behavior. Approximately one week after habituation, sexual behavior of adult male offspring, between P80-P88, was tested in a transparent glass chamber $(50 \mathrm{~cm} \mathrm{x} 25 \mathrm{~cm} \times$ $30 \mathrm{~cm}$ ) as previously described (Maciag et al. 2006a; Maciag et al. 2006b). For testing male sexual behavior, nonexperimental ovariectomized (OVX) females (Charles River Laboratories, France) were used as a stimulus. In order to bring OVX females into estrous they were given subcutaneous injections of estradiol benzoate $(10 \mu \mathrm{g} / 0,1 \mathrm{ml}$ sesame oil $) 48$ hours and 24 hours prior to a subcutaneous injection of progesterone $(500 \mu \mathrm{g} / 0,1 \mathrm{ml}$ sesame oil) as previously described (Mazzucco et al. 2008). OVX females were used for testing four hours after the progesterone injection.

At the start of testing a virgin male offspring was placed into the testing chamber and allowed to explore the chamber for two minutes. After two minutes, a stimulus OVX female was introduced for testing. Only one 60 minute test session took place per male. All sessions were videotaped and scored by an experimenter blind to experimental conditions. The chamber was cleaned between each session with $70 \%$ ethanol and dried between rats. Testing took place between $1200 \mathrm{~h}$ and $1800 \mathrm{~h}$. For each 60 minute test, the following behaviors were scored: frequency of ano-genital sniffing, number of mounts, time to first mount, number of intromissions, time to first intromission, number of ejaculations, and time to first ejaculation. The behaviors were defined as follows: Mount - a male grasping the female's flanks with his forepaws and thrusting to attempt penetration of the vagina; Intromission - penetrating the female's vagina; Ejaculation - a longer, deeper thrust, followed by a slower dismount (Maciag et al. 2006a; Pereira et al. 2006).

Anogenital distance. The anogenital distance was measured at sacrifice in adult male offspring as previously described in Exp 1.

Immunohistochemistry. Five days after sexual behavioral testing, adult offspring were deeply anesthetized (between $0800 \mathrm{~h}$ and noon) with an overdose of pentobarbital and perfused transcardially with saline followed by with $4 \%$ paraformaldehyde. Brains were postfixed in 4\% paraformaldehyde for 24 hours, cryoprotected in 30\% sucrose/phosphatebuffered saline solution for up to one week, frozen on dry ice and kept at $-80^{\circ} \mathrm{C}$. Brain tissue was sliced in $30 \mu \mathrm{m}$ sections on a cryostat (Leica). Tissue was stored in antifreeze solution and maintained at $-15^{\circ} \mathrm{C}$. The number of tyrosine hydroxylase positive cells in the AVPv were assessed. Every $6^{\text {th }}$ section throughout the AVPv was stained for TH-immunoreactivity as previously described (Simerly et al. 1985b). In addition, we measured the volume of the 
posterior BST (pBST) defined by AR-immunoreactivity. Every $3^{\text {rd }}$ section throughout the BST was stained as previously described (Bakker et al. 1997). We also measured the area of the SDN-POA defined by calbindin-immunoreactivity. Every $3^{\text {rd }}$ section throughout the SDN-POA was stained as previously described (Pei et al. 2006). Mouse anti-TH (1:1000; ImmunoStar), rabbit anti-AR (1:250; Santa Cruz Biotechnology), or mouse anti-calbindin (1:15000; Sigma) monoclonal primary antibodies were used and biotinylated goat anti-mouse (1:400; Dako), biotinylated goat anti-rabbit (1:500; Dako), or biotinylated donkey anti-mouse secondary antibody (1:500; Jackson ImmunoResearch) was used, respectively. Brain sections were further processed by using the avidine-biotine complex (ABC Elite kit; 1:1000; Vector laboratories) and DAB (3,3-diaminobenzidine; Sigma).

The number of TH immunoreactive (-ir) cells in the AVPv were counted under 40x objective with water as previously described (Patisaul et al. 2006). The area of SDN-POA, the volume of the pBST, and the area of the AVPv was measured under 10x objective using StereoInvestigator software (MicroBrightField, Williston, VT, USA) and estimates of pBST volumes were made according to Cavalieri's principle (Gundersen et al. 1988). For representative photomicrographs see Figure 1. 

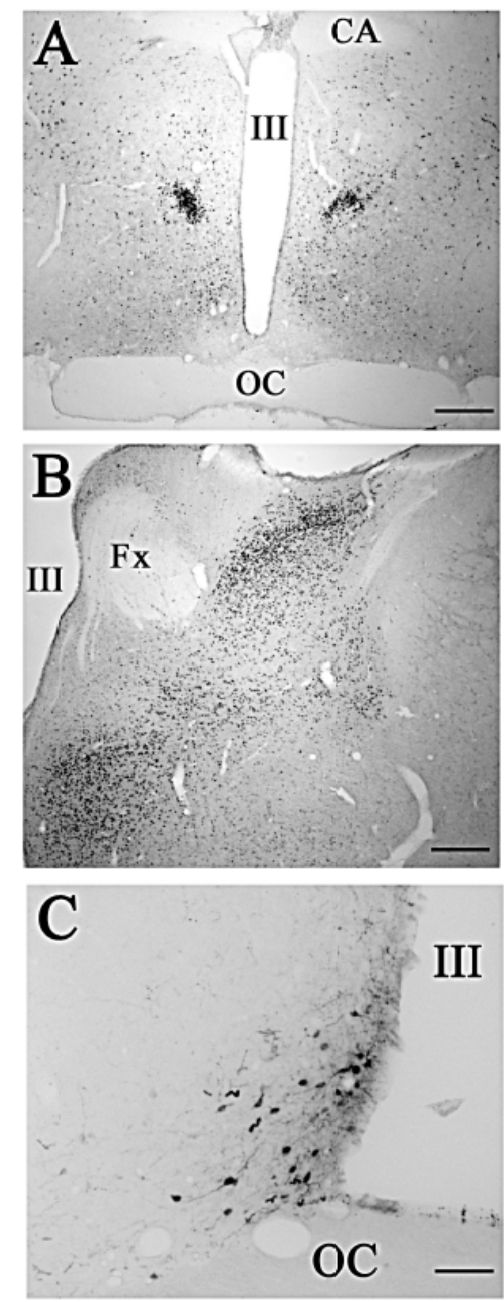

Figure 1. Photomicrographs of A) SDN-POA, highlighted by calbindin-ir cells, B) pBST (lateral to the fornix) and MPOA (lateral to the ventricle) and AR-ir cells and C) AVPv containing TH-ir cells. CA, Anterior commissure; III, Third ventricle; OC, Optic chiasma; FX, Fornix. Magnification bar is $120 \mu \mathrm{m}$.

Testosterone hormone assay. To investigate whether developmental SSRI exposure affected testosterone levels in adult male offspring, blood samples were taken at sacrifice, stored at $4^{\circ} \mathrm{C}$ overnight and centrifuged at $10,000 \mathrm{~g}$ for 10 minutes. Serum was collected and stored at $-80^{\circ} \mathrm{C}$ until analysis. Testosterone levels were analysed as described in Exp 1.

Statistical analysis. For Exp 1 analysis of variance tests (ANOVA) were done on anogenital distance in juvenile offspring, with condition (prenatal stress/no stress), treatment (fluoxetine/vehicle), and sex (male/female) as independent factors, and on estradiol and testosterone levels in juvenile female and male offspring with condition (prenatal stress/no 
stress) and treatment (fluoxetine/vehicle) as independent factors. For Exp 2, ANOVAs were done on behavioral measures, anogenital distance, weight, testosterone levels, THimmunoreactivity, volume of the pBST, and calbindin-immunoreactivity in the SDN-POA in adult male offspring, with condition (prenatal stress/no stress), and treatment (fluoxetine/vehicle) as independent factors. Pearson product moment correlations were conducted between factors. Any differences in age, weight, time of testing or test order of the litter, were accounted for, where appropriate, via an analysis of covariance. Posthoc comparisons utilized the Fisher LSD test.

\section{Results}

\section{Experiment 1: Juvenile offspring}

Anogenital distance. There was a significant sex by treatment interaction effect $(\mathrm{F}(1,39)=10.662, \mathrm{p}=.002$; Figure $2 \mathrm{~A})$ with fluoxetine-exposed juvenile male offspring, regardless of prenatal stress exposure, having significantly shorter anogenital distances compared to vehicle-exposed male offspring $(\mathrm{p} \leq .000004)$, while females were not affected by the treatment. As expected there was a significant main effect of sex on anogenital distance $(F(1,39)=183.76, p=.0000001$; Figure $2 A)$, controlling for any differences in weight and age, with juvenile male offspring having a significantly longer anogenital distance compared to juvenile female offspring. There was also a significant main effect of fluoxetine exposure $(F(1,39)=13.332, p=.0007)$. For the relative anogenital distance, there was also a significant treatment interaction effect $(F(1,39)=4.8201, \mathrm{p}=.034$; Figure $2 \mathrm{~B})$ and a main effect of sex on anogenital distance $(F(1,39)=94.700, p=.00000$; Figure $2 B)$, In addition, there was a main effect of fluoxetine exposure $(\mathrm{F}(1,39)=6.2062, \mathrm{p}=.017)$ as well as a tendency toward a main effect of prenatal stress $(F(1,39)=3.922, p=.055)$. There were no other significant main effects or interaction effects $(.149 \leq \mathrm{p} \leq .982)$. 

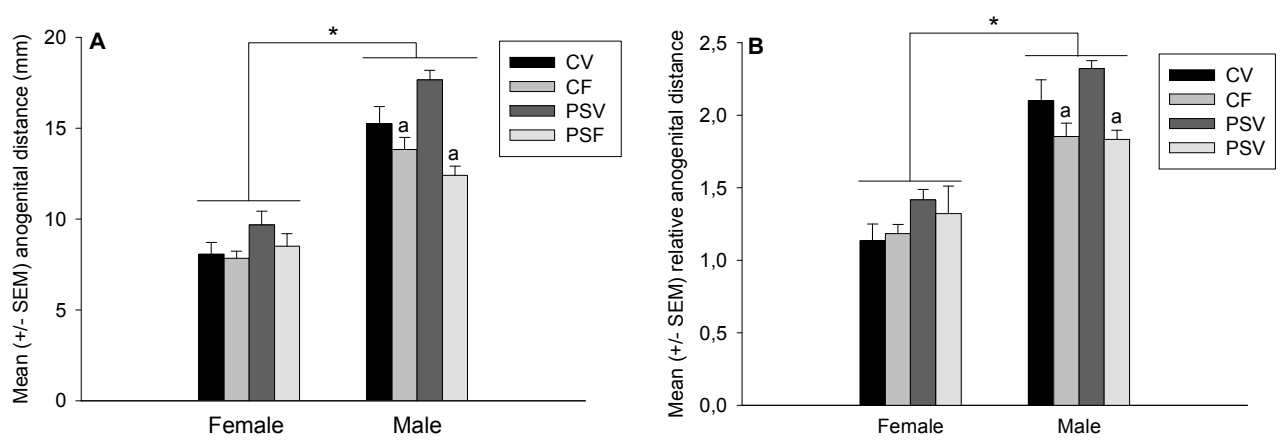

Figure 2. Mean ( \pm SEM) A) anogenital distance $(\mathrm{mm})$, and B) relative anogenital distance in juvenile male and female offspring (Exp 1). Fluoxetine-exposed juvenile male offspring had significantly A) shorter anogenital distance and B) smaller relative anogenital distance compared to all other groups. In general, males had significantly longer anogenital/relative anogenital distances compared to females. "a,denotes significantly different from $\mathrm{CV}$ and PSV male offspring. "*'denotes significantly different. ( $\mathrm{n}=6 / \mathrm{sex} /$ group). (ANOVA, Post-hoc test: Fisher LSD test). $\mathrm{CV}=$ Control + Vehicle, $\mathrm{CF}=$ Control + Fluoxetine, $\mathbf{P S V}=$ Prenatal Stress + Vehicle, and $\mathbf{P S F}=$ Prenatal Stress + Fluoxetine

Estradiol and testosterone levels. There were no significant main or interaction effects between groups in serum estradiol levels of juvenile female offspring $(.259 \leq \mathrm{p} \leq .631$; Table 1) or serum testosterone levels of juvenile male offspring $(.296 \leq p \leq .574$; Table 1$)$ at sacrifice.

Table 1. Mean $( \pm$ SEM) of the serum testosterone levels in juvenile male offspring and serum estradiol levels in juvenile female offspring (Exp 1). (n=6/group). (ANOVA)

\begin{tabular}{lcc}
\hline & Testosterone $(\mathbf{n g} / \mathbf{m l})$ & Estradiol $(\mathbf{p g} / \mathbf{m l})$ \\
\hline CV & $0.071 \pm 0.042$ & $2.48 \pm 0.92$ \\
CF & $0.029 \pm 0.029$ & $7.41 \pm 1.99$ \\
PSV & $0.014 \pm 0.014$ & $6.05 \pm 1.42$ \\
PSF & $0.022 \pm 0.021$ & $18.08 \pm 12.96$ \\
\hline
\end{tabular}

\section{Experiment 2: Adult male offspring}

There were no significant main effects or interaction effects on weight $(.170 \leq p \leq .943)$, anogenital distance $(.143 \leq \mathrm{p} \leq .910)$, relative anogenital distance $(.133 \leq \mathrm{p} \leq .792)$, or serum testosterone levels in adult male offspring at sacrifice (.399 $\leq \mathrm{p} \leq .405)$ (Table 2). There were no significant differences between groups in distance travelled during habituation $(.098 \leq \mathrm{p} \leq$ .747; Table 3). 
Chapter 5

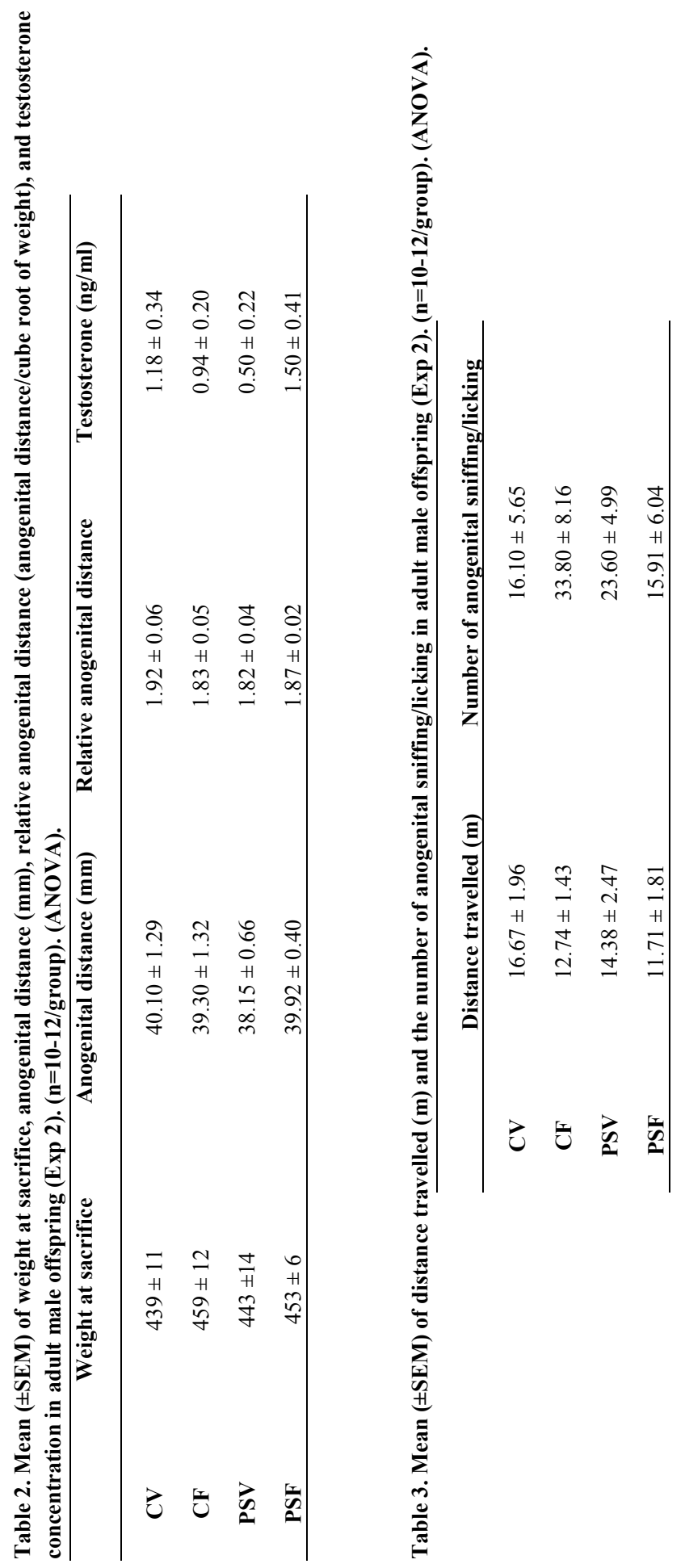


Male sexual behavior. For bouts of anogenital sniffs/licks, there was a strong tendency toward an interaction effect between condition and treatment $(F(1,38)=4.009, p=.052$; Table 2). For mounts, there was a tendency toward a main effect of fluoxetine on total number of mounts $(\mathrm{F}(1,38)=2.9430, \mathrm{p}=.09$; Figure 3A), with fluoxetine-exposed male offspring making fewer mounts than vehicle-exposed male offspring. There were no significant differences between groups in time to first mount $(.218 \leq \mathrm{p} \leq 1$; Figure $3 \mathrm{~B})$. For intromissions, there was a significant interaction effect between condition and treatment on number of intromissions $(\mathrm{F}(1,38)=4.2581, \mathrm{p}=.046$; Figure $3 \mathrm{C})$ and post-hoc analysis showed that CF male offspring made significantly fewer intromissions compared to $\mathrm{CV}$ male offspring ( $\mathrm{p} \leq .009$ ). There was also a tendency toward a main effect of fluoxetine on total number of intromissions $(\mathrm{F}(1,38)=3.5408, \mathrm{p}=.07)$, with male offspring exposed to fluoxetine making fewer intromissions compared to male offspring exposed to vehicle. There were no significant differences between conditions on time to first intromission $(.132 \leq \mathrm{p} \leq$ .915). However a priori we expected that CF offspring would take longer to intromit than CV offspring based on previous work (Maciag et al. 2006b), and a priori tests revealed that CF male offspring took significantly longer than $\mathrm{CV}$ offspring to intromit ( $\mathrm{p}=.04$; Figure $3 \mathrm{D})$. For ejaculatory behavior, there were no significant differences between groups in number of ejaculations $(.140 \leq \mathrm{p} \leq .843$; Figure $3 \mathrm{E})$ and there was a tendency toward a significant interaction effect between condition and treatment on time to first ejaculation $(\mathrm{F}(1,38)=3.1785, \mathrm{p}=.08$; Figure $3 \mathrm{~F})$. However, a priori, we also had reasons to expect that CF offspring would differ from CV offspring in ejaculatory behaviors (Maciag et al. 2006b), therefore a priori tests were conducted and found that $\mathrm{CF}$ offspring indeed took significantly longer than $\mathrm{CV}$ offspring to ejaculate $(\mathrm{p}=.036)$. There were no other significant differences between groups as a result of prenatal stress or fluoxetine exposure $(.132 \leq p \leq 1)$. 

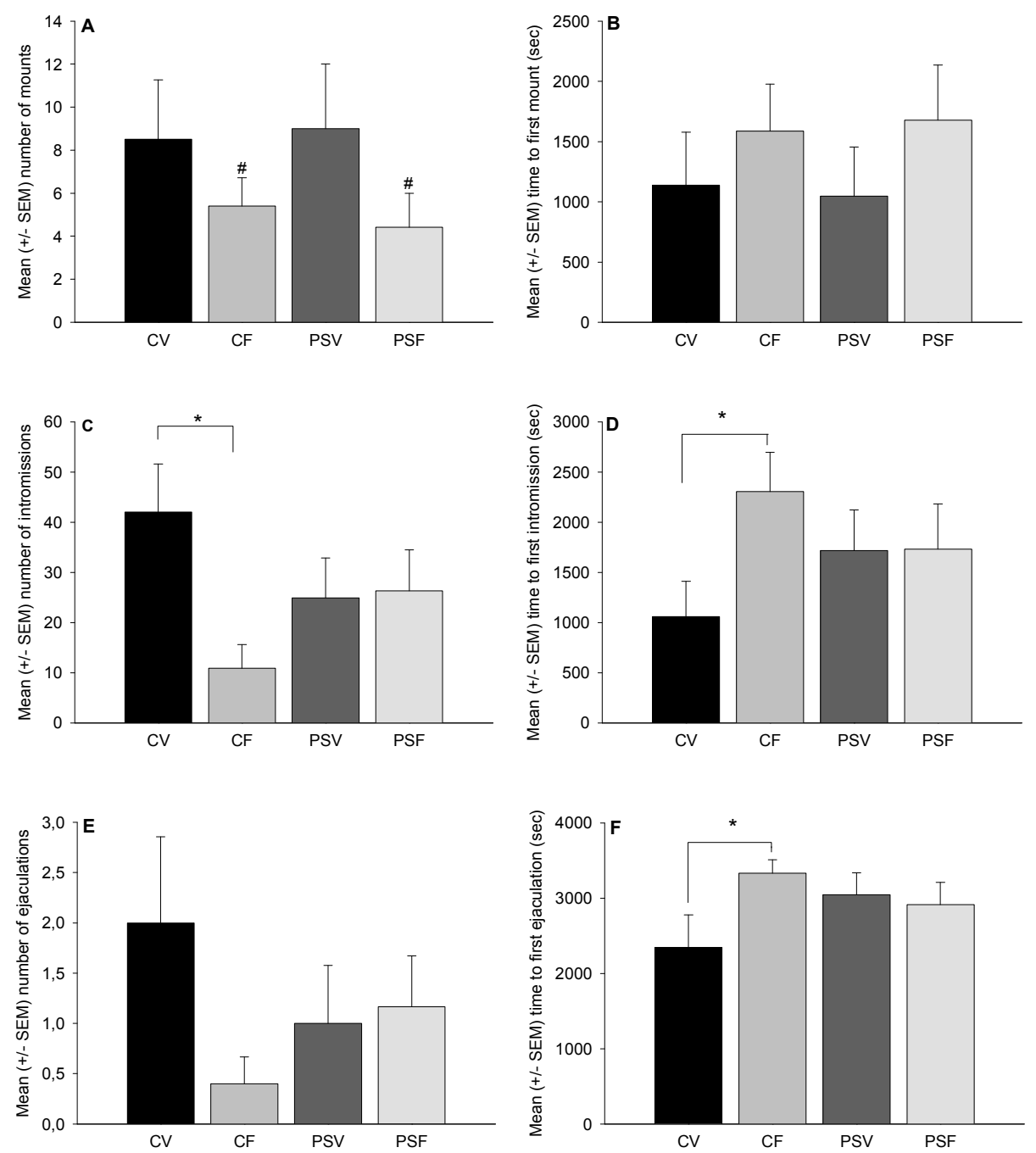

Figure 3. Mean ( $( \pm$ SEM) A) number of mounts, B) time to the first mount, C) number of intromissions, D) time to the first intromission, E) number of ejaculations, and F) time to the first ejaculation in adult male offspring (Exp 2). A) Fluoxetine-exposed male offspring tended to make fewer mounts compared to vehicle-exposed male offspring. B) There were no significant differences between the groups in the time to the first mount. C) CF male offspring made significantly fewer intromissions compared to CV male offspring. D) CF male offspring took a significantly longer time to intromit than CV male offspring. E) There were no significant differences between the groups in the number of ejaculations. F) CF offspring had a significantly longer latency to the first ejaculation compared to CV offspring. '\#'denotes tendency to be different from CV and PSV male offspring. "*'denotes significantly different. (n=10-12/group). (ANOVA, Post-hoc test: Fisher LSD test). CV $=$ Control + Vehicle, $\mathbf{C F}=$ Control + Fluoxetine, PSV $=$ Prenatal Stress + Vehicle, and $\mathbf{P S F}=$ Prenatal Stress + Fluoxetine. 
Area of SDN-POA. There was a significant main effect of fluoxetine $(F(1,18)=21,773, p=$ .00019 ; Figure 4A) and a significant main effect of stress $(F(1,18)=23,513, p=.00013$; Figure $4 \mathrm{~A}$ ) on the area of the SDN-POA defined by calbindin-immunoreactive cells, with male offspring exposed to fluoxetine and/or prenatal stress having a smaller area of the SDN-POA compared to control male offspring. There was no interaction effect on the area of calbindinir cells in the SDN-POA $(\mathrm{p}=.224)$.

Volume of the pBST. There was a significant main effect of stress on the volume of the pBST defined by AR-immunoreactive cells $(F(1,22)=5.401, p=.0297$; Figure 4B), with male offspring exposed to prenatal stress having significantly smaller volume of the pBST compared to male offspring not exposed to prenatal stress. In addition, there was a significant negative correlation between the volume of the pBST and the time to the first intromission $(\mathrm{r}=-.401, \mathrm{p}=.042$; Figure $4 \mathrm{C})$, with male offspring having a larger volume of the $\mathrm{pBST}$, displaying significantly less time to the first intromission.

TH-ir cells in the AVPv. There was a significant main effect of stress on the number of THir cells in the $\operatorname{AVPv}(F(1,18)=5.9176, p=.026$; Figure 4D), with male offspring exposed to prenatal stress having significantly fewer TH-ir cells in the AVPv compared to male offspring not exposed to prenatal stress. There were no other significant main or interaction effects on the area of AVPv defined by TH-ir cells in male offspring $(.511 \leq \mathrm{p} \leq .960)$. 

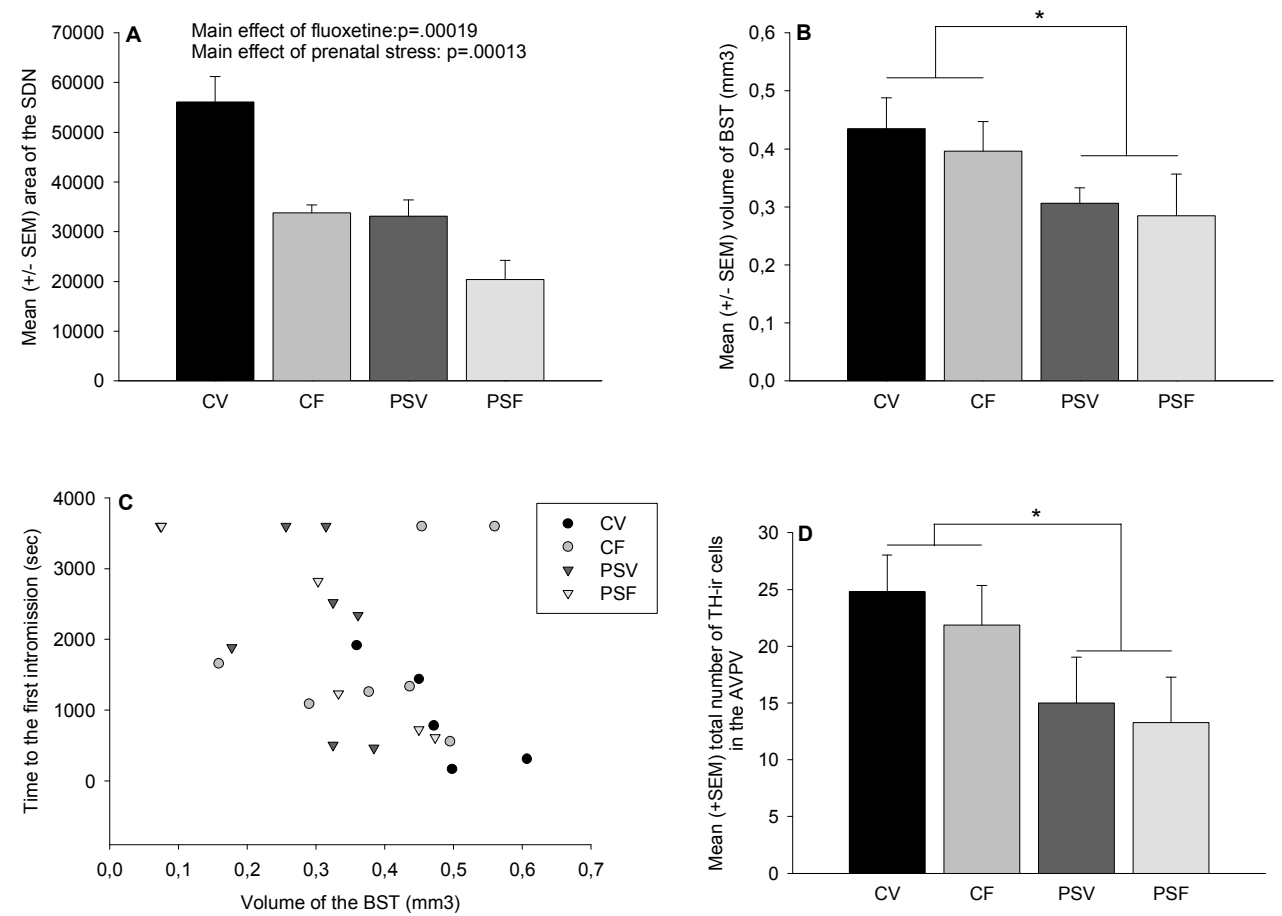

Figure 4. Mean ( $\left( \pm\right.$ SEM) A) area of the SDN-POA $\left(\mu \mathrm{m}^{2}\right)$ in adult male offspring $(\operatorname{Exp} 2)$, B) volume of the pBST $\left(\mathrm{mm}^{3}\right)$ in adult male offspring $\left(\operatorname{Exp~2),C)~correlation~between~the~volume~of~the~pBST~}\left(\mathrm{mm}^{3}\right)\right.$ and the time to the first intromission (sec) in adult male offspring, and D) total number of TH-ir cells in the AVPv in adult male offspring (Exp 2). A) There was a main effect of fluoxetine treatment and a main effect of prenatal stress on the volume of the SDN-POA. (n=5-6/group). (ANOVA). B) PSV and PSF male had a significantly smaller volume of the pBST than CV and CF male offspring. (ANOVA). C) Male offspring which had a larger volume of the pBST displayed significantly less time to the first intromission. Pearson product moment correlations. D) Prenatally stressed male offspring had significantly fewer THir cells in the AVPv compared to control male offspring, regardless of fluoxetine exposure. (ANOVA). '*'denotes significantly different. (n-5-7/group). $\mathrm{CV}=\mathrm{Control}+$ Vehicle, $\mathbf{C F}=$ Control + Fluoxetine, PSV $=$ Prenatal Stress + Vehicle, and $\mathbf{P S F}=$ Prenatal Stress + Fluoxetine. 


\section{Discussion}

The findings of this study show that developmental exposure to SSRI medications, in an animal model of maternal adversity, may have a long-term impact on sexual differentiation of the brain and behavior in male offspring. Main findings show that developmental exposure to maternal fluoxetine significantly decreased the anogenital distance in juvenile male offspring (Exp 1). In addition, developmental exposure to fluoxetine significantly altered male sexual behavior in adult offspring (Exp 2). Exposure to both fluoxetine and maternal stress significantly altered brain morphology of the SDN-POA, while maternal stress alone significantly altered the morphology of the pBST and AVPv (Exp 2).

\section{Developmental fluoxetine exposure reduces the anogenital distance in juvenile male} offspring. The anogenital distance is significantly larger in male compared to female, in rodents as well as in humans. This difference is set perinatally but the anogenital distance continues to be influenced during development by multiple physiological and environmental factors. Although testosterone plays a primary role in anogentical distance, we did not find marked differences in testosterone levels of juvenile or adult male offspring at sacrifice. However, it is likely that developmental exposure to fluoxetine, and its effects on the serotonergic system, alter the growth of the anogenital distance in male offspring. Interestingly, the reduction in anogenital distance after developmental fluoxetine exposure in juvenile male offspring disappears in adult male offspring exposed to developmental fluoxetine. Possibly, increases in serotonin levels during the organizational stage of sexual brain differentiation, which occurs early during development (Arnold and Breedlove 1985), affect the growth of the anogenital distance in juvenile males. During puberty, when the activation of sexual brain differentiation occurs, there is no interference with serotonin levels and it is likely that the growth of the genitals is normalized. Interestingly, alterations of the anogenital distance can be an early indicator of diminished sexual behavior into adulthood (Keshet and Weinstock 1995) which partially supports our findings in adult male offspring $(\operatorname{Exp} 2)$.

\section{Developmental fluoxetine exposure demasculinizes sexual behavior in male offspring.}

Numerous studies have investigated the effect of antidepressant medication in adulthood on sexual behavior (Bishop et al. 2012; Tufan et al. 2012) but very little work has investigated the effects of SSRI exposure during development on offspring sexual behavior. Vogel et al. 
(1990) were the first to report that neonatal exposure to the tricyclic antidepressant, clomipramine (15 mg/kg, s.c., twice daily), in male rats leads to diminished sexual behavior, including decreases in mounting, intromission and ejaculatory behavior (Vogel et al. 1990). Recent work on the developmental impact of SSRI medications on sexual behavior in male offspring, not exposed to maternal adversity, has shown that postnatal injection of citalopram results in impaired mounting behavior and a decrease in the number of intromissions and ejaculations (Maciag et al. 2006c). This impairment in sexual behavior in male rats neonatally exposed to citalopram is mimicked completely by the stimulation of the 5-HT1B receptor and partly by stimulation of the 5-HT1A and the 5HT2 receptor (Maciag et al. 2006a; Wilson et al. 1998). This indicates a contribution of the serotonin autoreceptors on sexual behavior during development.

Previous work investigating the effects of developmental exposure to the SSRI fluoxetine on copulatory behavior in male offspring is limited and has found varied results. For example, Olivier and colleagues (2011) report no effect of early exposure to fluoxetine on copulatory behavior in male offspring. However, Gouvea and colleagues have reported that developmental exposure to fluoxetine impairs sexual motivation in male mice (Gouvea et al. 2008). Discrepancies between these works and the present findings likely are due to the timing of fluoxetine administration, the route of administration, the dose of fluoxetine used, and the testing paradigm. For example, Olivier (2011) administered fluoxetine via oral gavage (12 mg/kg, 1 oral injection/day) to the mother during pregnancy only and investigated sexual behavior in sexually experienced male offspring (Olivier et al. 2011b). In the present study, and the study of Gouvea and colleagues, fluoxetine was administered during the postnatal period of brain development, when serotonin is known to be involved in the control of sexual differentiation (Dakin et al. 2008), and sexually naive male offspring were used. Further research is needed to determine mechanisms which are responsible for reductions in sexual behavior in male offspring exposed to SSRI medications during development. However, it should be noted that the effects of developmental exposure to SSRI medications on sexual behavior in male offspring appear only when given to healthy dams and/or offspring; we did not find any significant effects on sexual behavior in male offspring exposed to both maternal stress and maternal fluoxetine treatment. Possibly, the exposure to prenatal stress alters sexual differentiation in such a way that the further exposure to fluoxetine does not impact the behavioral outcomes. However, this is not always the case as our previous work has shown that developmental fluoxetine exposure reverses the reduction in immobilization in the forced swim test and the decrease in hippocampal neurogenesis in 
adolescent offspring exposed to prenatal stress (Rayen et al. 2011). It is likely that early exposure to SSRIs may have a very different outcome in the presence of maternal adversity, which likely more closely mimics the clinical situation. It has been shown that gestational stress increases the chance of developing depressive-like behavior in the rat dam by increasing the immobility scores by 35-40\% (O'Mahony et al. 2006). It also has been shown that increases in cortisol concentration contribute to development of depression (Sher 2004). Therefore, we have chosen the immobilization stress paradigm as a potential correlate to maternal depression.

We did not find a significant effect of prenatal maternal stress on any of the sexual behavioral parameters. Previous work has shown that prenatal stress in rats can affect sexual differentiation of the brain by feminizing and demasculinizing sexual behavior in male offspring (Ward 1972). It was proposed that higher circulating levels of stress steroids reduce copulatory patterns and augment lordotic behavior by decreasing exposure to androgens during male fetal life (Ward 1972; Ward and Weisz 1980). Other research has confirmed these data (Gerardin et al. 2005; Herrenkohl and Whitney 1976; Wang et al. 2006). Differences between our work and others may be attributed to different stress paradigms, the timing of exposure to prenatal stress, method of treatment administration, and also strain differences.

\section{Developmental fluoxetine exposure and/or prenatal stress affects the SDN-POA, while} prenatal stress alone affects the AVPv and pBST. This study demonstrated that developmental fluoxetine exposure and/or prenatal stress significantly reduced the area of the SDN-POA and that prenatal stress significantly reduced the number of TH-ir cells in the AVPv and the volume of the pBST in adult male offspring. The volume, structure and neurochemistry of the SDN-POA, pBST and AVPv are sexually dimorphic, with the two former nuclei being larger in males while the AVPv is larger in females (Hull et al. 2009).

In the present study, SDN-POA area, defined by calbindin-immunoreactive cells, was significantly reduced after developmental exposure to fluoxetine and/or prenatal stress. The deleterious effects of prenatal stress on the SDN-POA macrostructure have been previously shown (Anderson et al. 1986; Rhees et al. 1999). For example, a reduction of the SDN-POA volume was reported in male rats subjected to prenatal heat-light immobilization stress and this reduction was associated with a significant alteration in male copulatory behavior (Anderson et al. 1986; Rhees et al. 1999). It has been hypothesized that maternal stress causes a slight shift in testosterone increase during the gestational period (Rhees et al. 1999). 
Adequate masculinization of sexual behavioral is, in part, initiated by exposure of the developing brain to testosterone at day 18 after conception (Ward and Weisz 1980) and this earlier increase in testosterone would, therefore, miss the small window of action.

To our knowledge, no studies have investigated how developmental fluoxetine exposure affects the morphology of the SDN-POA. Serotonin is significantly reduced in males between the $2^{\text {nd }}$ and $3^{\text {rd }}$ week postnatal (Ladosky and Gaziri 1970). The drop in serotonin activity appears essential for full masculization of the brain, given that administration of the serotonin precursor 5-hydroxytryptophan or serotonin receptor 5-HT2 agonist $(\mathrm{K})[2,5$ dimethoxy-4-iodophenyl]-2-amino propane to males or androgenized females, over a period that covers the transient fall in endogenous serotonin, reduces the size of the SDN-POA, as well as the AVPv (Murray et al. 2004). Conversely, treatment with parachlorophenylalanine, a serotonin synthesis inhibitor, enhances masculinization and defeminization (Wilson et al. 1998). Interestingly, manipulation of serotonin synthesis during the first week after birth in males has no effect on subsequent adult reproductive function or behavior (Jarzab and Dohler 1984; Wilson et al. 1998). Therefore, inhibition of the natural serotonin drop, resulting from the maternal fluoxetine exposure, likely antagonizes the perinatal masculinization effects of testosterone during the second and/or third week postpartum. It should also be noted that developmental exposure to another SSRI, citalopram, led to a significant reduction of the number of androgen receptor-immunoreactive cells in the MPOA (Soga et al. 2012). Although estrogen receptor activation by estrogenic metabolites of testosterone is of primary importance to induce masculinization and defeminization of brain and male sexual behavior, androgen receptors are required to allow perinatal testosterone to induce complete masculinization of brain and behavior (Sato et al. 2004). The effect of SSRI medications and serotonin receptor activation on androgen receptors should be further investigated.

To our knowledge, this study is the first to report an effect of prenatal stress on pBST, where the volume, as defined by androgen receptor immunoreactive cells, was significantly reduced in male offspring exposed to prenatal stress. The BST, a sexually dimorphic structure, is an important structure where pheromonal, somatosensory and hormonal stimuli converge and is involved in the regulation of both sexual behavior and stress (Viau 2002). Stress will not only increase the level of endogenous corticosteroids that will activate both glucocorticoid and mineralocorticoid receptors, but will also affect other hormones acting on vasopressin and adrenergic receptors (Antoni 1993; Reul et al. 1987). The exact mechanisms underlying the reduction of pBST volume observed in our study is not clear but may be 
related to androgen receptor expression within this brain region as the number of androgen receptors in the pBST is inversely correlated to the magnitude of the HPA axis response to stress (Bingham and Viau 2008). Further research is needed to understand the mechanisms by which prenatal stress affects the BST volume and to define whether this reduction is directly responsible of the alteration of sexual behavior in male offspring.

Although previous work has found no differences in the volume of the AVPv after prenatal stress (Rhees et al. 1999), we found a decrease in the number of TH-ir cells in the $\mathrm{AVPv}$ following prenatal stress. The AVPv is involved in the control of gonadotrophin release (Ronnekleiv and Kelly 1986) and its volume, as well as the TH-expressing cells are significantly larger in females compared to males. It is also likely that the effect of prenatal stress on the number of $\mathrm{TH}$-ir cells in the AVPv, reported in the present study, is a direct effect of stress on cell proliferation and/or cell death and not a direct effect on sexual differentiation of the AVPv. There is a strong connection between the AVPv and the pBST in males (for example GABAergic: (Polston et al. 2004); galanin and substance P: (Polston and Simerly 2003)) and we cannot exclude a trophic effect of pBST cells to AVPv cells. Therefore, a decrease in pBST cell number would likely influence survival of AVPv cells, and explain the similar pattern of maternal stress effects on these two nuclei.

\section{Conclusions}

Depression during the pregnancy and in the postpartum period is a growing health concern (Leung and Kaplan 2009). The number of children exposed to SSRIs in the perinatal period is increasing (Cooper et al. 2007; Oberlander et al. 2006) and long-term knowledge of developmental exposure to SSRIs is rather limited. Findings from our work show that developmental exposure to SSRI medications, in an animal model of maternal adversity, may have a long-term impact on sexual differentiation of the brain, but have limited effects on sexual behavior in male offspring. Although these results show important evidence of longterm effects of developmental exposure to SSRIs on the HPG system, it is essential to note that these effects vary in the presence of maternal adversity. Before conclusions can be made about the outcomes of early exposure to SSRI medications, much more work is needed using appropriate models of maternal depression to determine underlying mechanisms responsible for changes in sexual behavior and/or brain morphology. 


\section{References}

Anderson RH, Fleming DE, Rhees RW, Kinghorn E (1986) Relationships between sexual activity, plasma testosterone, and the volume of the sexually dimorphic nucleus of the preoptic area in prenatally stressed and non-stressed rats. Brain Res 370: 1-10

Antoni FA (1993) Vasopressinergic control of pituitary adrenocorticotropin secretion comes of age. Front Neuroendocrinol 14: 76-122

Arnold AP, Breedlove SM (1985) Organizational and activational effects of sex steroids on brain and behavior: a reanalysis. Horm Behav 19: 469-98

Azmitia EC (2001) Modern views on an ancient chemical: serotonin effects on cell proliferation, maturation, and apoptosis. Brain Res Bull 56: 413-24

Bakker J, Pool CW, Sonnemans M, van Leeuwen FW, Slob AK (1997) Quantitative estimation of estrogen and androgen receptor-immunoreactive cells in the forebrain of neonatally estrogen-deprived male rats. Neuroscience 77: 911-9

Bingham B, Viau V (2008) Neonatal gonadectomy and adult testosterone replacement suggest an involvement of limbic arginine vasopressin and androgen receptors in the organization of the hypothalamicpituitary-adrenal axis. Endocrinology 149: 3581-91

Bishop JR, Chae SS, Patel S, Moline J, Ellingrod VL (2012) Pharmacogenetics of glutamate system genes and SSRI-associated sexual dysfunction. Psychiatry Res

Cooper WO, Willy ME, Pont SJ, Ray WA (2007) Increasing use of antidepressants in pregnancy. Am J Obstet Gynecol 196: 544 e1-5

Dakin CL, Wilson CA, Kallo I, Coen CW, Davies DC (2008) Neonatal stimulation of 5-HT(2) receptors reduces androgen receptor expression in the rat anteroventral periventricular nucleus and sexually dimorphic preoptic area. Eur J Neurosci 27: 2473-80

Dohler KD, Jarzab B, Sickmoller PM, Kokocinska D, Kaminski M, Gubala E, Achtelik W, Wagiel J (1991) Influence of neurotransmitters on sexual differentiation of brain structure and function. Exp Clin Endocrinol 98: 99-109

Fleschler R, Peskin MF (2008) Selective serotonin reuptake inhibitors (SSRIs) in pregnancy: a review. MCN Am J Matern Child Nurs 33: 355-61; quiz 362-3

Gallavan RH, Jr., Holson JF, Stump DG, Knapp JF, Reynolds VL (1999) Interpreting the toxicologic significance of alterations in anogenital distance: potential for confounding effects of progeny body weights. Reprod Toxicol 13: 383-90

Gentile S, Rossi A, Bellantuono C (2007) SSRIs during breastfeeding: spotlight on milk-to-plasma ratio. Arch Womens Ment Health 10: 39-51

Gerardin DC, Pereira OC, Kempinas WG, Florio JC, Moreira EG, Bernardi MM (2005) Sexual behavior, neuroendocrine, and neurochemical aspects in male rats exposed prenatally to stress. Physiol Behav 84: 97-104

Gouvea TS, Morimoto HK, de Faria MJ, Moreira EG, Gerardin DC (2008) Maternal exposure to the antidepressant fluoxetine impairs sexual motivation in adult male mice. Pharmacol Biochem Behav 90: 416-9

Gundersen HJ, Bagger P, Bendtsen TF, Evans SM, Korbo L, Marcussen N, Moller A, Nielsen K, Nyengaard JR, Pakkenberg B, et al. (1988) The new stereological tools: disector, fractionator, nucleator and point sampled intercepts and their use in pathological research and diagnosis. APMIS 96: 857-81

Herrenkohl LR, Whitney JB (1976) Effects of prepartal stress on postpartal nursing behavior, litter development and adult sexual behavior. Physiol Behav 17: 1019-21

Hull EM, Meisel RL, Sachs BD (2009) Male sexual behavior. In: Pfaff DW, Arnold AP, Etgen AM, Fahrbach SE, Rubin RT (eds) Hormones, Brain and Behavior. Academic Press, San Diego, CA, pp 1-139

Jarzab B, Dohler KD (1984) Serotoninergic influences on sexual differentiation of the rat brain. Prog Brain Res 61: 119-26

Keshet GI, Weinstock M (1995) Maternal naltrexone prevents morphological and behavioral alterations induced in rats by prenatal stress. Pharmacol Biochem Behav 50: 413-9

Kristensen JH, Ilett KF, Hackett LP, Yapp P, Paech M, Begg EJ (1999) Distribution and excretion of fluoxetine and norfluoxetine in human milk. Br J Clin Pharmacol 48: 521-7

Ladosky W, Gaziri LC (1970) Brain serotonin and sexual differentiation of the nervous system. Neuroendocrinology 6: 168-74

Laine K, Heikkinen T, Ekblad U, Kero P (2003) Effects of exposure to selective serotonin reuptake inhibitors during pregnancy on serotonergic symptoms in newborns and cord blood monoamine and prolactin concentrations. Arch Gen Psychiatry 60: 720-6

Leung BM, Kaplan BJ (2009) Perinatal depression: prevalence, risks, and the nutrition link--a review of the literature. J Am Diet Assoc 109: 1566-75 
Maccari S, Piazza PV, Kabbaj M, Barbazanges A, Simon H, Le Moal M (1995) Adoption reverses the long-term impairment in glucocorticoid feedback induced by prenatal stress. J Neurosci 15: 110-6

Maciag D, Coppinger D, Paul IA (2006a) Evidence that the deficit in sexual behavior in adult rats neonatally exposed to citalopram is a consequence of 5-HT1 receptor stimulation during development. Brain Res 1125: $171-5$

Maciag D, Simpson KL, Coppinger D, Lu Y, Wang Y, Lin RC, Paul IA (2006b) Neonatal antidepressant exposure has lasting effects on behavior and serotonin circuitry. Neuropsychopharmacology 31: 47-57

Maciag D, Williams L, Coppinger D, Paul IA (2006c) Neonatal citalopram exposure produces lasting changes in behavior which are reversed by adult imipramine treatment. Eur J Pharmacol 532: 265-9

Mazzucco CA, Walker HA, Pawluski JL, Lieblich SE, Galea LA (2008) ERalpha, but not ERbeta, mediates the expression of sexual behavior in the female rat. Behav Brain Res 191: 111-7

Murray JF, Dakin CL, Siddiqui A, Pellatt LJ, Ahmed S, Ormerod LJ, Swan AV, Davies DC, Wilson CA (2004) Neonatal 5HT activity antagonizes the masculinizing effect of testosterone on the luteinizing hormone release response to gonadal steroids and on brain structures in rats. Eur J Neurosci 19: 387-95

O'Mahony SM, Myint AM, van den Hove D, Desbonnet L, Steinbusch H, Leonard BE (2006) Gestational stress leads to depressive-like behavioural and immunological changes in the rat. Neuroimmunomodulation 13: $82-8$

Oberlander TF, Gingrich JA, Ansorge MS (2009) Sustained neurobehavioral effects of exposure to SSRI antidepressants during development: molecular to clinical evidence. Clin Pharmacol Ther 86: 672-7

Oberlander TF, Warburton W, Misri S, Aghajanian J, Hertzman C (2006) Neonatal outcomes after prenatal exposure to selective serotonin reuptake inhibitor antidepressants and maternal depression using population-based linked health data. Arch Gen Psychiatry 63: 898-906

Olivier JD, Valles A, van Heesch F, Afrasiab-Middelman A, Roelofs JJ, Jonkers M, Peeters EJ, Korte-Bouws GA, Dederen JP, Kiliaan AJ, Martens GJ, Schubert D, Homberg JR (2011b) Fluoxetine administration to pregnant rats increases anxiety-related behavior in the offspring. Psychopharmacology (Berl) 217: 419-32

Patisaul HB, Fortino AE, Polston EK (2006) Neonatal genistein or bisphenol-A exposure alters sexual differentiation of the AVPV. Neurotoxicol Teratol 28: 111-8

Pawluski JL, Brain UM, Underhill CM, Hammond GL, Oberlander TF (2012a) Prenatal SSRI exposure alters neonatal corticosteroid binding globulin, infant cortisol levels, and emerging HPA function. Psychoneuroendocrinology 37: 1019-28

Pawluski JL, Rayen I, Niessen NA, Kristensen S, van Donkelaar EL, Balthazart J, Steinbusch HW, Charlier TD (2012b) Developmental fluoxetine exposure differentially alters central and peripheral measures of the HPA system in adolescent male and female offspring. Neuroscience

Pei M, Matsuda K, Sakamoto H, Kawata M (2006) Intrauterine proximity to male fetuses affects the morphology of the sexually dimorphic nucleus of the preoptic area in the adult rat brain. Eur J Neurosci 23: $1234-40$

Pereira OC, Bernardi MM, Gerardin DC (2006) Could neonatal testosterone replacement prevent alterations induced by prenatal stress in male rats? Life Sci 78: 2767-71

Polston EK, Gu G, Simerly RB (2004) Neurons in the principal nucleus of the bed nuclei of the stria terminalis provide a sexually dimorphic GABAergic input to the anteroventral periventricular nucleus of the hypothalamus. Neuroscience 123: 793-803

Polston EK, Simerly RB (2003) Sex-specific patterns of galanin, cholecystokinin, and substance P expression in neurons of the principal bed nucleus of the stria terminalis are differentially reflected within three efferent preoptic pathways in the juvenile rat. J Comp Neurol 465: 551-9

Rayen I, van den Hove DL, Prickaerts J, Steinbusch HW, Pawluski JL (2011) Fluoxetine during development reverses the effects of prenatal stress on depressive-like behavior and hippocampal neurogenesis in adolescence. PLoS One 6: e24003

Reul JM, van den Bosch FR, de Kloet ER (1987) Relative occupation of type-I and type-II corticosteroid receptors in rat brain following stress and dexamethasone treatment: functional implications. $\mathrm{J}$ Endocrinol 115: 459-67

Rhees RW, Al-Saleh HN, Kinghorn EW, Fleming DE, Lephart ED (1999) Relationship between sexual behavior and sexually dimorphic structures in the anterior hypothalamus in control and prenatally stressed male rats. Brain Res Bull 50: 193-9

Ronnekleiv OK, Kelly MJ (1986) Luteinizing hormone-releasing hormone neuronal system during the estrous cycle of the female rat: effects of surgically induced persistent estrus. Neuroendocrinology 43: 564-76

Sato T, Matsumoto T, Kawano H, Watanabe T, Uematsu Y, Sekine K, Fukuda T, Aihara K, Krust A, Yamada T, Nakamichi Y, Yamamoto Y, Nakamura T, Yoshimura K, Yoshizawa T, Metzger D, Chambon P, Kato S (2004) Brain masculinization requires androgen receptor function. Proc Natl Acad Sci U S A 101: 1673-8 


\section{Chapter 5}

Sher L (2004) Daily hassles, cortisol, and the pathogenesis of depression. Med Hypotheses 62: 198-202

Simerly RB, Swanson LW, Gorski RA (1985a) The distribution of monoaminergic cells and fibers in a periventricular preoptic nucleus involved in the control of gonadotropin release: immunohistochemical evidence for a dopaminergic sexual dimorphism. Brain Res 330: 55-64

Simerly RB, Swanson LW, Handa RJ, Gorski RA (1985b) Influence of perinatal androgen on the sexually dimorphic distribution of tyrosine hydroxylase-immunoreactive cells and fibers in the anteroventral periventricular nucleus of the rat. Neuroendocrinology 40: 501-10

Soga T, Wong DW, Putteeraj M, Song KP, Parhar IS (2012) Early-life citalopram-induced impairments in sexual behavior and the role of androgen receptor. Neuroscience 225: 172-84

Talge NM, Neal C, Glover V (2007) Antenatal maternal stress and long-term effects on child neurodevelopment: how and why? J Child Psychol Psychiatry 48: 245-61

Tufan AE, Ozten E, Isik S, Cerit C (2012) Discerning the effects of psychopathology and antidepressant treatment on sexual dsyfunction*. Int J Psychiatry Clin Pract

Vandenbergh JG, Huggett CL (1995) The anogenital distance index, a predictor of the intrauterine position effects on reproduction in female house mice. Lab Anim Sci 45: 567-73

Viau V (2002) Functional cross-talk between the hypothalamic-pituitary-gonadal and -adrenal axes. J Neuroendocrinol 14: 506-13

Vogel G, Neill D, Hagler M, Kors D (1990) A new animal model of endogenous depression: a summary of present findings. Neurosci Biobehav Rev 14: 85-91

Wang CT, Shui HA, Huang RL, Tai MY, Peng MT, Tsai YF (2006) Sexual motivation is demasculinized, but not feminized, in prenatally stressed male rats. Neuroscience 138: 357-64

Ward IL (1972) Prenatal stress feminizes and demasculinizes the behavior of males. Science 175: 82-4

Ward IL, Weisz J (1980) Maternal stress alters plasma testosterone in fetal males. Science 207: 328-9

Weaver KJ, Paul IA, Lin RC, Simpson KL (2010) Neonatal exposure to citalopram selectively alters the expression of the serotonin transporter in the hippocampus: dose-dependent effects. Anat Rec (Hoboken) 293: 1920-32

Weinstock M (2001) Alterations induced by gestational stress in brain morphology and behaviour of the offspring. Prog Neurobiol 65: 427-51

Wilson CA, Gonzalez MI, Albonetti ME, Farabollini F (1998) The Involvement of Neonatal 5-HT ReceptorMediated Effects on Sexual Dimorphism of Adult Behavior in the Rat. Males, females and behavior. Praeger, Westport, USA: pp. 109-127

Wilson CA, Pearson JR, Hunter AJ, Tuohy PA, Payne AP (1986) The effect of neonatal manipulation of hypothalamic serotonin levels on sexual activity in the adult rat. Pharmacol Biochem Behav 24: 117583

Xu J, Kirigiti MA, Grove KL, Smith MS (2009) Regulation of food intake and gonadotropin-releasing hormone/luteinizing hormone during lactation: role of insulin and leptin. Endocrinology 150: 4231-40 


\section{Chapter 6}

Developmental fluoxetine exposure facilitates sexual

behavior in female offspring

Authors: Ine Rayen, Harry W.M. Steinbusch, Thierry D. Charlier,

Jodi L. Pawluski

Psychopharmacology 2013, Accepted 
Chapter 6

\begin{abstract}
Rationale. A growing number of infants are being exposed to selective serotonin reuptake inhibitor (SSRI) medications during the perinatal period. SSRIs target the serotoninergic system and are a popular treatment for maternal mood disorders. Serotonin, itself, plays a key role in the sexual differentiation through its role in the development of the hypothalamicpituitary-gonadal axis and previous research has shown that developmental SSRI exposure has an effect on sexual behavior in male offspring.

Objectives. Our aim was to determine the role of developmental exposure to a popular SSRI medication, fluoxetine, on sexual differentiation of the brain and behavior in female offspring using a rodent model of maternal adversity.

Methods. Stressed and non-stressed Sprague-Dawley rat dams were chronically treated with either fluoxetine $(5 \mathrm{mg} / \mathrm{kg} /$ day $)$ or vehicle beginning on postnatal day 1 . Four groups of female offspring were used: 1) Control + Vehicle, 2) Control + Fluoxetine, 3) Prenatal Stress + Vehicle, and 4) Prenatal Stress + Fluoxetine.

Results. Primary results show that in adult female offspring, developmental fluoxetine exposure facilitates proceptive and receptive behaviors with a significant increase in the number of proceptive behaviors, a significant increase in the lordosis quotient and a significant decrease in the rejection quotient.

Conclusions. This research contributes in the understanding of the long-term impact developmental fluoxetine exposure on the hypothalamus-pituitary-gonadal (HPG) system in adult female offspring.
\end{abstract}

Keywords: SSRIs, serotonin, development, proceptive behavior, receptive behavior, sexual differentiation, hypothalamus, depression, MPOA, reproduction, stress 


\section{Introduction}

A growing number of children are being exposed to selective serotonin reuptake inhibitor (SSRI) medications during the perinatal period (Leung and Kaplan 2009; Oberlander et al. 2006). SSRIs mainly target the serotoninergic system by blocking the serotonin transporter and increasing extracellular serotonin levels (Schloss and Williams 1998). SSRIs are the drug of choice for treating maternal mood disorders (Fleschler and Peskin 2008). However, these medications cross to the fetus, via the placenta, and are present in breast milk; consequently affecting offspring development (Kristensen et al. 1999). Although chronic SSRI treatment often has minimal side effects on the mother, recent research suggests long-term implications on neurodevelopment of offspring (Ansorge et al. 2004; Homberg et al. 2010; Pawluski 2011; Pawluski et al. 2012b; Rayen et al. 2013; Rayen et al. 2011).

The effect of SSRIs on neurodevelopment is perhaps not surprising as serotonin (5HT) plays a key role in brain development. Through the activation of 5-HT receptors, serotonin modulates processes such as cell division, differentiation, migration, and synaptogenesis (Azmitia 2001; Lipton and Kater 1989). For example, serotonin binds with the 5HT1A and 5HT2A receptors to control the neuronal morphology and apoptosis (Azmitia 2001). It has also been shown that over-activation of several 5HT receptors leads to irreversible changes in the maturation of some brain circuits, such as the thalamocortical and retinotectal pathways (Gaspar et al. 2003). Thus, altering serotonin levels, via SSRI exposure, may affect crucial developmental processes and physiological systems.

Serotonin is also a major neurotransmitter implicated in the control of sexual behavior during adulthood. Fibers originating from the serotoninergic-synthesizing cells in the dorsal raphe strongly innervate the medial preoptic area (MPOA), the bed nucleus of the stria terminalis (BST) and the anteroventral periventricular nucleus (AVPv) (Phelix et al. 1992; Simerly et al. 1985a). In addition, serotonin plays a key role in sexual differentiation through its role in the development of the hypothalamic-pituitary-gonadal (HPG) axis (Dohler et al. 1991; Jarzab and Dohler 1984). Postnatal stimulation of serotonin synthesis, by injection of L-tryptophan, results in an inhibition of female sexual behavior, without affecting the pattern of gonadotropin release (Dohler et al. 1991; Jarzab and Dohler 1984). Serotonin has also been shown to have an inhibitory effect on postnatal 'organization' of female sexual behavior as well as on 'activation' of female sexual behavior in adulthood (Dohler et al. 1991; Jarzab and 
Dohler 1984). In addition, a defeminization of sexually dimorphic brain structures in females has been shown upon stimulation of the serotonin synthesis (Wilson et al. 1986).

Although little work has been done on the effects of perinatal exposure to SSRIs on reproduction and sexual behavior in general, recent preclinical research has shown that developmental exposure to SSRIs may have a long-term impact on sexual behavior in male offspring (Maciag et al. 2006a; Maciag et al. 2006b; Rayen et al. 2013; Soga et al. 2012). This research shows that male offspring exposed to the SSRI, citalopram, during the postnatal period show inhibition of sexual behavior (Maciag et al. 2006a; Maciag et al. 2006b). We have also shown that maternal fluoxetine exposure significantly decreases sexual performance in adult male offspring by decreasing the number of intromissions and time to first ejaculation (Rayen et al. 2013). However, these effects were not evident in offspring exposed to maternal adversity, which may more precisely model the clinical situation (Rayen et al. 2013). This previous work highlights the impact of SSRIs on the development of the HPG in male offspring. To date, no research has investigated the developmental impact of perinatal SSRI exposure on the HPG in female offspring.

The aim of the current study was to determine how developmental fluoxetine exposure, a frequently used SSRI during gestation, affects reproductive behaviors in adult female offspring. In addition, to better model the clinical situation, we used a model of maternal adversity. To do this, dams were stressed during pregnancy, which has been shown to model maternal depression during the postpartum period (O'Mahony et al. 2006; Smith et al. 2004), and offspring were exposed to fluoxetine during the postnatal period, a time when neural development in rat offspring is similar to neural development during the $3^{\text {rd }}$ trimester in humans (Romijn et al. 1991). Using this paradigm, we investigated the long-term effect of fluoxetine via maternal exposure, on sexual behavior and the sexually differentiated brain regions, including the $\mathrm{AVPv}$, the posterior bed nucleus of the stria terminalis (pBST), and the sexually dimorphic nucleus of the preoptic area (SDN-POA) in adult female offspring. Sexual dimorphism of specific brain regions is established in the early postnatal period by the action of gonadal steroids and is modulated by the action of neurotransmitters such as serotonin (Dorner et al. 1987; Jarzab and Dohler 1984). Thus, we expected that early exposure to SSRI medication may markedly affect sexual behavior and brain sexual differentiation in adult female offspring. 


\section{Methods}

Animals. Twenty-one adult female Sprague-Dawley rats (250-300g; Charles River Laboratories, France) were used in the present study. Rats were kept under standard laboratory conditions in a 12h:12h light/dark schedule (lights on at $0700 \mathrm{~h}$ ), housed in pairs in clear polyutherane bins $(48 \mathrm{~cm} \times 27 \mathrm{~cm} \times 20 \mathrm{~cm})$ with ad libitum access to rat chow (Sniff) and tap water. All experiments were approved by the Animal Ethics Board of Maastricht University in accordance with Dutch governmental regulations (DEC 2010-150). All efforts were made to minimize the pain and stress levels experienced by the animals.

For breeding, 1 female was paired with 1 male in a wire mesh cage until release of a vaginal plug. The day of plug release was considered gestation day (GD) 1. On GD 15, dams were assigned to stress or control groups at random. Dams in the stress group were individually placed into restrainers in transparent plastic cylinders under bright light three times daily for $45 \mathrm{~min}$ (between 8-10am, 12-2pm, 4-6pm) on GD15-20 and twice on GD21 as previously described (Pawluski et al. 2012a; Pawluski et al. 2012b; Rayen et al. 2013; Rayen et al. 2011; Van den Hove et al. 2005). This time period during pregnancy is when stress can result in postpartum depressive-like behavior in the dam (O'Mahony et al. 2006; Smith et al. 2004) and, as there has yet to be an adequate model of antepartum depression, this paradigm was used as previously done (Pawluski et al. 2012b; Rayen et al. 2013; Rayen et al. 2011). On postpartum day 1 (birth day = P0), litters were culled to five males and five females, followed by the at random assignment of dams (with offspring) to either fluoxetine treatment $(5 \mathrm{mg} / \mathrm{kg} /$ day $)$ or vehicle treatment. A total of four groups of dams were obtained: 1) Control + Vehicle (CV), 2) Control + Fluoxetine (CF), 3) Prenatal Stress + Vehicle (PSV), and 4) Prenatal Stress + Fluoxetine (PSF). Weaning occurred on postpartum day 21 and offspring were housed in litter groups in clear polyutherane bins $(48 \mathrm{~cm} \times 27 \mathrm{~cm} \times 20 \mathrm{~cm})$.

Offspring were initially housed in litter groups after weaning and beginning on postpartum day 31-35 they were housed per sex (four animals/cage) and on postpartum day $45-49$ they were housed in pairs in clear polyurethane bins $(48 \mathrm{~cm} \times 27 \mathrm{~cm}$ x $20 \mathrm{~cm})$. A maximum of 2 female offspring per litter were used in the following groups 1) CV, 2) $\mathrm{CF}, 3$ ) PSV and 4) PSF ( $n=10-12$ /group). Only female offspring were used in the present study. Male offspring were used in additional work reported elsewhere (Rayen et al. 2013).

Adult female offspring were investigated for locomotor activity ( $\mathrm{n}=10-12$ /group) and sex behavior testing ( $\mathrm{n}=10-12$ /group) as stated below. Five days after testing female offspring were deeply anesthetized, weighed and sacrificed via transcardial perfusion. For 
immunohistochemical analyses of the AVPv, BST and SDN-POA a subset of female offspring were used ( $n=5-7 /$ group), with a maximum of two females being used from each litter. Fluoxetine treatment to dams. Fluoxetine treatment was administered to the dam via osmotic minipumps (Alzet Osmotic pumps, 2ML4, Charles River, the Netherlands) for four weeks, beginning on postpartum day 1 . It has been shown that fluoxetine, and its active metabolite norfluoxetine, are present in breast milk and can pass to offspring through lactation (Homberg et al. 2010). Therefore, this mode of administration was chosen instead of repeated injections or oral gavage to pups in order to prevent stress. In addition, minipumps have successfully been used during the postpartum period (Gentile et al. 2007; Pawluski et al. 2012a; Pawluski et al. 2012b; Rayen et al. 2013; Rayen et al. 2011). Minipump implants were filled with either fluoxetine (Fagron, Belgium) dissolved in vehicle (50\% propylenediol in saline; $5 \mathrm{mg} / \mathrm{kg} /$ day), or with vehicle as previously described (Pawluski et al. 2012a; Pawluski et al. 2012b; Rayen et al. 2013; Rayen et al. 2011). Minipumps were implanted subcutaneously in the dorsal region on postpartum day 1 , while the dams were under mild isofluorane anesthesia. Implants took a maximum of 20 minutes and offspring were separated from their mother for a maximum of 20 minutes. It should be noted that fluoxetine exposure to the pups occurred at a time period in neural development analogous to human neural development during the third trimester (Romijn et al. 1991).

Previous work we have done in rats, using a similar paradigm of fluoxetine administration to the dam, has shown that fluoxetine and its active metabolite, norfluoxetine are present in the serum of rat pups (Knaepen et al. 2013). Fluoxetine and norfluoxetine have also been detected in human breastmilk (Berle and Spigset 2011; Berle et al. 2004; Kim et al. 2006; Kristensen et al. 1999). In humans, there have been discrepancies about the levels of SSRIs in breastmilk and these discrepancies are likely due to many factors such as the halflife and lipid solubility of the SSRI as well as time of sampling during feeding (Kristensen et al. 1999).

Locomotion and habituation. Locomotor activity was tested in adult female offspring (P92103) to determine if developmental fluoxetine exposure or maternal stress had any gross effects on locomotor activity and to habituate each animal to the testing chamber used for sexual behavior testing (Maciag et al. 2006b; Prut and Belzung 2003; Rayen et al. 2011). In this test, each female offspring was individually placed in a transparent glass chamber $(50 \mathrm{~cm}$ x $25 \mathrm{~cm} \times 30 \mathrm{~cm}$ ) once for 15 minutes, once between $0830 \mathrm{~h}$ and $1230 \mathrm{~h}$. The chamber was cleaned with $70 \%$ ethanol and dried between rats. All sessions were recorded and an 
experimenter blind to conditions scored the distance travelled using a video-tracking system (Anymaze, Stoelting).

Sexual behavior. Approximately one week after habituation (P103-111), sexual behavior of adult female offspring was tested in a transparent glass chamber $(50 \mathrm{~cm} \times 25 \mathrm{~cm} \times 30 \mathrm{~cm})$ as previously described (Cameron et al. 2008; Guptarak et al. 2010). For testing sexual behavior, vasectomized males (VAS) (Charles River, France) were used as a stimulus. VAS males were made sexually experienced by placing them with a primed stimulus OVX female on two separate prior occasions.

For sex testing, intact virgin female offspring were hormonally primed to bring them into behavioral estrus as previously described (Snoeren et al. 2011). Briefly, female offspring were injected 36 hours prior to testing with estradiol benzoate $(50 \mu \mathrm{g} / 0.2 \mathrm{ml}$ sesame oil, s.c.) (Snoeren et al. 2011). For testing, females were paired with a VAS male once for 45 minutes. All sessions were videotaped and scored by an experimenter blind to conditions. The chamber was cleaned between each session with $70 \%$ ethanol and dried between rats. Testing took place between $0800 \mathrm{~h}$ and noon. The following behaviors were scored during the test: time to the first mount by the VAS male, number of ear wiggles, number of hops and darts, the number of lordoses and the number of rejections. The behaviors were defined as follows: Ear wiggling - rapid oscillatory movements of the ears, which is a consequence of increased tension in the axial muscles; Hops and darts - jump and scatter directly in front of the male; Lordosis - postural reflex with a dorsiflexion of the vertebral column; Rejection - defensive responses like fending, kicking and rolling. Ear wiggling, hops and darts were summed to provide the total number of proceptive behaviors. The lordosis quotient - a measure of sexual receptivity, was calculated by dividing the number of lordoses rated 3 or 4 by the number of mounts (Brandling-Bennett et al. 1999; Mazzucco et al. 2008). The lordosis rating - a measure of the intensity of the lordosis response was calculated by dividing the total lordosis ratings (1-4) by the number of mounts by a male (Brandling-Bennett et al. 1999; Mazzucco et al. 2008). The rejection quotient was calculated by dividing the number of rejections by the number of male mounts (Hardy and Debold 1971; Mazzucco et al. 2008). One female was removed from analyses as she failed exhibit any proceptive or receptive behaviors.

Estrous cycle determination. Prior to sexual behavior testing, adult female offspring were smeared daily for 11-12 days to determine treatment effects on estrus cycle (between 10:00 am and 12:00 am). For smears, a cotton swab dipped in saline solution was placed in the vagina and the substance was smeared on a microscope slide. Slides were examined under 10x objective. The stage of the ovarian cycle was determined by predominance of cell shape: 
proestrus (round nucleated cells), estrus (cornified cells of similar size), metestrus (round nucleated as well as cornified cells, and the much smaller leukocytes), or diestrus (mostly leukocytes) (Parker et al. 2001; Pawluski et al. 2012b).

Anogenital distance. The anogenital distance was measured at sacrifice (P108-116) in adult female offspring as previously described (Dela Cruz and Pereira 2012). The anogenital distance, which is the distance from the anus to the genitals, was measured by use of a vernier-caliper. The relative anogenital distance was determined by dividing the anogenital distance by the cube root of body weight (Gallavan et al. 1999).

Estradiol hormone assay. To investigate whether treatment affects $17 ß$-estradiol levels in adult female offspring, blood samples were taken at sacrifice (between 0800h and noon). Blood samples were stored at $4^{\circ} \mathrm{C}$ overnight and centrifuged at $10,000 \mathrm{~g}$ for 10 minutes. Serum was collected and stored at $-80^{\circ} \mathrm{C}$ until analysis. All samples were run in duplicate using a commercially available radioimmunoassay (RIA) kits from MP Biomedicals (MP Biomedicals, Belgium). A $17 \beta$-oestradiol (E2) $\mathrm{I}^{125}$ kit was used for detection of estradiol in female offspring serum. The average intra-coefficient of variation for the assay is $3.28 \%$ for the E2 assay. The lowest detection limit for estradiol was $1.4 \mathrm{pg} / \mathrm{ml}$.

Immunohistochemistry. Five days after sexual behavioral testing, adult offspring were deeply anesthetized (between $0800 \mathrm{~h}$ and noon) with an overdose of pentobarbital, weighed, and transcardially perfused with saline, followed by $4 \%$ paraformaldehyde. Brains were post-fixed in $4 \%$ paraformaldehyde for 24 hours, cryoprotected in 30\% sucrose/phosphatebuffered saline solution for up to one week, frozen on dry ice and kept at $-80^{\circ} \mathrm{C}$. Brain tissue was sliced in $30 \mu \mathrm{m}$ sections on a cryostat (Leica). Tissue was stored in antifreeze solution and maintained at $-15^{\circ} \mathrm{C}$. The number of tyrosine hydroxylase positive cells in the AVPv, was assessed. Every $6^{\text {th }}$ section throughout the AVPv was stained for TH-immunoreactivity as previously described (Simerly et al. 1985a; Simerly et al. 1985b). The volume of the pBST was defined by AR-immunoreactivity. Every $3^{\text {rd }}$ section throughout the brain was stained as previously described (Bakker et al. 1997). The area of the SDN-POA was measured by using calbindin-immunoreactivity. Every $3^{\text {rd }}$ section throughout the brain was stained as previously described (Pei et al. 2006). Mouse anti-TH (1:1000; ImmunoStar), rabbit anti-AR (1:250; Santa Cruz Biotechnology), and mouse anti-calbindin (1:15000; Sigma) monoclonal primary antibodies were used and biotinylated goat anti-mouse (1:400; Dako), biotinylated goat-anti rabbit (1:500; Dako) and biotinylated donkey anti-mouse (1:500; Jackson ImmunoResearch) secondary antibodies were used, respectively. Brain 
sections were further processed by using the avidine-biotine complex (ABC Elite kit; 1:1000; Vector laboratories) and DAB (3,3-diaminobenzidine; Sigma).

The number of TH immunoreactive (-ir) cells in the AVPv were counted under 40x objective with water as previously described (Patisaul et al. 2006). The area of the SDNPOA, the volume of the pBST, and the area of the AVPv was measured under 10x objective using StereoInvestigator software (MicroBrightField, Williston, VT, USA) and estimates of pBST volumes were made according to Cavalieri's principle (Gundersen et al. 1988). For representative photomicrographs see Fig. 1.
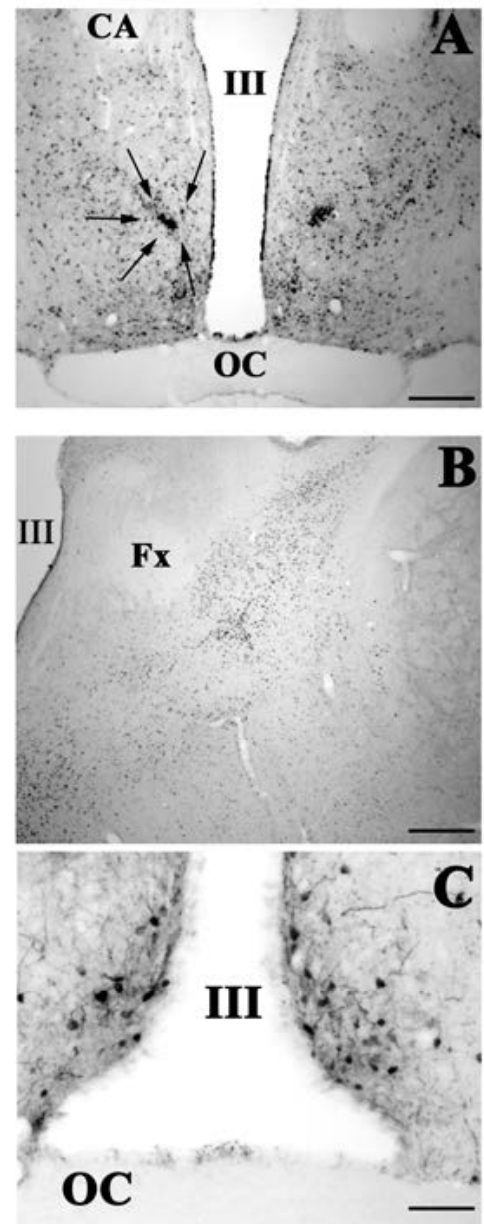

Figure 1. Photomicrographs of (A) calbindin-ir cells in SDN-POA, highlighted by the arrows, (B) AR-ir cells in pBST (lateral to the fornix) and MPOA (lateral to the ventricle) and (C) AVPv containing TH-ir cells. CA, anterior commissure; III, third ventricle; OC, optic chiasma; FX, fornix. Magnification bar is 120 um 
Statistical analysis. Analysis of variance tests (ANOVA) were performed on locomotion, sexual behaviors, estrus cycle, anogenital distance, weight at sacrifice, estradiol levels, number of TH-immunoreactive cells in the AVPv, the volume of the pBST, and the areas of the SDN-POA and AVPv in adult female offspring, with condition (prenatal stress/no stress) and treatment (fluoxetine/vehicle) as independent factors. Pearson product moment correlations were conducted between sexual behavior, anogenital distance, estradiol levels, number of TH-immunoreactive-cells in the AVPv, volume of the pBST and areas of the SDN-POA and AVPv. Any differences in age, weight, time of testing or test order of the litter, were accounted for, where appropriate, via an analysis of covariance. When necessary, data distributions were normalized using log transformations (this was done for proceptive behaviors). Posthoc comparisons utilized the Fisher LSD test. Significance was set at $\mathrm{p} \leq .05$.

\section{Results}

Female sexual behavior. Fluoxetine-exposed female offspring made significantly more proceptive behaviors than non-exposed female offspring (main effect of fluoxtetine: $\mathrm{F}(1,36)=4.13, \mathrm{p}=.049$; Fig 2a). Fluoxetine-exposed female offspring had a higher lordosis quotient compared to vehicle-exposed offspring (main effect of fluoxetine: $(F(1,36)=3.98$, p $=.05$; Fig. 2b). There was also a tendency for fluoxetine-exposed females to have a higher lordosis rating compared to vehicle exposed females (main effect of fluoxetine: $(F(1,36)=3.43, p=.07$; Fig. $2 c)$. For the rejection quotient, there was a significant main effect of fluoxetine $(\mathrm{F}(1,36)=5.47, \mathrm{p}=.03$; Fig. 2d), with fluoxetine-exposed female offspring having a significantly lower rejection quotient compared to vehicle-exposed female offspring. There were no other significant main effects or interaction effects of stress and fluoxetine on measures of sexual receptivity $(.18 \leq \mathrm{p} \leq .70)$. 

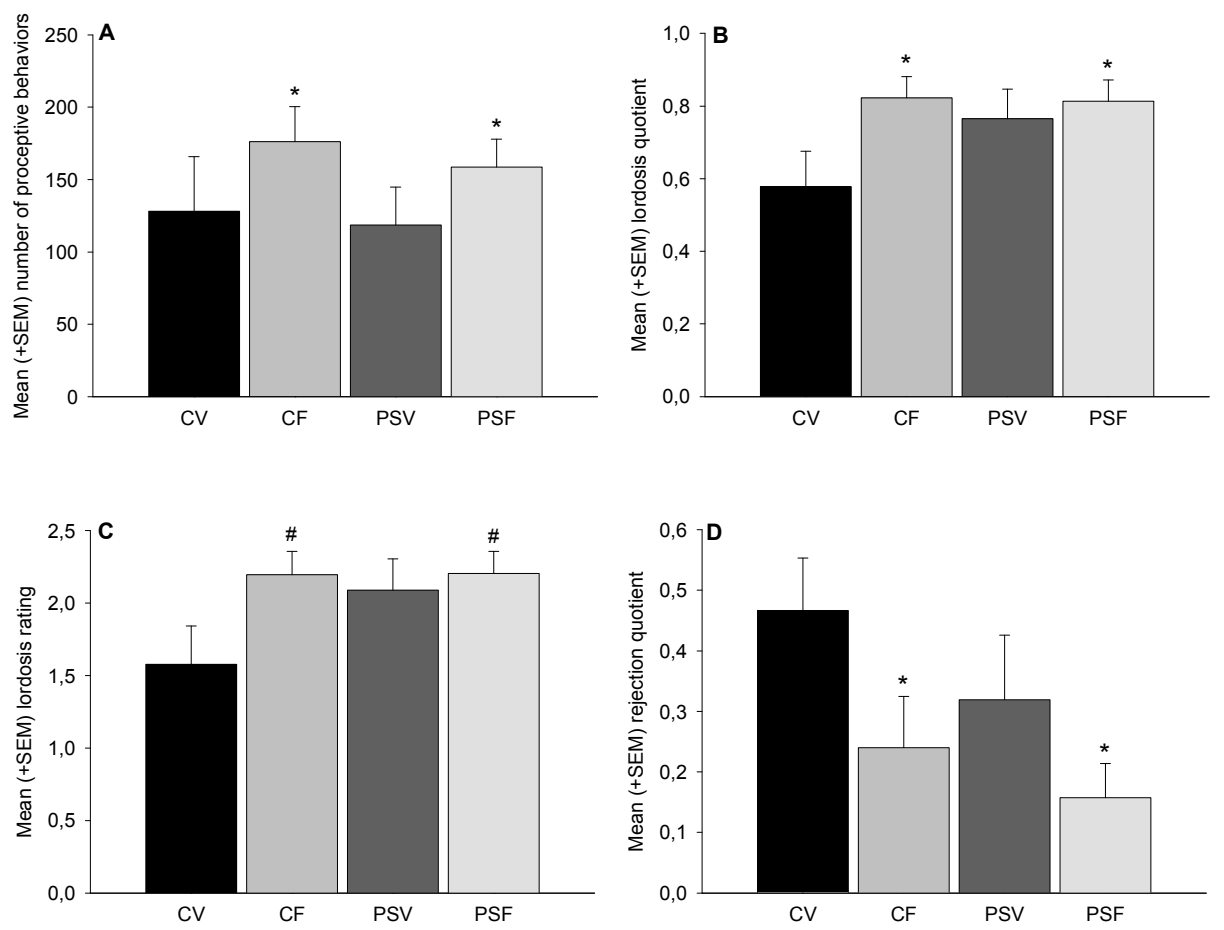

Figure 2. Mean ( \pm SEM) a) proceptive behaviors, b) lordosis quotient, c) lordosis rating, and d) rejection quotient. Fluoxetine-exposed female offspring a) made significantly more proceptive behaviors $(p=.049)$ b) had a significantly higher lordosis quotient $(p=.05)$, c) tended to have a higher lordosis intensity rating $(p=.06)$ and $d)$ had a significantly lower rejection quotient compared to vehicle-exposed female offspring (p=.03). '*'denotes significantly different from CV and PSV female offspring, '\#'denotes tendency to be different from CV and PSV female offspring. (n=9-12/group). $\mathrm{CV}=$ Control + Vehicle, $\mathrm{CF}=\mathrm{Control}+$ Fluoxetine, $\mathbf{P S V}=$ Prenatal Stress + Vehicle, and PSF $=$ Prenatal Stress + Fluoxetine

For specific proceptive behaviors, fluoxetine-exposed adult female offspring tended to make more hops and darts than vehicle-exposed offspring $(\mathrm{p}=.06$; Table 1$)$. There were no significant main or interaction effects for the time to first mount by VAS male or ear wiggling $(.10 \leq \mathrm{p} \leq .94$; Table 1$)$. 
Table 1. Mean $( \pm$ SEM) time to the first mount by VAS male, bouts of ear wiggling and number of hops and darts. There was a tendency toward a significant main effect of fluoxetine on number of hops and darts $(p=.06) . \mathrm{CV}=$ Control + Vehicle, $\mathrm{CF}=$ Control + Fluoxetine, $\mathrm{PSV}=$ Prenatal Stress + Vehicle, and PSF $=$ Prenatal Stress + Fluoxetine

\begin{tabular}{lcccc}
\hline & CV & CF & PSV & PSF \\
\hline Time to first mount (sec) & $124.60 \pm 68.40$ & $77.30 \pm 26.41$ & $65.11 \pm 17.95$ & $32.42 \pm 6.26$ \\
Ear wiggling & $5.80 \pm 2.64$ & $14.00 \pm 3.47$ & $13.89 \pm 3.47$ & $15.50 \pm 3.56$ \\
Hops and darts & $121.67 \pm 35.36$ & $162.10 \pm 22.99$ & $104.78 \pm 23.86$ & $143.33 \pm 16.64$
\end{tabular}

Anogenital distance. There was a significant main effect of stress on the relative anogenital distance $(\mathrm{F}(1,38)=4.2171, \mathrm{p}=.047$; Fig. 3), with prenatally stressed female offspring having a lower relative anogenital distance compared to non stressed female offspring.

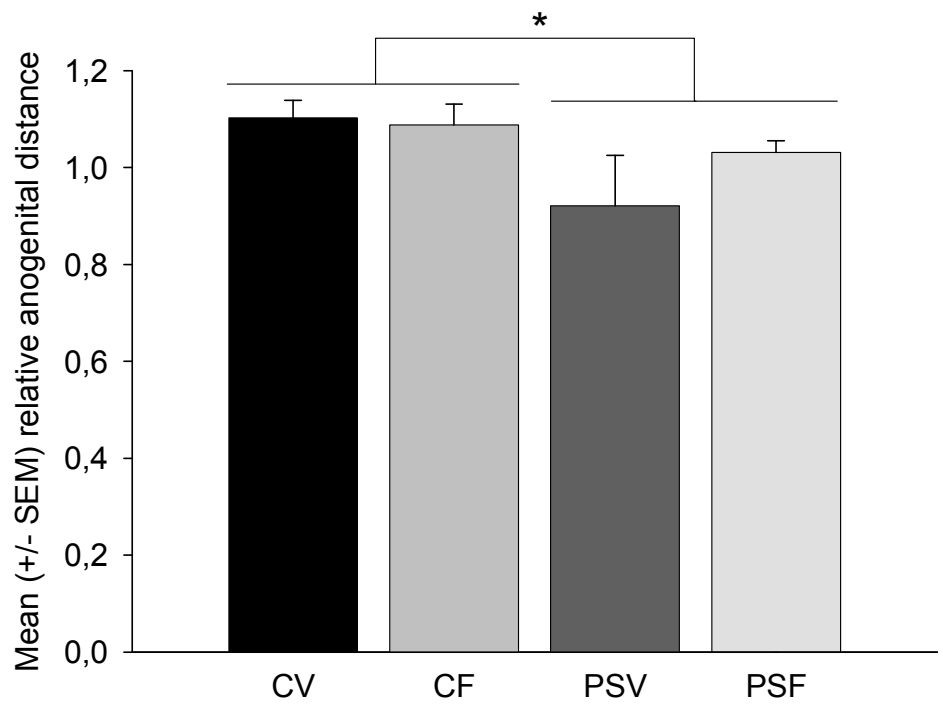

Figure 3. Mean $( \pm$ SEM) of the relative anogenital distance (anogenital distance/root cube of body weight) in female offspring. PSV and PSF female offspring had a significantly lower relative anogenital distance compared to $\mathrm{CV}$ and $\mathrm{CF}$ female offspring $(\mathrm{p}=.047)$. '*'denotes significantly different. (n=10-12/group). $\mathrm{CV}=$ Control + Vehicle, $\mathbf{C F}=$ Control + Fluoxetine, $\mathrm{PSV}=$ Prenatal Stress + Vehicle, and PSF $=$ Prenatal Stress + Fluoxetine

\section{Locomotor activity, estradiol levels, estrous cycle and brain immunohistochemistry}

There were no significant main or interaction effects of stress or fluoxetine on locomotion, weight at sacrifice (Table 2), serum estradiol levels at sacrifice (Table 2), time spent in estrus, proestrus, metestrus and diestrus (Table 2), the area and the total number of TH-ir cells of the AVPv, the volume of the pBST or the area of the SDN-POA $(.098 \leq \mathrm{p} \leq .989$; Table 3$)$. 
Table 2. Mean $( \pm$ SEM) distance travelled $(\mathrm{m})$, weight at sacrifice $(\mathrm{g})$, serum estradiol levels $(\mathrm{pg} / \mathrm{ml})$ at time of sacrifice and percent of time spent in estrus, proestrus, metestrus and diestrus. $\mathrm{CV}=\mathrm{Control}+$ Vehicle, $\mathbf{C F}=$ Control + Fluoxetine, PSV $=$ Prenatal Stress + Vehicle, and PSF $=$ Prenatal Stress + Fluoxetine

\begin{tabular}{lcccc}
\hline & CV & CF & PSV & PSF \\
\hline Distance travelled (m) & $22.06 \pm 2.36$ & $19.75 \pm 1.66$ & $24.69 \pm 1.31$ & $22.22 \pm 1.45$ \\
Weight (g) & $283.32 \pm 9.62$ & $288.55 \pm 5.61$ & $293.38 \pm 5.23$ & $287.96 \pm 5.72$ \\
Estradiol (pg/ml) & $5.59 \pm 1.05$ & $4.75 \pm 1.70$ & $4.09 \pm 0.78$ & $6.31 \pm 1.21$ \\
Estrus (\%) & $12.42 \pm 3.93$ & $7.27 \pm 2.97$ & $15.24 \pm 4.47$ & $17.42 \pm 3.62$ \\
Proestrus (\%) & $24.52 \pm 6.25$ & $23.52 \pm 3.40$ & $19.16 \pm 3.57$ & $18.94 \pm 3.06$ \\
Metestrus (\%) & $22.12 \pm 3.68$ & $19.88 \pm 1.51$ & $19.93 \pm 3.56$ & $21.97 \pm 2.61$ \\
Diestrus (\%) & $40.71 \pm 3.32$ & $49.33 \pm 5.95$ & $45.66 \pm 9.82$ & $41.67 \pm 5.42$ \\
\hline
\end{tabular}

Table 3. Mean $\left( \pm\right.$ SEM) area $\left(\mathrm{mm}^{2}\right)$ of TH-ir in AVPv, total number of TH-ir cells in AVPv, volume $\left(\mathrm{mm}^{3}\right)$ of AR-ir in BST, and area $\left(\mu \mathrm{m}^{2}\right)$ of calbindin-ir in SDN-POA in female offspring. TH $=$ tyrosine hydroxylase, $A V P v=$ anteroventral periventricular nucleus, $A R=$ androgen receptor, $\mathrm{pBST}=$ posterior bed nucleus of the stria terminalis, and SDN-POA = sexually dimorphic nucleus of the preoptic area, $\mathrm{CV}$ $=$ Control + Vehicle, $\mathbf{C F}=$ Control + Fluoxetine, $\mathbf{P S V}=$ Prenatal Stress + Vehicle, and PSF $=$ Prenatal Stress + Fluoxetine

\begin{tabular}{lcccc}
\hline & CV & CF & PSV & PSF \\
\hline AVPv area $\left(\mathbf{m m}^{\mathbf{2}}\right)$ & $0.180 \pm 0.034$ & $0.187 \pm 0.038$ & $0.190 \pm 0.016$ & $0.185 \pm 0.016$ \\
TH-ir cells (AVPv) & $185 \pm 88$ & $299 \pm 41$ & $222 \pm 18$ & $199 \pm 50$ \\
pBST Volume $\left(\mathbf{m m}^{\mathbf{3}}\right)$ & $0.202 \pm 0.051$ & $0.273 \pm 0.055$ & $0.259 \pm 0.047$ & $0.248 \pm 0.047$ \\
SDN-POA Area $\left(\boldsymbol{\mu m}^{2}\right)$ & $17414.6 \pm 1808.3$ & $14713.7 \pm 1532.1$ & $14659.8 \pm 2081.2$ & $16152.9 \pm 2070.5$ \\
\hline
\end{tabular}

\section{Discussion}

To our knowledge, findings of the present study are the first to show that developmental fluoxetine exposure facilitates proceptive and receptive behaviors in female offspring by a significant increase in the number of proceptive behaviors and the lordosis quotient, as well as a significant decrease in the rejection quotient. Interestingly, we did not find marked effects of developmental fluoxetine exposure or maternal adversity on the size of the sexually differentiated brain areas investigated (AVPv, pBST, and SDN-POA).

Developmental fluoxetine exposure facilitates sexual behavior in female offspring. In the present study we show that developmental exposure to fluoxetine, a popular SSRI, facilitates sexual behavior of female offspring, but did not affect estrous cyclicity. Previous research has shown that the actions of serotonin on sexual differentiation in the developing female are dependent on the timing of the serotonergic manipulations and often show a down regulation 
of female sexual behavior if the serotoninergic system is manipulated during the first week of life. For example, stimulation of serotonin synthesis by injection of L-tryptophan on postnatal days 1-7, results in an inhibition of female lordosis behavior (Dohler et al. 1991; Jarzab and Dohler 1984) and treatment with p-chlorophenylalanine (PCPA), a serotonin synthesis inhibitor, between postnatal days 1 to 7 reduces ear wiggling (Wilson et al. 1986). In addition, 5-hydroxytryptophan (5HTP), a serotonin precursor, administered on postnatal days 1 to 7 to female offspring, stimulates male-type behavior by reducing the latency to the first mount made by the female (Wilson et al. 1986).

Our present findings expand this previous work by showing that continual exposure to the SSRI, fluoxetine, during postnatal days 1-21, via suckling, increases proceptivity and receptivity in adult female offspring. This suggests that the timing of exposure to increased serotonin levels is important for the effect on female sexual behavior. Interestingly, sex differences in brain serotonin levels appear between days 11 and 16 of life, suggesting that manipulation of the serotonin levels during this period has a different effect on male and female sexual behavior (Jarzab and Dohler 1984; Wilson et al. 1986). Given our present data and recent data in male offspring (Harris et al. 2012; Maciag et al. 2006a; Maciag et al. 2006b; Maciag et al. 2006c; Rayen et al. 2013), it is likely that an increase in 5HT levels during this period of development, via SSRI exposure, has a feminizing effect on the brain, while decreases in 5HT levels have a masculizing effect. More research is needed to determine whether this idea holds true and the mechanisms behind the effects of developmental SSRIs exposure on the HPG system in both males and females.

Studies in adult females treated with fluoxetine have shown effects on sexual behavior and the estrous cycle (Sarkar et al. 2008b; Uphouse et al. 2006). For example, acute, subchronic, and chronic treatment of fluoxetine (given i.p) to adult female rats leads to a reduction in lordosis behaviors (Adams et al. 2012; Maswood et al. 2008; Matuszczyk et al. 1998; Sarkar et al. 2008a; Sarkar et al. 2008b; Uphouse et al. 2006). Furthermore, subchronic and chronic treatments have also resulted in a decrease in proceptive behaviors such as hops and darts (Maswood et al. 2008; Sarkar et al. 2008b). These effects on sexual behavior were evident in both cycling and primed ovariectomized rats with varying doses of fluoxetine, ranging from $5 \mathrm{mg} / \mathrm{kg}$ to $20 \mathrm{mg} / \mathrm{kg}$ (Adams et al. 2012; Maswood et al. 2008; Matuszczyk et al. 1998; Sarkar et al. 2008a; Sarkar et al. 2008b; Uphouse et al. 2006). With regards to cyclicity, there have been mixed results with repeated injections of fluoxetine $(10 \mathrm{mg} / \mathrm{kg} / \mathrm{day})$ resulting in a blockage of the estrus phase of the cycle (Sarkar et al. 2008b), however, others have shown that this does not occur (Maswood et al. 2008; Matuszczyk et al. 1998). This 
may be depending on the strain of the rat used (Maswood et al. 2008; Matuszczyk et al. 1998).

In the present study we found that development exposure to fluoxetine facilitates sexual behavior in adult female offspring, which is opposite to the effects of fluoxetine when it is administered to adult females. This shows both an organizational and activational effect of fluoxetine on female sexual behavior. Although the actions of SSRI medications are to increase the amount of serotonin at the synaptic cleft, SSRI exposure during the perinatal period appears to reduce the function of the serotoninergic system during development (Maciag et al. 2006b; Weaver et al. 2010). This is likely due to compensatory mechanisms during development which are permanent and leave to low serotoninergic activity during adulthood. This provides an explanation for why the timing of fluoxetine treatment differentially affects female sexual behavior.

Although this is the first study, to our knowledge, to investigate the effects of SSRI exposure on sexual behavior in female offspring, previous research has documented a long term impact of perinatal antidepressant medication exposure on sexual behavior in male offspring. We have recently shown that developmental fluoxetine exposure, in the absence of exposure to prenatal stress, demasculinized sexual behavior in male offspring, by a strong tendency in the reduced number of mounts, a significant decrease in number of intromissions, a longer latency to intromit, and a longer latency to first ejaculation (Rayen et al. 2013). Other research has shown that neonatal exposure to the tricyclic antidepressant, clomipramine (15 mg/kg, s.c., twice daily), in male rats leads to diminished sexual behavior, including decreases in mounting, intromission and ejaculatory behavior (Vogel et al. 1990). Further research has shown that postnatal injection of citalopram results in impaired mounting behavior and a decrease in the number of intromissions and ejaculations in adult male offspring (Maciag et al. 2006b; Weaver et al. 2010). However, it should be noted that developmental fluoxetine exposure did not have a significant effect on sexual behavior of male offspring when using a model of maternal adversity, which arguably is a more appropriate model of the clinical situation.

Developmental SSRI exposure has a very different effect on sexual behavior in male and in female offspring. While developmental fluoxetine exposure inhibits, and therefore demasculinizes, sexual behavior in males in the absence of maternal stress (Rayen et al. 2013), it facilitates sexual behavior in females regardless of maternal stress exposure (present study). Our findings, and those of others, on the effects of developmental antidepressant exposure support the hypothesis that increases in 5HT levels during the second week 
postnatal have a feminizing effect, while decreases in 5HT levels have a masculinizing effect, on sexual behavior (Wilson et al. 1986).

Although sex difference comparisons are limited in the literature, previous work has noted some sex differences in relation to developmental SSRI exposure on other aspects of neurobehavioral outcomes besides sexual behavior. Recent research has found that citalopram exposure to male and female rat offspring during the 2 nd and 3 rd postnatal weeks significantly reduced the density of the 5HT transporter (SERT) fibres in the olfactory bulb of adult male, but not female, offspring (Zhang et al. 2013). Developmental SSRI exposure also reduces juvenile play in male, but not female offspring (Simpson et al. 2011), and increases anxiety-like behavior in young male, but not young female, rat offspring (Rayen et al. 2011; Simpson et al. 2011). Perinatal fluoxetine exposure has also been shown to increase immobility in female, but not male, mouse offspring (Lisboa et al. 2007).

Prenatal maternal stress alters anogenital distance. Here we show that prenatal stress, regardless of developmental fluoxetine exposure, decreases the relative anogenital distance in female offspring. Although there is limited research in this area, we have previously found that prenatal stress did not alter the anogenital distance of juvenile female offspring (Rayen et al. 2013). Therefore, it is likely that reductions in anogenital distance, after exposure to prenatal stress, arise later during the process of sexual differentiation, such as at puberty, and persist in adulthood.

We did not find a significant effect of prenatal maternal stress on estrous cyclicity. This is in agreement with previous research showing that prenatal restraint stress does not affect female cyclicity (Beckhardt and Ward 1983). However, others have reported that prenatal stress increases the length of the estrous cycle by extending the estrus-metestrus stage (Herrenkohl and Politch 1978) and that exogenous corticosterone treatment during gestation results in an increased incidence of diestrus in female offspring (Harvey and Chevins 1985).

We also did not find a marked effect of prenatal stress on sexual behavior in female offspring. Previous findings in this area of research vary with females prenatally exposed to immobilization stress having an increase in the lordosis response (Gutierrez et al. 1989) and others reporting that prenatal restraint stress results in a lower incidence and intensity of lordosis in female offspring (Frye and Orecki 2002). Any discrepancies between our work and others with regards to female sexual behavior may be due to different stress paradigms, 
the timing of the stressor and the species involved. Clearly more research is needed on the exact role of prenatal stress in altering sexual behavior in female offspring.

\section{Developmental exposure to fluoxetine and sexually differentiated brain areas in adult}

female offspring. In the present study we found no marked effect of developmental fluoxetine exposure or prenatal maternal stress on the SDN-POA, pBST or AVPv. Manipulation of the serotoninergic system has been shown to alter the SDN-POA. For example, postnatal administration of L-tryptophan, but also PCPA, during the first week of life, increases the volume of the SDN-POA in the female rat offspring (Dohler et al. 1991). It remains unexplained why a stimulator and an inhibitor of serotonin synthesis exert the same effect on SDN-POA morphology. Discrepancies between this and our work can be explained in the way that serotonin levels were manipulated and the timing of the treatments. For example, in this study offspring were exposed to fluoxetine between postnatal days 1-21 via suckling whereas previous work injected L-tryptophan directly to pups during the postnatal period (Dohler et al. 1991). Sex differences in brain serotonin levels arise between postnatal days 11 and 16, suggesting that manipulation of the serotonin levels during this period has a different effect on female sexual behavior and probably sexual differentiation of the brain (Jarzab and Dohler 1984; Wilson et al. 1986).

It has been shown that prenatal stress can alter the morphology of MPOA neurons in adult female offspring (Martinez-Tellez et al. 2009). Cytoarchitectural changes, such as reduced primary dendritic branch number and reduced length of basal dendrites, are also reported after exposure to prenatal stress in female offspring (Gerecke et al. 2011). To our knowledge, no research has investigated the effects of prenatal stress or prenatal exposure to glucocorticoids on the pBST or AVPv in female offspring.

Although we did not find an effect of developmental fluoxetine exposure or prenatal maternal stress on the SDN-POA, pBST or AVPv, it is possible that changes exist at the cytoarchitectural level of these sexually dimorphic structures. For example, differences may exist in the density of dopaminergic fibers in the AVPv, since dopamine plays a role in the control of gonadotropin secretion in the AVPv (Simerly et al. 1985a). Therefore, it is important to determine at which level changes occur, in response to treatment, and whether these changes mediate the alterations in female sexual behavior. As such, the mechanisms behind the behavioral changes can be elucidated. 
Chapter 6

\section{Conclusion}

Our research has shown that developmental exposure to SSRIs has long-term effects on reproductive behaviors in female offspring. Here we show that developmental fluoxetine exposure facilitates proceptive and receptive behaviors in the adult female, by increasing the number of proceptive behaviors and the lordosis quotient as well as decreasing the rejection quotient. Clearly developmental exposure to SSRI medications has a long-term impact on reproduction in female offspring. However, the exact mechanisms responsible for these alterations have yet to be determined. 


\section{References}

Adams S, Heckard D, Hassell J, Uphouse L (2012) Factors influencing fluoxetine-induced sexual dysfunction in female rats. Behav Brain Res 235: 73-81

Ansorge MS, Zhou M, Lira A, Hen R, Gingrich JA (2004) Early-life blockade of the 5-HT transporter alters emotional behavior in adult mice. Science 306: $879-81$

Azmitia EC (2001) Modern views on an ancient chemical: serotonin effects on cell proliferation, maturation, and apoptosis. Brain Res Bull 56: 413-24

Bakker J, Pool CW, Sonnemans M, van Leeuwen FW, Slob AK (1997) Quantitative estimation of estrogen and androgen receptor-immunoreactive cells in the forebrain of neonatally estrogen-deprived male rats. Neuroscience 77: 911-9

Beckhardt S, Ward IL (1983) Reproductive functioning in the prenatally stressed female rat. Dev Psychobiol 16: 111-8

Berle JO, Spigset O (2011) Antidepressant Use During Breastfeeding. Curr Womens Health Rev 7: 28-34

Berle JO, Steen VM, Aamo TO, Breilid H, Zahlsen K, Spigset O (2004) Breastfeeding during maternal antidepressant treatment with serotonin reuptake inhibitors: infant exposure, clinical symptoms, and cytochrome p450 genotypes. J Clin Psychiatry 65: 1228-34

Brandling-Bennett EM, Blasberg ME, Clark AS (1999) Paced mating behavior in female rats in response to different hormone priming regimens. Horm Behav 35: 144-54

Cameron N, Del Corpo A, Diorio J, McAllister K, Sharma S, Meaney MJ (2008) Maternal programming of sexual behavior and hypothalamic-pituitary-gonadal function in the female rat. PLoS One 3: e2210

Dela Cruz C, Pereira OC (2012) Prenatal testosterone supplementation alters puberty onset, aggressive behavior, and partner preference in adult male rats. J Physiol Sci 62: 123-31

Dohler KD, Jarzab B, Sickmoller PM, Kokocinska D, Kaminski M, Gubala E, Achtelik W, Wagiel J (1991) Influence of neurotransmitters on sexual differentiation of brain structure and function. Exp Clin Endocrinol 98: 99-109

Dorner G, Docke F, Gotz F, Rohde W, Stahl F, Tonjes R (1987) Sexual differentiation of gonadotrophin secretion, sexual orientation and gender role behavior. J Steroid Biochem 27: 1081-7

Fleschler R, Peskin MF (2008) Selective serotonin reuptake inhibitors (SSRIs) in pregnancy: a review. MCN Am J Matern Child Nurs 33: 355-61; quiz 362-3

Frye CA, Orecki ZA (2002) Prenatal stress alters reproductive responses of rats in behavioral estrus and paced mating of hormone-primed rats. Horm Behav 42: 472-83

Gallavan RH, Jr., Holson JF, Stump DG, Knapp JF, Reynolds VL (1999) Interpreting the toxicologic significance of alterations in anogenital distance: potential for confounding effects of progeny body weights. Reprod Toxicol 13: 383-90

Gaspar P, Cases O, Maroteaux L (2003) The developmental role of serotonin: news from mouse molecular genetics. Nat Rev Neurosci 4: 1002-12

Gentile S, Rossi A, Bellantuono C (2007) SSRIs during breastfeeding: spotlight on milk-to-plasma ratio. Arch Womens Ment Health 10: 39-51

Gerecke KM, Kishore R, Jasnow A, Quadros-Menella P, Parker S, Kozub FJ, Lambert KG, Kinsley CH (2011) Alterations of sex-typical microanatomy: prenatal stress modifies the structure of medial preoptic area neurons in rats. Dev Psychobiol 54: 16-27

Gundersen HJ, Bagger P, Bendtsen TF, Evans SM, Korbo L, Marcussen N, Moller A, Nielsen K, Nyengaard JR, Pakkenberg B, et al. (1988) The new stereological tools: disector, fractionator, nucleator and point sampled intercepts and their use in pathological research and diagnosis. APMIS 96: 857-81

Guptarak J, Sarkar J, Hiegel C, Uphouse L (2010) Role of 5-HT(1A) receptors in fluoxetine-induced lordosis inhibition. Horm Behav 58: 290-6

Gutierrez J, Alvarez-Ordas I, Rojo M, Marin B, Menendez-Patterson A (1989) Reproductive function and sexual behaviour in female rats exposed to immobilization stress or ACTH injections during gestation. Physiol Bohemoslov 38: 13-20

Hardy DF, Debold JF (1971) Effects of mounts without intromission upon the behavior of female rats during the onset of estrogen-induced heat. Physiol Behav 7: 643-5

Harris SS, Maciag D, Simpson KL, Lin RC, Paul IA (2012) Dose-dependent effects of neonatal SSRI exposure on adult behavior in the rat. Brain Res 1429: 52-60

Harvey PW, Chevins PF (1985) Androstenedione or corticosterone treatment during pregnancy alters estrous cycle of adult female offspring in mice. Experientia 41: 492-4

Herrenkohl LR, Politch JA (1978) Effects of prenatal stress on the estrous cycle of female offspring as adults. Experientia 34: 1240-1

Homberg JR, Schubert D, Gaspar P (2010) New perspectives on the neurodevelopmental effects of SSRIs. Trends Pharmacol Sci 31: 60-5 
Jarzab B, Dohler KD (1984) Serotoninergic influences on sexual differentiation of the rat brain. Prog Brain Res 61: 119-26

Kim J, Riggs KW, Misri S, Kent N, Oberlander TF, Grunau RE, Fitzgerald C, Rurak DW (2006) Stereoselective disposition of fluoxetine and norfluoxetine during pregnancy and breast-feeding. Br J Clin Pharmacol 61: 155-63

Knaepen L, Rayen I, Charlier TD, Fillet M, Houbart V, van Kleef M, Steinbusch HW, Patijn J, Tibboel D, Joosten EA, Pawluski JL (2013) Developmental fluoxetine exposure normalizes the long-term effects of maternal stress on post-operative pain in Sprague-Dawley rat offspring. PLoS One 8: e57608

Kristensen JH, Ilett KF, Hackett LP, Yapp P, Paech M, Begg EJ (1999) Distribution and excretion of fluoxetine and norfluoxetine in human milk. Br J Clin Pharmacol 48: 521-7

Leung BM, Kaplan BJ (2009) Perinatal depression: prevalence, risks, and the nutrition link--a review of the literature. J Am Diet Assoc 109: 1566-75

Lipton SA, Kater SB (1989) Neurotransmitter regulation of neuronal outgrowth, plasticity and survival. Trends Neurosci 12: 265-70

Lisboa SF, Oliveira PE, Costa LC, Venancio EJ, Moreira EG (2007) Behavioral evaluation of male and female mice pups exposed to fluoxetine during pregnancy and lactation. Pharmacology 80: 49-56

Maciag D, Coppinger D, Paul IA (2006a) Evidence that the deficit in sexual behavior in adult rats neonatally exposed to citalopram is a consequence of 5-HT1 receptor stimulation during development. Brain Res 1125: $171-5$

Maciag D, Simpson KL, Coppinger D, Lu Y, Wang Y, Lin RC, Paul IA (2006b) Neonatal antidepressant exposure has lasting effects on behavior and serotonin circuitry. Neuropsychopharmacology 31: 47-57

Maciag D, Williams L, Coppinger D, Paul IA (2006c) Neonatal citalopram exposure produces lasting changes in behavior which are reversed by adult imipramine treatment. Eur J Pharmacol 532: 265-9

Martinez-Tellez RI, Hernandez-Torres E, Gamboa C, Flores G (2009) Prenatal stress alters spine density and dendritic length of nucleus accumbens and hippocampus neurons in rat offspring. Synapse 63: 794-804

Maswood N, Sarkar J, Uphouse L (2008) Modest effects of repeated fluoxetine on estrous cyclicity and sexual behavior in Sprague Dawley female rats. Brain Res 1245: 52-60

Matuszczyk JV, Larsson K, Eriksson E (1998) Subchronic administration of fluoxetine impairs estrous behavior in intact female rats. Neuropsychopharmacology 19: 492-8

Mazzucco CA, Walker HA, Pawluski JL, Lieblich SE, Galea LA (2008) ERalpha, but not ERbeta, mediates the expression of sexual behavior in the female rat. Behav Brain Res 191: 111-7

O'Mahony SM, Myint AM, van den Hove D, Desbonnet L, Steinbusch H, Leonard BE (2006) Gestational stress leads to depressive-like behavioural and immunological changes in the rat. Neuroimmunomodulation 13: $82-8$

Oberlander TF, Warburton W, Misri S, Aghajanian J, Hertzman C (2006) Neonatal outcomes after prenatal exposure to selective serotonin reuptake inhibitor antidepressants and maternal depression using population-based linked health data. Arch Gen Psychiatry 63: 898-906

Parker GC, McKee ME, Bishop C, Coscina DV (2001) Whole-body metabolism varies across the estrous cycle in Sprague-Dawley rats. Physiol Behav 74: 399-403

Patisaul HB, Fortino AE, Polston EK (2006) Neonatal genistein or bisphenol-A exposure alters sexual differentiation of the AVPV. Neurotoxicol Teratol 28: 111-8

Pawluski JL (2011) Perinatal Selective Serotonin Reuptake Inhibitor Exposure: Impact on Brain Development and Neural Plasticity. Neuroendocrinology

Pawluski JL, Charlier TD, Fillet M, Houbart V, Crispin HT, Steinbusch HW, van den Hove DL (2012a) Chronic fluoxetine treatment and maternal adversity differentially alter neurobehavioral outcomes in the rat dam. Behav Brain Res 228: 159-68

Pawluski JL, Rayen I, Niessen NA, Kristensen S, van Donkelaar EL, Balthazart J, Steinbusch HW, Charlier TD (2012b) Developmental fluoxetine exposure differentially alters central and peripheral measures of the HPA system in adolescent male and female offspring. Neuroscience

Pei M, Matsuda K, Sakamoto H, Kawata M (2006) Intrauterine proximity to male fetuses affects the morphology of the sexually dimorphic nucleus of the preoptic area in the adult rat brain. Eur J Neurosci 23: $1234-40$

Phelix CF, Liposits Z, Paull WK (1992) Serotonin-CRF interaction in the bed nucleus of the stria terminalis: a light microscopic double-label immunocytochemical analysis. Brain Res Bull 28: 943-8

Prut L, Belzung C (2003) The open field as a paradigm to measure the effects of drugs on anxiety-like behaviors: a review. Eur J Pharmacol 463: 3-33

Rayen I, Steinbusch HW, Charlier TD, Pawluski JL (2013) Developmental fluoxetine exposure and prenatal stress alter sexual differentiation of the brain and reproductive behavior in male rat offspring. Psychoneuroendocrinology 


\section{Chapter 6}

Rayen I, van den Hove DL, Prickaerts J, Steinbusch HW, Pawluski JL (2011) Fluoxetine during development reverses the effects of prenatal stress on depressive-like behavior and hippocampal neurogenesis in adolescence. PLoS One 6: e24003

Romijn HJ, Hofman MA, Gramsbergen A (1991) At what age is the developing cerebral cortex of the rat comparable to that of the full-term newborn human baby? Early Hum Dev 26: 61-7

Sarkar J, Hiegel C, Ginis GE, Hilbun E, Uphouse L (2008a) Subchronic treatment with fluoxetine attenuates effects of acute fluoxetine on female rat sexual behavior. Brain Res 1190: 56-64

Sarkar J, Hiegel C, Maswood N, Uphouse L (2008b) Daily male exposure attenuates estrous cycle disruption by fluoxetine. Behav Brain Res 189: 83-91

Schloss P, Williams DC (1998) The serotonin transporter: a primary target for antidepressant drugs. J Psychopharmacol 12: 115-21

Simerly RB, Swanson LW, Gorski RA (1985a) The distribution of monoaminergic cells and fibers in a periventricular preoptic nucleus involved in the control of gonadotropin release: immunohistochemical evidence for a dopaminergic sexual dimorphism. Brain Res 330: 55-64

Simerly RB, Swanson LW, Handa RJ, Gorski RA (1985b) Influence of perinatal androgen on the sexually dimorphic distribution of tyrosine hydroxylase-immunoreactive cells and fibers in the anteroventral periventricular nucleus of the rat. Neuroendocrinology 40:501-10

Simpson KL, Weaver KJ, de Villers-Sidani E, Lu JY, Cai Z, Pang Y, Rodriguez-Porcel F, Paul IA, Merzenich M, Lin RC (2011) Perinatal antidepressant exposure alters cortical network function in rodents. Proc Natl Acad Sci U S A 108: 18465-70

Smith JW, Seckl JR, Evans AT, Costall B, Smythe JW (2004) Gestational stress induces post-partum depression-like behaviour and alters maternal care in rats. Psychoneuroendocrinology 29: 227-44

Snoeren EM, Chan JS, de Jong TR, Waldinger MD, Olivier B, Oosting RS (2011) A new female rat animal model for hypoactive sexual desire disorder; behavioral and pharmacological evidence. J Sex Med 8: 44-56

Soga T, Wong DW, Putteeraj M, Song KP, Parhar IS (2012) Early-life citalopram-induced impairments in sexual behavior and the role of androgen receptor. Neuroscience 225: 172-84

Uphouse L, Hensler JG, Sarkar J, Grossie B (2006) Fluoxetine disrupts food intake and estrous cyclicity in Fischer female rats. Brain Res 1072: 79-90

Van den Hove DL, Blanco CE, Aendekerk B, Desbonnet L, Bruschettini M, Steinbusch HP, Prickaerts J, Steinbusch HW (2005) Prenatal restraint stress and long-term affective consequences. Dev Neurosci 27: $313-20$

Vogel G, Neill D, Hagler M, Kors D (1990) A new animal model of endogenous depression: a summary of present findings. Neurosci Biobehav Rev 14: 85-91

Weaver KJ, Paul IA, Lin RC, Simpson KL (2010) Neonatal exposure to citalopram selectively alters the expression of the serotonin transporter in the hippocampus: dose-dependent effects. Anat Rec (Hoboken) 293: 1920-32

Wilson CA, Pearson JR, Hunter AJ, Tuohy PA, Payne AP (1986) The effect of neonatal manipulation of hypothalamic serotonin levels on sexual activity in the adult rat. Pharmacol Biochem Behav 24: 117583

Zhang J, Dennis KA, Darling RD, Alzghoul L, Paul IA, Simpson KL, Lin RC (2013) Neonatal citalopram exposure decreases serotonergic fiber density in the olfactory bulb of male but not female adult rats. Front Cell Neurosci 7: 67 



\section{Chapter 7}

General discussion 
The general aim of this thesis was to determine how developmental exposure to fluoxetine, a commonly used SSRI, during pregnancy and the postpartum period in human, affects neurobehavioral outcomes in the offspring, using an animal model of maternal adversity. I have addressed these questions by stydying the effects of developmental fluoxetine on (1) affect-related behavior, (2) the hypothalamic-pituitary-adrenal (HPA) axis, (3) hippocampal neuroplasticity, and (4) the hypothalamic-pituitary-gonadal (HPG) axis in male and female offspring. The prescription and subsequent use of SSRI medications during the perinatal period is increasing (Oberlander et al. 2009), and it is, therefore, very important to determine how these medications affect the developing brain of the child. As such, treatment and intervention options should be improved. In this chapter, I will summarize the main findings of this thesis and discusses these main findings and future directions.

\section{Affect-related behavior.}

In chapter 2, the developmental effect of fluoxetine on anxiety- and depression-related behavior was investigated in adolescent male and female offspring. Main findings of this study showed that early postnatal exposure to maternal fluoxetine reverses the decrease in depression-related behavior seen after prenatal stress exposure (Rayen et al. 2011). The mechanism behind this strategy is unclear, thus how fluoxetine may act to reverse the effect of prenatal stress on depression-related behavior in adolescence. Evidence suggests that prenatal maternal stress programs the HPA axis as well as behavior, and that plasticity of the developing monoamine system in the brain is partly responsible for these changes (Charil et al. 2010; Glover et al. 2010). Also, developmental fluoxetine exposure likely impacts HPA function (Ishiwata et al. 2005; Morrison et al. 2004; Morrison et al. 2005; Oberlander et al. 2009; Pawluski et al. 2012) as it has been shown that postnatal fluoxetine reverses the high corticosterone levels in response to prenatal stress in juvenile mice offspring (Ishiwata et al. 2005) In chapter 3, we have shown that postnatal fluoxetine exposure reduces serum corticosterone levels and hippocampal GR and GRIP1 expression in adolescent male offspring (Pawluski et al. 2012). Moreover, sheep exposed to prenatal fluoxetine show reduced fetal plasma levels of cortisol (Morrison et al. 2004). Thus, early exposure to SSRIs may 'modulate' physiological systems, such as the HPA system, which are influenced by exposure to maternal adversity and play an important role in the development of mood disorders. 


\section{The HPA axis.}

Chapter 3 addresses the developmental effects of fluoxetine exposure, on peripheral and central measures of the HPA system in adolescent offspring. In this chapter, peripheral levels of corticosterone and its binding globulin, CBG, as well as hippocampal expression of the GR and MR in adolescent male and female offspring, were investigated (Pawluski et al. 2012). To determine the level of functionality of GRs and MRs, we looked at the expression of the glucocorticoid receptor interacting protein, GRIP1, a steroid receptor coactivator, which is required for the action of GRs and MRs during transcription (Charlier 2009; Tetel et al. 2009). Findings from this chapter show that developmental exposure to fluoxetine significantly affects the HPA axis with decreased levels of serum corticosterone, and a reduction of GR and GRIP1 expression throughout the hippocampus, in adolescent male offspring. In addition, increased CBG levels were evident in prenatally stressed male offspring exposed to maternal fluoxetine. Previous in vitro work has indicated that serotonin can increase GR mRNA in the hippocampus (Erdeljan et al. 2005; Erdeljan et al. 2001). In addition, it was also shown that the chronic use of SSRIs during adulthood generally increases GR expression in the rat hippocampus (Yau et al. 2002). However we found a decrease in GR expression and its coactivator, GRIP1, in adolescent males. This indicates that exposure to SSRI during development regulates the HPA axis in a very different way than exposure during adulthood.

Interestingly, the effects of developmental exposure to fluoxetine on the HPA system were particularly evident in male, but not female, adolescent offspring. Although, it is not known why there is such a sex difference in the HPA system after exposure to developmental fluoxetine, it is likely that sex steroids modulate these sex differences, as estradiol can influence HPA function (Atkinson and Waddell 1997; Viau 2002; Viau and Meaney 1991). Serotonin concentrations also differ in many brain regions in male and female offspring (Duchesne et al. 2009) and, therefore, changing the serotonin concentration via SSRI exposure during development may alter the serotoninergic system in a sexually dimorphic way.

\section{Hippocampal neuroplasticity.}

In chapter 2, the developmental effect of fluoxetine on hippocampal neurogenesis was investigated in adolescent male and female offspring. Chapter 4 further examined the longterm effects of developmental fluoxetine exposure on hippocampal cell proliferation and new 
cell survival in adult male and female offspring. Findings of chapter 2 show that early postnatal exposure to maternal fluoxetine reverses the reduction in hippocampal cell proliferation and hippocampal neurogenesis in adolescent offspring exposed to prenatal stress. When offspring were exposed to fluoxetine treatment alone, hippocampal cell proliferation was significantly decreased in adolescence (Ch 2). Findings from chapter 4 show that developmental fluoxetine exposure differentially affects hippocampal plasticity in adult male and female offspring, with developmental fluoxetine exposure reducing hippocampal cell proliferation in prenatally stressed adult female offspring, and prenatal stress, but not developmental fluoxetine exposure, reducing hippocampal cell proliferation in adult male offspring. Furthermore, no effects were seen on hippocampal new cell survival.

Results from chapter 2 show that the action of developmental fluoxetine exposure on hippocampal neurogenesis differs in the presence of maternal stress and these effects are similar in adolescent male and female offspring. Although, most preclinical research to date has investigated the developmental impact of SSRIs in offspring of healthy mothers, one study has shown that early treatment with fluoxetine may act to dampen the effect of maternal stress on neuronal morphology in the CA3 region of the hippocampus (Ishiwata et al. 2005). It is possible that developmental exposure to fluoxetine, in offspring exposed to maternal adversity, may act to regulate the HPA axis and therefore reverse the effect of glucocorticoids on hippocampal plasticity in prenatally stressed offspring, at least during adolescence.

In adult offspring, there was no 'reversing' effect of fluoxetine on hippocampal cell proliferation or new cell survival after prenatal stress exposure (Ch 4) and sex differences were clearly evident on measures of hippocampal cell proliferation. Studies have shown that after developmental SSRI exposure, there is a reduction of the serotoninergic tone in adulthood (Maciag et al. 2006b; Oberlander et al. 2009; Simpson et al. 2011; Weaver et al. 2010). In addition, increasing steroid levels during puberty and changes in the expression of estrogen and androgen receptors are likely responsible for sex differences in hippocampal plasticity during adulthood (Galea et al. 2006; Pawluski et al. 2009; Tabori et al. 2005; Weiland et al. 1997). Serotonin also plays an important role in sexual differentiation of the brain as it is implicated in the development of the HPG axis and may, therefore, be responsible for a different developmental effect of fluoxetine on hippocampal plasticity in male and female offspring during adolescence ( $\mathrm{Ch} \mathrm{2)}$ and adulthood (Ch 4) (Dohler et al. 1991; Jarzab and Dohler 1984). More research is needed to determine which mechanisms are responsible for these effects on hippocampal plasticity, as new neurons and plasticity in the 
hippocampus are important in the pathophysiology of depression and affect-related disorders (Dranovsky and Hen 2006; Mateus-Pinheiro et al. 2013; Santarelli et al. 2003),

\section{The HPG axis.}

In chapters 5 and 6 , the effect of developmental exposure to fluoxetine on the HPG system was determined. We focused on sexual behavior and the sexually differentiated brain regions of the AVPv, the pBST, and the SDN-POA in adult male (Ch 5) and female offspring (Ch 6). This was done in order to investigate the effect the potential SSRI medications may have on sexual differentiated behaviors in offspring, as we see sex differences in many neurobehavioral outcomes in this thesis (Chapters 3 and 4). Main findings of chapter 5 show that developmental exposure to fluoxetine alone significantly decreases the anogenital distance in juvenile male offspring and inhibits male sexual behavior in adult offspring. Exposure to both fluoxetine and maternal stress significantly decreased the area of the SDNPOA, while maternal stress alone significantly decreased the number of TH-ir cells in the AVPv and the volume of the pBST. In chapter 6, we have demonstrated that developmental fluoxetine exposure facilitates proceptive and receptive behaviors in female offspring. However, no marked effects of developmental fluoxetine exposure or maternal stress was evident on the size of the sexually differentiated brain areas investigated (AVPv, pBST, and SDN-POA).

It is likely that the increases in serotonin levels during the organizational stage of sexual brain differentiation, due to developmental exposure to SSRIs, alter sexual differentiation. Our findings in male offspring are in agreement with previous work showing that developmental SSRI exposure inhibits sexual behavior in adult offspring (Harris et al. 2012; Maciag et al. 2006a; Maciag et al. 2006b; Maciag et al. 2006c; Vogel et al. 1990). However, we did not observe marked effects of developmental fluoxetine exposure on sexual behavior of male offspring exposed to maternal stress (Ch 5). Perhaps exposure to maternal adversity, via prenatal stress, modifies sexual differentiation in such a way that the subsequent exposure to fluoxetine does not impact sexual behavior in male offspring.

Whereas in male offspring there was an inhibition of sexual behavior after developmental fluoxetine exposure ( $\mathrm{Ch} 5$ ), in female offspring a facilitation of sexual behavior was observed after exposure to fluoxetine during development, regardless of exposure to maternal stress (Ch 6). Sex differences in brain serotonin levels appear between days 11 and 16 of life, suggesting that altering serotonin levels during this period may cause a 
different effect on male and female sexual behavior (Jarzab and Dohler 1984; Wilson et al. 1986). Given our data in Chapter 6 on female sexual behavior, and recent studies in male offspring (Harris et al. 2012; Maciag et al. 2006a; Maciag et al. 2006b; Maciag et al. 2006c; Rayen et al. 2013), it is expected that an increase in serotonin levels during this period of development, via SSRI exposure, has a feminizing effect on the brain, while decreases in serotonin levels have a masculinizing effect. More research is needed to determine if this hypothesis is true and to determine the mechanisms behind the effects of developmental SSRIs exposure on the HPG system in both male and female offspring.

\section{General conclusions and future directions.}

This thesis has investigated how developmental exposure to SSRI medications has an impact on (1) affects-related behavior, (2) HPA axis, (3) hippocampal plasticity, and (4) HPG axis in male and female offspring. In general, these four areas of investigation are intricately related with alterations in the HPA system significantly affecting hippocampal plasticity (Koehl et al. 2009; Lemaire et al. 2000; Lucassen et al. 2009; Odagiri et al. 2008; Tamura et al. 2011; Weinstock 2011) which, in turn, can alter affect-related behaviors (Glover et al. 2010; Maccari et al. 2003; Maccari and Morley-Fletcher 2007; Weinstock 2008; Zagron and Weinstock 2006). Furthermore, these effects are often sexually differentiated, particularly during adulthood (Weinstock 2007; Weinstock 2011; Zagron and Weinstock 2006; Zuena et al. 2008), with a bidirectional relationship between the HPA and HPG axes (Li et al. 2010; Mastorakos et al. 2006; Viau 2002). This thesis showed that developmental SSRI exposure has a long-term effect on all these factors and these effects are often age and sex dependent (Table 1). This is not surprising as serotonin is a key player in the development and modulation of the HPA system (Andrews and Matthews 2004; Erdeljan et al. 2001), hippocampal plasticity (Brezun and Daszuta 1999; Djavadian 2004), affect-related behaviors (Ansorge et al. 2008; Ansorge et al. 2004; Hansen et al. 1997; Karpova et al. 2009; Lisboa et al. 2007; McAllister et al. 2012; Olivier et al. 2011; Popa et al. 2008; Simpson et al. 2011) and sexual differentiation of the brain and behavior (Dohler et al. 1991; Jarzab and Dohler 1984; Ladosky and Gaziri 1970). For example, serotonin is involved in HPA programming during development, as serotonin increases hippocampal GR transcription in a dosedependent way (Erdeljan et al. 2001), and there appears to be a bidirectional relationship between serotonin and glucocorticoids, with glucocorticoids altering neurotransmission mediated by serotonin (Joels et al. 1995; Meijer and de Kloet 1998). As mentioned 
previously, serotonin also plays an important role in sexual differentiation of the brain and behavior (Dohler et al. 1991; Jarzab and Dohler 1984; Ladosky and Gaziri 1970). For example, in male offspring developmental exposure to SSRIs inhibits sexual behavior (Harris et al. 2012; Maciag et al. 2006a; Maciag et al. 2006b; Maciag et al. 2006c; Rayen et al. 2013) (Ch. 5, this thesis), while in female offspring it facilitates sexual behavior (Rayen et al. 2013, accepted)(Ch. 6, this thesis). During adulthood, serotonin and SSRI medications play an important role in hippocampal plasticity (Brezun and Daszuta 1999; Djavadian 2004; Malberg et al. 2000; Varrault et al. 1992) and mood disorders (Eisch and Petrik 2012; Santarelli et al. 2003; Wainwright and Galea 2013). For example, increases in serotonin levels, following SSRI treatment, increase hippocampal neurogenesis considerably during adulthood (Malberg et al. 2000; Perera et al. 2007) and it is likely that hippocampal neurogenesis is essential for the behavioral effects acquired after antidepressant exposure (Eisch and Petrik 2012; Santarelli et al. 2003; Wainwright and Galea 2013). 
Chapter 7

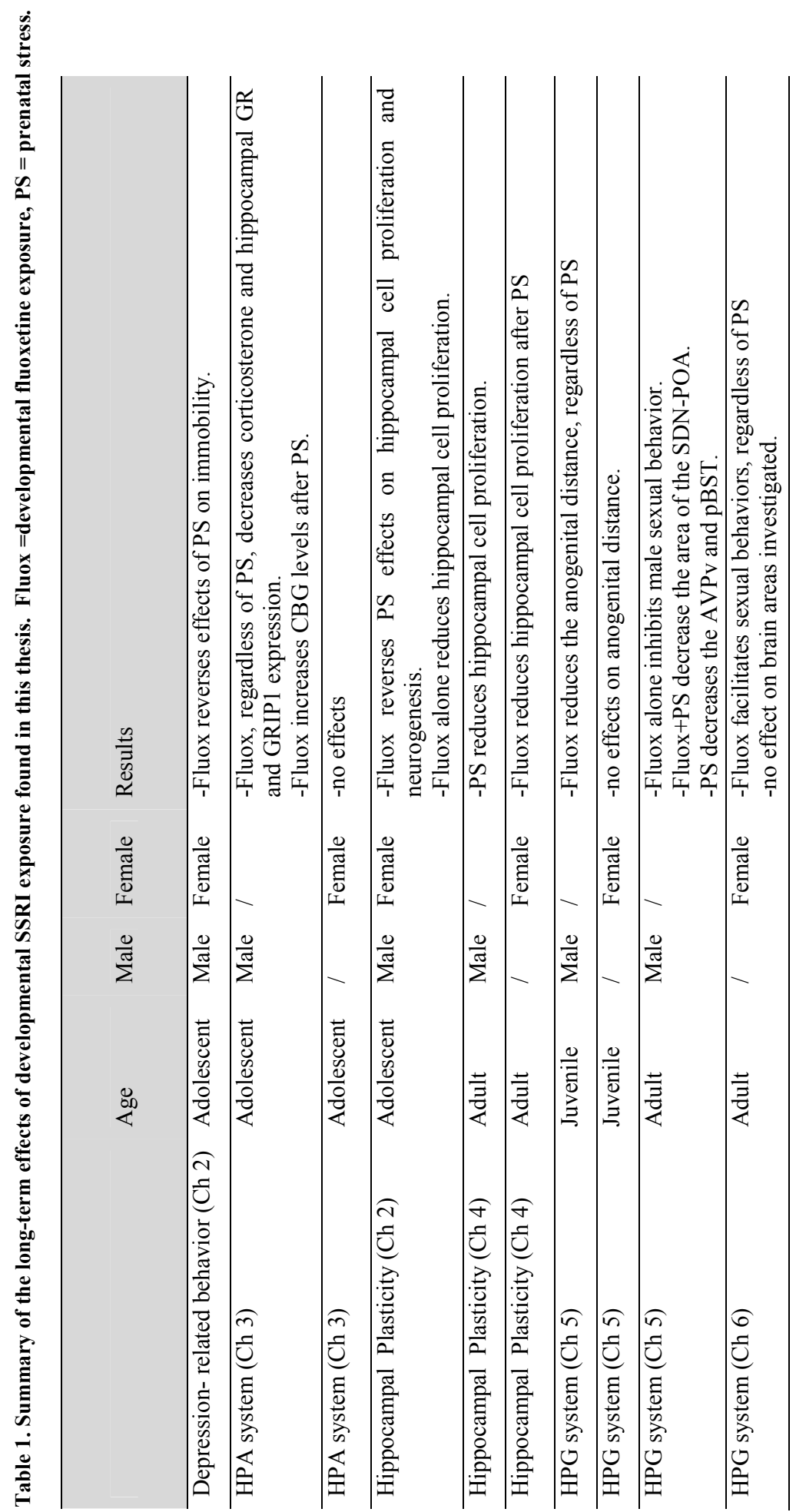


In order to mimick the clinical situation, preclinical models should use more clinically appropriate models of SSRI administration, throughout pregnancy and the postpartum period, such as medication exposure through food or drinking water. Most preclinical models administer SSRI medications via oral gavage to the dam (Lisboa et al. 2007; Olivier et al. 2011) or offspring (Ishiwata et al. 2005), or repeated injection to the offspring (Ansorge et al. 2004; Hansen et al. 1997; Karpova et al. 2009; Maciag et al. 2006a; Maciag et al. 2006b; Maciag et al. 2006c; McAdam et al. 2008). These methods of administration can be stressful. We chose to use administration via osmotic minipumps in order to reduce stress. However, administration via food (Knaepen et al 2013) or drinking water (McAllister et al. 2012) may be more appropriate and considerably less stressful. Improving the preclinical model will increase our understanding of the effects of developmental SSRI exposure on offspring outcomes.

The use of SSRI antidepressant medications to treat maternal mood disorders during the perinatal period is of increasing concern, as up to $10 \%$ of the women are on antidepressants during the pregnancy and in the postpartum period (Cooper et al. 2007; Oberlander et al. 2006) and these medications can pass through the placental and are also evident in breast milk (Gentile et al. 2007). It is, therefore, important to understand the longterm implications of developmental exposure to SSRIs, and other antidepressant medications, on offspring outcomes. Although this thesis is of great contribution, more research is needed, using appropriate models of maternal depression, to determine how early exposure to SSRI medications alter a host of neurobehavioral outcomes. With greater information on long-term effects of developmental SSRI exposure, appropriate recommendations can be made on the use of these medications during pregnancy and the postpartum period. 


\section{References}

Andrews MH, Matthews SG (2004) Programming of the hypothalamo-pituitary-adrenal axis: serotonergic involvement. Stress 7: 15-27

Ansorge MS, Morelli E, Gingrich JA (2008) Inhibition of serotonin but not norepinephrine transport during development produces delayed, persistent perturbations of emotional behaviors in mice. J Neurosci 28: 199-207

Ansorge MS, Zhou M, Lira A, Hen R, Gingrich JA (2004) Early-life blockade of the 5-HT transporter alters emotional behavior in adult mice. Science 306: 879-81

Atkinson HC, Waddell BJ (1997) Circadian variation in basal plasma corticosterone and adrenocorticotropin in the rat: sexual dimorphism and changes across the estrous cycle. Endocrinology 138: 3842-8

Brezun JM, Daszuta A (1999) Depletion in serotonin decreases neurogenesis in the dentate gyrus and the subventricular zone of adult rats. Neuroscience 89: 999-1002

Charil A, Laplante DP, Vaillancourt C, King S (2010) Prenatal stress and brain development. Brain Res Rev 65: 56-79

Charlier TD (2009) Importance of steroid receptor coactivators in the modulation of steroid action on brain and behavior. Psychoneuroendocrinology 34 Suppl 1: S20-9

Cooper WO, Willy ME, Pont SJ, Ray WA (2007) Increasing use of antidepressants in pregnancy. Am J Obstet Gynecol 196: 544 e1-5

Djavadian RL (2004) Serotonin and neurogenesis in the hippocampal dentate gyrus of adult mammals. Acta Neurobiol Exp (Wars) 64: 189-200

Dohler KD, Jarzab B, Sickmoller PM, Kokocinska D, Kaminski M, Gubala E, Achtelik W, Wagiel J (1991) Influence of neurotransmitters on sexual differentiation of brain structure and function. Exp Clin Endocrinol 98: 99-109

Dranovsky A, Hen R (2006) Hippocampal neurogenesis: regulation by stress and antidepressants. Biol Psychiatry 59: 1136-43

Duchesne A, Dufresne MM, Sullivan RM (2009) Sex differences in corticolimbic dopamine and serotonin systems in the rat and the effect of postnatal handling. Progress in neuro-psychopharmacology \& biological psychiatry 33: 251-61

Eisch AJ, Petrik D (2012) Depression and hippocampal neurogenesis: a road to remission? Science 338: 72-5

Erdeljan P, Andrews MH, MacDonald JF, Matthews SG (2005) Glucocorticoids and serotonin alter glucocorticoid receptor mRNA levels in fetal guinea-pig hippocampal neurons, in vitro. Reprod Fertil Dev 17: 743-9

Erdeljan P, MacDonald JF, Matthews SG (2001) Glucocorticoids and serotonin alter glucocorticoid receptor (GR) but not mineralocorticoid receptor (MR) mRNA levels in fetal mouse hippocampal neurons, in vitro. Brain Res 896: 130-6

Galea LA, Spritzer MD, Barker JM, Pawluski JL (2006) Gonadal hormone modulation of hippocampal neurogenesis in the adult. Hippocampus 16: 225-32

Gentile S, Rossi A, Bellantuono C (2007) SSRIs during breastfeeding: spotlight on milk-to-plasma ratio. Arch Womens Ment Health 10: 39-51

Glover V, O'Connor TG, O'Donnell K (2010) Prenatal stress and the programming of the HPA axis. Neurosci Biobehav Rev 35: 17-22

Hansen HH, Sanchez C, Meier E (1997) Neonatal administration of the selective serotonin reuptake inhibitor Lu 10-134-C increases forced swimming-induced immobility in adult rats: a putative animal model of depression? J Pharmacol Exp Ther 283: 1333-41

Harris SS, Maciag D, Simpson KL, Lin RC, Paul IA (2012) Dose-dependent effects of neonatal SSRI exposure on adult behavior in the rat. Brain Res 1429: 52-60

Huang Y, Shi X, Xu H, Yang H, Chen T, Chen S, Chen X (2010) Chronic unpredictable stress before pregnancy reduce the expression of brain-derived neurotrophic factor and N-methyl-D-aspartate receptor in hippocampus of offspring rats associated with impairment of memory. Neurochem Res 35: 1038-49

Ishiwata H, Shiga T, Okado N (2005) Selective serotonin reuptake inhibitor treatment of early postnatal mice reverses their prenatal stress-induced brain dysfunction. Neuroscience 133: 893-901

Jarzab B, Dohler KD (1984) Serotoninergic influences on sexual differentiation of the rat brain. Prog Brain Res 61: $119-26$

Joels M, Hesen W, de Kloet ER (1995) Long-term control of neuronal excitability by corticosteroid hormones. J Steroid Biochem Mol Biol 53: 315-23

Karpova NN, Lindholm J, Pruunsild P, Timmusk T, Castren E (2009) Long-lasting behavioural and molecular alterations induced by early postnatal fluoxetine exposure are restored by chronic fluoxetine treatment in adult mice. Eur Neuropsychopharmacol 19: 97-108 
Koehl M, Lemaire V, Le Moal M, Abrous DN (2009) Age-dependent effect of prenatal stress on hippocampal cell proliferation in female rats. Eur J Neurosci 29: 635-40

Ladosky W, Gaziri LC (1970) Brain serotonin and sexual differentiation of the nervous system. Neuroendocrinology 6: 168-74

Lemaire V, Koehl M, Le Moal M, Abrous DN (2000) Prenatal stress produces learning deficits associated with an inhibition of neurogenesis in the hippocampus. Proc Natl Acad Sci U S A 97: 11032-7

Li XF, Knox AM, O'Byrne KT (2010) Corticotrophin-releasing factor and stress-induced inhibition of the gonadotrophin-releasing hormone pulse generator in the female. Brain Res 1364: 153-63

Lisboa SF, Oliveira PE, Costa LC, Venancio EJ, Moreira EG (2007) Behavioral evaluation of male and female mice pups exposed to fluoxetine during pregnancy and lactation. Pharmacology 80: 49-56

Lucassen PJ, Bosch OJ, Jousma E, Kromer SA, Andrew R, Seckl JR, Neumann ID (2009) Prenatal stress reduces postnatal neurogenesis in rats selectively bred for high, but not low, anxiety: possible key role of placental 11beta-hydroxysteroid dehydrogenase type 2. Eur J Neurosci 29: 97-103

Maccari S, Darnaudery M, Morley-Fletcher S, Zuena AR, Cinque C, Van Reeth O (2003) Prenatal stress and long-term consequences: implications of glucocorticoid hormones. Neurosci Biobehav Rev 27: 119-27

Maccari S, Morley-Fletcher S (2007) Effects of prenatal restraint stress on the hypothalamus-pituitary-adrenal axis and related behavioural and neurobiological alterations. Psychoneuroendocrinology 32 Suppl 1: S10-5

Maciag D, Coppinger D, Paul IA (2006a) Evidence that the deficit in sexual behavior in adult rats neonatally exposed to citalopram is a consequence of 5-HT1 receptor stimulation during development. Brain Res 1125: $171-5$

Maciag D, Simpson KL, Coppinger D, Lu Y, Wang Y, Lin RC, Paul IA (2006b) Neonatal antidepressant exposure has lasting effects on behavior and serotonin circuitry. Neuropsychopharmacology 31: 47-57

Maciag D, Williams L, Coppinger D, Paul IA (2006c) Neonatal citalopram exposure produces lasting changes in behavior which are reversed by adult imipramine treatment. Eur J Pharmacol 532: 265-9

Malberg JE, Eisch AJ, Nestler EJ, Duman RS (2000) Chronic antidepressant treatment increases neurogenesis in adult rat hippocampus. J Neurosci 20: 9104-10

Mastorakos G, Pavlatou MG, Mizamtsidi M (2006) The hypothalamic-pituitary-adrenal and the hypothalamicpituitary-gonadal axes interplay. Pediatr Endocrinol Rev 3 Suppl 1: 172-81

Mateus-Pinheiro A, Pinto L, Bessa JM, Morais M, Alves ND, Monteiro S, Patricio P, Almeida OF, Sousa N (2013) Sustained remission from depressive-like behavior depends on hippocampal neurogenesis. Transl Psychiatry 3: e210

McAdam TD, Brien JF, Reynolds JN, Dringenberg HC (2008) Altered water-maze search behavior in adult guinea pigs following chronic prenatal ethanol exposure: lack of mitigation by postnatal fluoxetine treatment. Behav Brain Res 191: 202-9

McAllister BB, Kiryanova V, Dyck RH (2012) Behavioural outcomes of perinatal maternal fluoxetine treatment. Neuroscience 226: 356-66

Meijer OC, de Kloet ER (1998) Corticosterone and serotonergic neurotransmission in the hippocampus: functional implications of central corticosteroid receptor diversity. Crit Rev Neurobiol 12: 1-20

Morrison JL, Riggs KW, Chien C, Gruber N, McMillen IC, Rurak DW (2004) Chronic maternal fluoxetine infusion in pregnant sheep: effects on the maternal and fetal hypothalamic-pituitary-adrenal axes. Pediatr Res 56: 40-6

Morrison JL, Riggs KW, Rurak DW (2005) Fluoxetine during pregnancy: impact on fetal development. Reprod Fertil Dev 17: 641-50

Oberlander TF, Gingrich JA, Ansorge MS (2009) Sustained neurobehavioral effects of exposure to SSRI antidepressants during development: molecular to clinical evidence. Clin Pharmacol Ther 86: 672-7

Oberlander TF, Warburton W, Misri S, Aghajanian J, Hertzman C (2006) Neonatal outcomes after prenatal exposure to selective serotonin reuptake inhibitor antidepressants and maternal depression using population-based linked health data. Arch Gen Psychiatry 63: 898-906

Odagiri K, Abe H, Kawagoe C, Takeda R, Ikeda T, Matsuo H, Nonaka H, Ebihara K, Nishimori T, Ishizuka Y, Hashiguchi H, Ishida Y (2008) Psychological prenatal stress reduced the number of BrdU immunopositive cells in the dorsal hippocampus without affecting the open field behavior of male and female rats at one month of age. Neurosci Lett 446: 25-9

Olivier JD, Valles A, van Heesch F, Afrasiab-Middelman A, Roelofs JJ, Jonkers M, Peeters EJ, Korte-Bouws GA, Dederen JP, Kiliaan AJ, Martens GJ, Schubert D, Homberg JR (2011) Fluoxetine administration to pregnant rats increases anxiety-related behavior in the offspring. Psychopharmacology (Berl) 217: 419-32

Pawluski JL, Brummelte S, Barha CK, Crozier TM, Galea LA (2009) Effects of steroid hormones on neurogenesis in the hippocampus of the adult female rodent during the estrous cycle, pregnancy, lactation and aging. Front Neuroendocrinol 30: 343-57 
Pawluski JL, Rayen I, Niessen NA, Kristensen S, van Donkelaar EL, Balthazart J, Steinbusch HW, Charlier TD (2012) Developmental fluoxetine exposure differentially alters central and peripheral measures of the HPA system in adolescent male and female offspring. Neuroscience 220: 131-41

Perera TD, Coplan JD, Lisanby SH, Lipira CM, Arif M, Carpio C, Spitzer G, Santarelli L, Scharf B, Hen R, Rosoklija G, Sackeim HA, Dwork AJ (2007) Antidepressant-induced neurogenesis in the hippocampus of adult nonhuman primates. J Neurosci 27: 4894-901

Popa D, Lena C, Alexandre C, Adrien J (2008) Lasting syndrome of depression produced by reduction in serotonin uptake during postnatal development: evidence from sleep, stress, and behavior. J Neurosci 28: $3546-54$

Rayen I, Steinbusch HW, Charlier TD, Pawluski JL (2013) Developmental fluoxetine exposure and prenatal stress alter sexual differentiation of the brain and reproductive behavior in male rat offspring. Psychoneuroendocrinology

Rayen I, Steinbusch HW, Pawluski JL (2013, accepted) Developmental fluoxetine exposure facilitates sexual behavior in female offspring. Psychopharmacology (Berl)

Rayen I, van den Hove DL, Prickaerts J, Steinbusch HW, Pawluski JL (2011) Fluoxetine during development reverses the effects of prenatal stress on depressive-like behavior and hippocampal neurogenesis in adolescence. PLoS One 6: e24003

Santarelli L, Saxe M, Gross C, Surget A, Battaglia F, Dulawa S, Weisstaub N, Lee J, Duman R, Arancio O, Belzung C, Hen R (2003) Requirement of hippocampal neurogenesis for the behavioral effects of antidepressants. Science 301: 805-9

Simpson KL, Weaver KJ, de Villers-Sidani E, Lu JY, Cai Z, Pang Y, Rodriguez-Porcel F, Paul IA, Merzenich M, Lin RC (2011) Perinatal antidepressant exposure alters cortical network function in rodents. Proc Natl Acad Sci U S A 108: 18465-70

Tabori NE, Stewart LS, Znamensky V, Romeo RD, Alves SE, McEwen BS, Milner TA (2005) Ultrastructural evidence that androgen receptors are located at extranuclear sites in the rat hippocampal formation. Neuroscience 130: 151-63

Tamura M, Sajo M, Kakita A, Matsuki N, Koyama R (2011) Prenatal stress inhibits neuronal maturation through downregulation of mineralocorticoid receptors. J Neurosci 31: 11505-14

Tetel MJ, Auger AP, Charlier TD (2009) Who's in charge? Nuclear receptor coactivator and corepressor function in brain and behavior. Front Neuroendocrinol 30: 328-42

Varrault A, Bockaert J, Waeber C (1992) Activation of 5-HT1A receptors expressed in NIH-3T3 cells induces focus formation and potentiates EGF effect on DNA synthesis. Mol Biol Cell 3: 961-9

Viau V (2002) Functional cross-talk between the hypothalamic-pituitary-gonadal and -adrenal axes. J Neuroendocrinol 14: 506-13

Viau V, Meaney MJ (1991) Variations in the hypothalamic-pituitary-adrenal response to stress during the estrous cycle in the rat. Endocrinology 129: 2503-11

Vogel G, Neill D, Hagler M, Kors D (1990) A new animal model of endogenous depression: a summary of present findings. Neurosci Biobehav Rev 14: 85-91

Wainwright SR, Galea LA (2013) The Neural Plasticity Theory of Depression: Assessing the Roles of Adult Neurogenesis and PSA-NCAM within the Hippocampus. Neural Plast 2013: 805497

Weaver KJ, Paul IA, Lin RC, Simpson KL (2010) Neonatal exposure to citalopram selectively alters the expression of the serotonin transporter in the hippocampus: dose-dependent effects. Anat Rec (Hoboken) 293: 1920-32

Weiland NG, Orikasa C, Hayashi S, McEwen BS (1997) Distribution and hormone regulation of estrogen receptor immunoreactive cells in the hippocampus of male and female rats. J Comp Neurol 388: 60312

Weinstock M (2007) Gender differences in the effects of prenatal stress on brain development and behaviour. Neurochem Res 32: 1730-40

Weinstock M (2008) The long-term behavioural consequences of prenatal stress. Neurosci Biobehav Rev 32 : 1073-86

Weinstock M (2011) Sex-dependent changes induced by prenatal stress in cortical and hippocampal morphology and behaviour in rats: an update. Stress 14: 604-13

Wilson CA, Pearson JR, Hunter AJ, Tuohy PA, Payne AP (1986) The effect of neonatal manipulation of hypothalamic serotonin levels on sexual activity in the adult rat. Pharmacol Biochem Behav 24: 117583

Yau JL, Hibberd C, Noble J, Seckl JR (2002) The effect of chronic fluoxetine treatment on brain corticosteroid receptor mRNA expression and spatial memory in young and aged rats. Brain research. Molecular brain research 106: 117-23

Zagron G, Weinstock M (2006) Maternal adrenal hormone secretion mediates behavioural alterations induced by prenatal stress in male and female rats. Behav Brain Res 175: 323-8 


\section{Chapter 7}

Zuena AR, Mairesse J, Casolini P, Cinque C, Alema GS, Morley-Fletcher S, Chiodi V, Spagnoli LG, Gradini R, Catalani A, Nicoletti F, Maccari S (2008) Prenatal restraint stress generates two distinct behavioral and neurochemical profiles in male and female rats. PLoS One 3: e2170 

Summary 
Chapter 1 provides a general introduction. In this chapter an overview is given on the developmental effects of SSRI exposure on (1) affect-related behavior, (2) the hypothalamicpituitary-adrenal (HPA) axis, (3) hippocampal neuroplasticity, and (4) the hypothalamicpituitary-gonadal (HPG) axis in male and female offspring. This chapter also gives the general aim of the thesis.

Chapter 2 addresses the developmental effect of fluoxetine on affect-related behavior and neuroplasticity in adolescent male and female offspring. Main findings of this study show that early postnatal exposure to maternal fluoxetine reverses the decrease in depressionrelated behavior and hippocampal neurogenesis seen after prenatal stress.

Chapter 3 describes how developmental fluoxetine exposure affects peripheral and central measures of the HPA system in adolescent offspring. Main findings of this study show that developmental fluoxetine exposure affects the HPA axis with decreased levels of serum corticosterone, and a reduction of GR and GRIP1 expression throughout the hippocampus in adolescent male offspring.

Chapter 4 investigates the long-term effects of developmental fluoxetine exposure on hippocampal cell proliferation and new cell survival in adult male and female offspring. Main findings of this study show that developmental fluoxetine exposure differentially affects hippocampal plasticity in adult male and female offspring. Developmental fluoxetine exposure reduces hippocampal cell proliferation in prenatally stressed adult female offspring whereas prenatal stress, but not developmental fluoxetine exposure, reduces hippocampal cell proliferation in adult male offspring.

Chapter 5 examines the effect of developmental exposure to fluoxetine on sexual behavior and the sexually differentiated brain regions of the AVPv, the pBST, and the SDN-POA in adult male offspring. Main findings of this study show that developmental exposure to fluoxetine alone significantly decreases the anogenital distance in juvenile male offspring and inhibits male sexual behavior in adult offspring. Exposure to both fluoxetine and maternal stress significantly decreased the area of the SDN-POA, while maternal stress alone significantly decreased the number of TH-ir cells in the AVPv and the volume of the pBST. 
Summary

Chapter 6 addresses the effects of developmental fluoxetine exposure on sexual behavior and the sexually differentiated brain regions of the AVPv, the pBST, and the SDN-POA in adult female offspring. Main findings of this study show that developmental fluoxetine exposure facilitates proceptive and receptive behaviors in female offspring and there were no marked effects of developmental fluoxetine exposure or maternal stress on the size of the sexually differentiated brain areas investigated (AVPv, pBST, and SDN-POA).

Chapter 7 summarizes and discusses the main findings of this thesis with regards to my main areas of interest, namely, affect-related behavior, the HPA axis, neuroplasticity and the HPG axis. Also a general conclusion and future perspectives are provided in this chapter. 

Samenvatting 
Hoofdstuk 1 geeft een algemene inleiding. In dit hoofdstuk wordt een overzicht gegeven van de effecten van SSRI blootstelling tijdens de ontwikkeling op (1) affectie-gerelateerd gedrag, (2) het hypothalamic-pituitary-adrenal (HPA) systeem, (3) neuroplasticiteit in de hippocampus en (4) het hypothalamic-pituitary-gonadal (HPG) systeem in mannelijke en vrouwelijke nakomelingen. Dit hoofdstuk geeft ook de algemene doelstelling van het proefschrift weer.

Hoofdstuk 2 gaat het effect van fluoxetine blootstelling tijdens de ontwikkeling na op vlak van affectie-gerelateerd gedrag en neuroplasticiteit in adolescente mannelijke en vrouwelijke nakomelingen. De belangrijkste bevindingen van deze studie tonen aan dat vroege blootstelling aan postnatale fluoxetine via de moeder, de afname in depressie-gerelateerd gedrag en neurogenese in de hippocampus normaliseert na blootstelling aan prenatale stress.

Hoofdstuk 3 beschrijft hoe postnatale fluoxetine blootstelling, perifere en centrale parameters van het HPA system beïnvloedt in adolescente nakomelingen. De belangrijkste bevindingen van deze studie tonen aan dat blootstelling aan fluoxetine tijdens de ontwikkeling, de HPA as beïnvloedt door een verlaging van de serum corticosterone concentratie, en een afname van de GR en GRIP1 expressie in de hippocampus van adolescente mannelijke nakomelingen.

Hoofdstuk 4 onderzoekt de lange termijn effecten van fluoxetine blootstelling tijdens de ontwikkeling op cel proliferatie en de overleving van nieuwe cellen in de hippocampus in volwassen mannelijke en vrouwelijke nakomelingen. De belangrijkste bevindingen van deze studie tonen aan dat fluoxetine blootstelling tijdens de ontwikkeling een verschillend effect heeft op plasticiteit in de hippocampus bij volwassen mannelijke en vrouwelijke nakomelingen. Fluoxetine blootstelling tijdens de ontwikkeling vermindert cel proliferatie in de hippocampus van volwassen vrouwelijke nakomelingen blootgesteld aan prenatale stress, terwijl prenatale stress, maar niet fluoxetine blootstelling tijdens de ontwikkeling, cel proliferatie vermindert in de hippocampus van volwassen mannelijke nakomelingen.

Hoofstuk 5 bestudeert de effecten van fluoxetine blootstelling tijdens de ontwikkeling op seksueel gedrag en seksueel gedifferentiëerde gebieden in de hersenen, zoals de AVPv, de pBST en de SDN-POA in volwassen mannelijke nakomelingen. De belangrijkste bevindingen van deze studie tonen aan dat fluoxetine blootstelling tijdens de ontwikkeling de 
Samenvatting

anogenitale afstand significant verkleint in jonge mannelijke nakomelingen en seksueel gedrag onderdrukt in volwassen mannelijke nakomelingen. Blootstelling aan fluoxetine en prenatale stress verkleint significant het oppervlak van de SDN-POA, terwijl prenatale stress alleen significant het aantal TH-ir cellen vermindert in de AVPv en het volume vermindert van de pBST.

Hoofdstuk 6 beschrijft de effecten van fluoxetine blootsteling tijdens de ontwikkeling op seksueel gedrag en seksueel gedifferentieerde gebieden in de hersenen, zoals de AVPv, de pBST en de SDN-POA in volwassen vrouwelijke nakomelingen. De belangrijkste bevindingen van deze studie tonen aan dat fluoxetine blootstelling tijdens de ontwikkeling proceptief en receptief gedrag stimuleert in vrouwelijke nakomelingen. Maar er werden geen effecten gevonden van fluoxetine blootstelling tijdens de ontwikkeling op de grootte van de seksueel gedifferentieerde hersen gebieden (AVPv, pBST en SDN-POA).

Hoofdstuk 7 vat de belangrijkste bevindingen samen van dit proefschrift en bediscussiëerd deze bevindingen met het oog op de belangrijkste onderzoeksdomeinen, namelijk affectiegerelateerd gedrag, de HPA as, neuroplasticiteit en de HPG as. Er wordt ook een algemene conclusie en toekomst perspectieven weergegeven in dit hoofdstuk. 



\section{Co-authors and affiliations}


Co-authors and affiliations

Balthazart J.

GIGA-Neurosciences, University of Liège, Liège,

Belgium

Charlier T.D.

Department of Biological Sciences, Ohio University, Athens, Ohio, USA

van Donkelaar E.

School for Mental Health and Neuroscience, Maastricht

University, Maastricht, The Netherlands

van den Hove D.

School for Mental Health and Neuroscience, Maastricht

University, Maastricht, The Netherlands

Molecular Psychiatry, Department of Psychiatry,

Psychosomatics and Psychotherapy, University of

Wuerzburg, Wuerzburg, Germany

Kristensen S.

School for Mental Health and Neuroscience, Maastricht University, Maastricht, The Netherlands

GIGA-Neurosciences, University of Liège, Liège,

Niessen N.

Belgium

Prickaerts J.

School for Mental Health and Neuroscience, Maastricht University, Maastricht, The Netherlands

Pawluski J.L.

School for Mental Health and Neuroscience, Maastricht University, Maastricht, The Netherlands

GIGA-Neurosciences, University of Liège, Liège, Belgium

Steinbusch H.W.M

School for Mental Health and Neuroscience, Maastricht University, Maastricht, The Netherlands 


\section{Curriculum Vitae}


Ine Rayen was born on $29^{\text {th }}$ of August 1987 in Bree, Belgium. In 2005, she graduated from the 'Koninklijk Atheneum' in Maaseik, were she studied Maths-Science. In 2005, she started with a bachelor in Biomedical Sciences at the University of Hasselt. In 2008, when she started with her master in Clinical Molecular Sciences, she performed a first internship at the department of Neuroscience at Maastricht University. During this internship, she investigated the effects of fetal asphyxia on brain morphology. In 2009, she performed a second internship at the department of Neuroscience at Maastricht University. During this internship, she worked under supervision of dr. Jodi Pawluski, and investigated how developmental fluoxetine exposure affects neurobehavioral outcomes in an animal model of maternal adversity. This collaboration resulted in a PhD project in 2010, under supervision of Prof. dr. Steinbusch, dr. Jodi Pawluski and dr. Thierry Charlier, at the department of Neuroscience at Maastricht University, in which she further explored the developmental effects of fluoxetine and maternal adversity on neurobehavioral outcomes. The results of her $\mathrm{PhD}$ project are described in this thesis. 
Ine Rayen werd geboren op 29 augustus 1987 te Bree, België. In 2005 studeerde ze af aan het 'Koninklijk Atheneum' te Maaseik, waar ze Wiskunde-Wetenschappen studeerde. In 2005 startte ze met een bachelor in Biomedische Wetenschappen aan de Universiteit Hasselt. In 2008, wanneer ze startte met haar master in Klinische Moleculaire Wetenschappen aan Universiteit Hasselt, voerde ze een eerste stage uit op de afdeling Neurowetenschappen aan Universiteit Maastricht. Tijdens deze stage, onderzocht ze de effecten van foetale asphyxie op de morfologie van de hersenen. In 2009, voerde ze een tweede stage uit op de afdeling Neurowetenschappen aan Universiteit Maastricht. Tijdens deze stage werkte ze onder supervisie van dr. Jodi Pawluski, en onderzocht ze hoe blootstelling aan fluoxetine tijdens de ontwikkeling effect heeft op neurogedrags parameters in een diermodel van prenatale stress. Deze samenwerking resulteerde in een PhD project in 2010, onder supervisie van Prof. dr. Steinbusch, dr. Jodi Pawluski en dr. Thierry Charlier, op de afdeling Neurowetenschappen aan Universiteit Maastricht, waarin ze verder de effecten van fluoxetine blootstelling tijdens de ontwikkeling en prenatale stress exploreerde op neurogedrags parameters. De resultaten van haar $\mathrm{PhD}$ project worden beschreven in dit proefschrift. 



\section{List of publications}




\section{Publications}

1. Rayen I., Charlier T.D., Steinbusch H.W.M., Pawluski J.L. Developmental fluoxetine exposure facilitates sexual behavior in female offspring, Psychopharmacology, 2013 accepted.

2. Rayen I., Charlier T.D., Steinbusch H.W.M., Pawluski J.L. Developmental fluoxetine exposure and prenatal stress alter sexual differentiation of the brain and reproductive behavior in male rat offspring, Psychoneuroendocrinology, 2013, Feb 13; pii: S03064530(13)00012-7.

3. Knaepen L., Rayen I., Charlier T.D., Fillet M., Houbart V., van Kleef M., Steinbusch H.W.M., Patijn J., Tibboel D., Joosten E.A., Pawluski J.L. Developmental fluoxetine exposure normalizes the long-term effects of maternal stress on post-operative pain in Sprague-Dawley rat offspring, PlosOne, 2013, 8(2):e57608

4. Pawluski J.L., Rayen I., Niessen N., Kristinsen S., van Donkelaar E.L., Steinbusch H.W.M., Charlier T.D. Developmental fluoxetine exposure differentially alters central and peripheral measures of the HPA system in adolescent male and female offspring, Neuroscience, 2012, Sep 18;220:131-41.

5. Rayen I., van den Hove D., Prickaerts J., Steinbusch H.W.M., Pawluski J.L.. Fluoxetine during development reverses the effects of prenatal stress on depressivelike behavior and hippocampal neurogenesis in adolescence, PlosOne, 2011;6(9):e24003.

6. Pawluski J.L., van den Hove D.L., Rayen I., Prickaerts J., Steinbusch H.W.M. Stress and the pregnant female: Impact on hippocampal cell proliferation, but not affectivelike behaviors, Hormones and Behavior. 2011 Apr;59(4):572-80.

\section{Publication in preparation}

1. Rayen I., Steinbusch H.W.M., Pawluski J.L. Developmental fluoxetine exposure and prenatal stress differentially affect hippocampal cell proliferation in adult male and female offspring 


\section{Poster abstracts}

1. Rayen I., Steinbusch H.W.M., Pawluski J.L. Developmental fluoxetine exposure and prenatal stress differentially affect hippocampal cell proliferation in adult male and female offspring. Behavioral Neuroscience Society annual meeting. June 25-30, Dublin, Ireland.

2. Rayen I., Steinbusch H.W.M., Pawluski J.L. Developmental fluoxetine exposure and prenatal stress differentially affect hippocampal cell proliferation in adult male and female offspring. Research day MHeNS, June 6, 2013, Maastricht, the Netherlands.

3. Rayen I., Charlier T.D., Balthazart J., Steinbusch H.W.M., Pawluski J.L. Developmental fluoxetine exposure, but not prenatal stress, demasculinizes sexual behavior in males and facilitates sexual behavior in females. Euron PhD days, September 27-28, 2012, Maastricht, the Netherlands.

4. Rayen I., Charlier T.D., Balthazart J., Steinbusch H.W.M., Pawluski J.L. Developmental fluoxetine exposure, but not prenatal stress, demasculinizes sexual behavior in males and facilitates sexual behavior in females. International Behavioral Neuroscience Society annual meeting. June 5-10, 2012, Kailua-Kona, Hawaii.

5. Rayen I., Charlier T.D., Balthazart J., Steinbusch H.W.M., Pawluski J.L. Developmental fluoxetine exposure, but not prenatal stress, demasculinizes sexual behavior in males and facilitates sexual behavior in females. Dutch Endo-NeuroPsycho Meeting, May 29-31, 2012, Lunteren, the Netherlands.

6. Rayen I., Charlier T.D., Balthazart J., Steinbusch H.W.M., Pawluski J.L. Developmental fluoxetine exposure, but not prenatal stress, demasculinizes sexual behavior in males and facilitates sexual behavior in females. Research day MHeNS, May 16, 2012, Maastricht, the Netherlands.

7. Rayen I., van den Hove D., Prickaerts J., Steinbusch H.W.M., Pawluski J.L.. Developmental fluoxetine exposure counteracts the effects of maternal stress on depressive-like behavior and hippocampal neurogenesis. Research day MHeNS, February 23, 2011, Maatsricht, the Netherlands.

8. Niessen N.A., Pawluski J.L., Rayen I., van den Hove D.L., Steinbusch H.W.M., Balthazart J., Charlier T.D. Effect of prenatal stress and developmental fluoxetine exposure on hippocampal glucorticoid receptors and coactivator GRIP1 in adolescent offspring. Euron PhD Days, September 22-23, 2011. Bonn, Germany. 
9. Rayen I., Charlier T.D., Mollegaard Kristensen S., Balthazart J., Steinbusch H.W.M., Pawluski J.L.. Maternal fluoxetine exposure, regardless of prenatal stress, affects physiological systems involved in sexual development of offspring. Euron PhD days, September 22-23, Bohn, Germany.

10. Pawluski J.L., van den Hove D.L., Rayen I., Prickaerts J., Steinbusch H.W.M. Stress increases hippocampal cell proliferation during late pregnancy in the adult female. Abcam Neurogenesis: Structure and Function meeting. May 27-10, 2010, Frauenchiemsee, Germany.

11. Pawluski J.L., van den Hove D.L., Rayen I., Prickaerts J., Steinbusch H.W.M. Stress during gestation alters antepartum anxiety and hippocampal cell proliferation in the pregnant female. International Behavioral Neuroscience Society annual meeting. June 8-13, 2010, Villisimius, Italy

12. Pawluski J.L., van den Hove D.L., Rayen I., Prickaerts J., Steinbusch H.W.M. Postnatal maternal fluoxetine exposure increases depressive-like behavior in prenatally stressed juvenile offspring. International Behavioral Neuroscience Society annual meeting. June 8-13, 2010, Villisimius, Italy.

13. Pawluski J.L., van den Hove D.L., Rayen I., Prickaerts J., Steinbusch H.W.M. Stress during gestation alters antepartum anxiety and hippocampal cell proliferation in the pregnant female. $57^{\text {th }}$ FENS forum of European Neuroscience. July 5-8, 2010, Amsterdam, the Netherlands.

14. Rayen I., van den Hove D., Prickaerts J., Steinbusch H.W.M., Pawluski J.L.. Postnatal maternal fluoxetine affects hippocampal neurogenesis and depressive-like behavior in prenatally stressed adolescent offspring, Society for Neuroscience annual meeting, November 2010, San Diego, USA. 


\section{Oral presentations}

1. Rayen I., Steinbusch H.W.M., Pawluski J.L. Effects of developmental fluoxetine exposure on hippocampal neurogenesis in model of maternal adversity. Mental Health and Neuroscience department, to be presented in May 2013, Maastricht, The Netherlands.

2. Rayen I., Charlier T.D., Mollegaard Kristensen S., Balthazart J., Steinbusch H.W.M., Pawluski J.L. Maternal fluoxetine exposure, regardless of prenatal stress, affects physiological systems involved in sexual development of offspring. Euron PhD days, September 2011, Bohn, Germany.

3. Rayen I., Charlier T.D., van den Hove D., Prickaerts J., Mollegaard Kristensen S., Balthazart J., Steinbusch H.W.M., Pawluski J.L. Effects of developmental exposure to maternal stress and fluoxetine on neurobehavioral outcomes. Mental Health and Neuroscience department, September 2011, Maastricht, the Netherlands.

4. Rayen I., van den Hove D., Prickaerts J., Steinbusch H.W.M., Pawluski J.L.. Effects of maternal stress and postnatal fluoxetine exposure on affective-like behaviors and hippocampal neurogenesis in adolescent rats, Euron PhD days, September 2010, Hasselt, Belgium. 

Dankwoord 


\section{Dankwoord}

Tot slot rest mij nog een aantal mensen te bedanken, die hebben bijgedragen aan het tot stand komen van dit proefschrift. Zonder de hulp en steun van anderen was dit proefschrift er nooit geweest.

In de eerste plaats wil ik mijn promotor, Prof. dr. Harry Steinbusch bedanken om mij de kans te geven dit geweldige project uit te voeren. $U$ hebt mij geleerd om nog kritischer te denken en de dingen ook vanuit een globaal perspectief te bekijken om ze zo met elkaar te relateren. Ook wil ik $U$ bedanken dat uw deur altijd voor mij heeft open gestaan als ik vragen had. $U$ gaf mij steeds een frisse kijk op mijn project en reikte me verschillende mogelijkheden aan om experimenten te realiseren. Ook bedank ik $U$ voor de feedback op mijn publicaties en proefschrift.

Jodi, my Master internship with you resulted in doing a $\mathrm{PhD}$ with you. Thank you for giving me the opportunity for realizing this nice project with you. I have always enjoyed working together with you, as I liked your punctuality and could always count on you. You gave me the perfect guidance to grow to an independent researcher. I couldn't imagine a better supervisor than you and 1 thing I know for sure is that I am going to miss collaborating with you. I would like to wish you all the best in the future with lots of love, happiness and high impact papers.

Thierry, thanks for giving me the chance to complete part of my $\mathrm{PhD}$ project in Liège. It was a great opportunity for me to work in a different lab, and learn about some more molecular techniques. I totally liked your enthusiasm, positivism and your dedication to research. Thanks to your help, I could realize the HPG project, which was my favorite one. I also like to wish you a happy future with great research, and hopefully, au revoir!

Verder zou ik nog graag enkele mensen uit het labo bedanken die hebben bijgedragen in mijn promotie onderzoek. Prof. dr. Jacques Balthazart, I would like to thank you that I could work in your lab together with Thierry as part of Euron. Jos, bedankt om me aan Jodi voor te stellen en me zo de kans te geven om dit interessante onderzoeksdomein te exploreren. Daniël, bedankt voor de hulp met de dieren en extra uitleg over het prenatale stress model. Fred, dankzij uw hulp heb ik wat meer inzicht gekregen in de verschillende nuclei die in de hersenen aanwezig zijn. Bedankt om met mij achter de microscoop te gaan zitten. Hellen, je hebt me veel praktische kennis bijgebracht en me veel geleerd over microscopie. Bedankt dat 


\section{Dankwoord}

ik altijd op je kon rekenen, ook wanneer Jodi er niet was. Denise en Marjan, jullie hebben me altijd goed geholpen met de dieren en andere praktische zaken in het labo en altijd met een glimlach. Ik heb enorm veel respect voor jullie inzet voor de afdeling.

Natuurlijk wil ik ook graag mijn collega's bedanken. In de eerste plaats natuurlijk Romina. Bedankt dat je er altijd voor me was, voor de gezellige praatjes, de ontspannende lunch pauzes. Ik heb enorm veel steun aan je gehad tijdens mijn promotie onderzoek en vond het fijn om af en toe stoom te kunnen afblazen bij jou. We kennen elkaar al sinds ons eerste jaar Biomedische Wetenschappen. Toen hebben we veel plezier gehad en gelachen toen we samen een werkje moesten maken. Daarna hebben we samen veel uren doorgebracht in de auto, onderweg naar de een of andere les of labo in Maastricht en later naar onze stage. Ik wens jou nog veel succes met de afronding van je $\mathrm{PhD}$, je zoektocht naar een nieuwe baan en natuurlijk veel geluk met je gezin. Liesbeth, ik vond het heel leuk om met jou een kamer te delen. Er was altijd een goede balans tussen werk en ontspannen. Veel geluk met je verdere carrière en je gezin. Ramona, bedankt voor de gezellige praatjes in het labo. Ik wens je ook heel veel geluk met je verdere onderzoeksloopbaan. Yuan, I would like to thank you for our nice conversations and your interest in my project. I was a pleasure for me to meet you. Tatyana, thanks for sharing an office with me and our nice conversations. It was nice to meet you.

In mijn privéleven heb ik veel steun gehad van familie en vrienden, die mij enorm dierbaar zijn.

Giulio en Carola, ik wil jullie graag bedanken voor de prachtige momenten die we al samen hebben beleefd hebben. We hebben een mooie vriendschap die ik koester. Bart, Samira en Sorah, bedankt dat jullie er altijd voor me zijn. Pieterjan en Anke, het zijn ook altijd geweldige tijden die ik met jullie beleef. Zingen, lachen, dansen, gek doen, het kan allemaal met jullie. Ook bedank ik jullie voor de interesse in mijn $\mathrm{PhD}$ project. Hannelore, je bent me af en toe een categorie apart, maar voor mij ben je als een zus, dat weet je. Bedankt dat je er altijd voor me bent, al 10 jaar lang, in goede en slechte tijden. We hebben al vele mooie momenten beleefd. Natuurlijk ga ik Jeanke hier ook niet vergeten te bedanken. Jean-Jeff ook bedankt voor de leuke tijden die we samen hebben mogen beleven en jullie gastvrijheid daar in Retie. Sofie en Rodolfo, ik wil jullie graag bedanken voor jullie vriendschap en de leuke momenten de afgelopen jaren. Jullie hebben altijd veel interesse in mijn werk getoond, dat 


\section{Dankwoord}

heb ik altijd gewaardeerd. Gino en Manuela, ik vond het leuk dat ik jullie de laatste jaren wat beter heb leren kennen. Het is altijd lachen met Gino zijn humor. Dat etentje in Maastricht ga ik nooit vergeten. Nele, ik had jou ook willen bedanken om altijd mijn haren zo mooi te doen. We hebben altijd zo gezellige praatjes in het kapsalon. Sara en Tommy, bedankt voor de vriendschap afgelopen jaren. Ik vind het super dat we nog steeds contact hebben. Guido en Eveline, jullie zijn als familie voor mij. Guido, je brengt me al eens soep groenten of pompoenen uit je tuin of komt hier het onkruid behandelen. Dat apprecieer ik heel hard dat je die dingen allemaal voor me doet. Ook vind ik het geweldig om met jullie mijn passie voor wijn en gastronomie te kunnen delen.

Giulio, Carola, Bart, Samira, Sorah, PJ, Anke, Hannelore, Jeanke, Sofie, Rodolfo, Gino, Maunela, Nele, Sara, Tommy, Guido, Eveline ik hou van jullie, TI AMO!

Oma, bomma en bompa, ik had jullie graag bedankt voor de steun die jullie mij al jaren geven. Ook wil ik jullie bij deze nog eens bedanken voor jullie bijdrage in mijn opvoeding. Zonder jullie liefde had ik nooit gestaan waar ik vandaag sta. Jullie zijn de beste grootouders die ik mij kan wensen. Tante Miet en nonkel Domminique, bedankt om het laatste jaar van mijn minderjarigheid de voogdij over mij te nemen en voor mij die laatste jaren nog een thuis gegeven. Jullie hebben mij goed geholpen met de juiste keuzes te maken. Hiervoor zal ik jullie altijd dankbaar zijn. Tante Ria en nonkel Peter, bedankt dat jullie er altijd voor me zijn geweest. Tante Els en nonkel Jos, bedankt om na al die jaren terug contact met mij te zoeken. Ik vind het fijn dat we terug overeenkomen. Tante Ann en nonkel Luc, bedankt voor jullie interesse in mijn werk en jullie steun en motiverende woorden. Tante Rita en nonkel Bart, bedankt voor jullie steun de afgelopen jaren en alles wat jullie voor Liesbeth doen. Ik heb hier heel veel waardering voor.

Lisette en Peter, mijn schoonouders, voor jullie heb ik een paragraaf apart gereserveerd. Dit omdat jullie toch een heel bijzondere rol in mijn leven hebben gespeeld in de tijden van mijn studies en PhD. Jullie hebben me altijd warm opgenomen in jullie gezin en mij een tweede thuis gegeven. Ik wil jullie bedanken dat ik altijd bij jullie terecht kan met vragen over praktische zaken. Ook wil ik jullie bedanken voor de hulp in ons huisje, van terras aanleggen tot schilderen, tot een tuinhuis/hondenhok bouwen, ... Zonder jullie steun en liefde had ik vandaag nooit gestaan waar ik nu sta. Bedankt voor alles. 


\section{Dankwoord}

Liesbeth, jou wil ik graag bedanken dat je er altijd voor me bent geweest. Ook al konden we als kind niet altijd goed met elkaar opschieten en verstopte ik vaak uwe Titi, onze band is de laatste jaren toch echt hecht geworden. Bedankt voor de leuke momenten die we samen hebben gehad, springen op het balkon, zatte Rita nadoen, singstar spelen, etentjes, feestjes, ... Je bent een zus uit de 1000000 !

Lieve Maarten, jij bent de belangrijkste persoon in mijn leven, dus mijn laatste woorden zijn voor jou. Ik wil je graag bedanken voor je liefde en steun de afgelopen 10 jaar. Je hebt me nooit in de steek gelaten en bent altijd voor ons gegaan in goede en slechte tijden. We hebben prachtige momenten beleefd samen. Je stond altijd aan mijn zijde, ten tijde van mijn studies en $\mathrm{PhD}$. Je gaf me rust in mijn hoofd en een leven. Met jou wil ik verder voor de rest van mijn leven. Ik hou van je, onvoorwaardelijk, ... 
